SAND95-2939

Unlimited Release

UC-1301

\title{
Heat Loss from an Open Cavity
}

Christopher G. McDonald

College of Engineering

California State Polytechnic University

Pomona, CA 91768

Prepared by Sandia National Laboratories Albuquerque, New Mexico 87185 and Livermore, California 94550 for the United States Department of Energy under Contract DE-AC04-94AL85000

Printed December 1995 
Issued by Sandia National Laboratories, operated for the United States Department of Energy by Sandia Corporation.

NOTICE: This report was prepared as an account of work sponsored by an agency of the United States Government. Neither the United States Government nor any agency thereof, nor any of their employees, nor any of their contractors, subcontractors, or their employees, makes any warranty, express or implied, or assumes any legal liability or responsibility for the accuracy, completeness, or usefulness of any information, apparatus, product, or process disclosed, or represents that its use would not infringe privately owned rights. Reference herein to any specific commercial product, process, or service by trade name, trademark, manufacturer, or otherwise, does not necessarily constitute or imply its endorsement, recommendation, or favoring by the United States Government, any agency thereof or any of their contractors or subcontractors. The views and opinions expressed herein do not necessarily state or reflect those of the United States Government, any agency thereof or any of their contractors.

Printed in the United States of America. This report has been reproduced directly from the best available copy.

Available to DOE and DOE contractors from

Office of Scientific and Technical Information

PO Box 62

Oak Ridge, TN 37831

Prices available from (615) 576-8401, FTS 626-8401

Available to the public from

National Technical Information Service

US Department of Commerce

5285 Port Royal Rd

Springfield, VA 22161

NTIS price codes

Printed copy: A10

Microfiche copy: A01

This report was printed as submitted to Sandia National Laboratories by the author and California State Polytechnic University. 
Distribution

Category UC-1301

SAND95-2939

Unlimited Release

Printed December 1995

\title{
HEAT LOSS FROM AN OPEN CAVITY
}

\author{
Christopher G. McDonald \\ College of Engineering \\ California State Polytechnic University \\ Pomona, CA 91768
}

Sandia Contract 02-5759

\begin{abstract}
This report presents the results of an investigation into the heat-loss characteristics of a cavity-type receiver for a parabolic dish concentrating solar collector. The receiver is similar to the type used in the Solar Total Energy Project in Shenandoah, Georgia. This investigation examines the effects of aperture size, orientation, and operating temperature on the heat loss of the receiver. The total receiver heat loss is quantitatively separated into its three modes: radiative, conduction, and convection. The testing was performed in a controlled environment, thereby eliminating any potential wind contribution. It was executed off flux, i.e., with no incident insulation. The receiver was operated in reverse of its typical operating configuration, whereby the heat-transfer fluid was heated externally. Previous heat-loss models or correlations with similar cavity receivers are compared with the experimental results from this study. A convective heat-loss correlation is presented from these experimental results. A theoretical model for the radiative heat loss is developed and compared with two methods used to quantitatively determine the radiative component of total heat loss.
\end{abstract}




\section{ACKNOWLEDGMENTS}

I would like to thank Dr. William Stine for his unending support and guidance. Dr. Stine provided overall project management. He has extended enormous patience and understanding through all the delays.

I would also like to thank Dr. Carl Rathmann for his advice regarding the analytical radiative heat loss, and the general assumptions used in experimentally determining convective heat loss.

Technical assistance was provided by Jack Kovar, Mechanical Engineering Department Technician, and Jim Rounds, Chemical Engineering Department Technician. Their knowledge and experience provided most valuable advice.

Special thanks go to all the undergraduate students who worked long, hard hours bringing the test phase of the project to conclusion. Working with so many students on this project, established quite a few lasting friendships. These students provided support in the design and fabrication of test apparatus. They also extended valuable assistance during testing, wherein, shifts would often run more than 15 hours. They continuosly exhibitied dedication and determination.

Finally, I would like to extend my gratitude to Sandia National Laboratories for their financial and technical support. This project could never have taken place without the strong support of this company. 


\section{CONTENTS}

LIST OF ILLUSTRATIONS ................................................... $x$

LIST OF TABLES ............................................................ xi

LIST OF ABBREVIATIONS......................................................... xii

Chapter

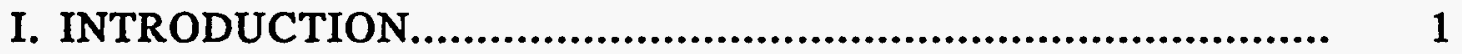

II. APPARATUS.............................................................. 4

A. Receiver: ...................................................................... 4

B. Flow Loop ................................................................... 7

C. Radiometer Setup ................................................................ 9

D. Data Acquisition................................................................ 9

III. TEST METHOD ..........................................................

A. Temperature and Receiver Angle Effects.................................. 10

B. Aperture Size Effects ................................................. 12

V. RESULTS.............................................................. 13

A. Temperature and Angle Effects on Total and Convective Heat Losses 13

B. Aperture Size Effects on Total and Convective Heat Losses............. 15

C. Radiative and Conductive Heat Losses................................. 18

VI. PREVIOUS CAVITY CONVECTION LOSS MODELS ..................... 21

A. LeQuere, Penot, and Mirenayat .......................................... 21

B. Koenig \& Marvin ..................................................... 26

C. Clausing Model............................................................... $\quad 30$

1. Convective Energy Loss Through the Aperture.................. 32

2. Convective Energy Loss Within the Receiver ........................ 34

3. Radiative Energy Loss Through the Aperture ..................... 36

4. Conductive Energy Loss From the Receiver........................... 36

5. Zone Area Formulas .............................................. 37

6. Shear Plane Area ........................................................... 38

7. Clausing Model Analysis................................................... 39

D. Siebers \& Kraabel........................................................... 40

VII. COMPARISON OF CAVITY HEAT LOSS MODELS ...................... 45

A. Comparison of Previous Models with Experimental Data.................. 46

B. Stine and McDonald Correlation ...................................... 50 
VIII. ANALYTICAL RADIATION HEAT LOSS............................. 51

A. Internal Geometry ........................................................ 51

1. Nomenclature.................................................... 52

B. Assumptions........................................................... 53

C. Shape Factors.............................................................. 53

D. Thermal Radiation Heat Loss Equations ................................ 54

E. Assumed Cavity Temperature Distribution............................. 56

F. Comparison with Measurements ....................................... 57

1. Radiometer Method ................................................. 58

2. Analytical Method..................................................... 59

IX. INSTRUMENTATION CALIBRATION................................. 59

A. Flow Meter Calibration................................................... 59

1. Flow Meters Calibration................................................... 63

B. Thermocouple Calibration.................................................... 66

1. Thermocouple Calibration Apparatus................................ 68

2. Thermocouple Calibration Procedure................................ 70

3. Thermocouple Calibration Results ..................................... 70

C. Radiometer Calibration .................................................... 77

1. Radiometer Window Evaluations ......................................... 78

2. Radiometer Positioning.................................................. 85

X. ERROR ANALYSIS....................................................... 87

A. Flow Measurement Error Analysis.............................................. 88

B. Temperature Measurement Error Analysis ............................. 89

C. Normalization Error Analysis................................................ 92

XI. CONCLUSIONS........................................................ 99

XII. RECOMMENDATIONS ............................................... 99

Appendix

1. Phase One, Temperature and Angle Test Results................................. 100

2. Phase Two, Aperture Size Test Results .................................... 102

3. LeQuere, Penot and Mirenayat Model Computer Program Listing............ 106

4. LeQuere, Penot and Mirenayat Model Heat Loss Data............................. 110

5. Koenig and Marvin Model Computer Program Listing...................... 112

6. Koenig and Marvin Model Heat Loss Data........................................... 116

7. Zone and Shear Area Formulas.......................................... 120

8. Clausing Model Computer Program Listing ............................... 131

9. Clausing Model Heaț Loss Data ............................................ 139

10. Siebers and Kraabel Model Computer Program Listing ...................... 143

11. Siebers and Kraabel Model Heat Loss Data ................................. 149 
12. Stine and McDonald Model Computer Program Listing...................... 153

13. Stine and McDonald Heat Loss Data....................................... 156

14. Shape Factor Formulas .................................................. 160

15. Analytical Thermal Radiation Heat Loss Program Listing........................ 177

16. Flow Meter Factory Calibration Specifications .............................. 192

17. Flow Meters Voltage Output ............................................ 193

18. Calibrated Thermocouple Probe Specifications.............................. 194

19. Radiometer Calibration Specifications .................................... 195

20. Pyromark ${ }^{\circledR}$ Paint Specifications................................................ 196

21. Radiometer Windows Test Data ......................................... 198

22. Saran Wrap ${ }^{\circledR}$ Specifications.............................................. 200

23. Radiometer Displacement Sensitivity Test Data................................... 202

REFERENCE LIST ........................................................ 203 


\section{LIST OF ILLUSTRATIONS}

Figure

Page

1. Solar collector............................................................... 1

2. Heat transfer system boundary.................................................... 2

3. Cavity receiver cross section ................................................... 4

4. Receiver test stand ......................................................... 5

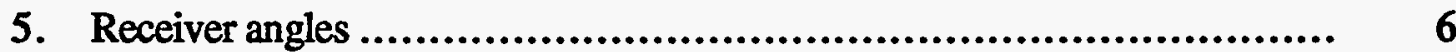

6. Receiver thermocouple locations................................................... 6

7. Annulus and plug.............................................................. 7

8. Heat transfer fluid heating system .......................................... 8

9. Total receiver heat loss versus operating temperature ......................... 13

10. Total heat loss versus receiver angle for $18 \mathrm{inch}$ aperture .................... 14

11. Convective heat loss for $18 \mathrm{in}$. aperture versus receiver.angle................ 15

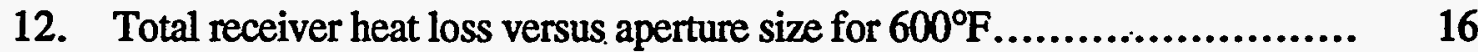

13. Convective heat loss versus aperture size for $400^{\circ} \mathrm{F} . . . . . . . . . . . . . . . . . . . . . . . . . . . \quad 17$

14. Convective heat loss versus aperture size for $600^{\circ} \mathrm{F} . . . . . . . . . . . . . . . . . . . . . . . . . . . .17$

15. Radiative and conductive heat losses versus receiver temperature............. 18

16. Radiative heat loss versus receiver aperture diameter at $400^{\circ} \mathrm{F} . . . . . . . . . . . . .20$

17. Radiative heat loss versus receiver aperture diameter at $600^{\circ} \mathrm{F} . . . \ldots \ldots \ldots . . . .20$

18. Percent heảt loss modes versus aperture size for $600^{\circ} \mathrm{F}$ at $45^{\circ}$ angle .......... 21

19. Convective heat loss for LeQuere, Penot, and Mirenayat model................ 25

20. Convective heat loss for Koenig and Marvin model................................ 30

21. Convective heat loss balance ............................................ 31

22. Receiver internal cavity zones.............................................. 31

23. Cavity zone areas ........................................................ 37

24. Cavity sections........................................................ 38 
25. View looking down showing the effective shear plane area.................. 39

26. Convective heat loss for Clausing model .................................... 40

27. Siebers and Kraabel cavity Areas........................................... 43

28. Convective heat loss for the Siebers and Kraabel model.......................... 45

29. LeQuere, Penot, Mirenayat convective heat loss model correlation ........... 47

30. Koenig and Marvin convective heat loss model correlation ................... 48

31. Clausing convective heat loss model correlation.............................. 49

32. Siebers and Kraabel convective heat loss model correlation...................... 49

33. Stine and McDonald convective heat loss model correlation .................. 51

34. Receiver internal surface sections................................................. 52

35. Experimentally determined radiometer method correlation .................... 58

36. Analytically determined radiative heat loss correlation........................ 59

37. Flow measurement system ............................................. 61

38. Factory calibrated flow meter flow rate versus frequency output............. 62

39. In-house calibrated flow meters correlation curves......................... 64

40. In-house calibrated flow meter errors ..................................... 65

41. Calibrated thermocouple probe curve ....................................... 67

42. Thermocouple calibrator .................................................. 69

43. Thermocouple calibrator heat sink .......................................... 69

44. Modified soldering iron...................................................... 70

45. Inlet and outlet thermocouple calibration histories........................... 71

46. Factory calibrated versus inlet thermocouple readings ....................... 72

47. Factory calibrated versus outlet thermocouple readings............................ 72

48. Inlet thermocouple errors ................................................. 73

49. Outlet thermocouple errors ................................................. 74

50. Differential thermocouple connection ..................................... 74

51. Differential thermocouple readings history ............................... 75

52. Differential thermocouple errors history ................................... 76 
53. Differential thermocouple output versus mean temperature.

54. Radiometer section view

55. Film window bezel

56. Radiometer calibration test stand................................................ 79

57. Pyromark paint emittance................................................... 80

58. Hot plate thermocouple distribution ...................................... 82

59. Radiometer windows transmittance ......................................... 84

60. Radiometer displacement effects............................................ 86

61. Error in total heat loss for various operating temperatures........................ 94

62. Error in total heat loss for various.aperture diameter operating at $400^{\circ} \mathrm{F}$...... 94

63. Error in total heat loss for various aperture diameter operating at $600^{\circ} \mathrm{F} . . . .99$

64. Error in convective heat loss for various operating temperatures.............. 96

65. Error in convective heat loss for various aperture diameter operating at $400^{\circ} \mathrm{F} \quad 97$

66. Error in convective heat loss for various aperture diameter operating at $600^{\circ} \mathrm{F} \quad 97$

67. Error In radiative heat loss from phase 1 test................................... 98

68. Error In radiative heat loss from phase 2 test..................................... 98

69. Critical angles ...................................................... 122

70. Cylindrical section shear plane angles........................................... 127

71. Frustum section shear plane angles....................................... 129 


\section{LIST OF TABLES}

Table

Page

1. Empirical correlation coefficients and exponents ............................ 24

2. Siebers and Kraabel uncertainty analysis .................................. 44

3. Inlet and outlet temperatures.............................................. 57

4. Pulse rate converter calibration points............................................ 62

5. Factory calibrated thermocouple probe error ............................. 68

6. Radiometer window test parameters...................................... 81

7. Radiometer position sensitivity test parameters ............................ 85 


\section{LIST OF ABBREVIATIONS}

$\mathrm{ADC} \quad$ analog to digital converter

AC alternating current

HTF heat transfer fluid

$\mathbf{N}$

number of sectioned elements of the receiver cavity intemal surface area

STEP

Solar Total Energy Project

TC

thermocouple 


\section{INTRODUCTION}

Cavity type receivers are used extensively in concentrating solar thermal energy collecting systems. The Solar Total Energy Project (STEP) in Shenandoah, Georgia is a large scale field test for the collection of solar thermal energy.(1) The STEP experiment consists of a large field array of solar collectors used to supplement the process steam, cooling and other electrical power requirements of an adjacent knitwear manufacturing facility.

The main components of each collector are the concentrator, the tracking mechanism, and the receiver (Fig. 1). The concentrator is a 7 meter diameter parabolic dish with a highly reflective coating on the inside surface. Each collector has two axes of rotation for tracking the sun all throughout the days of the year. The collectors are subjected to continuous changes in ambient conditions such as wind, solar insulation, and ambient temperature.

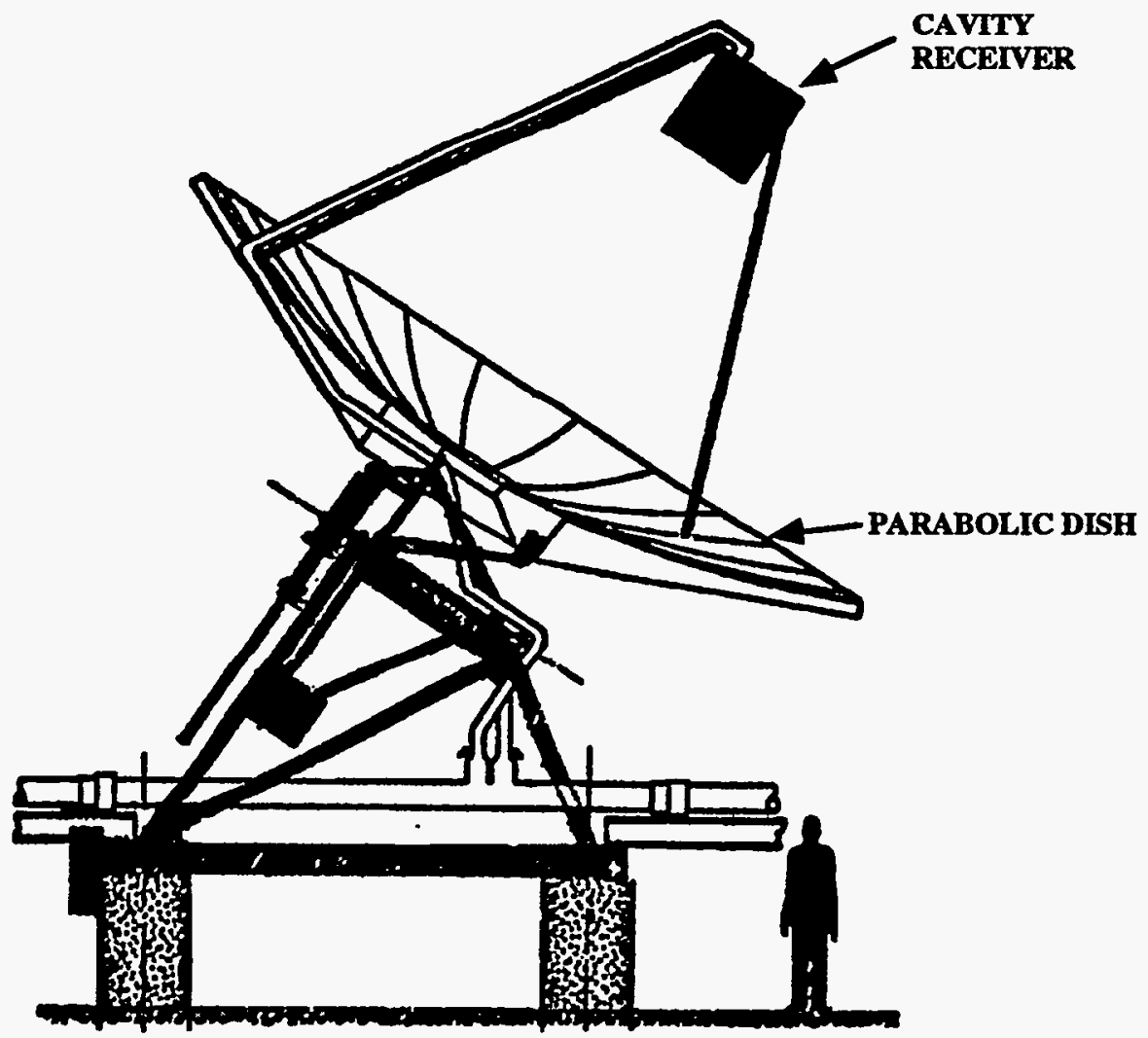

Figure 1. Solar Collector $(1)$

These environmental variations, as well as changes in receiver tilt, affect the overall receiver performance. The receiver used in this study is a parabolic collector. 
A thorough understanding of receiver heat loss characteristics is essential for future development of solar receivers, and optimization of the STEP system presently in use. The system boundary of the receiver is defined as the outer skin of the receiver and the aperture opening (Fig. 2). The portion of the boundary formed by solid walls are only subject to conductive heat transfer. The aperture, however; is subject to convective, conductive and radiative heat transfer. Mass transfer occurs across the aperture and through the heat transfer fluid lines crossing the system boundary.

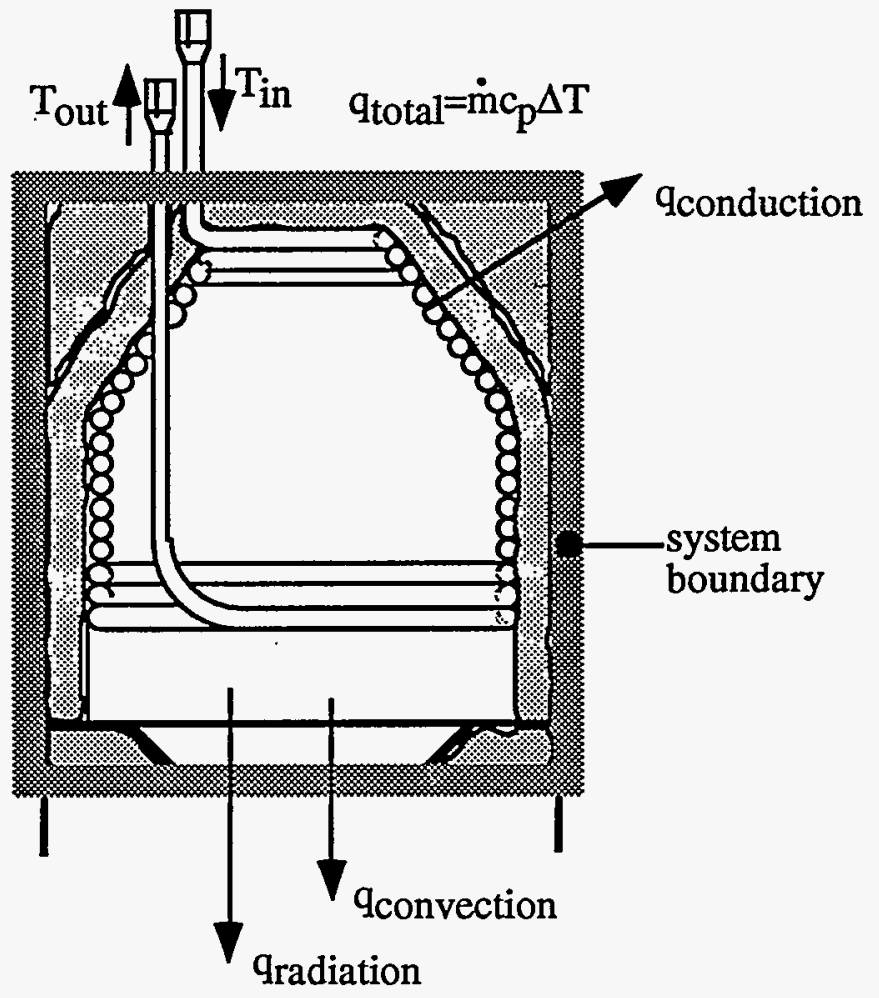

Figure 2. Heat transfer system boundary

Analytical methods for predicting the conductive and radiative heat losses from a cavity receiver are fairly straight forward. This, however; is not the case for convective heat loss analysis. The complex geometry of the cavity makes it difficult to use existing analytical models for predicting convective heat loss. Few convective heat loss correlations, for cavity receivers, exist due to the lack of significant empirical data. Correlations for receivers with simple geometry are not considered valid for this receiver. 
An extensive search of current literature produced only a few studies on heat loss from cavities. A study was performed by LeQuere, Penot, and Mirenayat in which heat loss characteristics of two different sized cubical cavities were examined.(2) They considered variations in receiver operating temperature and angle, in their study. A study performed by Koenig and Marvin, presented by Harris and Lenz, gave an empirically derived correlation for convective heat loss from cylindrical cavity type receivers, including the effects of variation in operating temperature and angle.(3) An analytical model for convective heat loss for an open cubical cavity receiver was presented by A. M. Clausing. ${ }^{(4)}$ The Clausing model was developed for a central receiver operating at much higher temperatures than the receiver studied here. Siebers and Kraabel presented a model for the convective heat loss from a central cylindrical cavity receiver. ${ }^{(5)}$

There is some experimental data available for this type of receiver from previous tests on off-flux field measurements conducted with limited instrumentation at STEP.(6) Field measurement experiments, such as the one conducted at STEP, provide no control over environmental conditions such as wind, and ambient temperature. In order to control the environmental conditions, receiver testing for this study, took place indoors.

The purpose of the tests, conducted for this study, was to isolate and quantify the radiative, conductive, and convective components of total heat loss, and to determine the effects of operating temperature, receiver angle, and aperture size on cavity heat loss. An analytical model for radiative heat loss was developed and compared with two other methods used to determine radiative heat loss. A proposed convective heat loss correlation, including effects of aperture size, receiver operating temperature, and receiver angle is presented. The resulting data is a source to evaluate the STEP measurements. 


\section{APPARATUS}

\section{A. Receiver}

A drawing of the receiver studied in this work is shown in cross section in Figure 3. The cavity of the receiver is composed of a single tube wound in a conical frustum-cylinder shape with the aperture at the cylindrical end of the tube bundle. The tube bundle is wrapped in a thick blanket of Kaowool ${ }^{\circledR}$ insulation. The outer skin of the receiver is formed by a single cylindrical wrap of sheet metal. The outer skin extends beyond the aperture face to serve as a wind break. The flow lines to and from the receiver are heavily insulated. The inlet and outlet lines for these tests, as shown in Figure 3, are the reverse of those for an on-flux receiver in field operation.

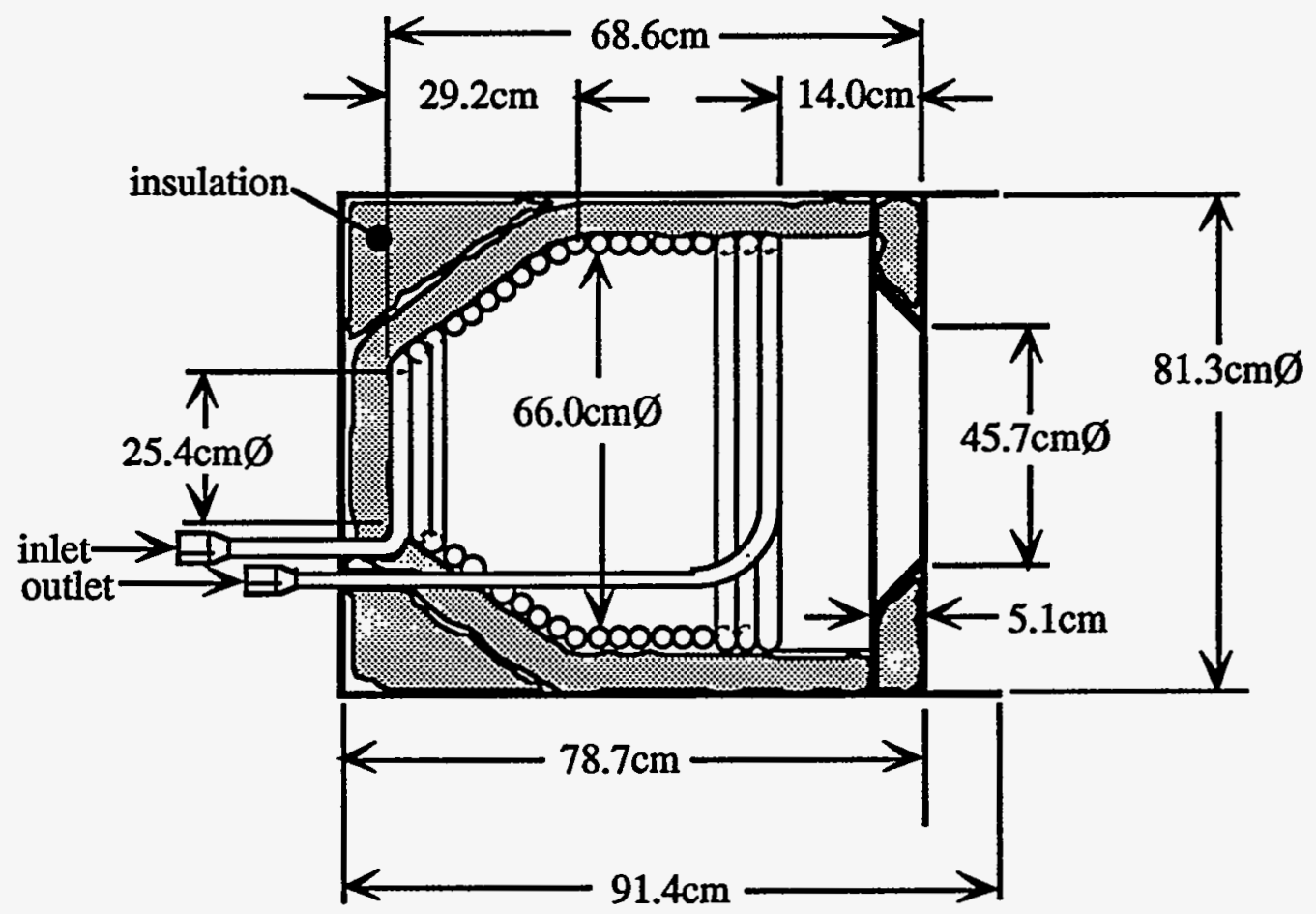

Figure 3. Cavity receiver cross section.

The receiver is cradled in a frame that allows it to rotate $180^{\circ}$ (Fig. 4). The receiver can be fixed at $15^{\circ}$ increments from $-90^{\circ}$, where the aperture is upward, to $+90^{\circ}$, where the aperture is downward (Fig. 5). The high pressure flexible lines on the sides of the receiver 
test stand allow the receiver to rotate freely for each test position.

Thermocouples were used to measure the receiver inlet and outlet temperatures. Two inhouse calibrated K-type thermocouples were immersed in each of the heat transfer fluid (HTF) inlet and outlet lines of the receiver. One of the thermocouples from the inlet and outlet lines measured absolute temperature. The remaining two thermocouples were connected in series to yield a direct measure of the temperature difference between the inlet and the outlet. The receiver was further instrumented with seventeen surface thermocouples and thirteen internal air thermocouples (Figure 6). The surface thermocouples were spot welded in place with the lead ends spaced approximately one-eighth inch apart.

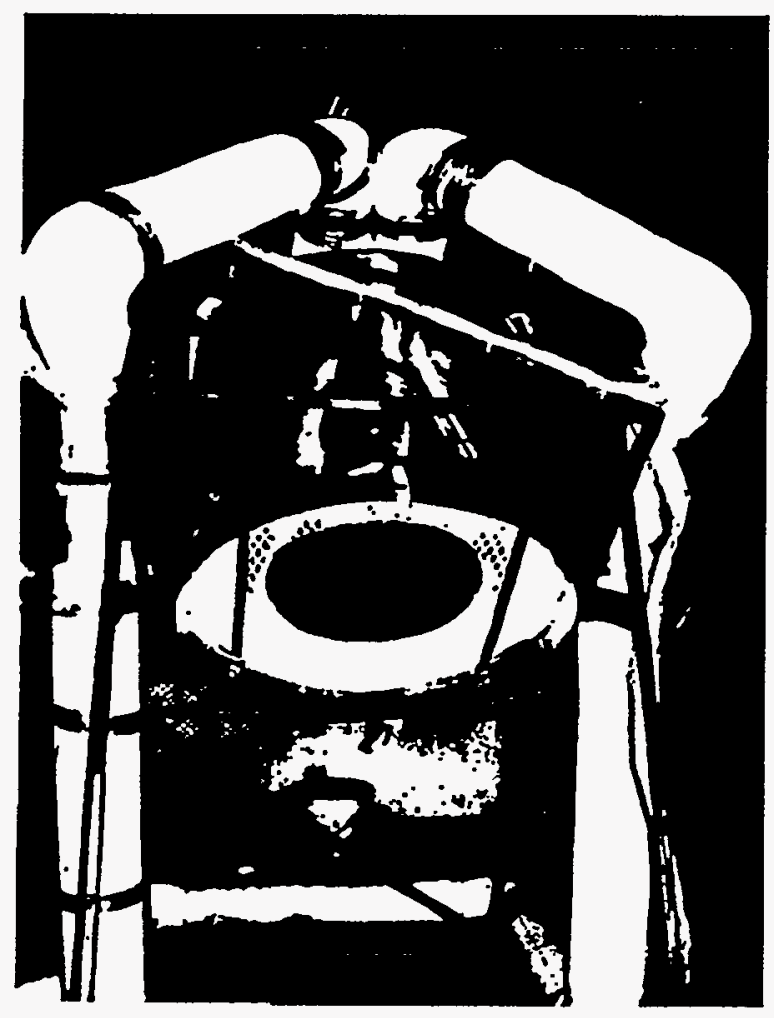

Figure 4. Receiver test stand 


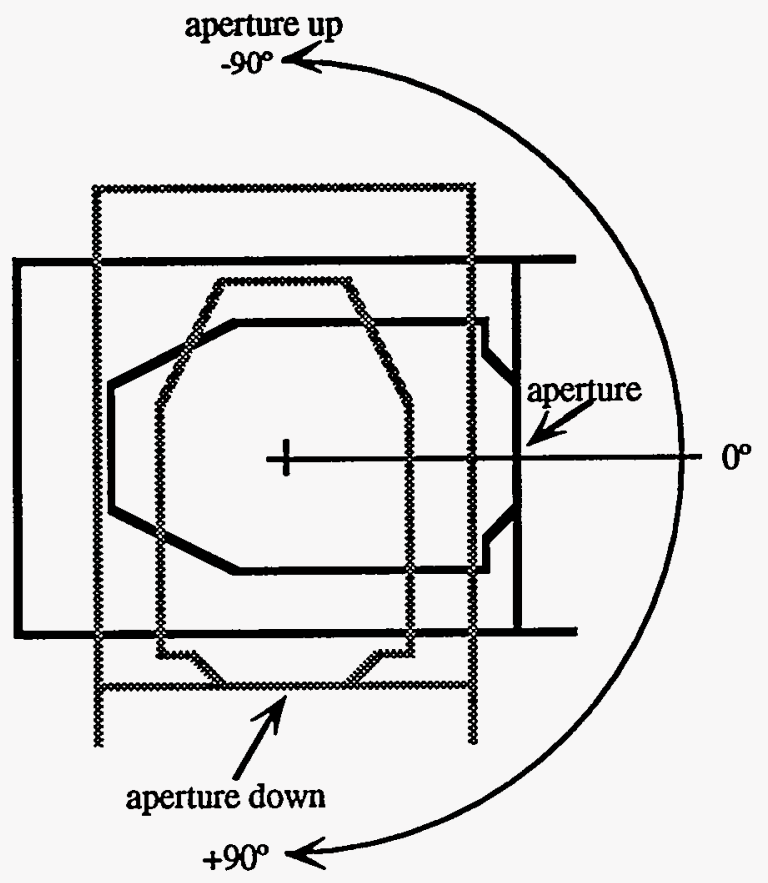

Figure 5. Receiver angles

Thermocouple Identification

A: air TC

T: tube surface TC

S: outer skin surface TC

$\mathrm{C}$ : back cover surface TC
TC/Switch Correlation

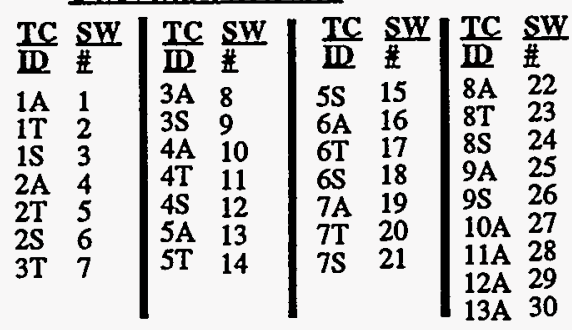

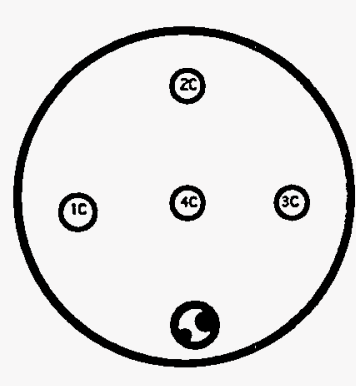

Back View

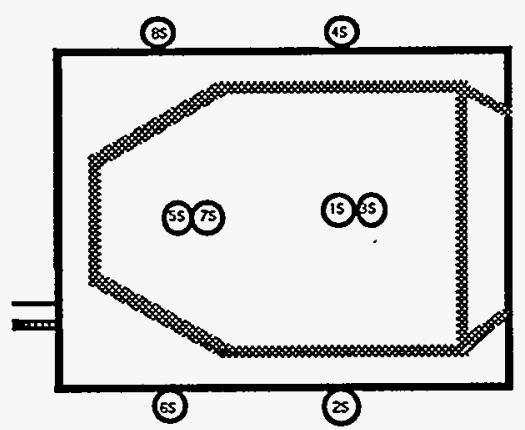

Side View

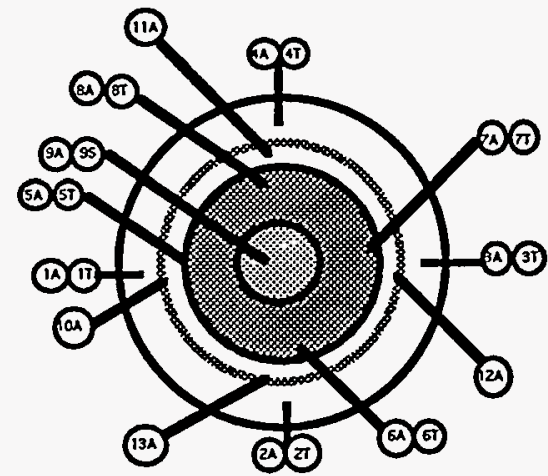

Front view

Figure 6. Receiver thermocouples locations 
An insulating annulus with a corresponding center plug were fabricated for each of the aperture sizes tested (Fig. 7). The aperture sizes tested were 6 inch diameter, 12 inch diameter, 18 inch diameter, and 26 inch diameter. The 18 inch diameter aperture is the size presently being used for this model of receiver. The 26 inch diameter, the internal diameter of the cavity, aperture leaves no lip to the cavity. The aperture plug and annulus were fabricated of 1 inch thick solid insulation boards. The plug was tapered inward to fit snugly in the respective aperture annulus. The plugs were held in place by two wooden straps extending across the aperture end of the receiver.

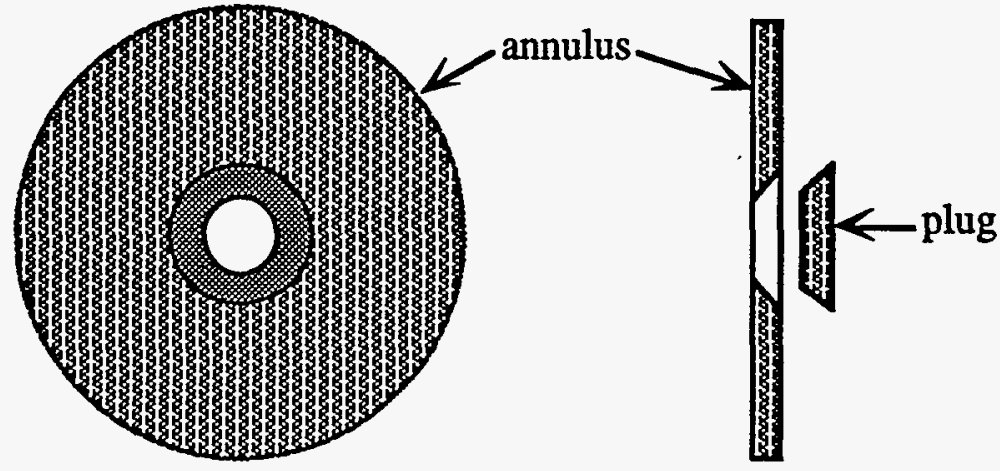

Figure 7. Annulus and plug

\section{B. Flow Loop}

The heat transfer fluid was heated by a heating and pumping station adjacent to the receiver (Fig 8). The flow system consists of two parallel flow loops- the primary heating loop and the receiver feed loop. The primary heating loop has available two in-line $12 \mathrm{~kW}$ electric heaters. A minimum flow rate of $5 \mathrm{gpm}$ was maintained in the heating loop to prevent excessive film temperatures of the HTF in the heaters. The receiver feed loop was throttled for a flow rate through the receiver of $1 \mathrm{gpm}$. The HTF flow rate through the receiver was measured using three turbine flow meters connected in a series on the inlet line to the receiver. The flow meters are located in a straight section of piping allowing ample upstream and downstream damping lengths. Three flow meters are used for measurement redundancy. One flow meter was factory calibrated. The remaining two flow meters were 
calibrated against the factory calibrated flow meter.

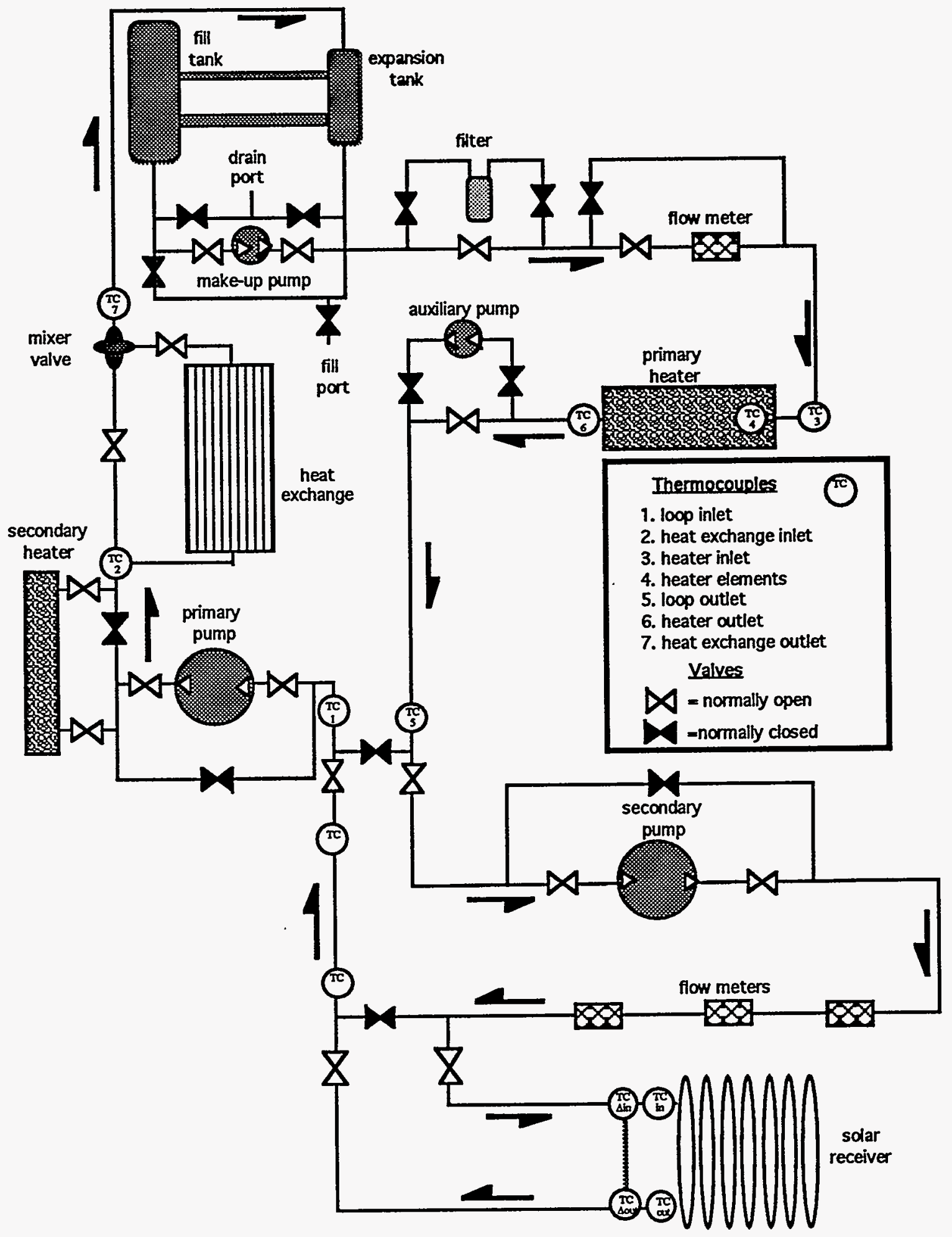

Figure 8. Heat transfer fluid heating system 


\section{Radiometer Setup}

One method used to determine the thermal radiative heat loss from the aperture was with a radiometer. The radiometer was mounted on a tripod and placed directly below and centered on the receiver. The radiometer was water cooled and the return water temperature was monitored. The radiometer signal output leads were connected to the computer data acquisition system. A Saran Wrap window assembly was positioned over the radiometer in place of the quartz window bezel. The radiometer window serves to isolate the temperature sensitive thermopile surface from localized convective currents. This is discussed further in radiometer calibration section.

\section{Data Acquisition}

A computer was used for data acquisition and display. This consisted of an Apple IIe computer with two 16-channel data acquisition cards each connected to a thermocouple cold junction terminal box. The following transducers were connected to the data acquisition system; receiver inlet and outlet thermocouples, two ambient thermocouples, three receiver flow meters; radiometer; radiometer water thermocouple; loop inlet and outlet thermocouples; and the main flow loop flow meter. The surface and air thermocouples on the receiver were connected to a digital display unit via a multi-channel thermocouple switch. The surface and air receiver temperature readings were recorded manually when steady state conditions were obtained for each test point.

\section{TEST METHOD}

The testing was conducted in two phases. Phase One of the testing examined the effects of receiver operating temperature and receiver angle on the receiver heat loss. Phase Two looked at the effects of receiver aperture size on the receiver heat loss: After Phase One, and before Phase Two, the receiver was overhauled. The overhaul of the receiver included 
replacing the insulation in the walls, repainting the tube surfaces, and resealing the seams and ports through the outer skin of the receiver.

\section{A. Temperature and Receiver Angle Effects}

The model of the effects of temperature and receiver angle on heat loss developed in this study utilizes results from both Phase One and Phase Two tests. The overlap portion of the Phase One and Phase Two tests were compared for ease of repetition. The four nominal operating temperatures in $\mathrm{Phase}$ One testing were $300^{\circ} \mathrm{F}, 400^{\circ} \mathrm{F}, 500^{\circ} \mathrm{F}$, and $600^{\circ} \mathrm{F}$ with the standard 18 inch aperture. The Phase Two study was conducted at operating temperatures of $400^{\circ} \mathrm{F}$ and $600^{\circ} \mathrm{F}$ and incorporated $6,12,18$, and 26 inch apertures. The nominal operating temperature was based on the average of the inlet and outlet temperatures. For each operating temperature the receiver was tested at ten angles from $-90^{\circ}$ to $+90^{\circ}$ in Phase One. The receiver angles tested were from 0 to $+90^{\circ}$, every $15^{\circ}$ and from 0 to $-90^{\circ}$, every $30^{\circ}$. Phase Two included receiver angles from $0^{\circ}$ to $+90^{\circ}$, every $15^{\circ}$. More angles were tested in the positive range, since most cavity receivers operate in this range. The negative angles were tested to provide a clearer understanding of heat loss characteristics, as a function of receiver angle. However, some concentrating solar collector designs operate with inverted cavity receivers.

At the beginning of each test, the receiver was placed in the $+90^{\circ}$ position with the aperture facing down. The flow system was started and the fluid was heated as close to the operating temperature as possible. Obtaining the nominal HTF temperature at the receiver inlet usually meant setting the heater temperature $25^{\circ} \mathrm{F}$ to $50^{\circ} \mathrm{F}$ higher, accounting for heat loss from the connecting line. The flow rate through the receiver was adjusted to approximately one gallon per minute. The one gallon per minute flow rate is typical for these type of receivers at STEP. Thermal stabilization is attained when there is less than 0.1 degree change in the inlet and outlet temperatures over the two minute data sampling 
interval. Reaching thermal stabilization often takes several hours depending upon the nominal operating temperature and the ambient laboratory conditions. When thermal stabilization was reached, temperature and flow measurements were recorded.

The convective heat loss from the cavity of the receiver is assumed to be negligible when the receiver is in the $+90^{\circ}$ position. This assumption is supported in two ways. First, smoke flow visualization techniques revealed negligible air flow across the aperture with the receiver in the $+90^{\circ}$ position. The second is the minimal variance between experimentally determined radiative heat loss at $+90^{\circ}$ and the calculated values and radiometer measurements.

Therefore, the total heat loss from the receiver in the $+90^{\circ}$ position is composed of radiative losses from the aperture and conductive losses through the side, back, and annulus walls of the receiver. The aperture of the receiver was then fitted with an insulated plug to eliminate the radiative component from the total heat loss. With the plug in place, the system was again allowed to reach steady state and again the temperature and flow measurements were recorded. In this manner, the radiative and conductive components of the total heat loss from the receiver for a particular operating temperature were isolated. The radiative and conductive heat losses are assumed constant with receiver angle.

The receiver was then positioned in the $+75^{\circ}$ attitude and the system allowed to stabilize. The temperature and flow measurements were again recorded. The total heat loss measurements were normalized linearly to the nominal test temperature for comparison purposes. This accounted for the variation in the operating temperature from one test setup to the next. The thermal stabilization procedure was repeated for each receiver angle tested. The entire procedure was repeated for each nominal operating temperature test point. 
The total heat loss from the receiver can be expressed as a mathematical relation. The preceding appears as:

$$
q_{\text {total }}=\dot{\mathrm{m}} \mathrm{Cp}\left(\mathrm{T}_{\mathrm{in}}-\mathrm{T}_{\text {out }}\right)
$$

where:

$$
\begin{aligned}
& T_{\text {in }}=\text { temperature of fluid at the inlet to the receiver }[K] \\
& T_{\text {out }}=\text { temperature of fluid at outlet to receiver }[K] \\
& \dot{\mathrm{m}}=\text { mass flow rate of the fluid }[\mathrm{g} / \mathrm{m}] \\
& \mathrm{Cp}=\text { specific heat of the fluid }[\mathrm{K}]
\end{aligned}
$$

The mass flow rate is given by:

$$
\dot{\mathrm{m}}=\dot{\mathrm{ip}}
$$

where:

$$
\begin{aligned}
& \dot{v}=\text { volumetric flow rate } \\
& \rho=\text { heat transfer fluid density at the inlet temperature }
\end{aligned}
$$

The conductive heat loss is given by:

$$
q_{\text {conductive }}=q_{\text {plugged } @+90^{\circ}}<
$$

The radiative heat loss is given by:

$$
\mathrm{q}_{\text {radiative }}=\mathrm{q}_{\text {unplugged } @+90^{\circ}<-} \mathrm{q}_{\text {plugged } @+90^{\circ}} \angle
$$

The convective heat loss at any angle, $\alpha$, is then given by:

$$
\mathrm{q}_{\text {convective } @ \alpha \angle}=\mathrm{q}_{\text {total } @ \alpha<}-\mathrm{q}_{\text {conduction }}-\mathrm{q}_{\text {radiative }}
$$

The HTF volumetric flow rate, inlet temperature, outlet temperature, and temperature difference were all measured with transducers. The density and heat capacity were both calculated as functions of temperature.

\section{B. Aperture Size Effects}

The second Phase of the testing examined the effects of receiver aperture size on the 
receiver heat loss. This Phase of the testing was performed at two operating temperatures of $400^{\circ} \mathrm{F}$ and $600^{\circ} \mathrm{F}$, and seven receiver angles from 0 to $+90^{\circ}$ at $15^{\circ}$ increments. The four aperture sizes tested were 6 inches, 12 inches, 18 inches, and 26 inches. The 18 inch diameter aperture is the standard size for this receiver. The Phase Two testing followed the same procedure used in Phase One testing with the additional step of changing aperture size. Heat loss values from Phase One were compared with Phase Two.

\section{RESULTS}

\section{A. Temperature and Angle Effects on Total and Convective Heat Losses}

The data summary of the receiver operating temperature and receiver angle effects from the Phase One tests are tabulated in Appendix 1. These results were first presented by Stine and McDonald(8). Total receiver heat loss varies, approximately, linearly with operating temperature (Fig. 9).

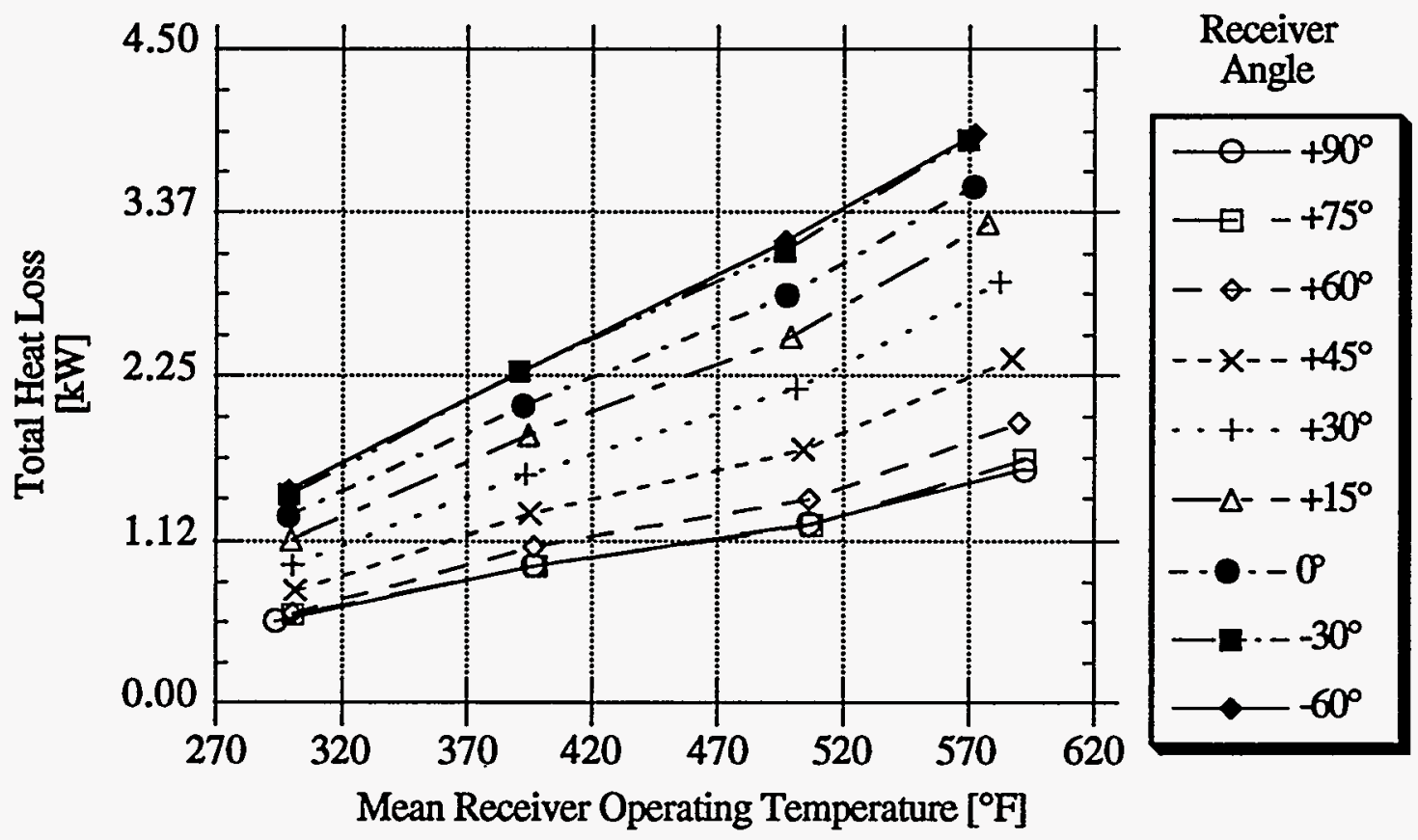

Figure 9. Total receiver heat loss versus operating temperature 
The total receiver heat loss varies non-linearly with receiver angle (Fig. 10). The total heat loss is at a minimum when the receiver aperture orientation is downward. This supports the assumption of negligible convective heat loss with the receiver in this position. The maximum heat loss occurs when the receiver aperture is oriented at approximately $+45^{\circ}$ above horizontal. This particular receiver would not normally operate at angles above horizontal as these are negative angles.

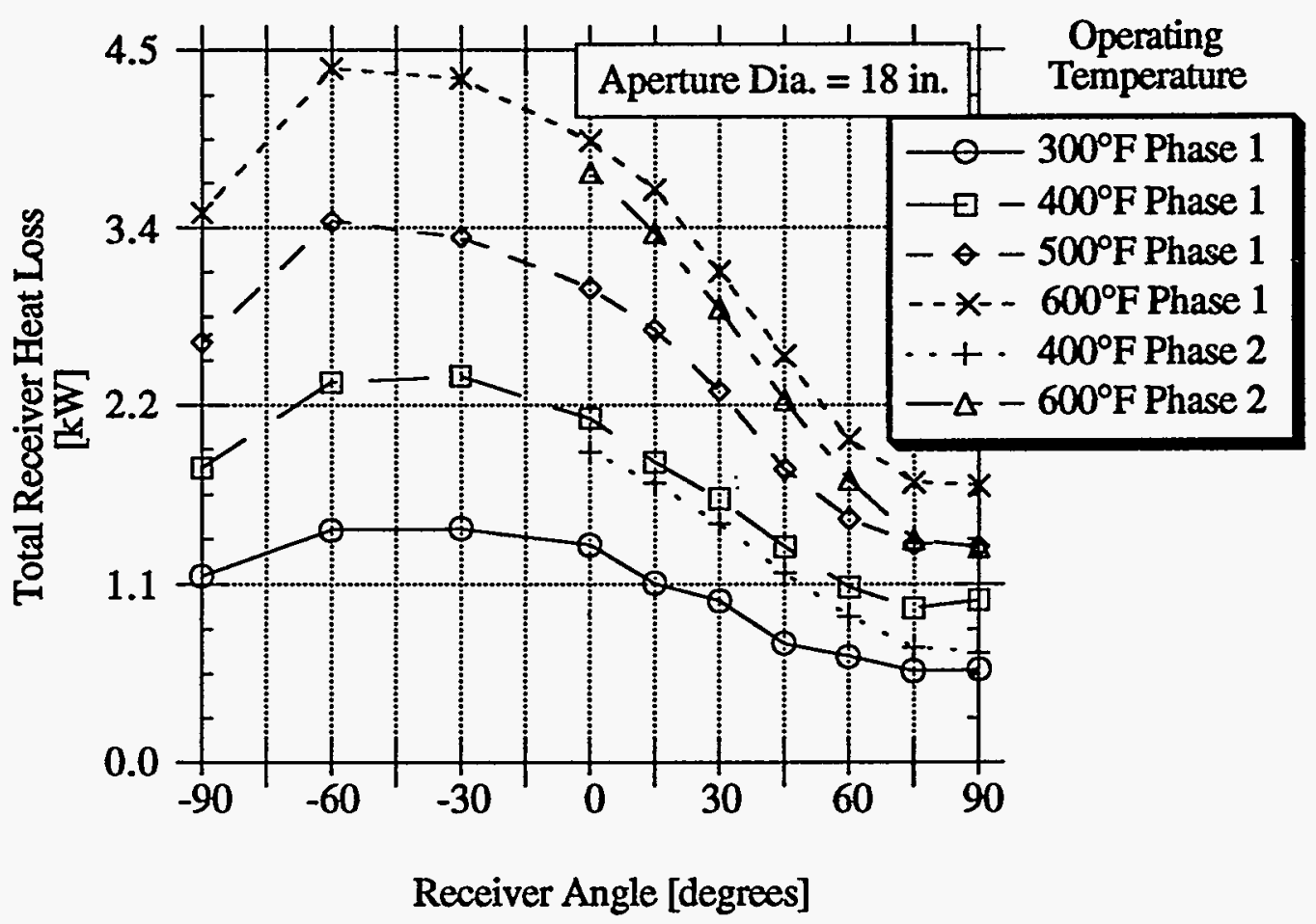

Figure 10. Total heat loss versus receiver angle for 18 inch aperture

Results from duplicate test conditions from Phase Two are also presented in Figure 10. As discussed previously, the convective heat loss through the aperture is determined by the difference between the total heat loss at any angle and the total heat loss for the $+90^{\circ}$ angle (Fig. 11). This requires that the convective heat loss be zero when the receiver is positioned at $+90^{\circ}$, with the aperture down. The maximum convective heat loss occurred with the receiver in the $-45^{\circ}$ position. The reduction in total heat loss from Phase One to Phase Two 
testing, for receiver angles less than $+60^{\circ}$, was assumed to be primarily due to the improved insulating properties of the cavity walls. The larger difference in the total receiver heat loss from Phase One to Phase Two for receiver angles greater than $+60^{\circ}$ resulted from the combined effects of improved insulation in the cavity walls and better sealing of the outer receiver skin. Apparently, sealing of the skin had little effect on heat loss from the receiver for angles less than $+60^{\circ}$.

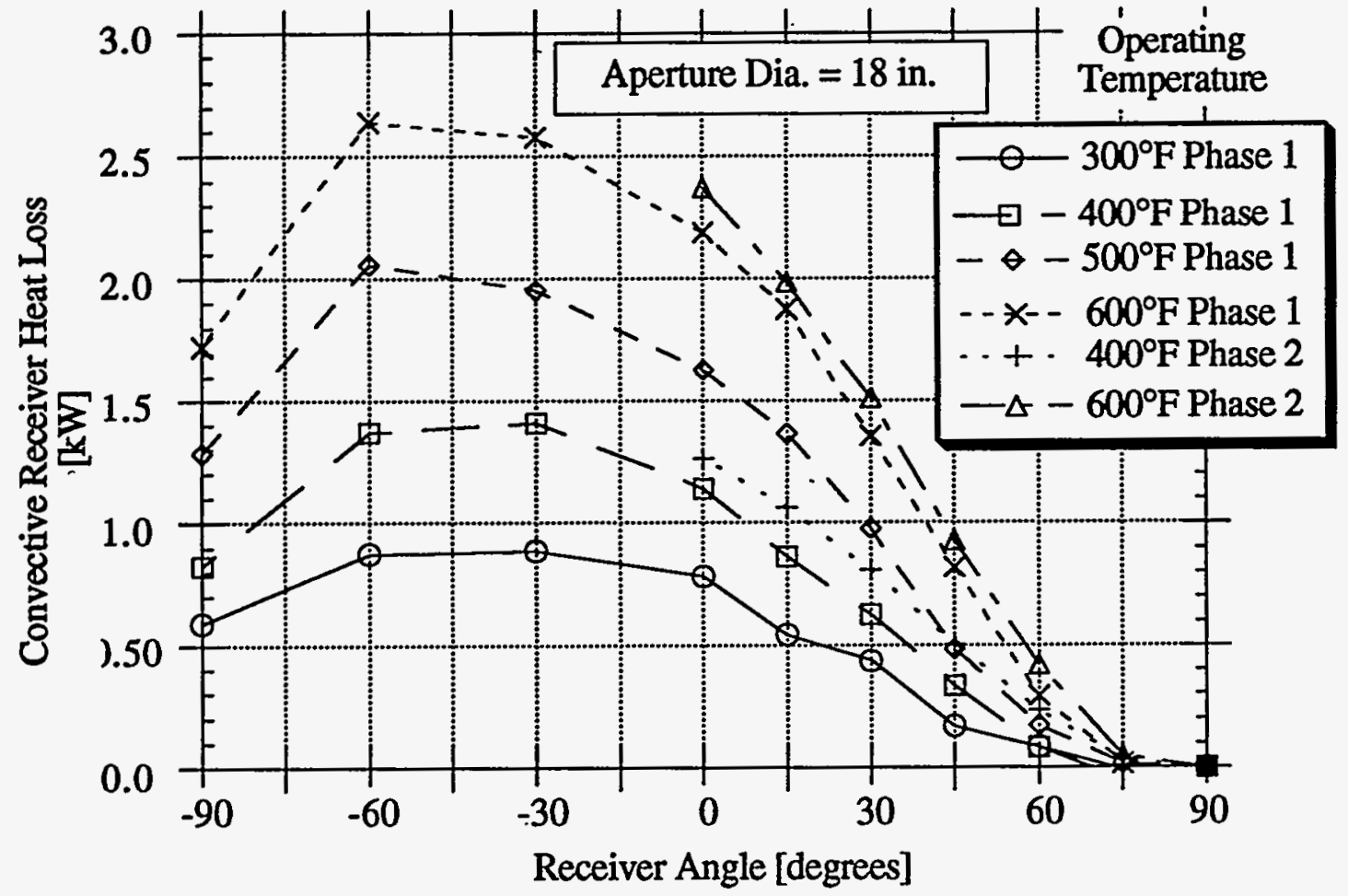

Figure 11. Convective heat loss for 18 inch aperture versus receiver angle

\section{B. Aperture Size Effects on Total and Convective Heat Losses}

The data summary of the Phase Two aperture size testing are tabulated in Appendix 2. These results were first presented by Stine and McDonald ${ }^{(8)}$. The effect of aperture size on the receiver total heat loss is shown (Fig. 12) for an operating temperature of $600^{\circ} \mathrm{F}$. At a receiver angle of $0^{\circ}$, the total receiver heat loss increases by a factor of three as the aperture diameter increases from 6 inches to 26 inches. The total heat loss at the $+75^{\circ}$ and $+90^{\circ}$ 
receiver angles are approximately equal. This agrees with a previous study (Stein and McDonald) on the effects of receiver angle( $\left.{ }^{(}\right)$. At these positions the total receiver heat loss increases by a factor of two when the aperture diameter increases from 6 inches to 26 inches for a $600^{\circ} \mathrm{F}$ operating temperature. At $+45^{\circ}$ the total heat loss increases approximately linearly with increase in aperture size. The receiver angle has less effect on the total heat loss for small apertures. The maximum variation due to receiver angle in the total heat loss is $0.4 \mathrm{~kW}$ for the 6 inch diameter aperture as compared to $1.2 \mathrm{~kW}$ loss with no aperture (26 inch aperture).

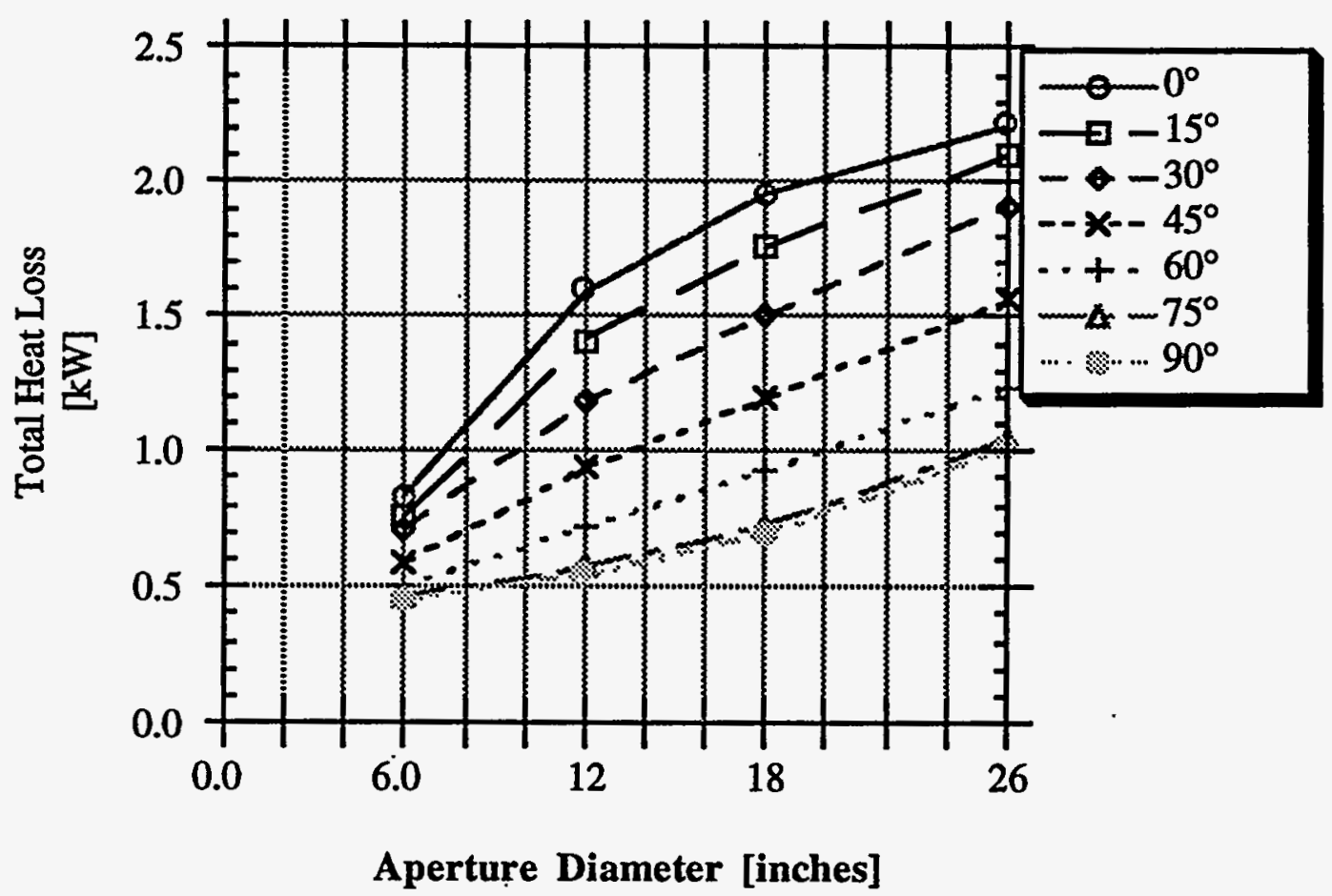

Figure 12. Total Receiver Heat Loss versus Aperture Size for $600^{\circ} \mathrm{F}$

The effect of aperture size on the convective component of the total heat loss is shown in Figures 13 and 14. Aperture size has a much greater effect for low receiver angles than high receiver angles. The results also showed the convective loss increased dramatically when the aperture increased from 6 inches to 18 inches. There was little change in the convective loss as the aperture increased beyond 18 inches. 


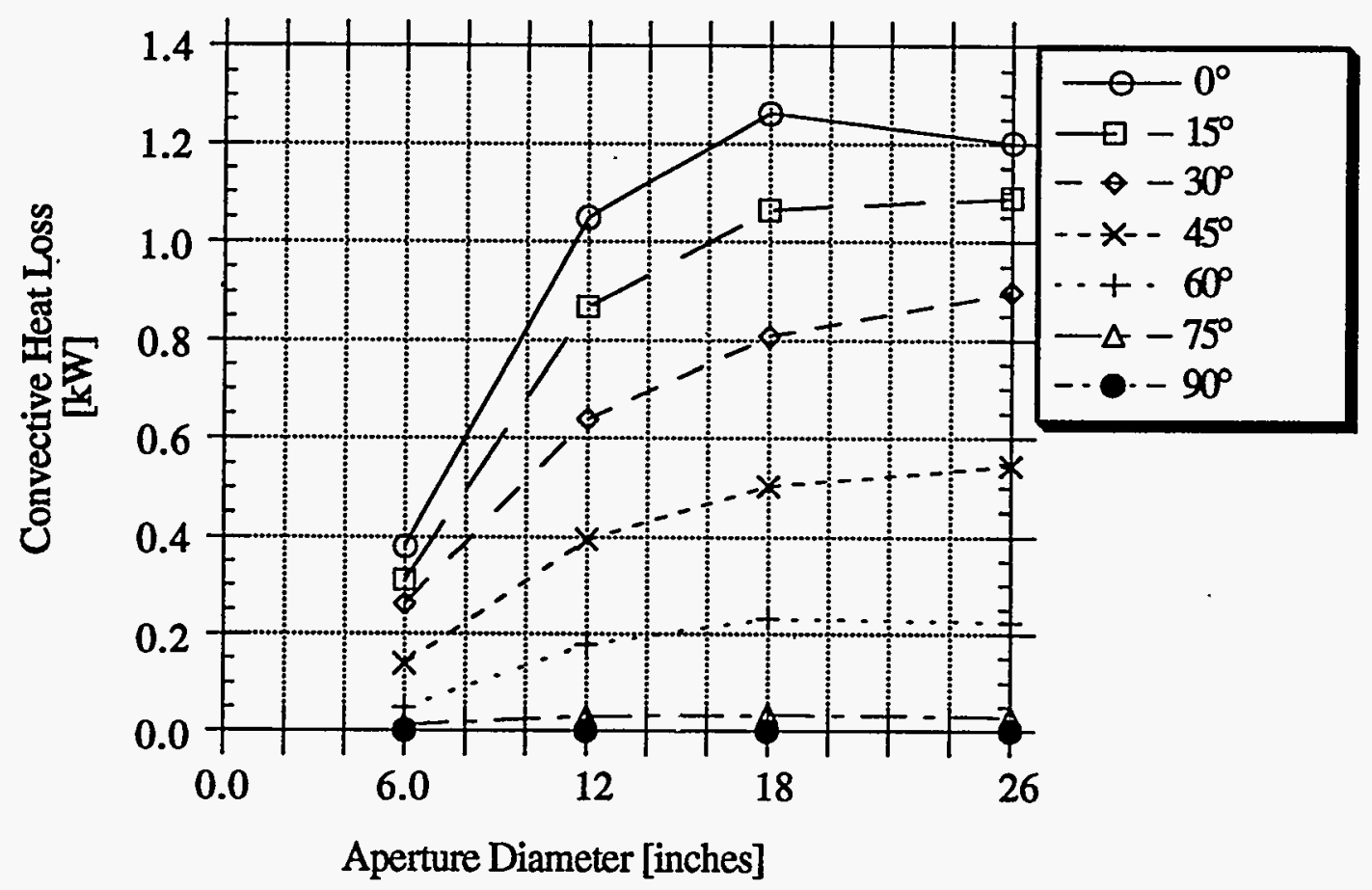

Figure 13. Convective Heat Loss versus Aperture Size for $400^{\circ} \mathrm{F}$

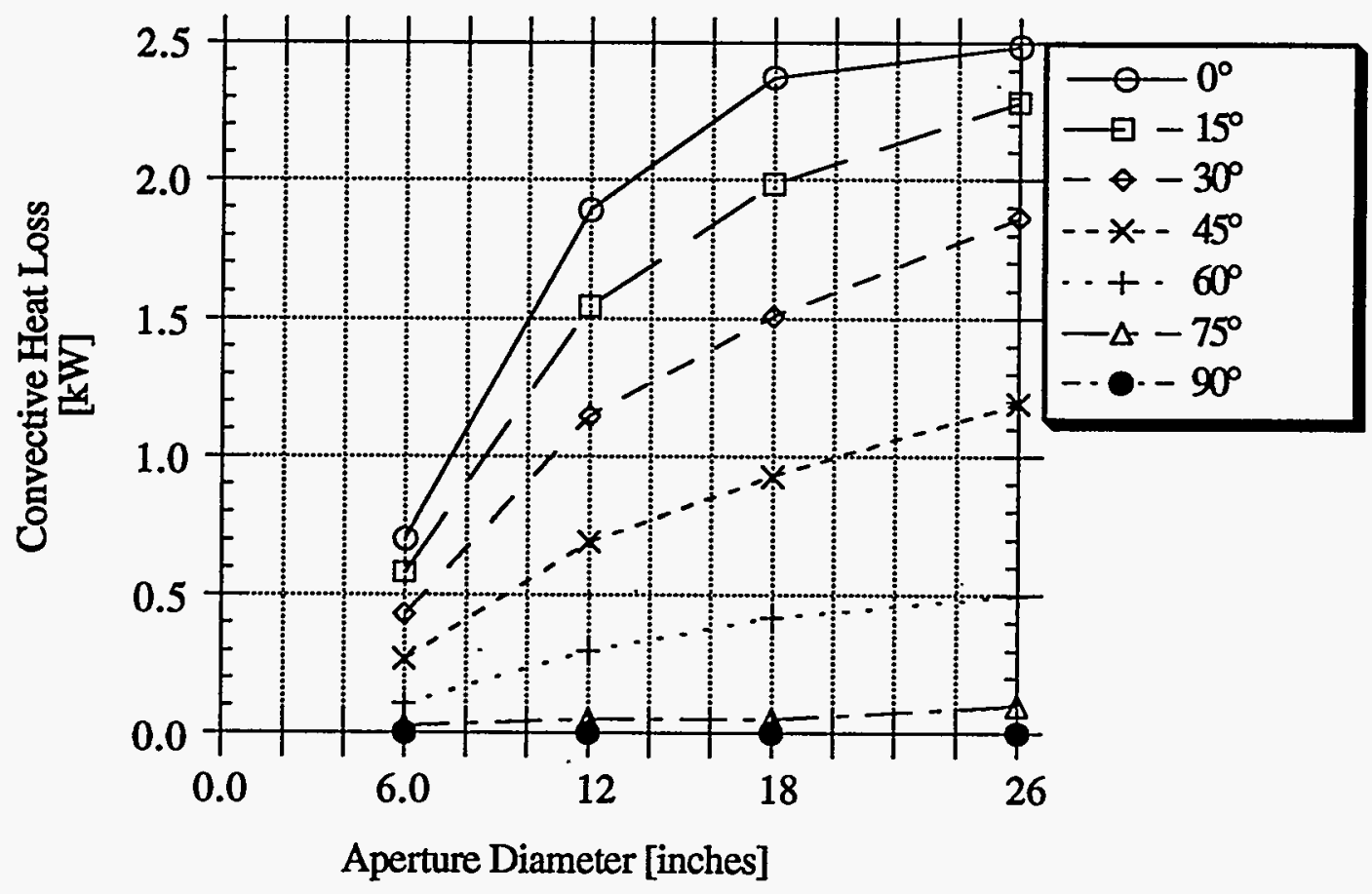

Figure 14. Convective Heat Loss versus Aperture Size for $600^{\circ} \mathrm{F}$ 


\section{Radiative and Conductive Heat Losses}

In these tests, the radiative heat loss was determined from the difference between the plugged and unplugged values of the total heat when the receiver is in the $+90^{\circ}$ position. The radiative heat loss was assumed constant for all receiver angles. The conductive heat loss, through the receiver walls, was given by the total receiver heat loss when the receiver was in the $+90^{\circ}$ position with the aperture plugged. The conductive heat loss was also assumed constant for all receiver angles. The radiative and conductive heat losses from Phase One and Two of the testing were compared for repeatability (Fig. 15). Some differences were expected as a result of overhauling the receiver after the Phase One tests.

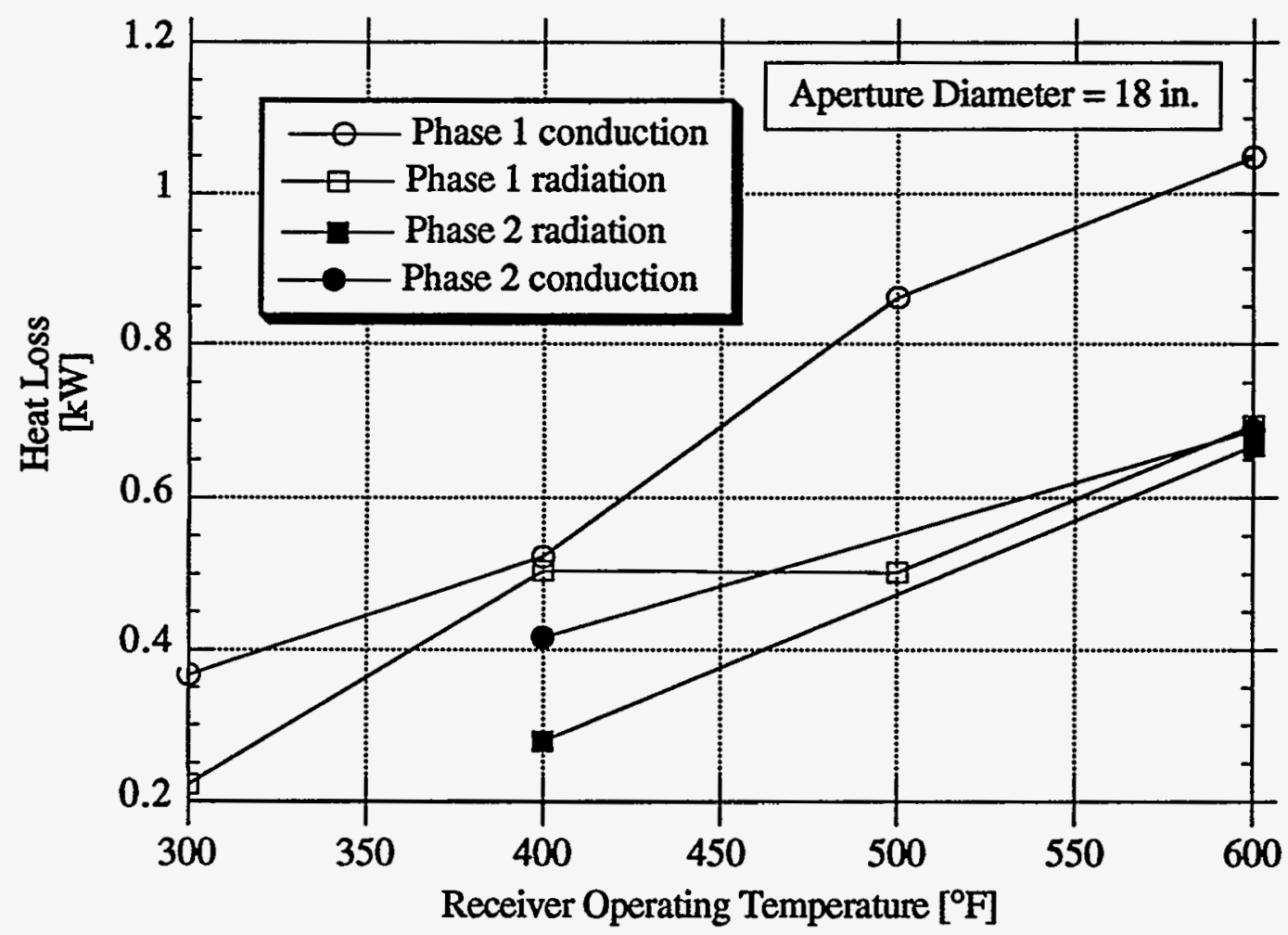

Figure 15. Radiative and Conductive Heat Losses versus Receiver Temperature 
An infrared radiometer was another method used to determine radiative heat loss. The difference between radiometer readings taken with the receiver plugged and unplugged measured the radiative heat loss through the aperture. The two methods for determining the radiative heat loss are compared for operating temperatures of $600^{\circ} \mathrm{F}$ and $400^{\circ} \mathrm{F}$ (Figs. 16 and 17). The radiative heat loss increased approximately with the square of the aperture area. For each of the two nominal operating temperatures, the analytical heat loss was slightly higher. The difference between the analytical and experimental data, radiative heat loss, increased positively with aperture size. The disparity was accounted for via the estimated parameters used in analysis. These parameters include surface emissivity, temperature distribution, refractory and non-refractory. For small aperture diameters to cavity volume ratios, the cavity will radiate through the aperture essentially as a black body regardless of the emittances of the internal surfaces. However, as the ratio increases the cavity becomes less of a black body emitter. For large aperture diameter to cavity volume ratios, the emittances of the internal surfaces become critical in determining the cavity emittance. Also, for larger apertures the temperature difference between the inlet and outlet becomes significant. The fixed difference used in the analysis for all aperture sizes could affect the results. Further investigation is required to provide more accurate temperature distributions. 


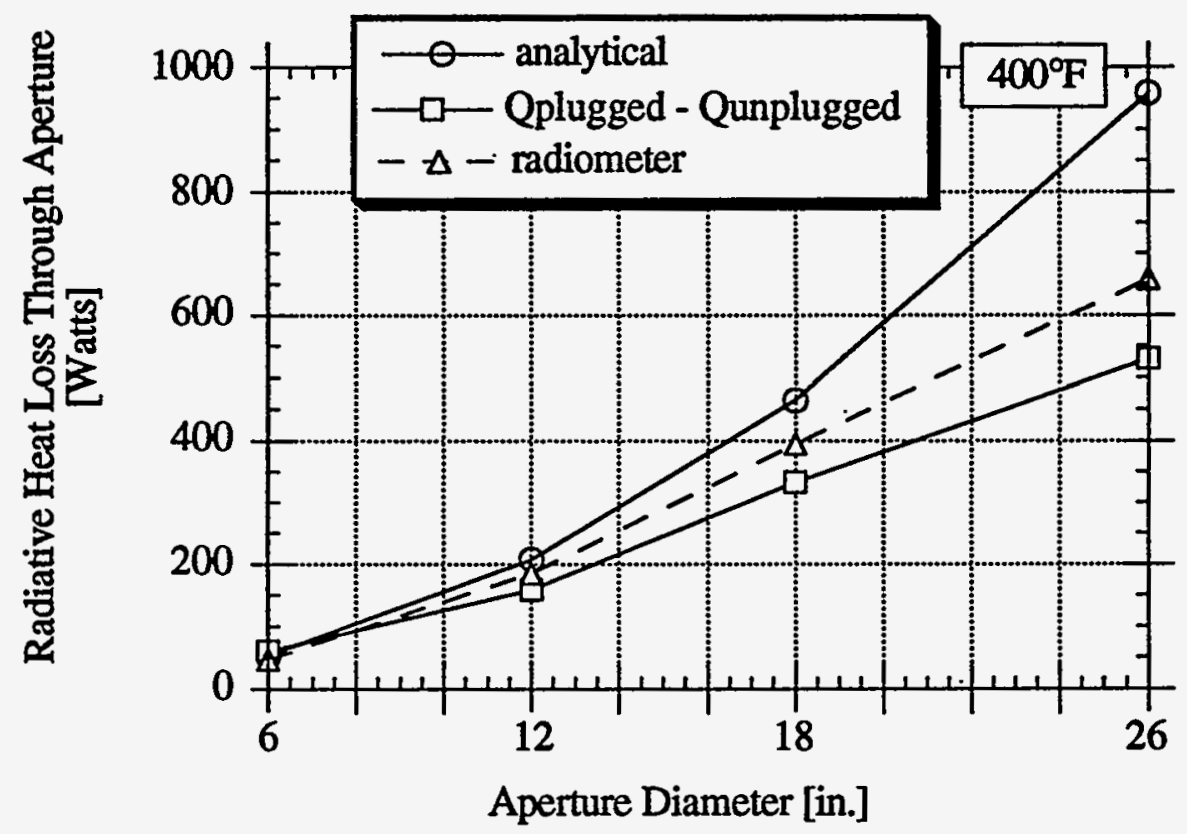

Figure 16 Radiative Heat Loss versus Aperture Size at $400^{\circ} \mathrm{F}$

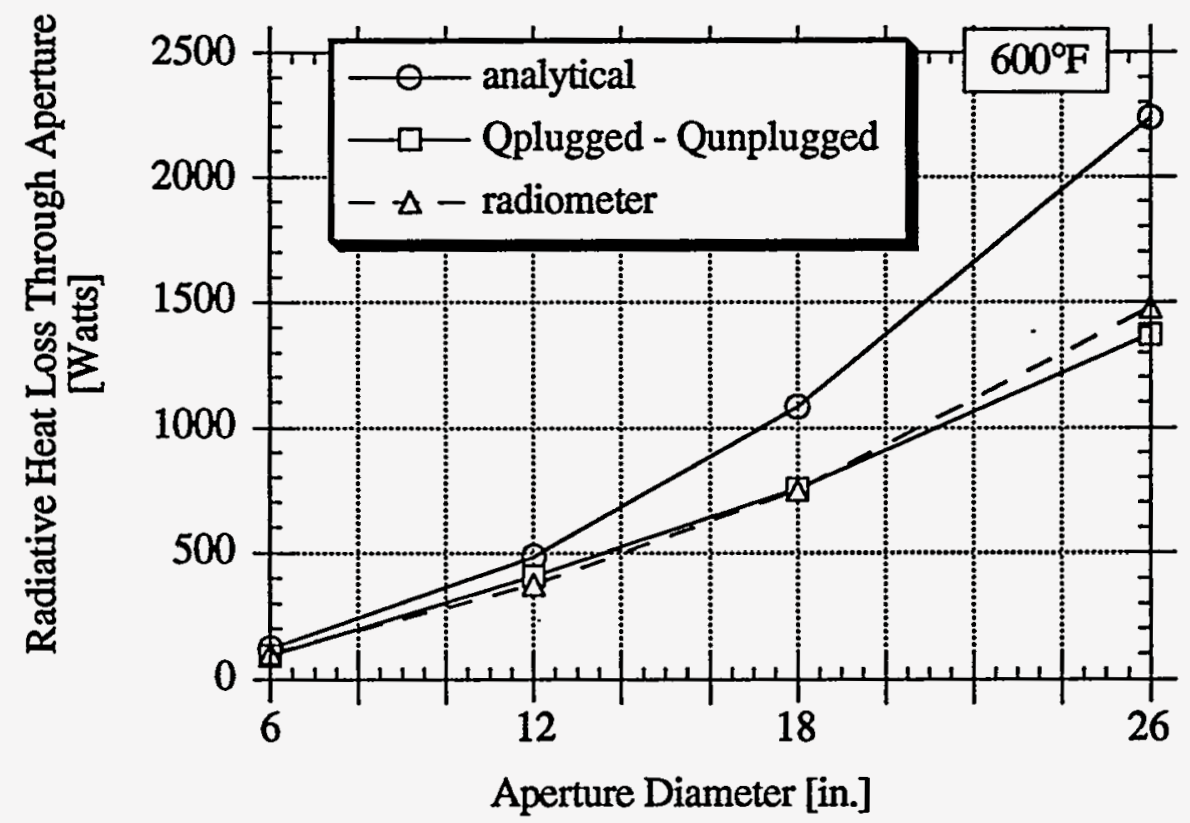

Figure 17 Radiative Heat Loss versus Aperture Size at $600^{\circ} \mathrm{F}$ 
The total heat loss make-up, in terms of the radiative, conductive, and convective components, changes with aperture size. With a 6 inch aperture and the receiver at $45^{\circ}$ the conduction loss forms about $65 \%$ of the total heat loss. With the receiver at a typical operating angle of $45^{\circ}$ and an operating temperature of $600^{\circ} \mathrm{F}$, radiative and convective percentages of total heat loss are approximately equal to an aperture of 26 inches (Fig. 18).

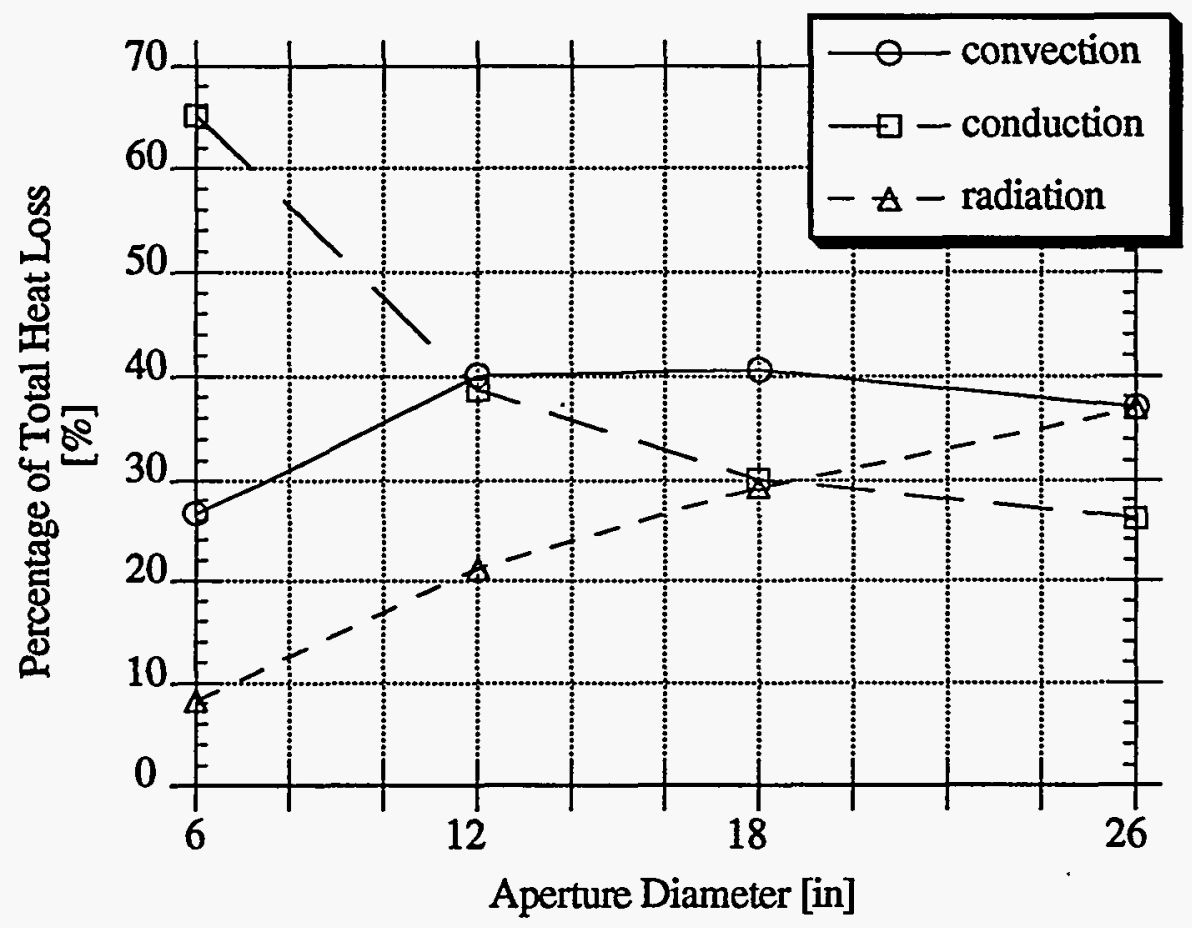

Figure 18. Percent Heat Loss Modes versus Aperture Size for $600^{\circ} \mathrm{F}$ at $45^{\circ}$ angle

\section{PREVIOUS CAVITY CONVECTION LOSS MODELS}

\section{A. LeQuere, Penot, and Mirenayat Model}

LeQuere, Penot and Mirenayat presented an experimental correlation for Nusselt number as a function of Grashof number. ${ }^{(9)}$ Their study used a cubical cavity typical of those used in central receiver systems. The study investigated varying receiver temperatures and angles. The model was developed for a maximum temperature difference between cavity walls and 
the ambient, $230^{\circ} \mathrm{F}$. Variation in receiver angles used in the model were from $0^{\circ}$, where the aperture is upward, to $180^{\circ}$, where the aperture is downward.

The cavity used in their testing was modular in design so that each panel could be heated independently. The panels were electrically heated. The electrical power and temperature of each panel were measured. Modular design allowed for local as well as global heat loss analysis. The total heat loss of the cavity was determined from the total electrical power used by all the panels. They determined the radiative component for total heat loss by summing the radiative heat loss of each panel to the cavity aperture.

$$
\mathrm{q}_{\text {radiative }}=\sum_{\mathrm{i}}^{\mathrm{Nm}} \varepsilon \sigma S\left(\mathrm{~T}_{\text {panel }}^{4}-\mathrm{T}_{\text {ambient }}^{4}\right) \mathrm{F}_{\mathrm{i}-\mathrm{o}}
$$

where:

$$
\begin{aligned}
& \bar{\sigma}=\text { Stefan-Boltzmann constant }\left[\mathrm{W} / \mathrm{m}^{2}-\mathrm{K}^{4}\right] \\
& \varepsilon=\text { emissivity of each panel } \\
& S=\text { panel surface area }\left[\mathrm{m}^{2}\right] \\
& T_{\text {panel }}=\text { individual panel temperature }[\mathrm{K}] \\
& T_{\text {ambient }}=\text { ambient temperature }[\mathrm{K}] \text { opening } \\
& F_{\mathrm{i}-\mathrm{o}}=\text { view factor for a panel to cavity opening } \\
& N_{\mathrm{m}}=\text { total number of panels that compose the cavity }
\end{aligned}
$$

The conduction heat loss component is determined by the total heat loss of a plugged cavity. By plugging the aperture of the receiver, the radiative and convective components of the total heat loss are eliminated.

The convective heat loss is determined by subtracting the conductive and radiative 
components from the total heat loss.

$$
\mathrm{q}_{\text {convection }}=\mathrm{q}_{\text {total }}-\mathrm{q}_{\text {conductive }}-\mathrm{q}_{\text {radiative }}
$$

Their Nusselt number is given by:

$$
\mathrm{Nu}=\frac{\mathrm{q}_{\text {convection }} \mathrm{L}}{\mathrm{Sk}\left(\mathrm{T}_{\text {panel }}-\mathrm{T}_{\text {ambient }}\right)}
$$

where:

$$
\begin{aligned}
& L=\text { dimension of cavity aperture }[\mathrm{m}] \\
& \mathbf{k}=\text { thermal conductivity of air }[\mathrm{W} / \mathrm{m} \cdot \mathrm{K}] \\
& \mathrm{S}=\text { total interior cavity surface area }\left[\mathrm{m}^{2}\right]
\end{aligned}
$$

The Grashof number is given by:

$$
\mathrm{Gr}=\frac{\mathrm{g} \beta\left(\mathrm{T}_{\text {panel }}-\mathrm{T}_{\text {ambient }}\right) \mathrm{L}^{3}}{v^{2}}
$$

where:

$$
\begin{aligned}
& g=\text { local gravitational acceleration }\left[\mathrm{m} / \mathrm{s}^{2}\right] \\
& \beta=\text { thermal expansion coefficient of air }\left[\mathrm{K}^{-1}\right] \\
& \mathrm{v}=\text { kinematic viscosity of air }\left[\mathrm{m}^{2} / \mathrm{s}\right]
\end{aligned}
$$

All fluid properties were evaluated at the ambient temperature. The experimental correlation for Nusselt number as a function of the Grashof number is given by:

$$
\mathrm{Nu}=\mathrm{a} \mathrm{Gr}^{\mathrm{b}}
$$

The coefficient ' $a$ ' and the exponent ' $b$ ' are empirically derived and are both a function of receiver angle. The values of ' $a$ ' and ' $b$ ' are presented in Table 1 for receiver angles of interest in this study. Equation 10 is valid for a Grashof number between $10^{7}$ and $5 \times 10^{9}$. 
Table 1.

Empirical correlation coefficients and exponents

\begin{tabular}{|c|c|c|}
\hline $\begin{array}{c}\text { Receiver Angle } \\
\boldsymbol{\phi}\end{array}$ & $\begin{array}{c}\text { Coefficient } \\
\mathbf{a}\end{array}$ & $\begin{array}{c}\text { Exponent } \\
\mathbf{b}\end{array}$ \\
\hline \hline-90 & 0.0570 & 0.353 \\
-75 & 0.0470 & 0.360 \\
-60 & 0.0545 & 0.360 \\
-45 & 0.0465 & 0.370 \\
-30 & 0.0480 & 0.369 \\
-15 & 0.0465 & 0.368 \\
0 & 0.0925 & 0.330 \\
15 & 0.0810 & 0.331 \\
30 & 0.0640 & 0.332 \\
45 & 0.0605 & 0.316 \\
60 & 0.0685 & 0.292 \\
75 & 0.0330 & 0.302 \\
90 & NA & NA \\
\hline
\end{tabular}

Consideration must be given to the difference in the cavity geometry from receiver used by LeQuere, Penot and Mirenayat and that used in this study. The receiver used by LeQuere, Penot and Mirenayat was cubical whereas the receiver used in this test was cylindrical and conical. The LeQuere, Penot and Mirenayat receiver aperture is the same as the characteristic interior dimension. They did not study the effect of varying aperture sizes.

LeQuere, Penot and Mirenayat modeled convective heat loss through the aperture is given by:

$$
q_{\text {convective }}=h A\left(T_{\text {cav }}-T_{\text {ambient }}\right)
$$

where:

$\mathrm{h}=$ convective heat transfer coefficient $\left[\mathrm{w} / \mathrm{m}^{2} \mathrm{k}\right]$

$A=$ total interior cavity surface area $\left[\mathrm{m}^{2}\right]$

$T_{\text {cav }}=$ area average cavity surface temperature $[K]$

$\mathrm{T}_{\text {ambient }}=$ ambient air temperature $[\mathrm{K}]$ 
The convective heat transfer coefficient is given by:

$$
\mathrm{h}=\frac{\mathrm{kNu}}{\mathrm{L}}
$$

where:

$$
\begin{aligned}
& \mathbf{L}=\text { dimension of cavity aperture }[\mathrm{m}] \\
& \mathbf{k}=\text { thermal conductivity of air }[\mathrm{W} / \mathrm{m}-\mathrm{K}] \\
& \mathrm{Nu}=\text { Nusselt number }
\end{aligned}
$$

A BASIC computer language program was written to solve for the convective heat loss from the receiver used in this study applying the LeQuere, Penot, and Mirenayat model. For a listing of the computer program see Appendix 3. The results are presented in Appendix 4. The variations in the convective heat loss with receiver angles for operating temperatures from $300^{\circ} \mathrm{F}$ to $600^{\circ} \mathrm{F}$ and aperture sizes from 6 inches to 26 inches are presented (Fig. 19).

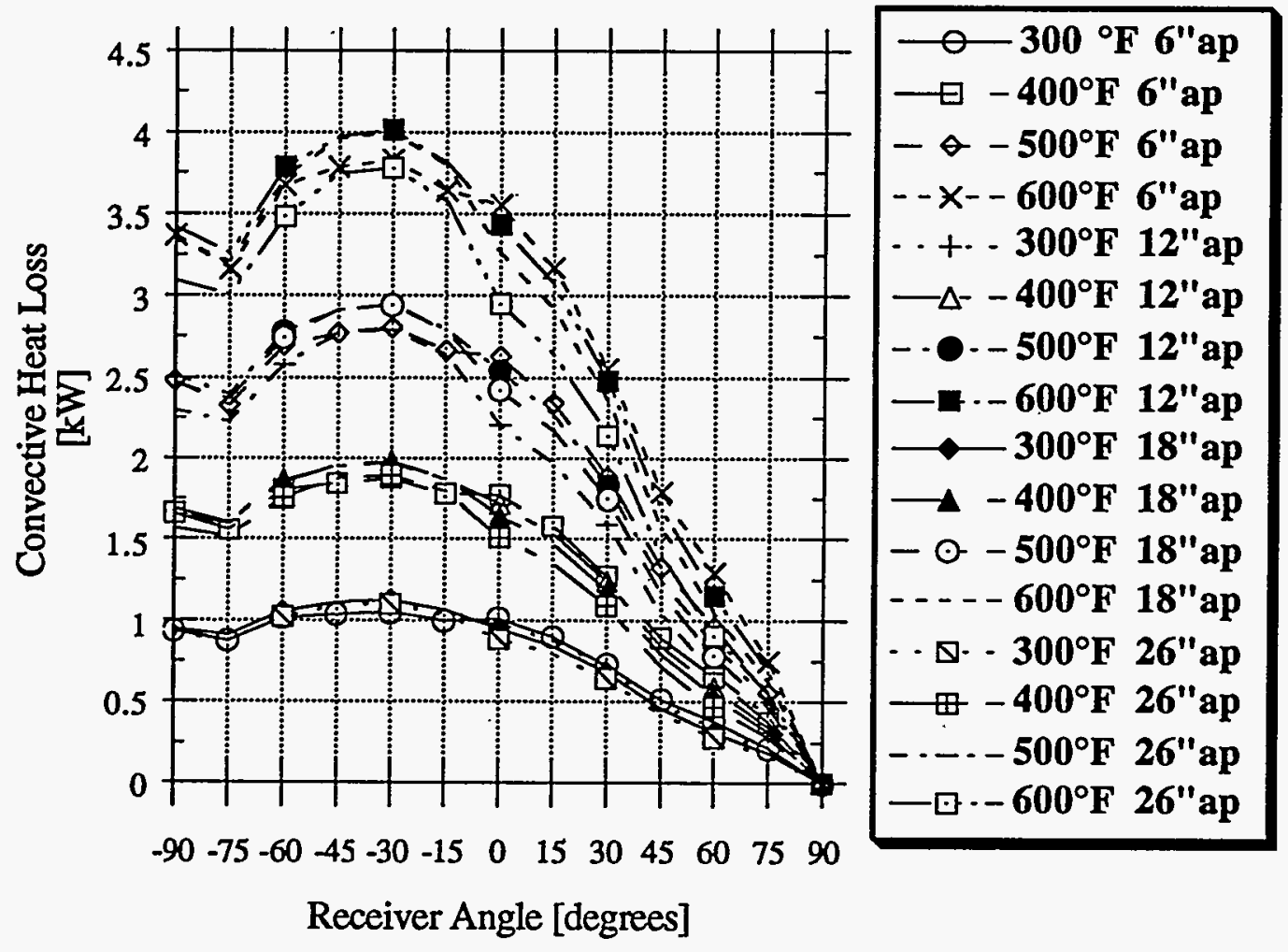

Figure 19. Convective heat loss for LeQuere, Penot, and Mirenayat model 


\section{B. Koenig and Marvin Model}

The Koenig and Marvin model for predicting convective heat loss from a cavity receiver is presented by Harris and Lenz.(10) Their model is based on operating temperatures between $550^{\circ} \mathrm{C}\left(1022^{\circ} \mathrm{F}\right)$ and $900^{\circ} \mathrm{C}\left(1652^{\circ} \mathrm{F}\right)$ for an on-flux analysis. The operating temperature range used by Koenig and Marvin is considerably higher than any receiver temperature tested in this study. The Koenig and Marvin receiver was designed to operate at higher temperatures.

For the Koenig and Marvin model the convective heat loss through the cavity aperture is given by:

$$
\dot{\mathrm{q}}_{\mathrm{cav}}=\mathrm{h} \mathrm{A}_{\mathrm{T}}\left(\mathrm{T}_{\mathrm{cay}}-\mathrm{T}_{\mathrm{amb}}\right)
$$

where:

$$
\begin{aligned}
& A_{T}=\text { area of heat transfer tubing facing inside cavity }\left[\mathrm{m}^{2}\right] \\
& T_{c a v}=\text { inside cavity temperature or mean operating temperature }[\mathrm{K}] \\
& T_{\mathrm{amb}}=\text { ambient air temperature }[\mathrm{K}] \\
& \mathrm{h}=\text { cavity convective heat transfer coefficient }\left[\mathrm{W} / \mathrm{m}^{2} \mathrm{k}\right]
\end{aligned}
$$

The heat transfer coefficient is given by:

$$
\mathrm{h}=\frac{\mathrm{k} \mathrm{Nu} \text { cav }}{\mathrm{L}}
$$

where:

$\mathrm{k}=$ thermal conductivity of air $[\mathrm{W} / \mathrm{m}-\mathrm{K}]$

$\mathrm{Nu}_{\text {cav }}=$ Nusselt number of the cavity

$\mathrm{L}=$ characteristic length of the cavity $[\mathrm{m}]$ 
The characteristic length of the cavity used by Koenig and Marvin is given by:

$$
\mathbf{L}=\sqrt{2} \mathbf{R}_{\mathrm{cav}, \mathbf{i}}
$$

where:

$$
\mathrm{R}_{\text {cav }, \mathrm{i}}=\text { mean inner cavity radius }[\mathrm{m}]
$$

The Nusselt number is given by:

$$
\mathrm{Nu}_{\mathrm{cav}}=0.52 \mathrm{P}(\phi) \ell_{\mathrm{c}}^{1.75}\left(\mathrm{Gr}_{\mathrm{L}} \mathrm{Pr}\right)^{1 / 4}
$$

where:

$$
\begin{aligned}
& \mathrm{P}(\phi)=\text { is an expression that accounts for the effects of receiver angle } \\
& \ell_{\mathrm{c}}=\text { is an expression that corrects for aperture size } \\
& \mathrm{Gr}_{\mathrm{L}}=\text { Grashof number } \\
& \mathrm{Pr}=\text { Prandtl number }
\end{aligned}
$$

The receiver angle function is given by:

$$
\begin{array}{cc}
P(\phi)=\cos ^{3.2} \phi & \text { for } 0^{\circ} \leq \phi \leq 45^{\circ} \\
P(\phi)=0.707 \cos ^{2.2} \phi & \text { for } 45^{\circ} \leq \phi \leq 90^{\circ}
\end{array}
$$

where:

$$
\phi=\text { angle of cavity axis with the horizontal [degrees] }
$$

The aperture size function is given by:

where:

$$
\ell_{\mathrm{c}}=\frac{\mathrm{R}_{\mathrm{ap}}}{\mathrm{R}_{\mathrm{cav}, \mathrm{i}}}
$$




$$
\mathbf{R}_{\text {ap }}=\text { cavity aperture radius }[\mathrm{m}]
$$

The Grashof number is given by:

$$
\mathrm{Gr}_{\mathrm{L}}=\frac{\mathrm{L}^{3} \mathrm{~g} \beta\left(\mathrm{T}_{\mathrm{cav}}-\mathrm{T}_{\mathrm{amb}}\right)}{v^{2}}
$$

where:

$$
\begin{aligned}
& g=\text { gravitational acceleration }\left[\mathrm{m} / \mathrm{sec}^{2}\right] \\
& \beta=\text { coefficient of volumetric expansion }[\mathrm{K}-1] \\
& v=\text { kinematic viscosity }\left[\mathrm{m}^{2} / \mathrm{sec}\right]
\end{aligned}
$$

The volumetric expansion coefficient for air is calculated as:

$$
\beta=\frac{1}{T_{\text {prop }}}
$$

where:

$\mathrm{T}_{\mathrm{prop}}=$ temperature at which the air properties are evaluated $[\mathrm{K}]$

The Koenig and Marvin air properties temperature is given by:

$$
T_{\text {prop }}=\frac{11}{16} T_{c a v}+\frac{3}{16} T_{\text {amb }}
$$

The thermal radiative losses through the cavity aperture from the hot interior surface is given by:

$$
\dot{\mathrm{q}}_{\mathrm{rad}}=\pi \mathrm{R}_{\mathrm{ap}}^{2} \varepsilon_{\mathrm{a}} \bar{\sigma}\left(\mathrm{T}_{\mathrm{cav}}^{4}-\mathrm{T}_{\mathrm{amb}}^{4}\right)
$$

where: 
$\varepsilon_{\mathrm{a}}=$ emissivity of the aperture

$\bar{\sigma}=$ Stefan-Boltzmann constant $\left[\mathrm{W} / \mathrm{m}^{2}-\mathrm{K}^{4}\right]$

$\varepsilon_{\mathrm{a}} \approx 0.9$ for these studies

The conduction heat loss through the walls of the cavity is given by:

$$
\dot{q}_{\text {cond }}=\frac{k_{\mathrm{i}} A_{c}\left(T_{c a v}-T_{a m b}\right)}{t}
$$

where:

$$
\begin{aligned}
& A_{c}=\text { area for conduction through the cavity }\left[\mathrm{m}^{2}\right] \\
& k_{i}=\text { thermal conductivity of the cavity insulation }[\mathrm{W} /(\mathrm{m}-\mathrm{K})] \\
& t=\text { thickness of cavity insulation }[\mathrm{m}]
\end{aligned}
$$

The conduction area of the cavity for the receiver considered in this study is given by:

$$
\mathrm{A}_{\mathrm{c}}=\pi\left(\frac{\mathrm{R}_{\mathrm{cav}, \mathrm{i}}+\mathrm{R}_{\mathrm{cav}, \mathrm{o}}}{2}\right)^{2}+2 \pi\left(\frac{\mathrm{R}_{\mathrm{cav}, \mathrm{i}}+\mathrm{R}_{\mathrm{cav}, \mathrm{o}}}{2}\right)+\pi\left(\mathrm{R}_{\mathrm{cav}, \mathrm{i}}^{2}-\mathrm{R}_{\mathrm{ap}}^{2}\right)
$$

where:

$$
\mathbf{R}_{\text {cav }, 0}=\text { cavity outside radius }[\mathrm{m}]
$$

Application of the Koenig and Marvin model to the receiver under study here was accomplished using a BASIC computer language program. The program is listed in Appendix 5. The results of the Koenig and Marvin modeling are found in Appendix 6. Figure 20 summarizes the values in Appendix 6. 


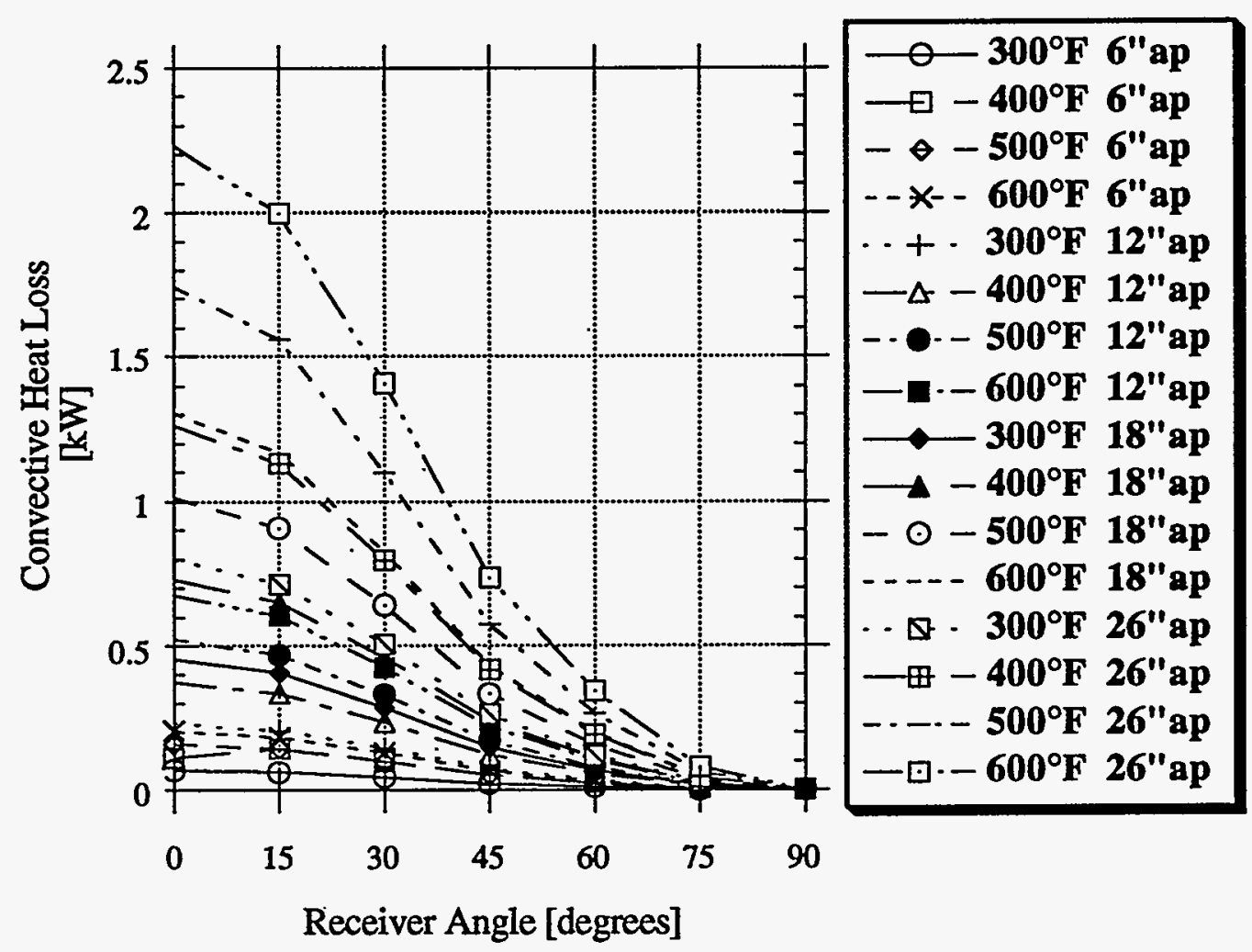

Figure 20. Convective heat loss for Koenig and Marvin model

\section{ClAUSING MODEL}

The Clausing model of convective heat loss from cavities was developed for large central receivers as opposed to the small receiver, used in this study. ${ }^{(11)}$ The receivers utilized for the development of the Clausing model were simple in geometry with no curved surfaces. The Clausing model has been modified for application to the receiver provided in this study. The model was developed for on-flux mode of operation. For on-flux analysis the refractory surfaces are assumed to have a higher temperature than the active surfaces, whereas, for off-flux analysis the temperature conditions are reversed. Many of the temperature terms used in the Clausing model required modification to work for an off-flux situation.

Clausing's convective heat loss is based on an energy balance between the convective 
energy loss within the cavity, $q_{c}$, and the energy transported through the aperture of the cavity, $q_{a}\left(\right.$ i.e. $\left.q_{a}=q_{c}\right)($ Fig 21$)$.

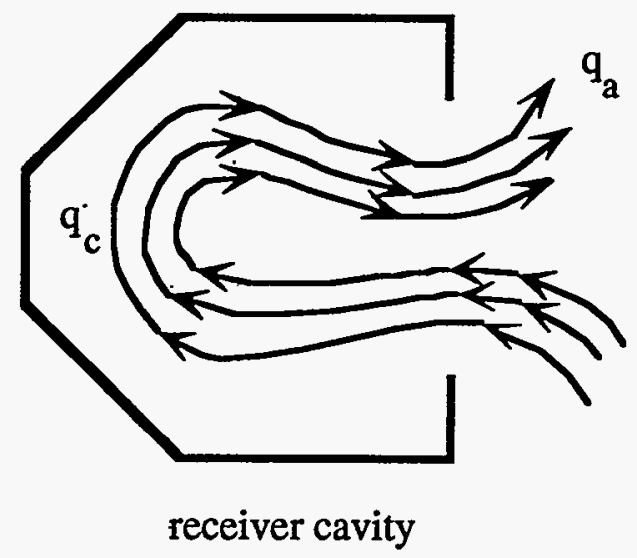

Figure 21. Convective heat loss balance

The cavity is divided into two zones: a convective zone and a stagnation zone (Fig. 22). The horizontal plane cutting through the upper lip of the cavity aperture divides the convective zone from the stagnation zone. The convective current in the cavity flow over the heated surfaces, the refractory surfaces, and the area of the horizontal plane dividing the stagnation zone from the convective zone. The heated and refractory walls in the stagnation zone do not participate in any convective heat transfer.

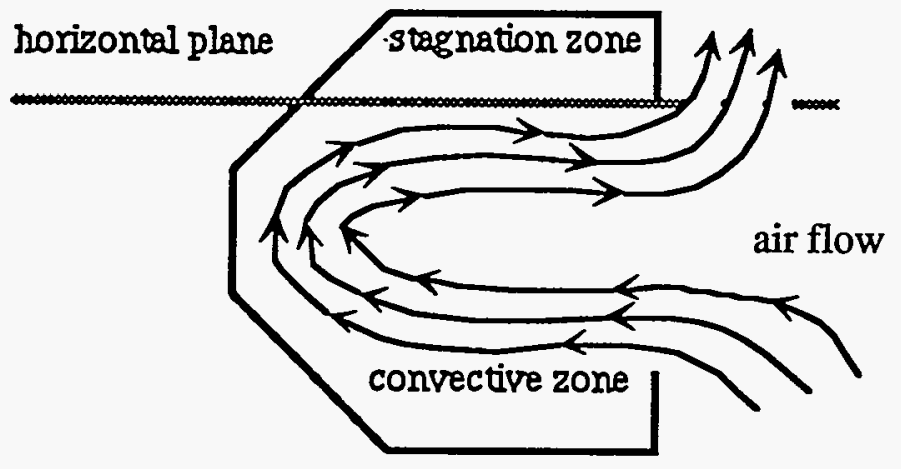

receiver cavity

Figure 22. Receiver internal cavity zones 


\section{Convective Energy Loss Through the Aperture}

According to Clausing, the convective energy loss through the aperture is given by:

$$
q_{a}=c_{p}\left(\rho_{\infty} V_{a} A_{a}\right)\left(T_{c}-T_{\infty}\right)
$$

where:

$\rho_{\infty}=$ ambient air density $\left[\mathrm{kg} / \mathrm{m}^{3}\right]$

$\mathrm{V}_{\mathrm{a}}=$ average air flow velocity into the aperture $[\mathrm{m} / \mathrm{s}]$

$A_{a}=$ area of the aperture through which air flows into the aperture $\left[\mathrm{m}^{2}\right]$

$c_{p}=$ specific heat of ambient air $[\mathrm{J} / \mathrm{kg}-\mathrm{K}]$

$\mathrm{T}_{\mathrm{c}}=$ temperature of the exiting air $[\mathrm{K}]$

$\mathrm{T}_{\infty}=$ ambient air temperature $[\mathrm{K}]$

The average exiting velocity is given by $(11)$ :

$$
V_{a}=\frac{1}{2} \sqrt{\left[\left(C_{3} V_{b}\right)^{2}+\left(C_{4} V\right)^{2}\right]}
$$

where:

$$
\begin{aligned}
& C_{3}=1 \\
& C_{4}=1 / 2 \\
& V=\text { wind speed }[\mathrm{m} / \mathrm{s}] \\
& V_{b}=\text { buoyancy induced velocity }[\mathrm{m} / \mathrm{s}]
\end{aligned}
$$

For the no-wind condition, the interest of study, the equation reduces to:

$$
\mathrm{V}_{\mathrm{a}}=\frac{1}{2} \mathrm{~V}_{\mathrm{b}}
$$


The buoyancy induced velocity is given by:

$$
V_{b}=\sqrt{g \beta\left(T_{\dot{c}}+T_{\infty}\right) L_{a}}
$$

where:

$$
\begin{aligned}
& g=\text { local gravitational acceleration }\left[\mathrm{m} / \mathrm{s}^{2}\right] \\
& \beta=\text { coefficient of volume expansion }\left[\mathrm{k}^{-1}\right] \\
& \mathrm{L}_{\mathrm{a}}=\text { projected vertical height of the aperture }[\mathrm{m}]
\end{aligned}
$$

For air the temperature coefficient of volume expansion is given by:

$$
\beta=\frac{1}{T_{b}}
$$

where:

$$
\mathrm{T}_{\mathrm{b}}=\text { bulk air temperature in the convective zone of the cavity [K] }
$$

The bulk air temperature is given by:

$$
T_{b}=\frac{T_{c}+T_{\infty}}{2}
$$

The projected vertical height of the cavity is given by:

$$
\mathrm{L}_{\mathrm{a}}=\mathrm{D}_{\mathrm{a}} \cos \theta
$$

where:

$$
\begin{aligned}
& D_{a}=\text { the cavity aperture diameter }[\mathrm{m}] \\
& \theta=\text { receiver angle [degrees] }
\end{aligned}
$$




\section{Convective Energy Loss Within the Receiver}

The Clausing model for convective heat loss within the cavity is given by:

$$
q_{c}=h A_{t}\left(T_{t}-T_{b}\right)+h A_{w}\left(T_{w}-T_{b}\right)+h A_{s}\left(T_{s}-T_{b}\right)
$$

where:

$\mathrm{h}=$ average heat transfer coefficient $\left[\mathrm{W} / \mathrm{m}^{2}-\mathrm{K}\right]$

$A_{t}=$ tube surface area in convective zone $\left[\mathrm{m}^{2}\right]$

$T_{t}=$ average tube surface temperature $[\mathrm{K}]$

$A_{w}=$ refractory surface area of cavity in convective zone $\left[\mathrm{m}^{2}\right]$

$T_{\mathrm{w}}=$ average refractory surface temperature $[\mathrm{K}]$

$A_{s}=$ area of interface plane between convective zone and stagnation zone $\left[\mathrm{m}^{2}\right]$

$T_{s}=$ average temperature of interface plane $[K]$

The average heat transfer coefficient is determined from the Nusselt number and is given by:

$$
h=\frac{N u k}{L_{a}}
$$

where:

$$
\begin{aligned}
& \mathrm{Nu}=\text { Nusselt number } \\
& \mathrm{k}=\text { kinematic viscosity of air at the bulk fluid temperature }[\mathrm{W} / \mathrm{m}-\mathrm{K}]
\end{aligned}
$$

For small receivers with a Grashof number of around $2.6 \times 10^{9}$ the Nusselt number is given by:

$$
\mathrm{Nu}=0.10(\mathrm{Gr} \mathrm{Pr})^{1 / 3}
$$


where:

$$
\begin{aligned}
& \mathrm{Pr}=\text { Prandtl number }=0.7 \text { (air) } \\
& \mathrm{Gr}=\text { Grashof number }
\end{aligned}
$$

The Grashof number is given by:

$$
\mathrm{Gr}=\frac{g \beta}{v^{2}}\left(T_{w}-T_{\infty}\right) L_{a}^{3}
$$

where:

$$
v=\text { kinematic viscosity of air at the film temperature }\left[\mathrm{m}^{2} / \mathrm{s}\right]
$$

The film temperature is given by:

$$
T_{f}=\frac{T_{w}+T_{b}}{2}
$$

For the Grashof number expression the coefficient of expansion is given by:

$$
\beta=\frac{1}{T_{f}}
$$

Clausing assumes the temperature of the shear plane to be equal to the tube surface temperature in the convective zone (i.e. $T_{s}=T_{t}$ ). The cavity convective heat loss is then given by:

$$
q_{c}=h A_{t}\left(T_{t}-T_{b}\right)+h A_{w}\left(T_{w}-T_{b}\right)+h A_{s}\left(T_{t}-T_{b}\right)
$$

In this work, the refractory surface temperature is assumed to be $100^{\circ} \mathrm{F}$ cooler than the tube surface temperature. This temperature difference is typical for measured values at the end 
plate refractory surface and a heated tube surface near the end plate.

The convective heat transfer areas within the convective zone will vary in size with changes in receiver angle. The expressions for the convective heat transfer areas as a function of receiver angle area are developed in the Zone Area Formulas section.

\section{Radiative Energy Loss Through the Aperture}

An approximation for the radiative energy loss from the cavity through the aperture, as presented by Clausing, is given by:

$$
\mathrm{q}_{\mathrm{r}}=\mathrm{A}_{\mathrm{a}} \varepsilon \sigma\left[\frac{\mathrm{A}_{\mathrm{c}}}{\mathrm{A}_{\mathrm{c}}+\mathrm{A}_{\mathrm{h}}}\left(\mathrm{T}_{\mathrm{w}}^{4}-\mathrm{T}_{\mathrm{a}}^{4}\right)+\frac{\mathrm{A}_{\mathrm{h}}}{\mathrm{A}_{\mathrm{c}}+\mathrm{A}_{\mathrm{h}}}\left(\mathrm{T}_{\mathrm{m}}^{4}-\mathrm{T}_{\mathrm{a}}^{4}\right)\right]
$$

where:

$$
\begin{aligned}
& \varepsilon=\text { emittance of the cavity } \\
& \sigma=\text { Stefan-Boltzmann constant }\left[\mathrm{W} / \mathrm{m}^{2}-\mathrm{K}^{4}\right]
\end{aligned}
$$

If the aperture is assumed to radiate as a black body then the emissivity of the cavity is equal to one; especially when the ratio of aperture size to cavity volume is small.

\section{Conductive Energy Lös From the Receiver}

The Clausing model for the conductive heat loss through the cavity walls is given by:

$$
q_{k}=\frac{k}{t}\left[A_{h}\left(T_{m}-T_{a}\right)+A_{w}\left(T_{w}-T_{a}\right)\right]
$$


where:

$$
\begin{aligned}
& k=\text { thermal conductivity of the cavity walls }[\mathrm{W} / \mathrm{mK}] \\
& t=\text { thickness of the cavity walls }[\mathrm{m}]
\end{aligned}
$$

For this study:

$$
\begin{aligned}
& k=.04756[\mathrm{~W} / \mathrm{mK}] \\
& \mathrm{t}=.0889[\mathrm{~m}]=(3.5[\mathrm{in} .])
\end{aligned}
$$

\section{Zone Area Formulas}

The receiver cavity is divided into two zones (Fig. 23). The boundary between the zones is formed by a horizontal plane cutting through the cavity at the upper lip of the aperture. The upper zone is assumed stagnant while the lower zone has active convective currents. The area in zone 1 is represented by the internal surface area of the receiver above the horizontal plane. The area in zone 2 is represented by the internal surface area of the receiver below the horizontal plane. The areas of zone 1 and zone 2 vary with receiver angle for a given receiver geometry.

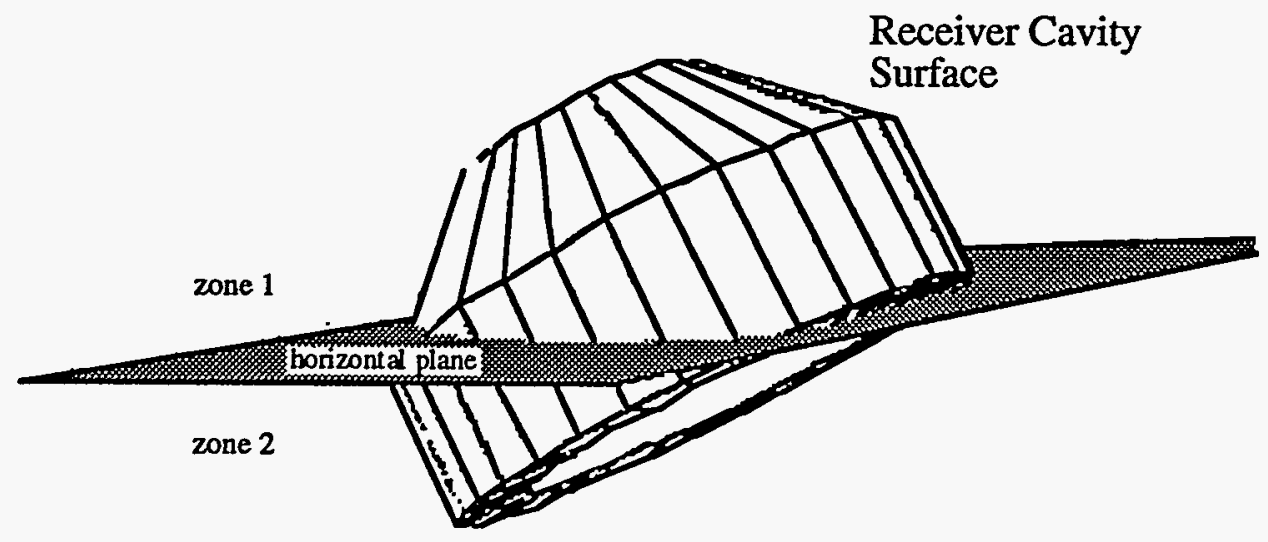

Figure 23. Cavity zones areas 
The receiver internal geometry is divided into five sections representing the hot and cold surfaces in the receiver (Fig. 24). The hot surfaces are actively heated. The cold surfaces represent the refractory surfaces. Section 1 is the circular plate at the end of the frustum. Section 2 is the frustum portion of the tube bundle. Section 3 is the cylindrical portion of the tube bundle. Section 4 is the short refractory portion of the cylindrical section. Section 5 is the refractory ring that forms the aperture.

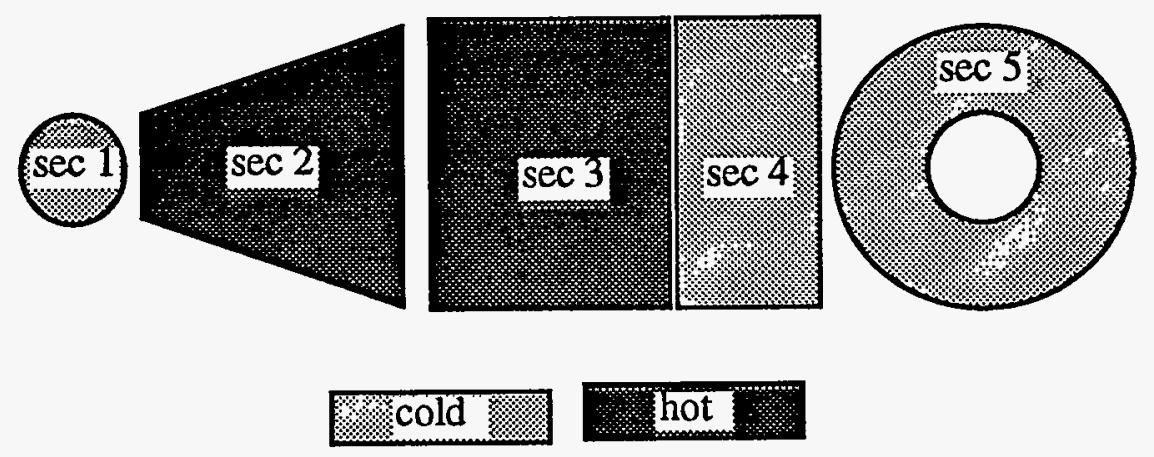

Figure 24. Cavity sections

As the receiver is rotated through various angles, each section of the internal receiver geometry may be divided by the horizontal plane that cuts through the upper inside edge of section 5. The formulas defining the portion of the area of each section that is in zone 1 for a given receiver angle range are derived in Appendix 7.

\section{Shear Plane Area}

The shear plane area is the area of the horizontal plane within the cavity (Fig. 25). The shear plane area is divided into two sections. The first section is formed by the horizontal plane cutting through the cylindrical portion of the receiver cavity. Not all of the horizontal plane in the cylindrical portion participates in the convective heat loss. The sides of the aperture reduce the effective shear plane area by restricting flow along the horizontal plane at the sides of the cavity near the aperture. The shear plane expands from the upper lip of 
the aperture in the horizontal plane. The second section is formed where the horizontal plane cuts the frustum portion of the receiver cavity. The formulas that describe the shear plane area in the specified portion of the cavity for a given receiver angle are derived in Appendix 7.

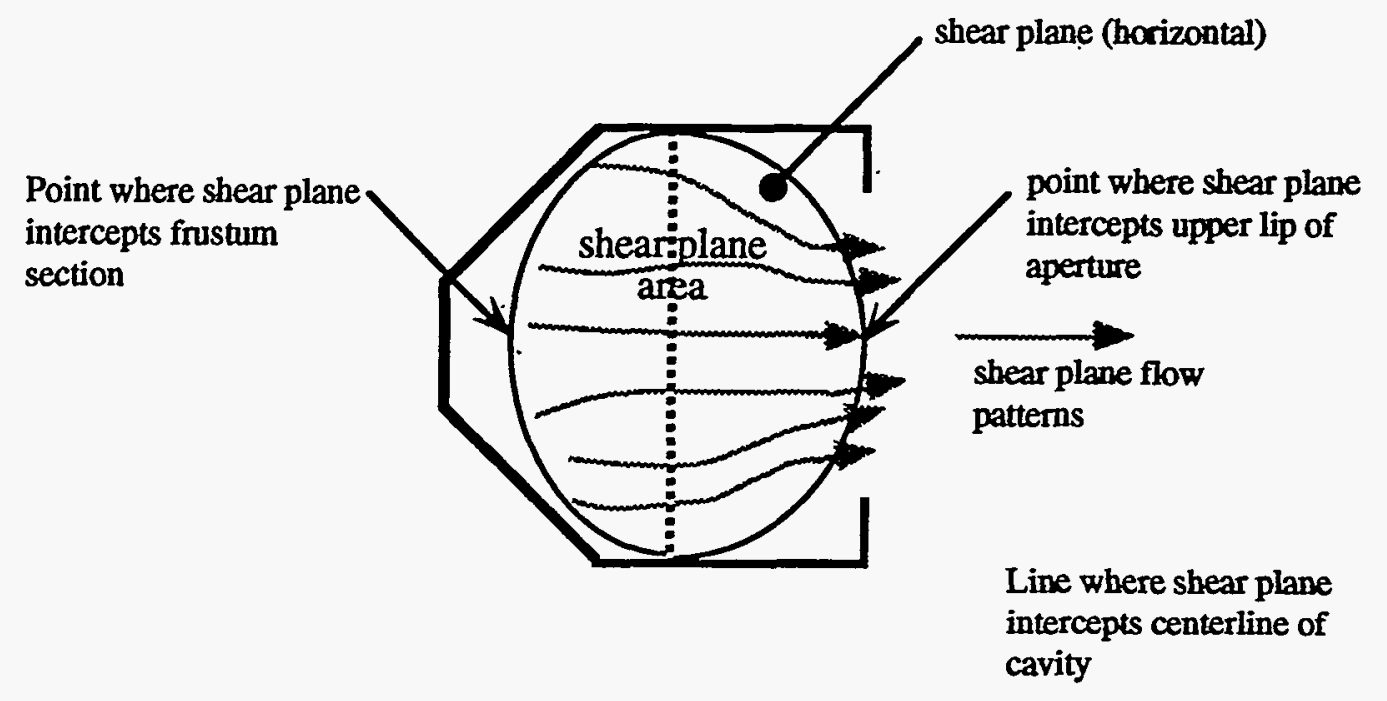

Figure 25. View looking down showing the effective shear plane area

\section{Clausing Model Analysis}

A BASIC computer language program was written to solve the convective heat transfer equations (Appendix 8). The mean operating temperature in the program is taken as the tube surface temperature in the convective zone of the receiver. The program calculates the convective energy loss from the receiver cavity for receivers at operating temperatures of $300^{\circ} \mathrm{F}, 400^{\circ} \mathrm{F}, 500^{\circ} \mathrm{F}$, and $600^{\circ} \mathrm{F}$, receiver angles from 0 to $90^{\circ}$ at $15^{\circ}$ increments, and aperture diameters of 6 inches, 12 inches, 18 inches, and 26 inches. The results of the Clausing heat loss analysis are presented in Appendix 9. The results of the Clausing model analysis are shown in Figure 26. 


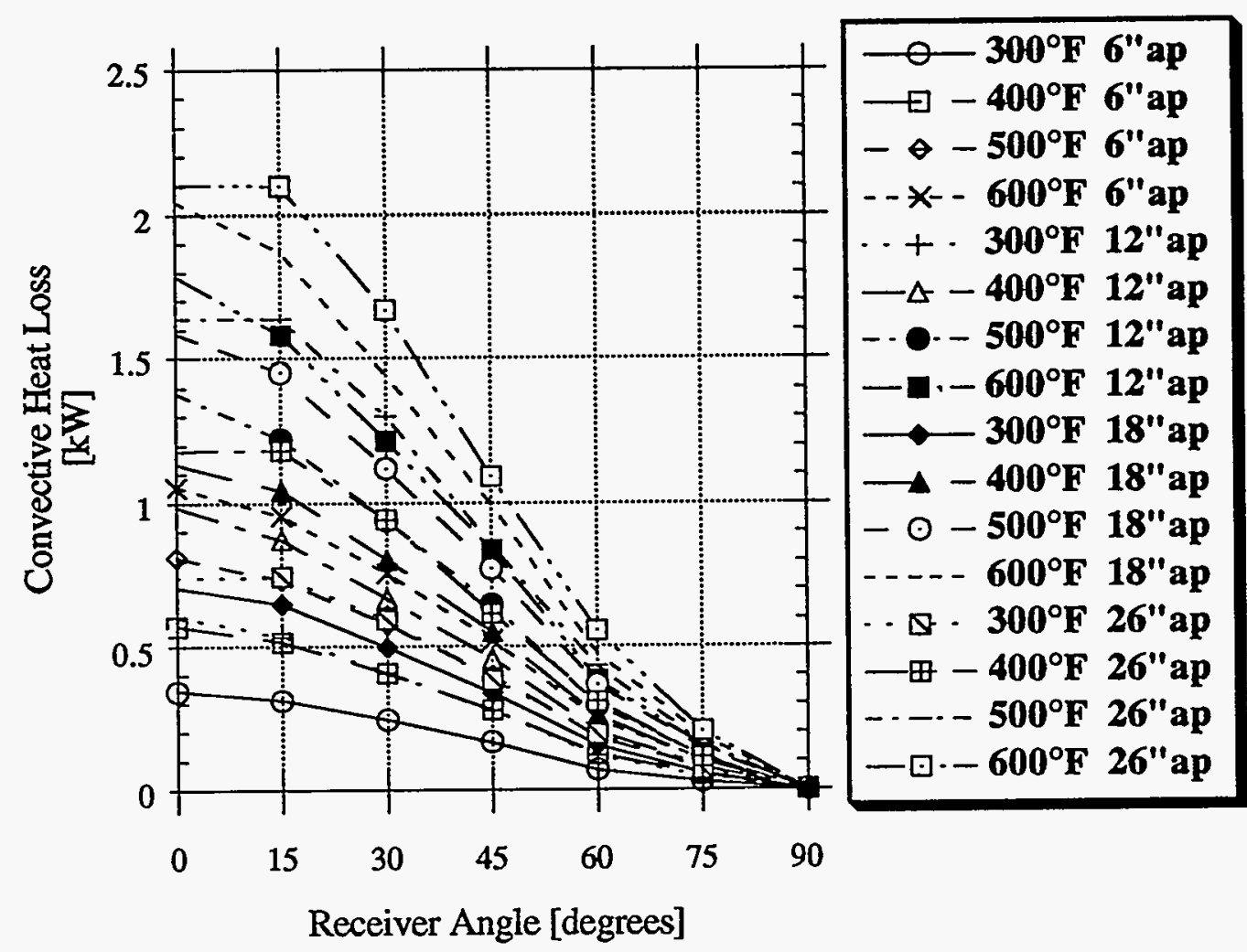

Figure 26. Convective heat loss for Clausing model

\section{Siebers and Kraabel Model}

Siebers and Kraabel present a simple model for the convective heat transfer from a solar cavity receiver.(12) They emphasize that the model has a large degree of uncertainty due to the lack of sufficient data on cavity receivers. The model was developed for a large central receiver cavity operations on-flux. This model is based primarily on the results of experimental studies from cubical cavities.

The following are the equations used to determine the convective loss from a solar cavity receiver. For natural convection the Nusselt number is given by:

$$
\mathrm{Nu}_{\mathrm{L}}=0.088 \mathrm{Gr}_{\mathrm{L}}^{1 / 3}\left[\frac{\mathrm{T}_{\mathrm{w}}}{\mathrm{T}_{\infty}}\right]^{0.18}
$$


for $10^{5} \leq \mathrm{Gr}_{\mathrm{L}} \leq 10^{2}$

where:

$$
\begin{aligned}
& \mathrm{Gr}_{\mathrm{L}}=\text { Grashoff number } \\
& \mathrm{T}_{\mathrm{w}}=\text { average interior cavity wall temperature }[\mathrm{K}] \\
& \mathrm{T}_{\infty}=\text { ambient temperature }[\mathrm{K}] \\
& {[]_{\mathrm{L}}=\text { the projected vertical height of the receiver aperture }[\mathrm{m}]}
\end{aligned}
$$

An approximation for the average interior surface area of the cavity is given by:

$$
\overline{\mathrm{T}}_{\mathrm{w}}=\frac{\mathrm{T}_{\mathrm{h}} \mathrm{A}_{\mathrm{h}}+\mathrm{T}_{\mathrm{c}} \mathrm{A}_{\mathrm{c}}}{\mathrm{A}_{\text {total }}}
$$

where:

$$
\begin{aligned}
& T_{h}=\text { average operating temperature of the system }\left[{ }^{\circ} \mathrm{C}\right] \\
& T_{c}=\text { average refractory surface temperature in the cavity }\left[{ }^{\circ} \mathrm{C}\right] \\
& T_{c}=T_{h}-56^{\circ} \mathrm{C} \\
& A_{h}=\text { heated surface area in the cavity }\left[\mathrm{m}^{2}\right] \\
& A_{c}=\text { refractory surface area in the cavity }\left[\mathrm{m}^{2}\right]
\end{aligned}
$$

The $1 / 3$ exponent on the Grashof number results in a heat transfer coefficient that is independent of cavity dimensions. All fluid properties are evaluated at $\mathrm{T}_{\infty}$. The natural convective heat transfer coefficient is given by:

$$
h_{n c, 0}=0.81\left(\bar{T}_{w}-T_{\infty}\right)^{0.426}
$$

where:

$$
[]_{\mathrm{nc}}=\text { natural convection }
$$




$$
[]_{0}=\text { no lip heat transfer coefficient }
$$

The convective heat loss energy is given by:

$$
Q_{\text {conv }}=\bar{h}_{n c, o} A\left(\bar{T}_{w}-T_{\infty}\right)
$$

where:

$A=$ the total interior surface area of the cavity receiver $\left[\mathrm{m}^{2}\right]$

$\overline{\mathrm{T}}_{\mathrm{w}}=$ the average receiver heated surface temperature $\left[{ }^{\circ} \mathrm{C}\right]$

Siebers and Kraabel account for aperture effects by multiplying the natural convective heat transfer coefficient by an area ratio factor. The natural convective heat transfer coefficient including the effects of the aperture lip is given by:

$$
\overline{\mathrm{h}}_{\mathrm{nc}}=\mathrm{h}_{\mathrm{nc}, \mathrm{o}}\left[\frac{\mathrm{A}_{1}}{\mathrm{~A}_{2}}\right]\left[\frac{\mathrm{A}_{3}}{\mathrm{~A}_{1}}\right]^{\mathrm{n}}
$$

where:

$\mathrm{n}=0.63$ for $0^{\circ} \leq \varnothing \leq 30^{\circ}$

$n=0.8$ for $30^{\circ} \leq \varnothing \leq 90^{\circ}$

$\mathrm{A}_{1}=$ total interior cavity surface area $\left[\mathrm{m}^{2}\right]$ (Fig. 27)

$\mathrm{A}_{3}=$ interior cavity surface area below the horizontal plane $\left[\mathrm{m}^{2}\right]$ (Fig. 27)

$A_{2}=A_{1}$ minus the area of the lower lip [ $\left.\mathrm{m}^{2}\right]$ (Fig. 27) 


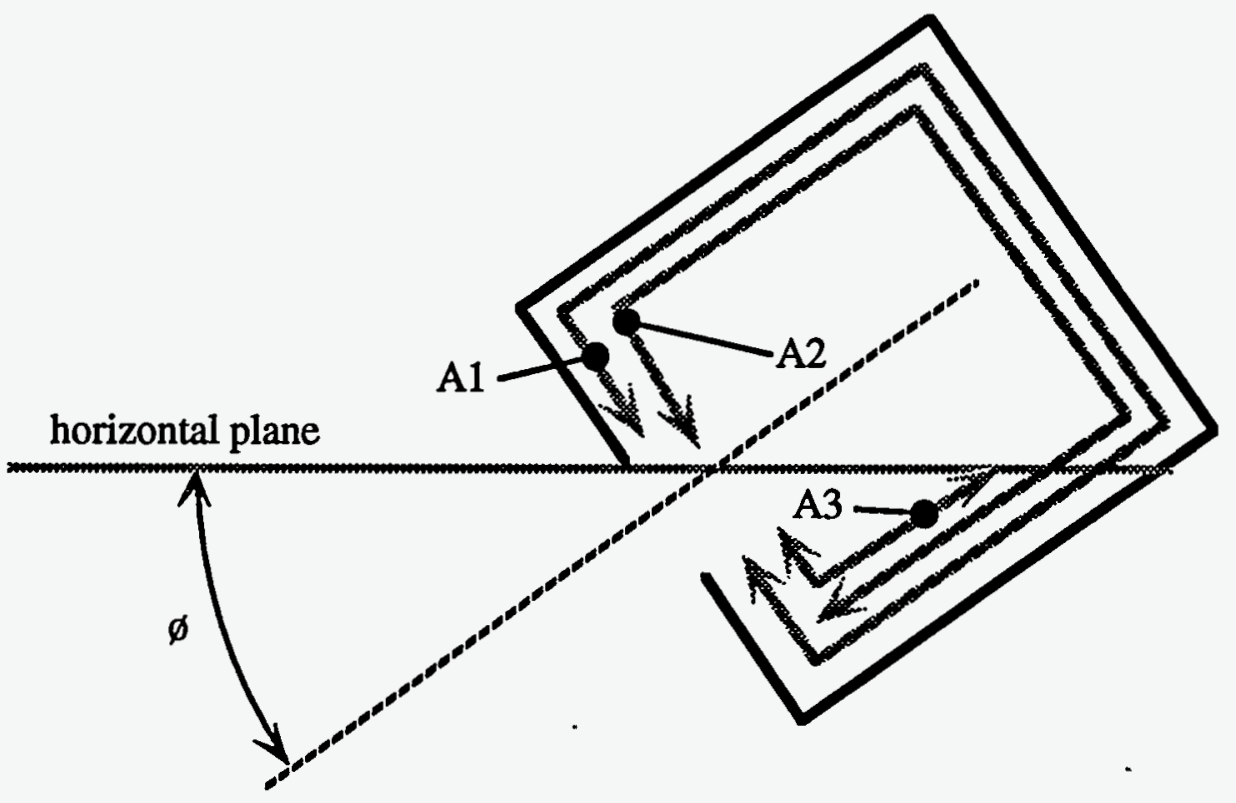

Figure 27. Siebers and Kraabel cavity areas

The refractory surfaces are assumed to be $56^{\circ} \mathrm{C}$ cooler than the mean operating temperature of the receiver. The formulas for areas $\mathrm{A} 1$ and $\mathrm{A} 2$ are given as follows:

$$
\begin{gathered}
A_{1}=\pi\left(R_{e}+R_{c}\right) \sqrt{L_{f}^{2}+\left(R_{c}-R_{e}\right)^{2}}+2 \pi R_{c} L_{h}+\pi R_{e}^{2}+\pi\left(R_{c}^{2}-R_{a}^{2}\right)+2 \pi R_{c} L_{c} \\
A_{2}=A_{1}-R_{c}^{2} \cos ^{-1} \frac{R_{a}}{R_{c}}+R_{a} \sqrt{\left(R_{c}^{2}-R_{a}^{2}\right)}
\end{gathered}
$$

The formula for $\mathrm{A}_{3}$ depends on the particular receiver angle. The expressions developed for the variation of the cavity internal zone areas as a function of receiver angle can be found in Appendix 7.

The Grashof number is given by:

$$
\mathrm{Gr}_{\mathrm{L}}=\mathrm{g} \beta\left(\overline{\mathrm{T}}_{\mathrm{w}}-\mathrm{T}_{\infty}\right) \frac{\mathrm{L}^{3}}{v^{2}}
$$


where:

$$
\begin{aligned}
& \mathrm{g}=\text { gravitational constant, } 9.81 \mathrm{~m} / \mathrm{s}^{2} \\
& \mathrm{~L}=\text { cavity diameter }[\mathrm{m}] \\
& v=\text { kinematic viscosity }\left[\mathrm{m}^{2} / \mathrm{s}\right] \\
& \beta=\text { coefficeint of volumetric expansion }\left[\mathrm{K}^{-1}\right]
\end{aligned}
$$

The uncertainty analysis provided by Siebers and Kraabel is presented in Table 2.

Table 2

Siebers and Kraabel Uncertainty Analysis

\begin{tabular}{|c|c|}
\hline Parameters & Uncertainty \\
\hline $\mathrm{A}_{1}$ & $\pm 10 \%$ \\
\hline $\mathrm{A}_{2}$ & $\pm 10 \%$ \\
\hline $\mathrm{A}_{3}$ & $\pm 10 \%$ \\
\hline $\mathrm{A}_{\mathrm{ap}}$ & $\pm 5 \%$ \\
\hline $\mathrm{T}_{\mathrm{w}}$ & $\pm 10 \%$ \\
\hline $\mathrm{T}_{\infty}$ & $\pm 2 \%$ \\
\hline natural convection correlation & $\pm 20 \%$ \\
\hline
\end{tabular}

A computer program was used to solve for the Siebers and Kraabel convective heat loss for various aperture diameters, receiver operating temperatures, and receiver angle. A listing of the computer program is in Appendix 10. The results of the convective heat loss analysis using the Siebers and Kraabel model are presented in Appendix 11. The Siebers and Kraabel predictions for the receiver convective heat loss variation with receiver angle are presented in Figure 28. 


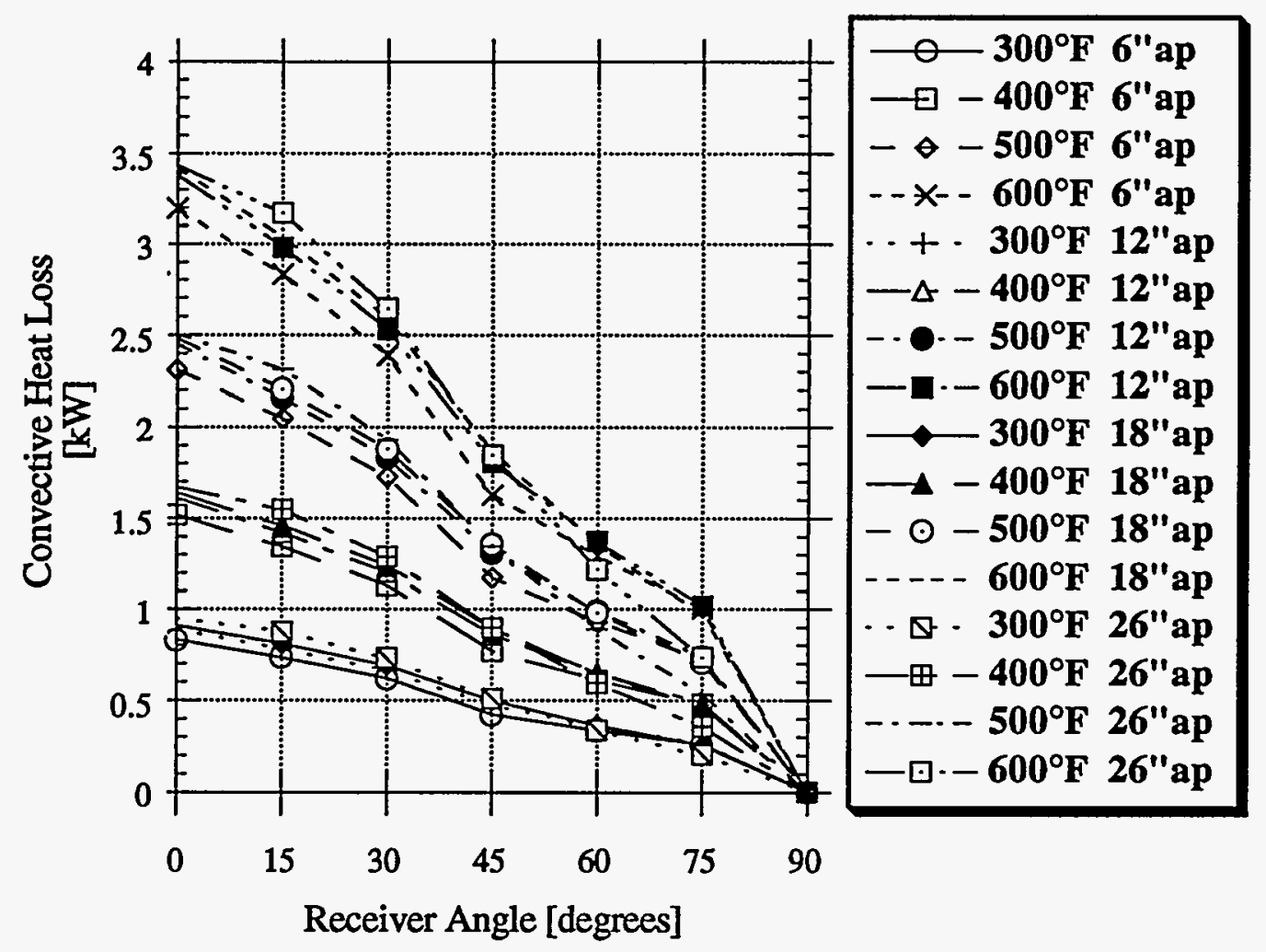

Figure 28. Convective heat loss for the Siebers and Kraabel model

\section{COMPARISON OF CAVITY HEAT LOSS MODELS}

With increasing aperture diameter there is a decrease in convective heat loss (Fig. $13 \& 14$ ). The effect of receiver angle on the convective heat loss is more pronounced on larger aperture diameters.

The conduction heat loss forms approximately $65 \%$ of the total heat loss for all operating temperatures when the aperture diameter is small and the receiver is placed at a typical operating angle of $45^{\circ}$ (Fig. 21).

The percent conduction is reduced and the percent radiative increased with increases in the aperture. With an aperture greater than 12 inches, the percent conduction of the total heat 
loss is constant at about $38 \%$. With the 6 inch diameter the percent conduction of the total heat loss is reduced to $25 \%$.

Of primary interest is how well the various models compare with the experimental results. Of the six models examined, only the LeQuere, Penot and Mirenayat model provides for negative receiver angles.

\section{A. Comparison of Previous Models with Experimental Data}

The convective heat loss values predicted by the LeQuere, Penot and Mirenayat model are compared with the experimental results of Phase One and Phase Two(Fig. 29). For an ideal correlation, all the data points would fall on the equal value line. An ideal correlation occurs when the predicted results equal the experimental results. All the convective heat loss values predicted by the LeQuere, Penot and Mirenayat model are lower than the experimental results. The large degree of data scattering for higher heat loss values makes it difficult to apply a simple correction factor to the model.

The Koenig and Marvin model for convective heat loss demonstrates more agreement with experimental result than the LeQuere, Penot and Mirenayat model (Fig. 30). The Koenig and Marvin model yields higher convective heat loss values, as compared to the experimental results. The data shows increasing scatter for higher heat loss values. The model only works for positive receiver angles. 


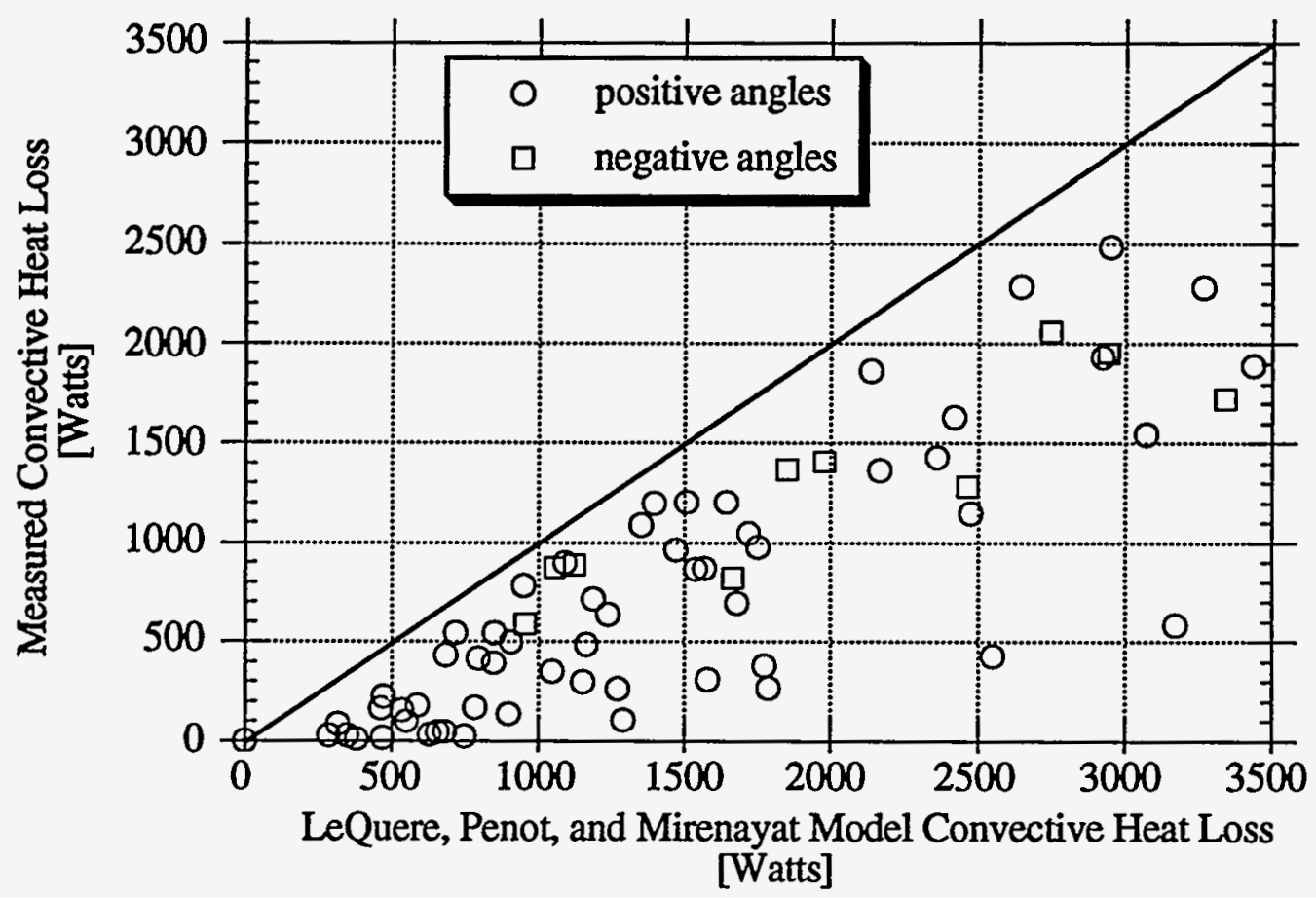

Figure 29. LeQuere, Penot, Mirenayat Convective Heat Loss Model Correlation 


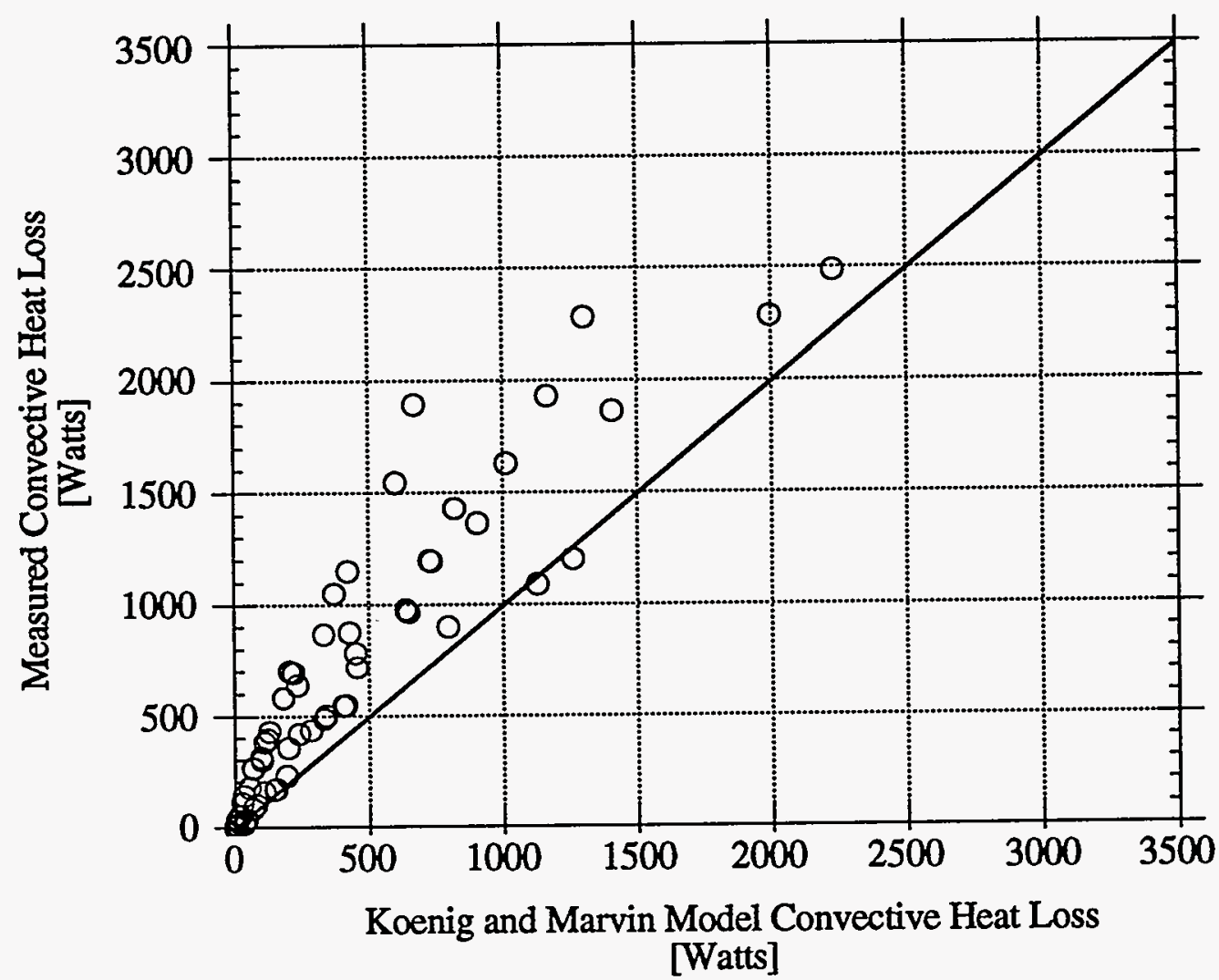

Figure 30. Koenig and Marvin Convective Heat Loss Model Correlation

The Clausing model provides the best fit of all the previous models examined (Fig. 31). This model predicts only heat loss values for positive receiver angles. The Clausing model is considerably more complicated than any of the other models. The Clausing model overestimates the convective heat loss for lower heat loss conditions and underestimates the convective heat loss for higher heat loss conditions. 


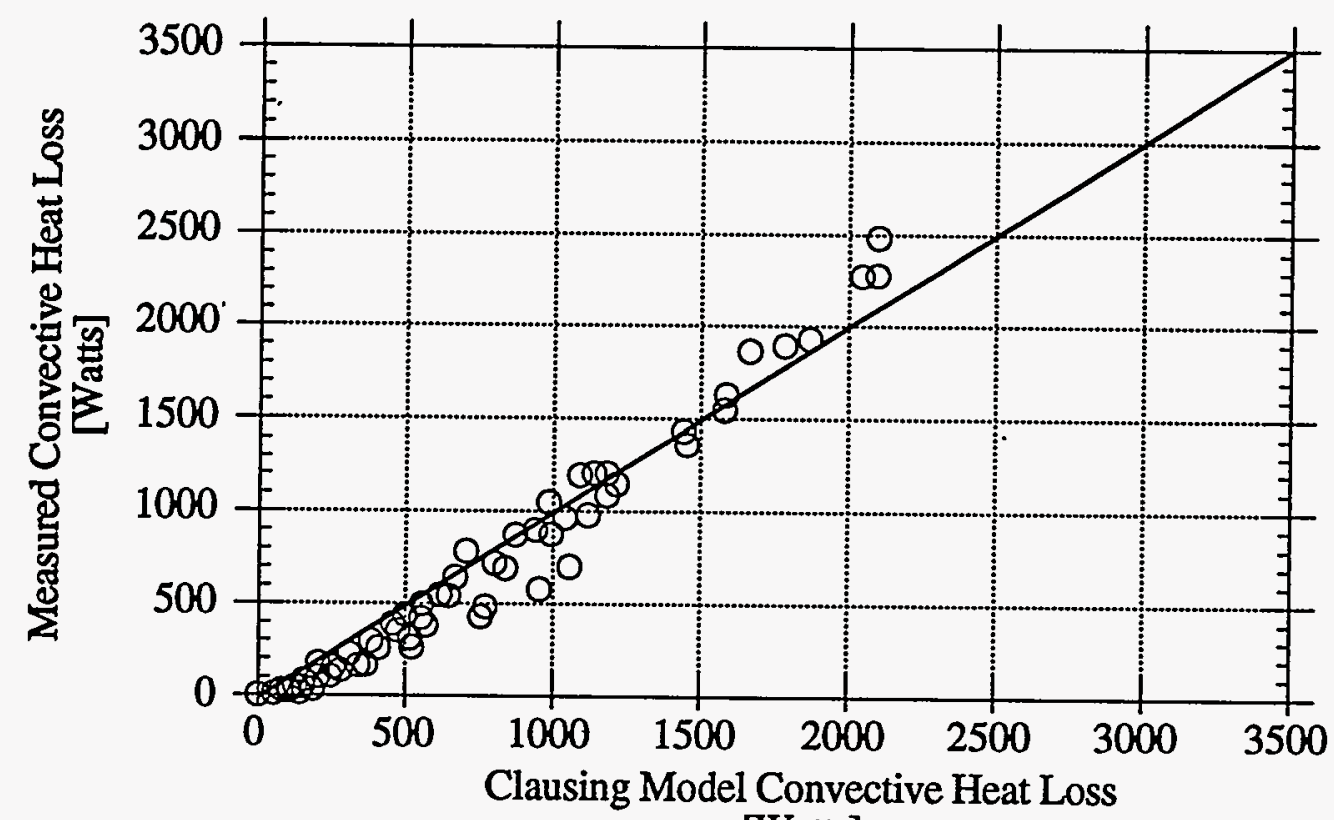

[Watts]

Figure 31. Clausing Convective Heat Loss Model Correlation

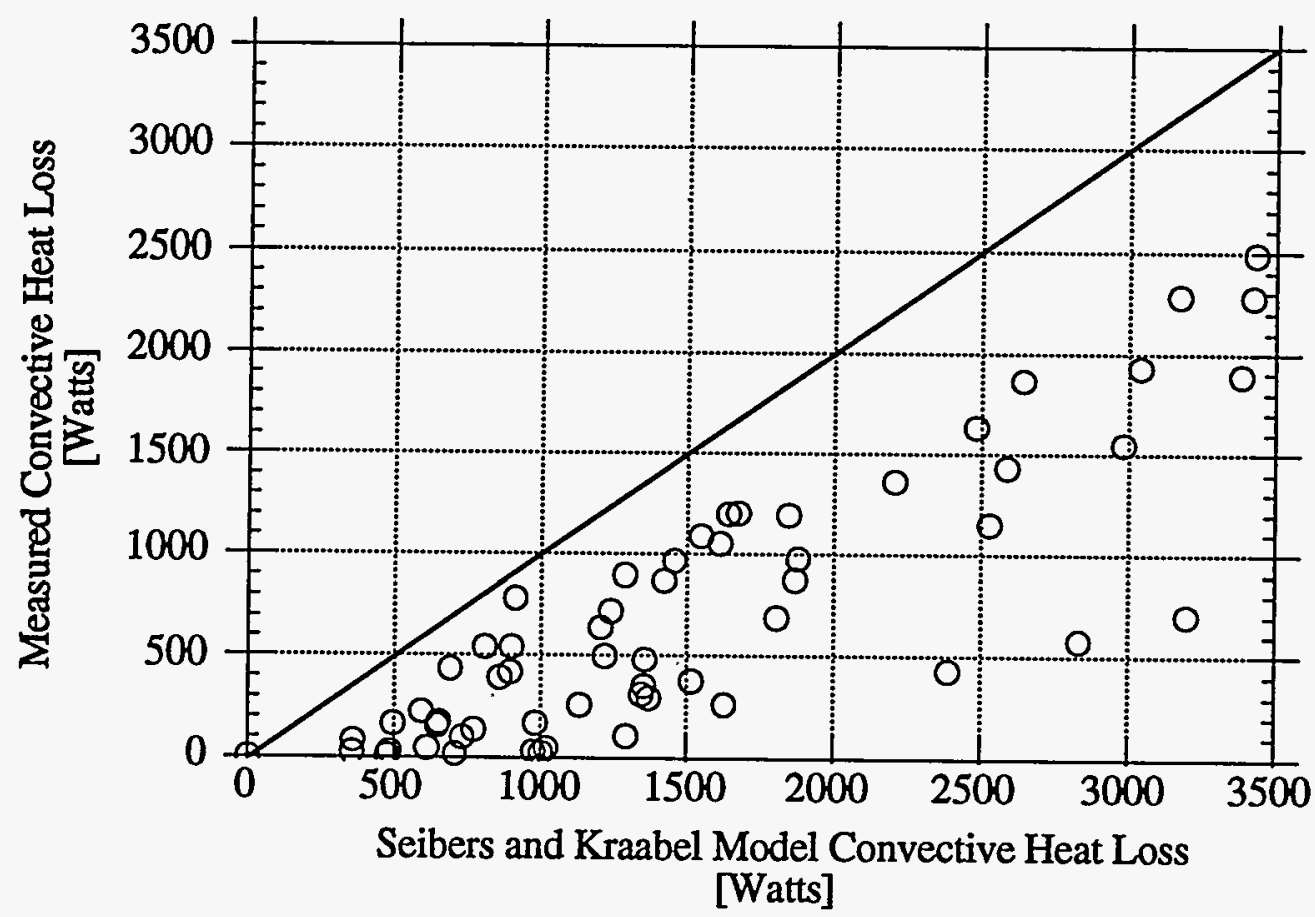

Figure 32. Siebers and Kraabel Convective Heat Loss Model Correlation 
The Siebers and Kraabel model over estimates the convective heat loss as compared with the experimental results (Fig. 32). This model also shows considerable scatter for all heat loss conditions.

\section{B. Stine and McDonald Correlation}

The Stine and McDonald model is an extension of the Siebers and Kraabel model to include the effects of varying receiver aperture size and receiver angle ${ }^{(8)}$. The complex set of area determinations are not used in the Stine and McDonald model. The Stine and McDonald correlation for the Nusselt number is given as follows:

$$
\mathrm{Nu}_{\mathrm{L}}=0.088 \mathrm{Gr}_{\mathrm{L}}^{\frac{1}{3}}\left(\frac{\mathrm{T}_{\mathrm{w}}}{\mathrm{T}_{\infty}}\right)^{0.18}(\cos \phi)^{2.47\left(\frac{\mathrm{d}}{\mathrm{L}}\right)^{5}}
$$

and

$$
s=1.12-0.98\left(\frac{\mathrm{d}}{\mathrm{L}}\right)
$$

where:

$$
\begin{aligned}
& \mathrm{d}=\text { aperture diameter [m] } \\
& \mathrm{Gr}_{\mathrm{L}}=\text { Grashof number based on length } \mathrm{L} \\
& \mathrm{L}=\text { average internal dimension of cavity [m] } \\
& \mathrm{Nu}_{\mathrm{L}}=\text { Nusselt number based on length } \mathrm{L} \\
& \mathrm{T}_{\infty}=\text { ambient temperature }[\mathrm{K}] \\
& \mathrm{T}_{\mathrm{w}}=\text { average internal wall temperature }[\mathrm{K}] \\
& f=\text { tilt angle of cavity } \\
& \left(f=90^{\circ} \text { is aperture-down, } f=0^{\circ}\right. \text { is aperture-sideways ) }
\end{aligned}
$$

The aspect ratio term, $d / L$, accounts for the combined effects of internal surface area and aperture flow area. The effect of the receiver aspect diminishes with increase in aperture size, with the exponent 's'. The Stine and McDonald model predictions compare well with experimental results (Fig. 33). This model can only be applied for positive receiver angles. 


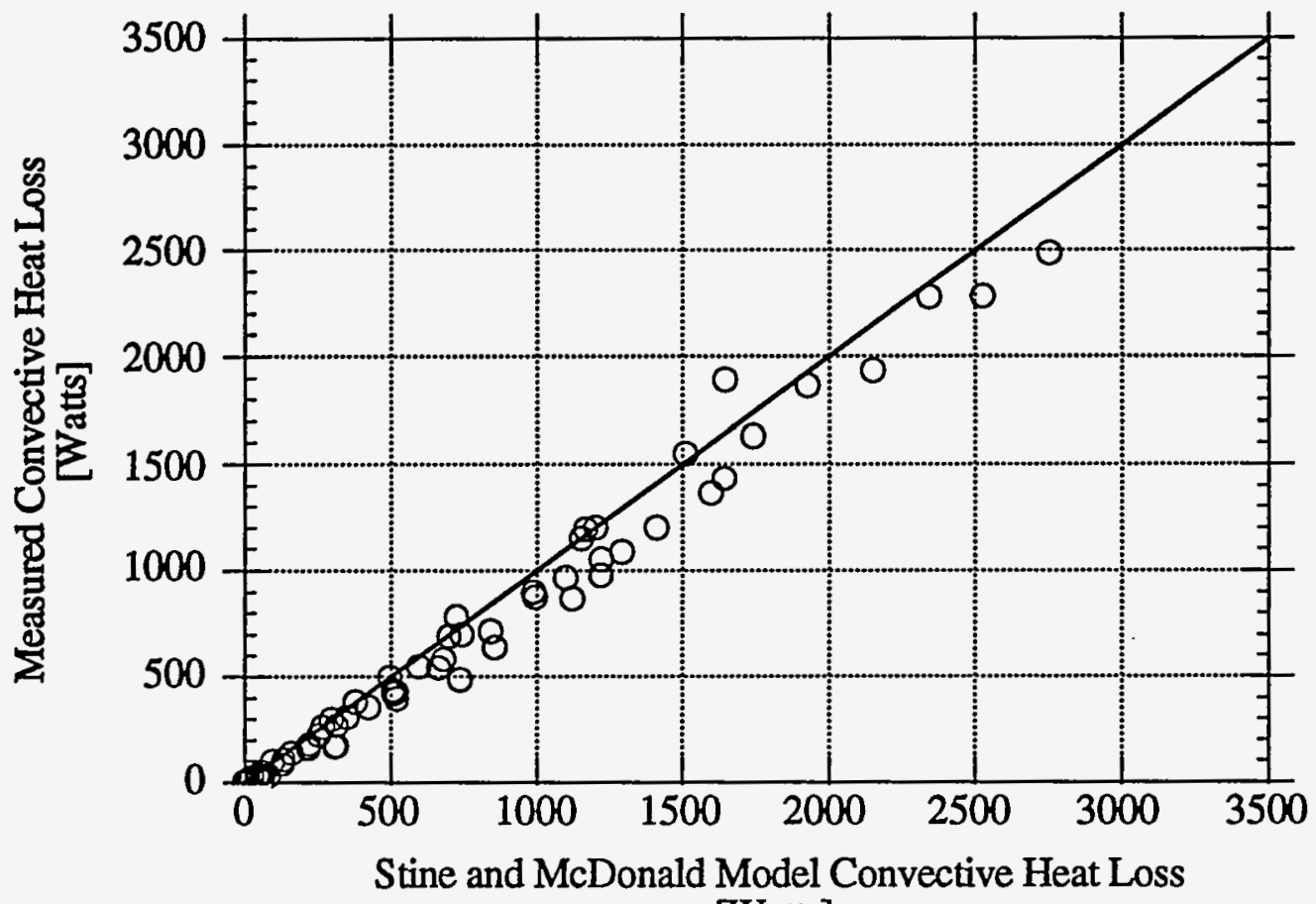

[Watts]

Figure 33. Stine and McDonald Convective Heat Loss Model Correlation

The computer program used to generate the Stine and McDonald convective heat loss values is provided in Appendix 12. The data output from the program is presented in Appendix 13.

\section{ANALYTICAL RADIATIVE HEAT LOSS}

In this section the equations used to predict the thermal radiative heat loss through the aperture of the cavity solar receiver are developed. The receiver cavity surfaces are assumed to radiate as gray bodies. The internal geometry is simplified to aid in the formulation of the shape factor expressions.

\section{A. Internal Geometry}


The internal receiver surfaces were divided into five main sections (Fig. 34). The sections are defined as either hot or cold. The hot sections were those whose walls were formed by the heat transfer tubing. The hot sections were divided into an integer number of flat, concentric, isothermal bands. The number of bands in each section was determined by the number of turns the heat transfer tubing made in that section. The frustum section has 23 bands and the hot cylindrical section has 15 bands. The width of each band is equal to the surface length of each section divided by the number of bands in each section. The actual spacing between adjacent tubes was not considered significant.

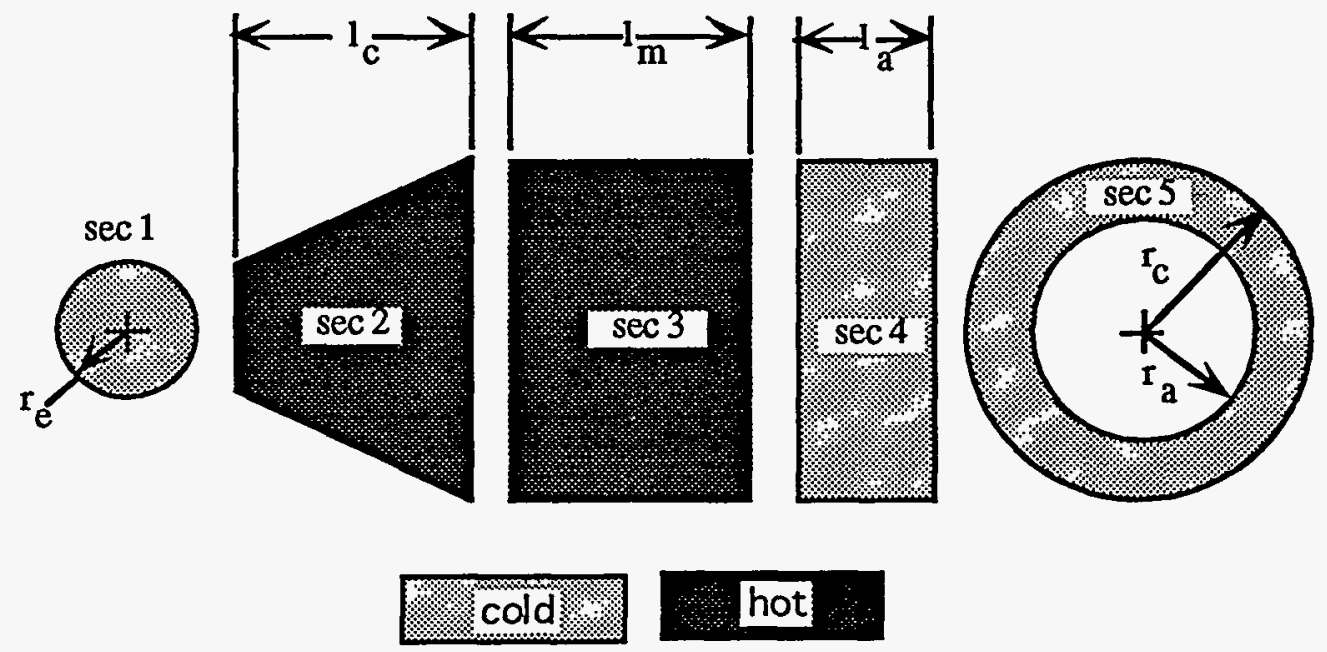

Figure 34. Receiver internal surface sections.

\section{Nomenclature}

The following list defines the nomenclature used in the thermal radiative heat loss formulas.

$$
\begin{array}{ll}
r_{e}= & \text { end plate radius }[12.7 \mathrm{~cm}] \\
r_{c}= & \text { cavity radius }[33.0 \mathrm{~cm}] \\
r_{2}= & \text { aperture radius }[7.6,15.2,22.9,33.0 \mathrm{~cm}] \\
l_{c}= & \text { length of frustum section }[29.2 \mathrm{~cm}] \\
l_{m}= & \text { length of hot cylindrical section }[25.4 \mathrm{~cm}] \\
l_{\mathrm{a}}= & \text { length of cold cylindrical section }[14.0 \mathrm{~cm}] \\
\mathrm{l}_{\mathrm{b}}= & \text { width of hot isothermal bands }[1.7 \mathrm{~cm}]
\end{array}
$$


$\mathrm{N}_{\mathrm{c}}=$ number of bands in frustum section (23)

$\mathrm{N}_{\mathrm{m}}=$ number of bands in hot cylindrical section (15)

$$
l_{c} \equiv\left[\left(l_{b} N_{c}\right)^{2}-\left(r_{c}-r_{e}\right)^{2}\right]^{1 / 2}
$$

\section{B. Assumptions}

A number of assumptions are necessary to simplify the thermal radiative heat loss calculations. The assumptions made for this analysis are listed as follows:

1. Each band is isothermal based on a linear interpolation between the inlet temperature at the narrow end of the frustum section to the outlet temperature at the bottom end of the hot cylindrical section.

2. Each band is considered as a flat surface.

3. Each tube band is diffuse and gray with emissivity, $\varepsilon=0.85$.

4. The incident and reflected energy flux is uniform over each area.

5. Each band is adjacent to the next (i.e., no gaps between bands).

6. Each refractory surface has an emissivity of 0.70 .

\section{Shape Factors}

All formulas are developed from the basic disc-to-disc shape factor formula. ${ }^{(20)}$ The $\mathrm{N}$ by $\mathrm{N}$ coefficient matrix of the surface energy balance equation (Eqn. 64) requires $\mathrm{N}^{2}$ shape factors. The equations are solved using a digital computer. Equation 64 is conservation of energy from all the surfaces. Shape factors describe the geometric relationship between surfaces. The derivation of the shape factor formulas used in the coefficient matrix are presented in Appendix 14. 


\section{Thermal Radiative Heat Loss Equations}

The general equation for thermal radiative heat loss from the receiver through the aperture for internal black body surfaces is given by:

$Q_{a}=-\sigma T_{e}^{4} A_{e} F_{A_{e}-A_{a}}-\sigma T_{s}^{4} A_{s} F_{A_{s}}-A_{a}-\sigma A_{n_{m}} \sum_{n_{m}=1}^{N_{m}} T_{n_{m}}^{4} F_{n_{m}}-A_{a}-\sigma \sum_{n_{c}=1}^{N_{c}} T_{n_{c}}^{4} A_{n_{c}} F_{n_{c}}-A_{a}$

where:

[]$_{\mathrm{s}}=$ annuls

[]$_{\mathrm{e}}=$ end plate

[]$_{\mathrm{a}}=$ aperture

[ ] $\mathrm{nm}$ cylindrical section

[]$_{\mathrm{nc}}=$ frustum section

As the aperture size to cavity volume ratio decreases, the radiative characteristics of the receiver cavity approach those of a black body emitter. To account for the various aperture sizes studied, the diffuse gray surface formulas were used. Using the net radiative method, the radiative heat loss for a cavity with diffuse gray surfaces is given by:

$$
\begin{gathered}
Q_{k}=q_{k} A_{k}=\left(q_{o, k}-q_{i, k}\right) A_{k} \\
q_{o, k}=\varepsilon_{k} \sigma T_{k}^{4}+\rho_{k} q_{i, k} \\
q_{o, k}=\varepsilon_{k} \sigma T_{k}^{4}+\left(1-\varepsilon_{k}\right) q_{i, k}
\end{gathered}
$$

where:

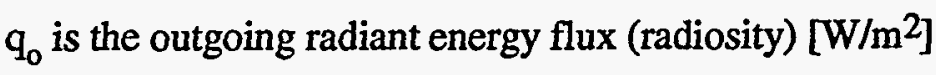

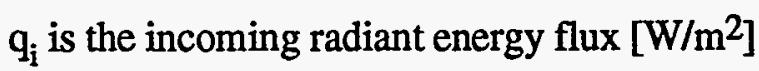


For the aperture:

$$
\begin{aligned}
& q_{o, \text { opening }}=0 \\
& T_{\text {opening }}=0 \\
& \varepsilon_{\text {opening }}=1
\end{aligned}
$$

For the cavity:

$$
\sum_{j=1}^{N}\left[\delta_{k j}-\left(1-\varepsilon_{k}\right) F_{k-j}\right] q_{o, j}=\varepsilon_{k} \sigma T_{k}^{4}
$$

where

$$
\begin{aligned}
& N=\text { total number of surfaces } \\
& F_{k-j}=\text { shape factor for surface } k \text { to surface } j \\
& \partial_{k j}=\text { Kronecker delta } \\
& \delta_{k j}=\left\{\begin{array}{l}
1 \text { when } k=j \\
0 \text { when } k \neq j
\end{array}\right.
\end{aligned}
$$

therefore:

$$
\mathrm{Q}_{\mathrm{k}}=\mathrm{A}_{\mathrm{k}} \frac{\varepsilon_{\mathrm{k}}}{\left(1-\varepsilon_{\mathrm{k}}\right)}\left(\sigma \mathrm{T}_{\mathrm{k}}^{4}-\mathrm{q}_{\mathrm{o}, \mathrm{k}}\right)
$$

and

$$
q_{i, k}=\sum_{j=1}^{N} F_{k-j} q_{o, j}
$$

letting

and

$$
a_{k j}=\delta_{k j}-\left(1-\varepsilon_{k}\right) F_{k-j}
$$

$$
\mathrm{C}_{\mathrm{k}}=\varepsilon_{\mathrm{k}} \sigma \mathrm{T}_{\mathrm{k}}^{4}
$$


then

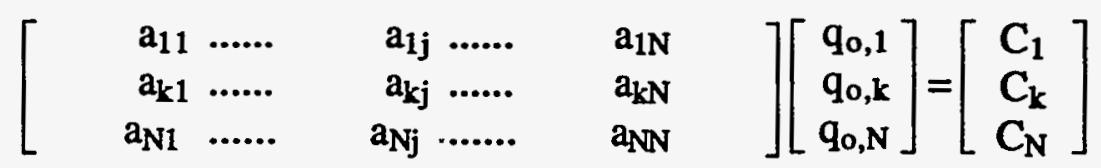

The solutions for $\mathrm{q}_{0, \mathrm{k}}$ are accomplished using a BASIC computer language program (Appendix 15). The heated surfaces are assumed to have an emissivity of 0.85 based on the paint coating specifications. The refractory surfaces are assumed to have a emissivity of 0.70 .

\section{E. Assumed Cavity Temperature Distribution}

The axial temperature distribution along the heating surface sections is assumed to vary linearly from the top of the frustum section to the bottom of the cylindrical section. The temperature of the top band of the frustum section is equal to the receiver inlet temperature. The temperature of the bottom band of the cylindrical section is equal to the receiver outlet temperature. The inlet and outlet temperature values used in the computer program are assumed to be plus and minus $7.5^{\circ} \mathrm{F}$ of the operating temperature, respectively. 
Table 3

Inlet and Outlet temperatures

\begin{tabular}{|c|c|c|c|}
\hline Test Phase & $\begin{array}{c}\text { Aperture Diameter } \\
{[\mathbf{i n}]}\end{array}$ & $\begin{array}{c}\text { Inlet } \\
{\left[{ }^{\circ} \mathbf{F}\right]}\end{array}$ & $\begin{array}{c}\text { Outlet } \\
{\left[{ }^{\circ} \mathbf{F}\right]}\end{array}$ \\
\hline 1 & 18 & 297.7 & 289.0 \\
\hline 1 & 18 & 402.4 & 389.6 \\
\hline 1 & 18 & 515.6 & 497.1 \\
\hline 1 & 18 & 603.9 & 581.3 \\
\hline 2 & 6 & 395.2 & 389.9 \\
\hline 2 & 6 & 609.3 & 595.9 \\
\hline 2 & 12 & 429.4 & 419.1 \\
\hline 2 & 12 & 611.3 & 592.9 \\
\hline 2 & 18 & 429.3 & 415.7 \\
\hline 2 & 18 & 600.3 & 576.2 \\
\hline 2 & $26^{*}$ & 414.3 & 399.5 \\
\hline 2 & $26^{*}$ & 602.6 & 570.4 \\
\hline
\end{tabular}

* There is no annulus therefore the aperture diameter is equal to the cavity diameter.

\section{F. Comparison with Measurements}

The radiometer and the analytical methods are compared with the experimental method, $\mathrm{Q}_{\text {unplugged }}$ minus $\mathrm{Q}_{\text {plugged }}$, for determining the radiative heat loss from the cavity through the aperture. The experimentally determined radiative heat loss was the difference between the open and plugged total receiver heat loss when the receiver aperture was down. A correction was made to account for the heat loss through the aperture plug. The heat loss through the plug must be added to the experimentally determined radiative heat loss data to get the total radiative heat loss from the receiver. The conductive heat loss through the plug is given by:

where:

$$
\mathrm{Q}_{\text {plug }}=\frac{\mathrm{k}_{\mathrm{plug}} \Delta \mathrm{TA} \mathrm{A}_{\mathrm{plug}}}{\Delta \mathrm{x}}
$$


$\mathbf{k}_{\text {plug }}=$ thermal conductivity of the plug[W/m-K]

$\Delta \mathrm{T}=$ temperature difference between the inner and outer surface[K]

$A_{\text {plug }}=$ mean surface area of the plug $[\mathrm{m}]$

$\Delta \mathrm{x}=$ distance over which $\Delta \mathrm{T}$ occurs (the thickness of the plug)[m]

The plugs were fabricated from one inch thick Cera Form ${ }^{\circledR}$ boards. The boards have a mean thermal conductivity of $0.32 \mathrm{Btu}-\mathrm{in} / \mathrm{hr}-\mathrm{sq} . \mathrm{ft} .-\Delta^{\circ} \mathrm{F}(0.0462 \mathrm{~W} / \mathrm{m}-\mathrm{K})$.

Log-log scales are used to provide linear constant percent difference lines.

\section{Radiometer Method}

The radiometer determined heat loss values compared well with the experimentally determined radiative heat loss, $Q_{\text {unplugged }}$ minus $Q_{\text {plugged }}$, with differences within $\pm 20 \%$ (Fig. 35).

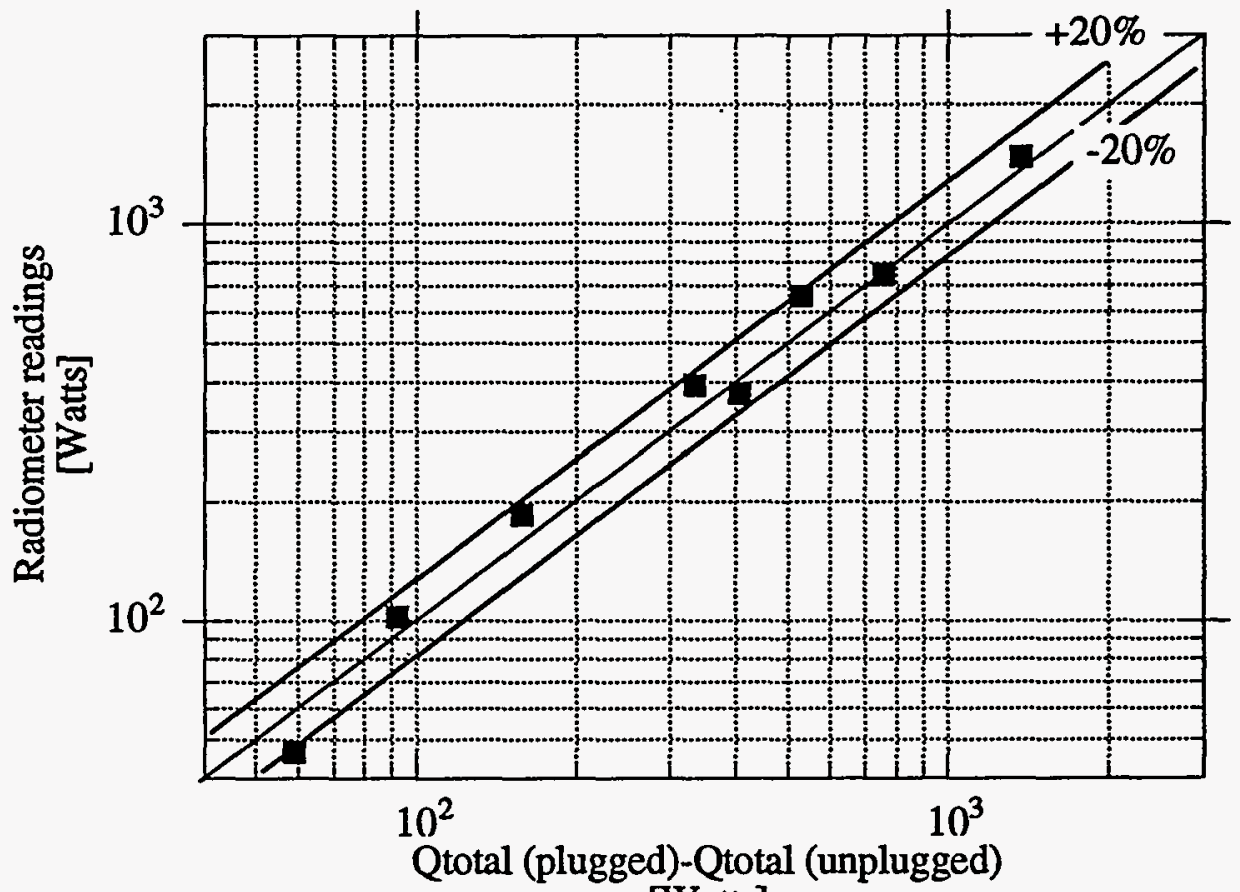

Figure 35. Experimentally determined radiometer method correlation 


\section{Analytical Method}

The analytical method (Fig. 36) did not compare well with the experimental method for determining the radiative heat loss from the receiver. A number of possible reasons for the discrepancies have been discussed previously.

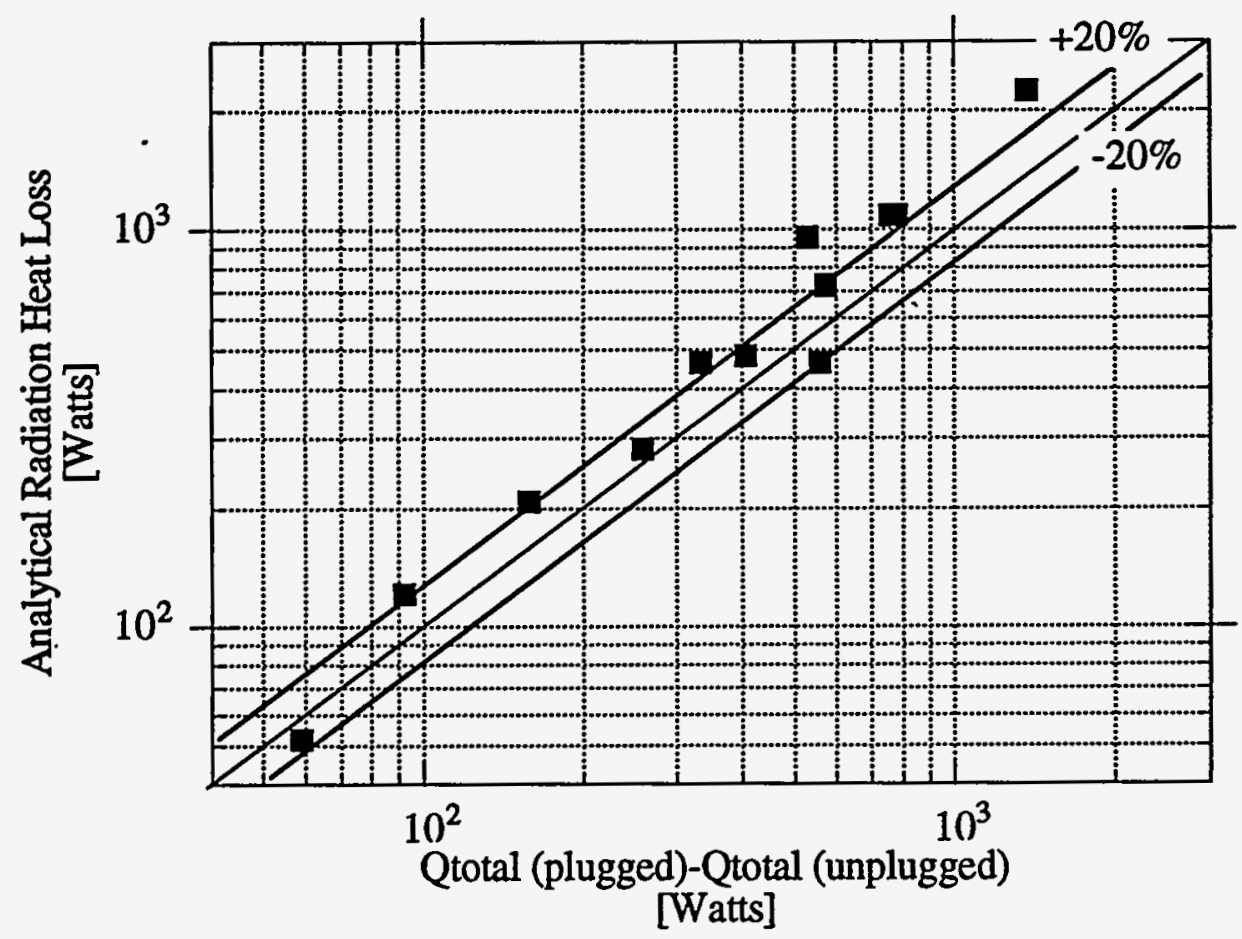

Figure 36. Analytically determined radiative correlation

\section{INSTRUMENTATION CALIBRATION}

\section{A. Flow Meter Calibration}

The flow measurement apparatus consists of three basic parts: the turbine flow meter, the inductive pick-off, and the pulse rate counter (Fig. 37). The turbine flow meter rotates at a specific rate for a given fluid type and volumetric fluid flow rate. The rate of rotation is linearly proportional to the fluid flow rate within the specified range. The flow meter must 
be calibrated for a specific fluid viscosity, temperature, and flow rate range for accurate measurement.

The inductive pick-off is positioned above the turbine flow meter. When a turbine blade passes the inductive pick-off, an electromagnetically induced pulse signal is sent to the pulse rate converter (PRC). The PRC changes the pulse rate signal to voltage or current outputs. The current or voltage signal is then read by the data acquisition computer. The voltage signal should be used when the distance from the PRC to the computer input terminal is less than ten feet. For distances greater than ten feet the current signal should be used, as long leads result in substantial voltage drops. Voltage drops may significantly skew the voltage signal. The current signal is not affected by the voltage drop. The current signal requires a precision resistor across the computer input terminals. The resistor effectively converts the current signal to a voltage input at the computer terminals. Since precision resistors are expensive, economy requires the voltage signal should be used whenever possible.

Voltage signal output was used during testing for the reasons stated above. The computer displays the equivalent fluid volumetric flow rate based on the voltage input. The slope and offset values of the flow rate versus voltage linear function were inputted into the computer. 


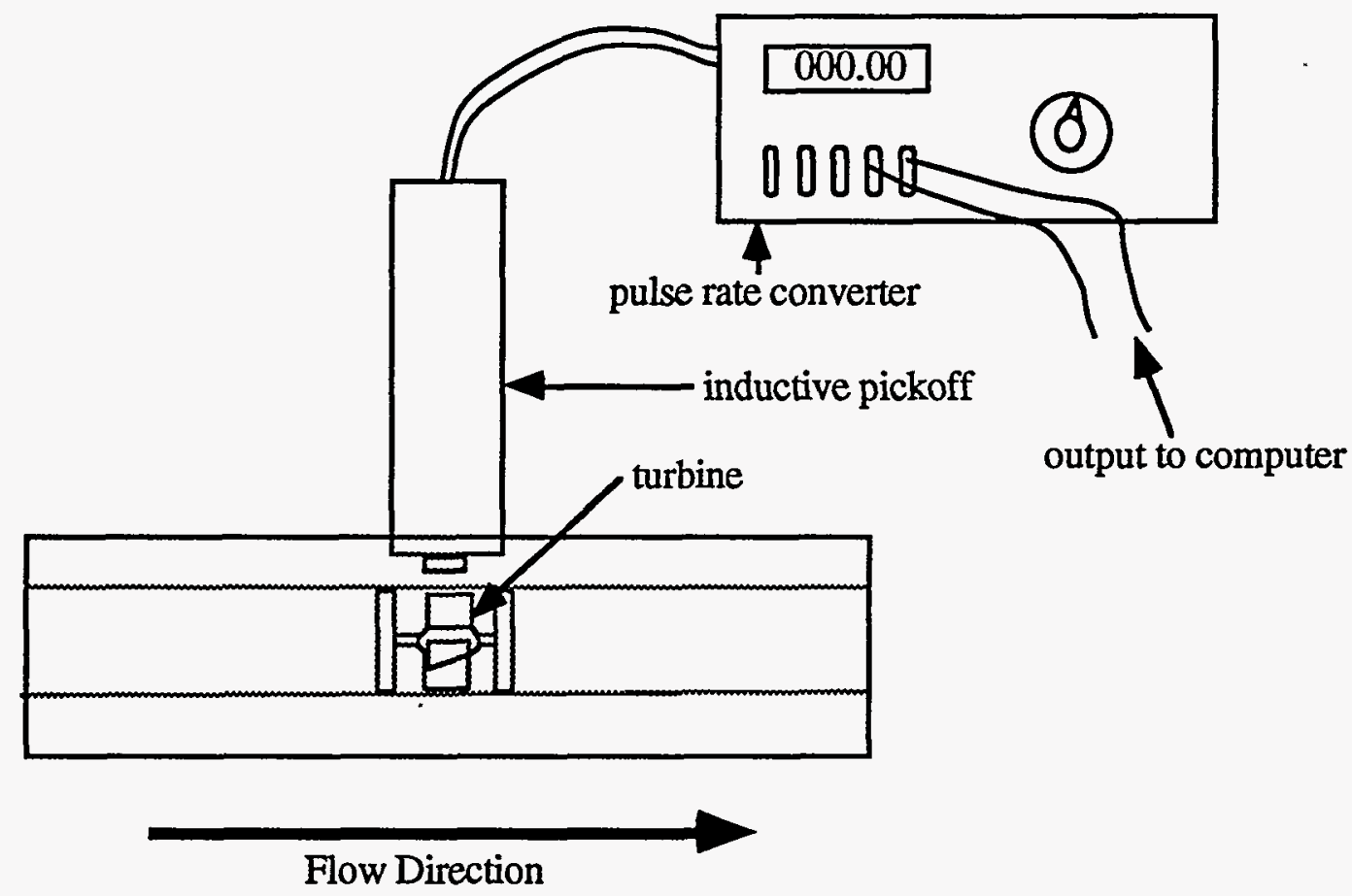

Figure 37. Flow measurement system

The heat transfer fluid flow rate is measured with three turbine type flow meters in series. Three flow meters are used for measurement redundancy. One of these flow meters was factory calibrated. The factory calibration specifications sheet is Appendix 16. The calibration curve for the factory calibrated flow meter is presented in Figure 38. The equation of the volumetric flow rate as a function of flow meter output frequency for the factory calibrated flow meter is:

$$
\dot{\mathrm{v}}=0.0039578+0.001489 f
$$

where:

$f=$ is the flow meter output frequency $[\mathrm{Hz}]$

$\dot{\mathrm{v}}=$ volumetric flow rate $[\mathrm{gpm}]$ 


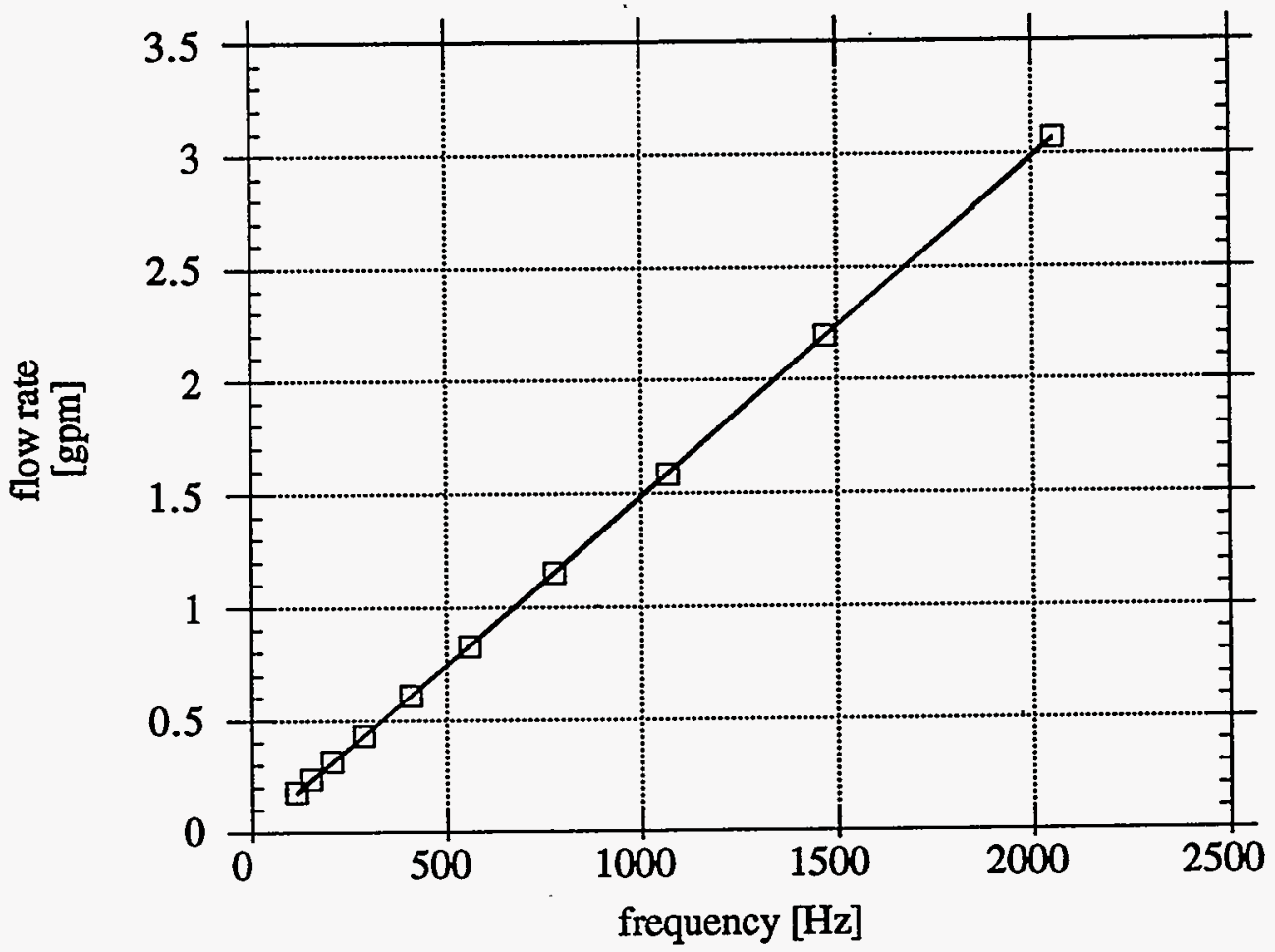

Figure 38. Factory calibrated flow meter flow rate versus frequency output

The pulse rate converters (PRCs) were calibrated in-house according to the manufacturer's procedure (13). The calibration points for the PRC used with the factory calibrated flow meter are presented in Table 4.

Table 4

Pulse Rate Converter Calibration Points

\begin{tabular}{|c|c|}
\hline $\begin{array}{c}\text { frequency } \\
{[\mathrm{Hz}]}\end{array}$ & $\begin{array}{c}\text { output voltage } \\
\text { [volts] }\end{array}$ \\
\hline 1600 & 8.0 \\
\hline 2000 & 10.0 \\
\hline
\end{tabular}


The linear relationship for the frequency as a function of output voltage, as determined by the calibration points, is given as:

$$
f=200 E
$$

where:

$$
\begin{aligned}
& f=\text { is the frequency input to the PRC [Hz] } \\
& \mathrm{E}=\text { is the output signal from the PRC [volts] }
\end{aligned}
$$

Substituting the frequency equation of the PRC calibration into the flow rate equation of the factory calibrated flow meter yields an expression for the volumetric flow rate as a function of voltage as follows:

$$
\dot{\mathrm{v}}=0.0039578+0.001489(200 \mathrm{E})
$$

which reduces to:

$$
\dot{\mathrm{v}}=0.0039578+0.2978 \mathrm{E}
$$

which can be approximated as:

$$
\dot{\mathrm{v}}=0.2978 \mathrm{E}
$$

Because E $>3.36$ volts at typical flow rates the error due to this approximation is less than:

$$
0.0039578
$$

The remaining two flow meters were calibrated against the factory calibrated flow meter. Three meters were used for redundancy in the event one meter fails during testing.

\section{Flow Meters Calibration}

The outputs from the three flow meters were compared for various flow rates. The voltage outputs of the three flow meters were recorded (Appendix 17) (Fig. 39). The heat transfer fluid temperature was maintained at $300^{\circ} \mathrm{F}$. Corrective slope and offset values were determined for each of the two uncalibrated flow meters. Applying the linear corrections 
will bring the two uncalibrated flow meter voltage outputs into agreement with the factory calibrated flow meter output.

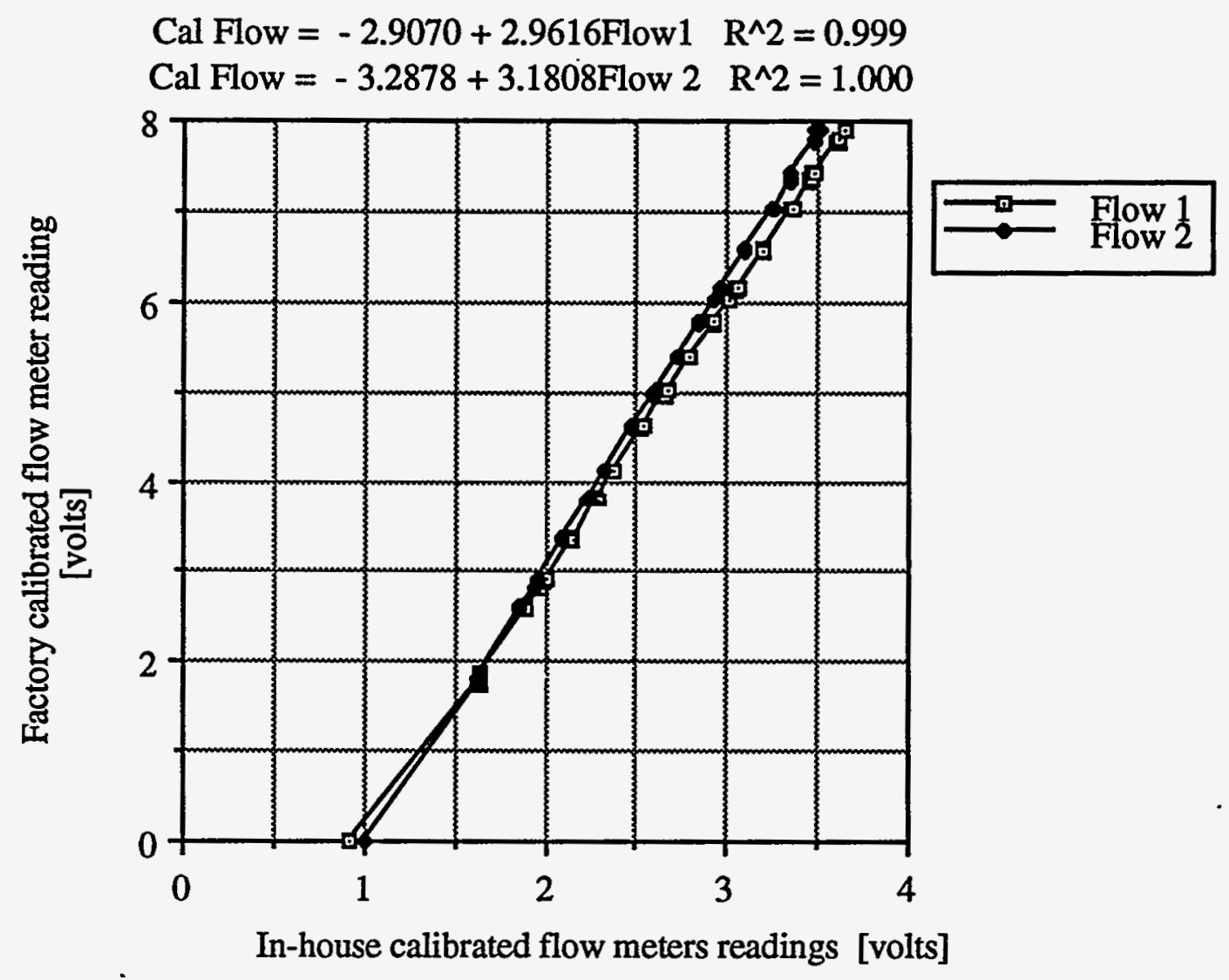

Figure 39. In-house calibrated flow meters correlation curves

The difference between the corrected readings and the factory calibrated readings are compared (Fig. 40). The minimum flow rate for all testing never went below one gallon per minute or 3.36 volts. This flow rate is well within the manufacture specified flow range. The maximum difference between the backup flow meters and the factory calibrated flow meter is \pm 0.15 volts or \pm 0.045 gallons per minute. Temperature effects are negligible (14). 


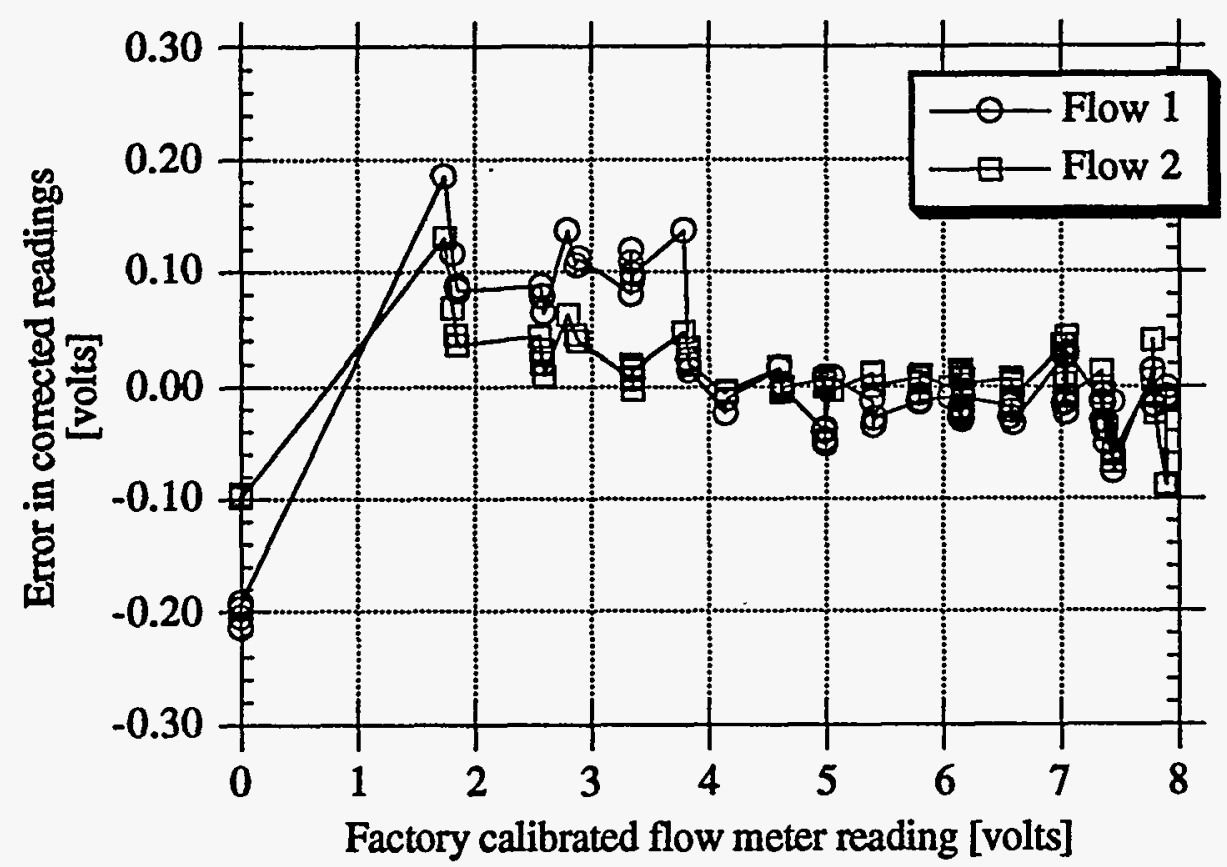

Figure 40. In-house calibrated flow meters errors.

Substituting the linear correction expression for the in-house calibrated flow meters into the volumetric flow rate expression of the factory calibrated flow meter yields expressions for the volumetric flow rates as a function of voltage inputs to the computer. The resulting expressions are given as follows:

$$
\begin{aligned}
& \dot{\mathrm{v}}_{\text {flow } 1}=0.2978\left(-2.9070+2.9616 \mathrm{E}_{\text {flow } 1}\right) \\
& \dot{\mathrm{v}}_{\text {flow } 2}=0.2978\left(-3.2878+3.1808 \mathrm{E}_{\text {flow } 2}\right)
\end{aligned}
$$

which reduce to:

$$
\begin{aligned}
& \dot{\mathrm{v}}_{\text {flow } 1}=-0.8657+0.88196 \mathrm{E}_{\text {flow } 1} \\
& \dot{\mathrm{v}}_{\text {flow } 2}=-0.9791+0.94724 \mathrm{E}_{\text {flow } 2}
\end{aligned}
$$

The scale and offset values from these expressions were inputted into the computer. The computer then displays the flow rate for each flow meter in gallons per minute (gpm). 


\section{B. Thermocouple Calibration}

The total receiver heat loss, $Q_{T}$, was given by the product of the mass flow rate, the specific heat of the heat transfer fluid and the temperature difference between the fluid inlet and outlet temperatures $(\Delta T)$. Of the three variables, the largest error in the heat loss was due to the measurement of $\Delta T$. Two redundant methods were used to measure $\Delta T$ for these experiments. One method of determining $\Delta T$ was by subtracting the fluid outlet temperature from the fluid inlet temperature. The other method utilized a direct temperature difference measurement from two thermocouples, one in each of the fluid inlet and outlet lines. This differential thermocouple connection avoids inaccuracies due to reference junction compensation but still requires knowledge of the absolute temperature values. To reduce the error introduced to the total heat loss calculation by the thermocouple readings it was necessary to calibrate the inlet, outlet, and delta temperature thermocouples used in the receiver. Standard thermocouple probes have a maximum error of $\pm 2.2^{\circ} \mathrm{C}$ or $0.75 \%$, whichever is greater (15). Using two absolute temperature measurements from standard thermocouple probes would result in a $\Delta \mathrm{T}$ error of $\pm 3.11^{\circ} \mathrm{C}\left( \pm 5.60^{\circ} \mathrm{F}\right)$ or $1.06 \%$ whichever is greater. With temperature differences as low as $2.78^{\circ} \mathrm{C}\left(5^{\circ} \mathrm{F}\right)$ recorded, the standard thermocouples did not yield values within an acceptable error.

A single factory calibrated K-type thermocouple probe was purchased and all other probes were calibrated against it. Only one calibrated probe could be purchased due to budget constraints. The calibrated probe has an accuracy of $\pm 0.2^{\circ} \mathrm{F}$ after linear correction is applied (Fig. 41). The three point calibration data for the factory calibrated thermocouple is provided in Table 7. The calibration is certified traceable to the U.S. National Bureau of Standards (Appendix 18). 


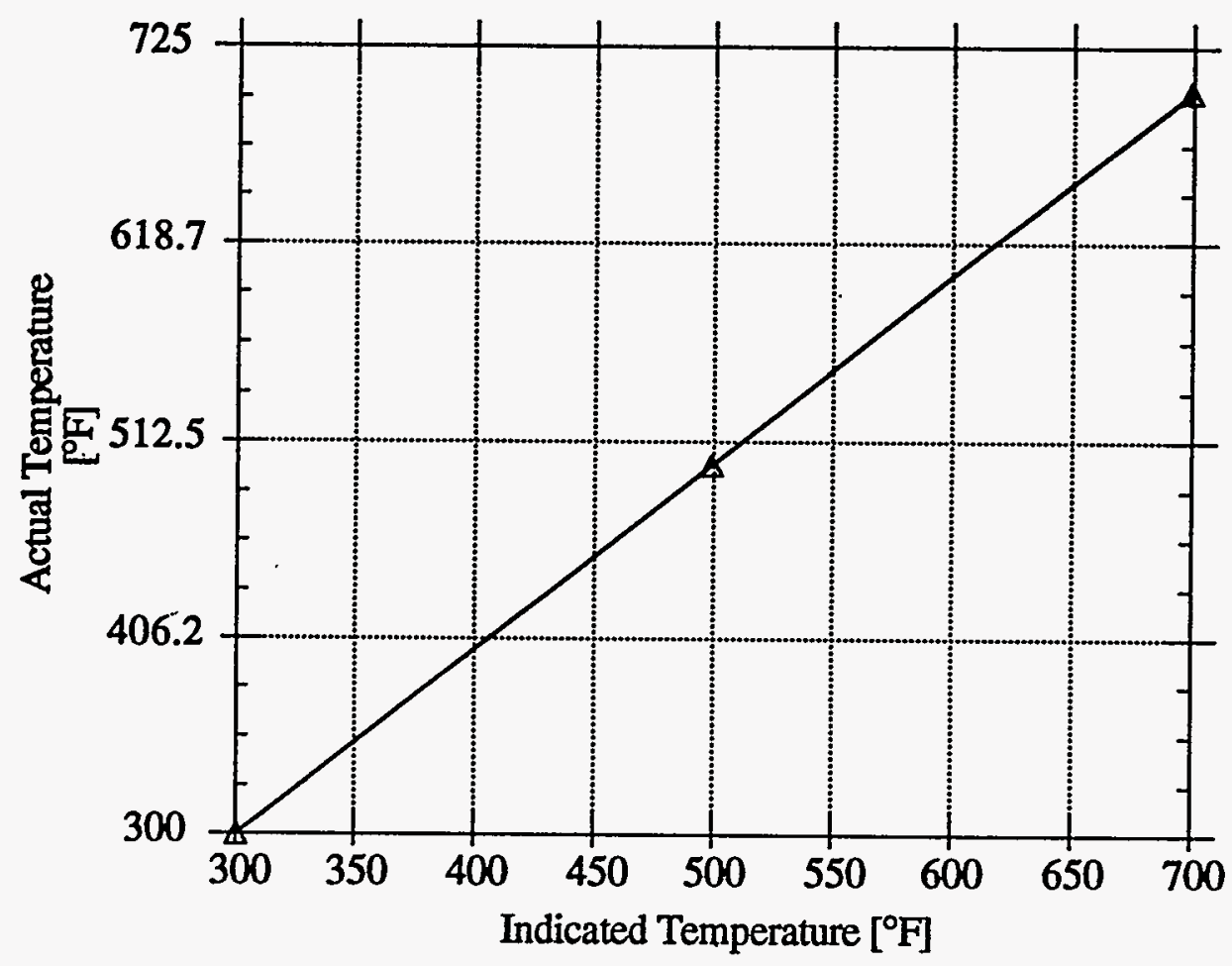

Figure 41 Calibrated thermocouple probe curve

A linear variation of the actual temperature as a function of the indicated temperature is given by:

$$
\mathrm{T}_{\mathrm{actual}}=-2.4256+1.006 \mathrm{~T}_{\text {indicated }}
$$

with a correlation coefficient, $R=1.00$

Table 5 shows the error in the calibrated probe after linear correction is applied. 
Table 5

Factory Calibrated thermocouple probe error

\begin{tabular}{|c|c|c|c|}
\hline $\begin{array}{c}\text { Indicated } \\
\text { Temperature } \\
{\left[{ }^{\circ} \mathbf{F}\right]}\end{array}$ & $\begin{array}{c}\text { Actual } \\
\text { Temperature } \\
{\left[{ }^{\circ} \mathbf{F}\right]}\end{array}$ & $\begin{array}{c}\text { Corrected } \\
\text { Temperature } \\
{\left[{ }^{\circ} \mathbf{F}\right]}\end{array}$ & $\begin{array}{c}\text { Absolute } \\
\text { Error } \\
{\left[{ }^{\circ} \mathbf{F}\right]}\end{array}$ \\
\hline 300.56 & 300.06 & 299.94 & 0.12 \\
\hline 499.39 & 499.77 & 499.96 & $\mathbf{0 . 1 9}$ \\
\hline 699.09 & 701.00 & 700.86 & $\mathbf{0 . 1 4}$ \\
\hline
\end{tabular}

\section{Thermocouple Calibration Apparatus}

A thermocouple calibrating device was fabricated (Fig. 42). The calibrator consisted of a heat source, a heat sink, and an insulated cover. The heat sink was formed from a solid brass cylinder with three holes drilled in one end to accommodate thermocouple probes and a single hole in the other end to accommodate the heat source (Fig. 43). The soldering iron used was an Ungar CI-45, 0.38 A $120 \mathrm{~V}$ AC/DC. The soldering iron tip was modified for a snug fit in the heat sink (Fig. 44). The soldering iron was connected to a variable AC power supply. The brass block was insulated to control the rate of heat loss. The thermocouple leads were connected to a data acquisition system. 


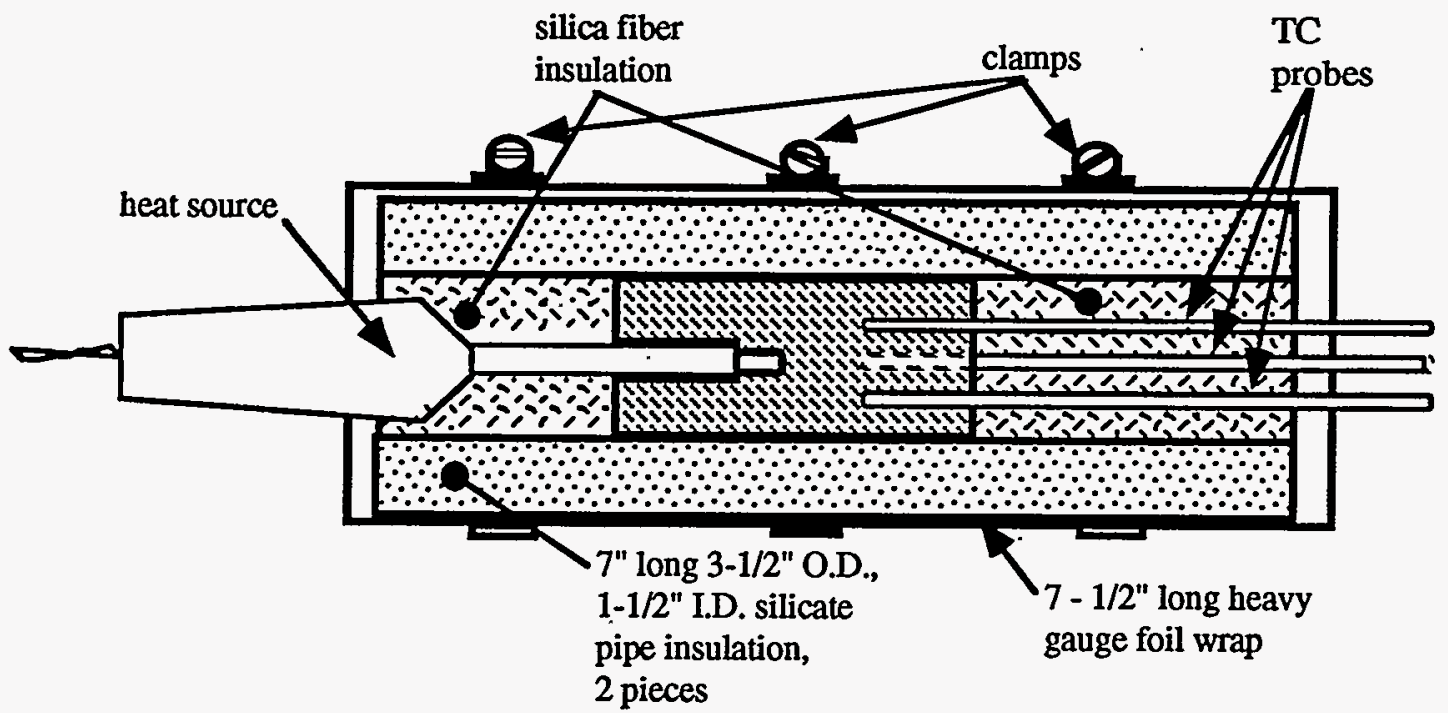

Figure 42. Thermocouple calibrator

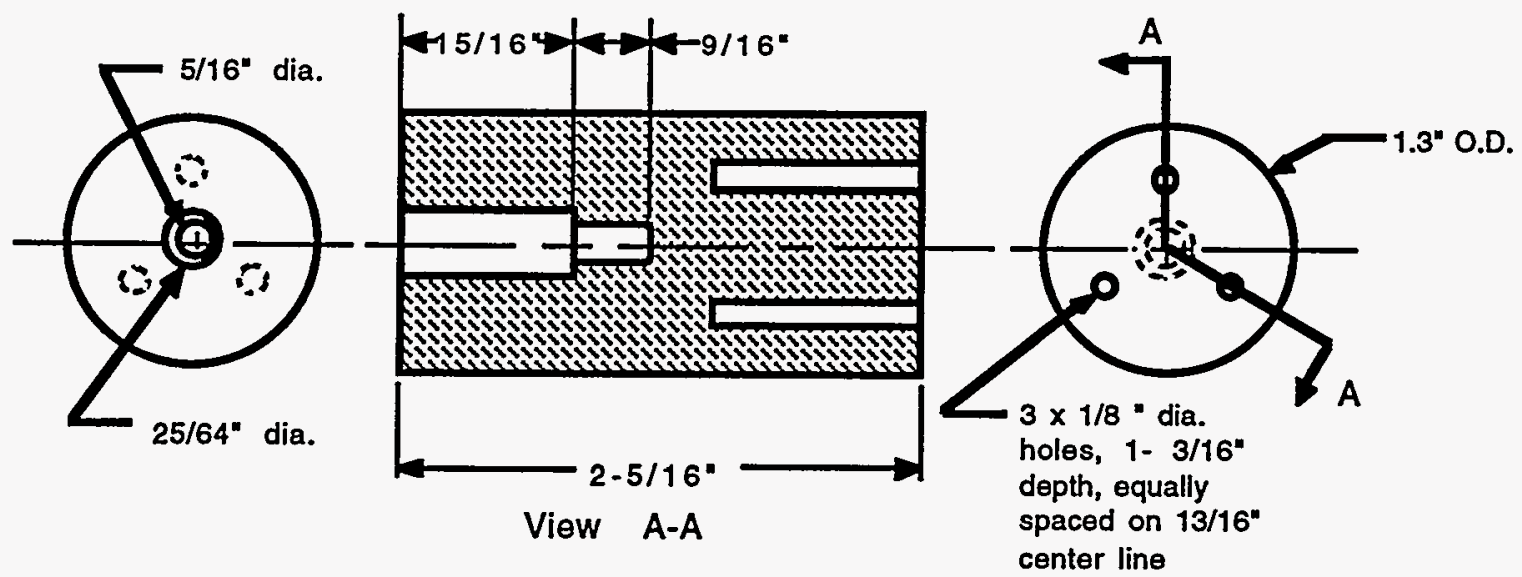

Figure 43. Thermocouple calibrator heat sink 


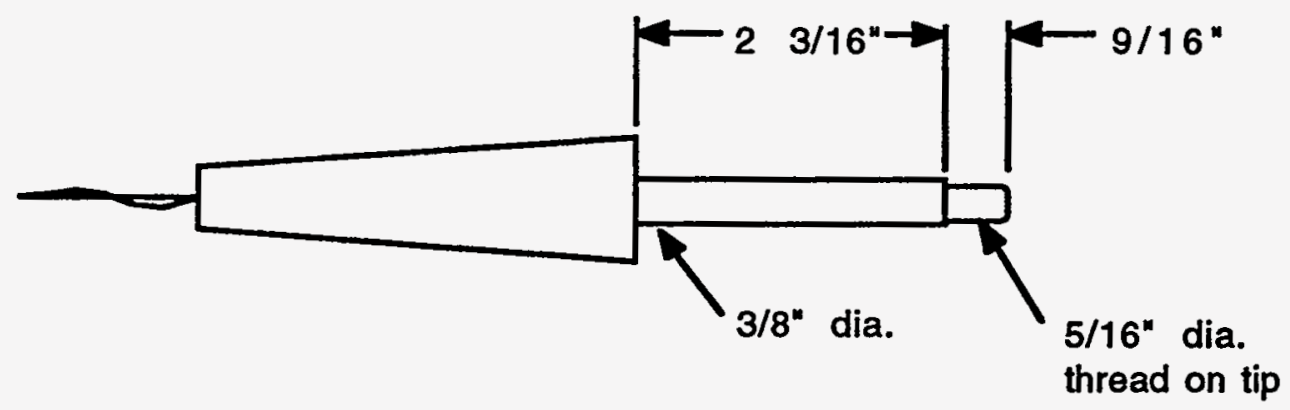

Figure 44. Modified soldering iron heat source

\section{Thermocouple Calibration Procedure}

Three separate tests were required to accomplish calibration of the two absolute and the two differential thermocouples. In the first test, the absolute inlet and outlet TC probes were inserted in the heat sink along with the calibrated TC probe. The heat source was plugged into a variable $\mathrm{AC}$ power supply. The variable $\mathrm{AC}$ supply was adjusted until a maximum temperature of approximately $700^{\circ} \mathrm{F}$ was indicated for the calibrated $\mathrm{TC}$. The power supply was then removed and the system allowed to cool slowly. The temperature time histories for the absolute temperature inlet and outlet thermocouples were recorded. The heat sink was assumed to be isothermal at all TC junctions for any time. Correction factors for the TC's were obtained by comparing the TC outputs to that of the calibrated TC output.

\section{Thermocouple Calibration Results}

The temperature time history curves for the absolute temperature inlet and outlet thermocouples are presented in Figure 45. The relationship for the inlet thermocouple is quite linear as indicated in Fig. 46. The linear relationship between the inlet TC reading and the calibrated TC reading is given by;

$$
\mathrm{T}_{\mathrm{cal}}=-.2217+1.0027 \mathrm{Tin}
$$


The relationship for the outlet thermocouple is quite linear as indicated in Fig. 47. The linear relationship between the outlet TC reading and the calibrated TC reading is given by;

$$
\mathrm{T}_{\text {cal }}=-.1850+1.0047 \text { Tout }
$$

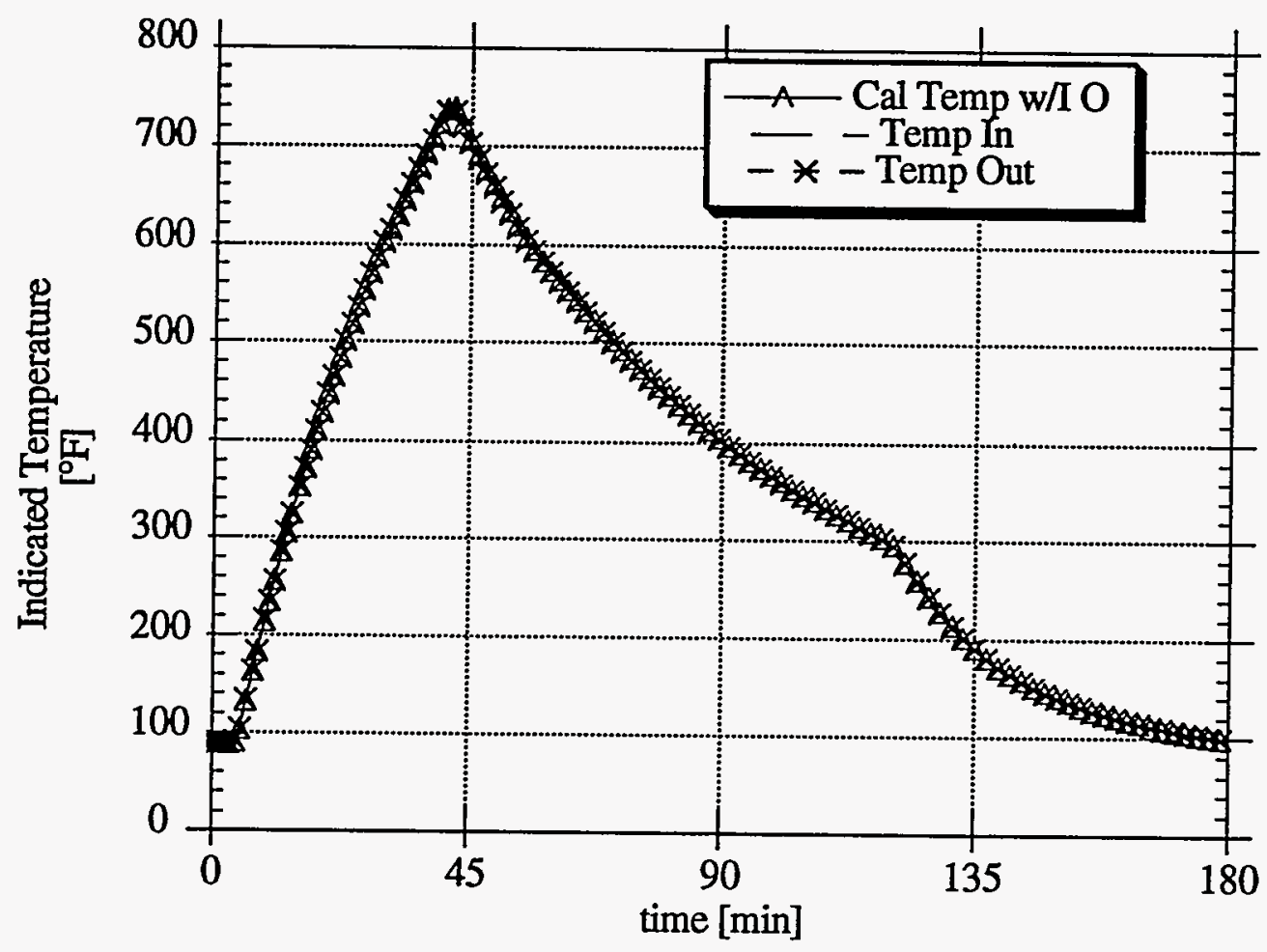

Figure 45. Inlet and Outlet thermocouples calibration histories 


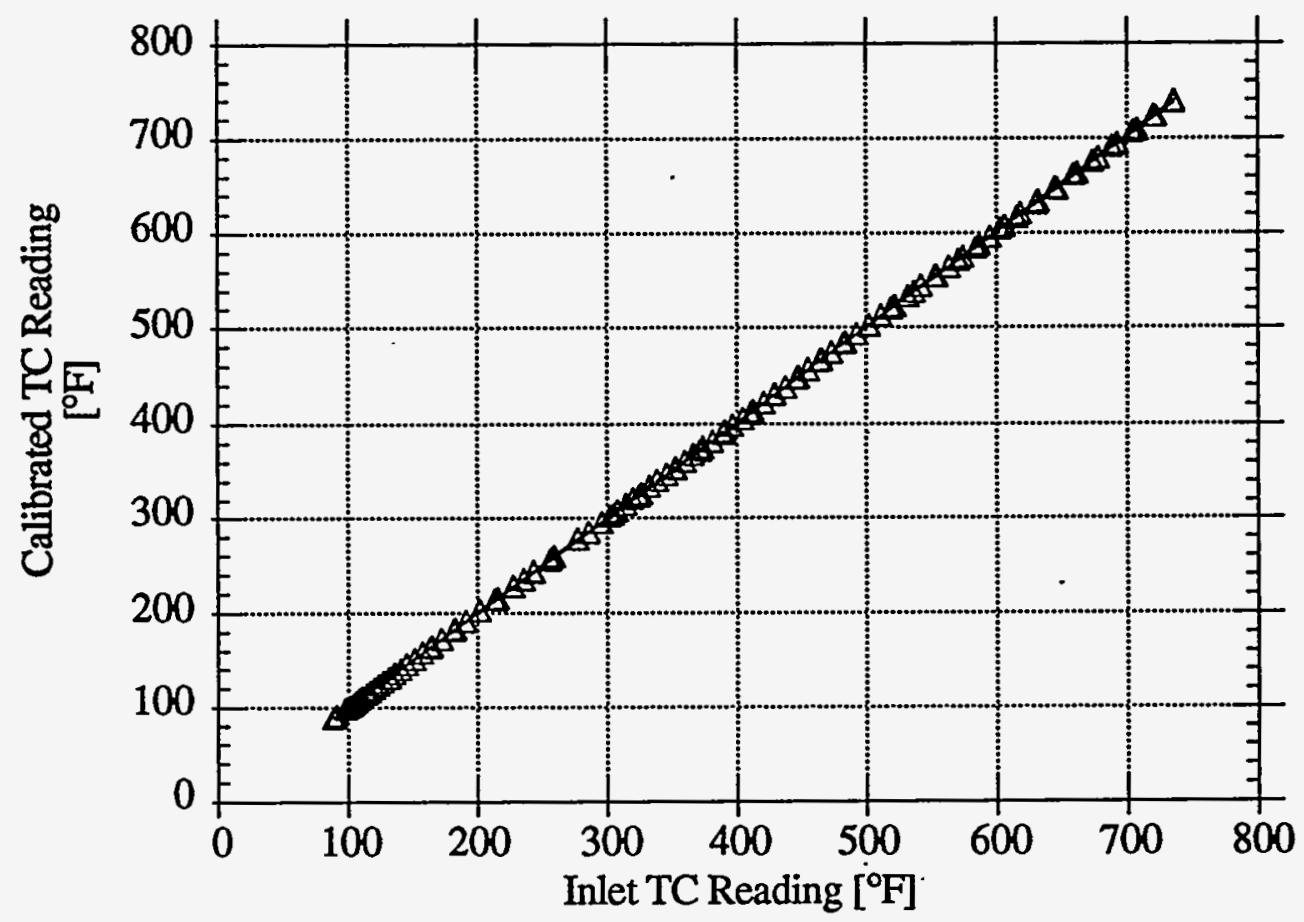

Figure 46. Factory Calibrated versus inlet thermocouple readings

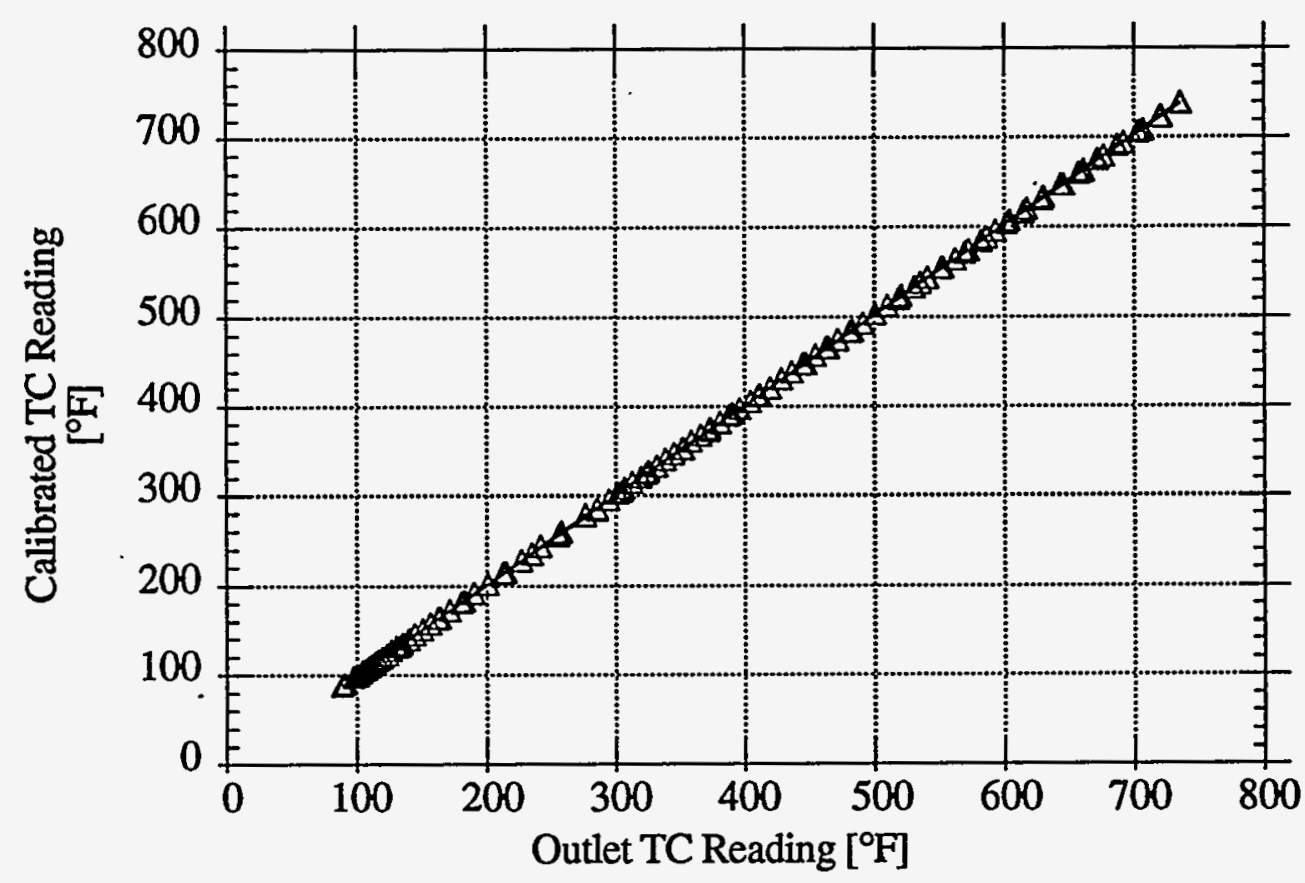

Figure 47. Factory Calibrated versus outlet thermocouple readings 
These equations are used to correct the outlet $\mathrm{TC}$ readings to the calibrated $\mathrm{TC}$ readings. The difference between the calibrated and inlet $\mathrm{TC}$ readings are compared before and after the linearized correction factors were applied (Fig. 48). The maximum difference between the calibrated TC reading and the inlet TC reading before the correction is applied is $2.6^{\circ} \mathrm{F}$. After application of the correction factors the maximum difference is $1.02^{\circ} \mathrm{F}$. The maximum difference between the calibrated $\mathrm{TC}$ readings and the outlet $\mathrm{TC}$ readings before the linear correction is applied is $4.2^{\circ} \mathrm{F}$. After the linear correction is applied the maximum difference is $1.44^{\circ} \mathrm{F}$ (Fig. 49).

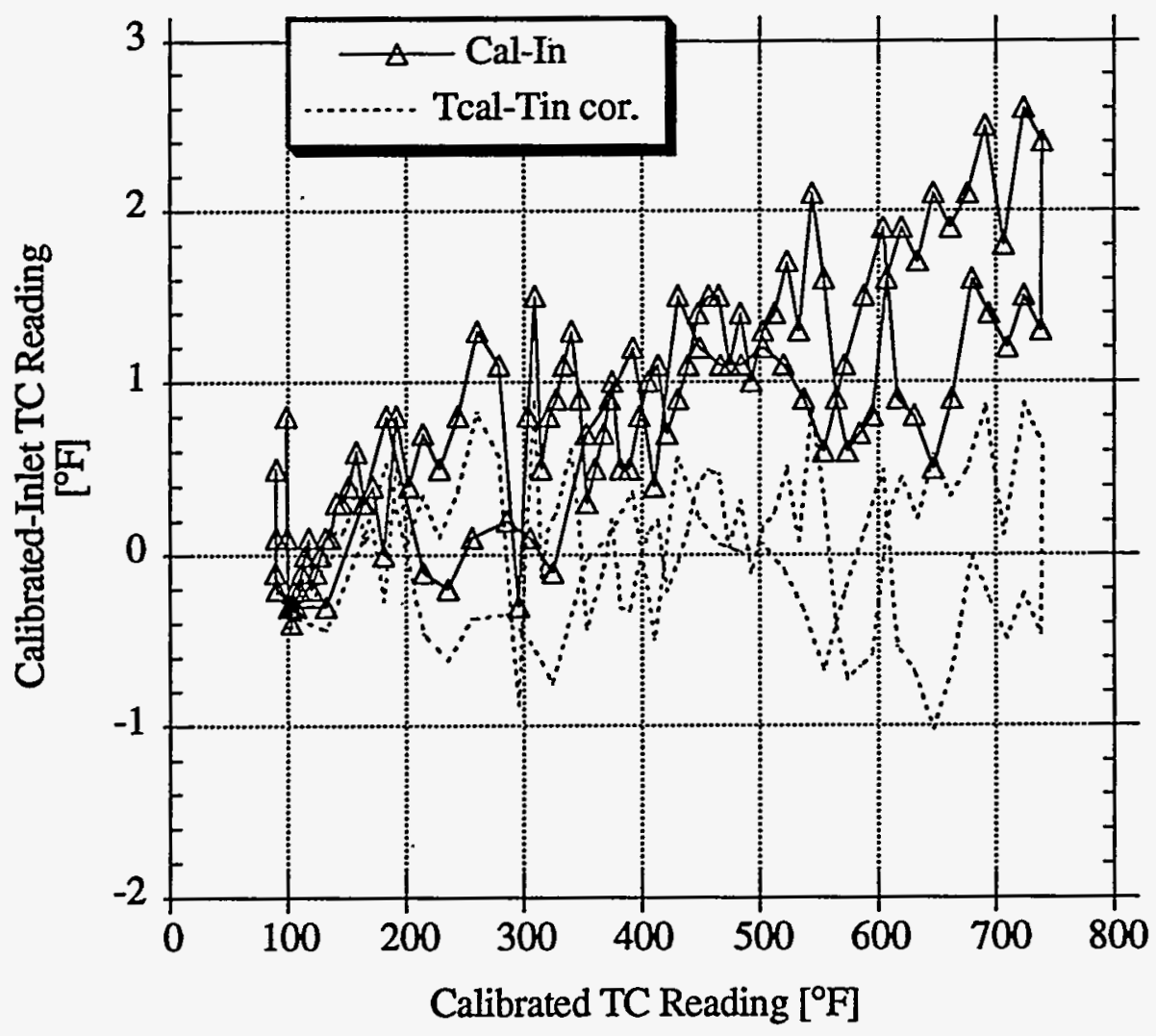

Figure 48. Inlet thermocouple errors 


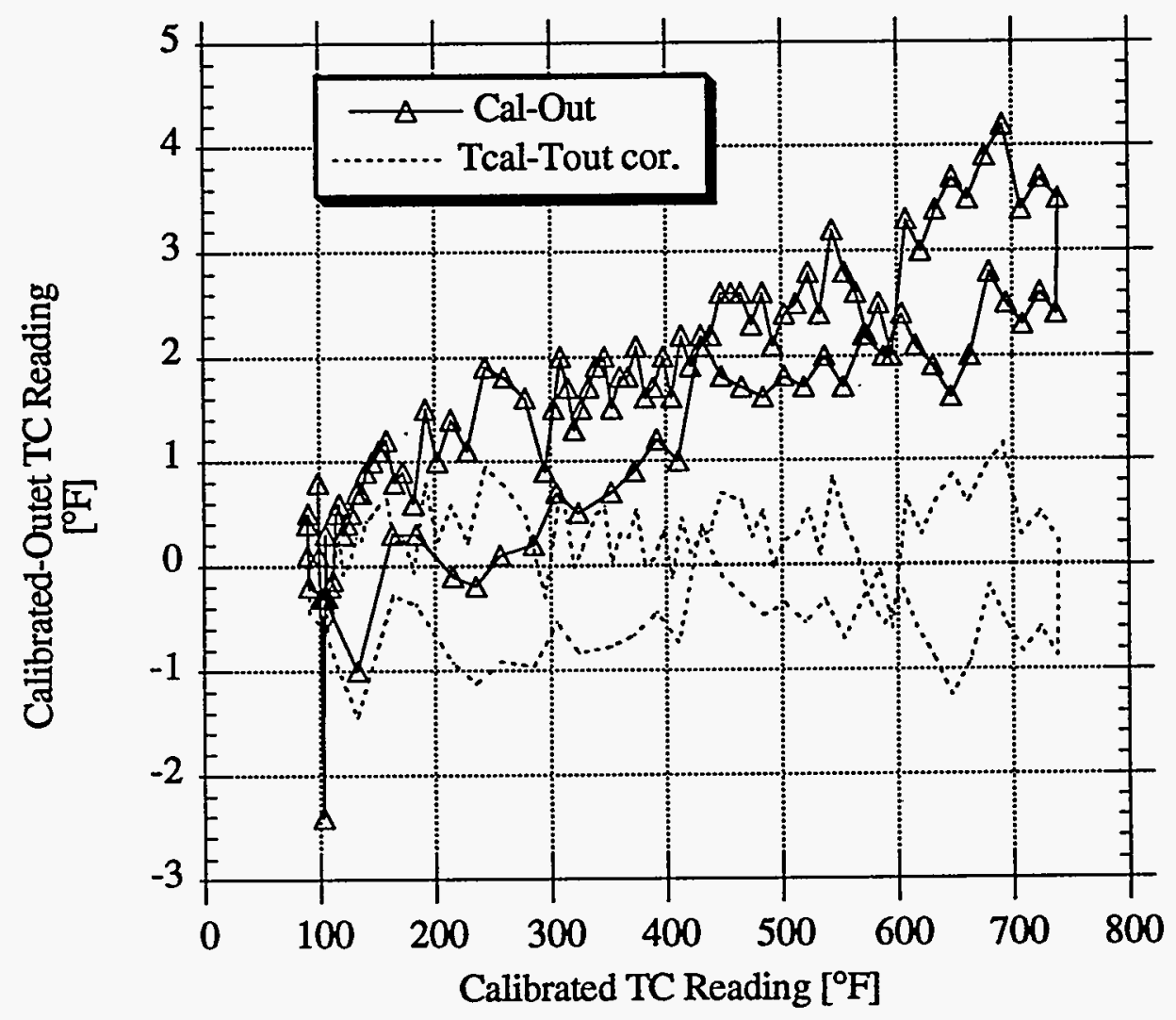

Figure 49. Outlet thermocouple errors

Two thermocouples can be arranged to provide a voltage output proportional to the temperature difference of the two junctions (Fig. 50). When both thermocouple junctions are at the same temperature the voltage output is zero.

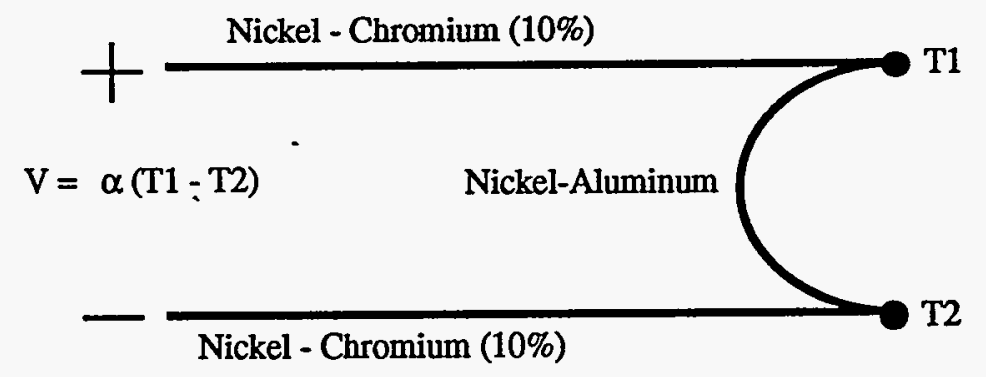

Figure 50. Differential thermocouple connection 
The two thermocouple probes used for the direct temperature difference measurement were inserted in the thermocouple calibrator along with the calibrated thermocouple. The unit was then heated and cooled as per the procedure used for calibrating the inlet and outlet absolute temperature thermocouple probes. Ideally, the net voltage output from the temperature differential connection should be zero regardless of the calibrator temperature. The temperature and micro volt output histories for the calibration procedure are presented in Figure 51. Comparing the differential thermocouple's output with the calibrated thermocouple reading indicates no linear correlation (Fig. 52). The step function of the voltage output is an indication of the minimum computer analog to digital converter (ADC) resolution.

The maximum error in the differential voltage output is $25.45 \mu \mathrm{V}$ which corresponds to a temperature difference error of $1.147^{\circ} \mathrm{F}$.

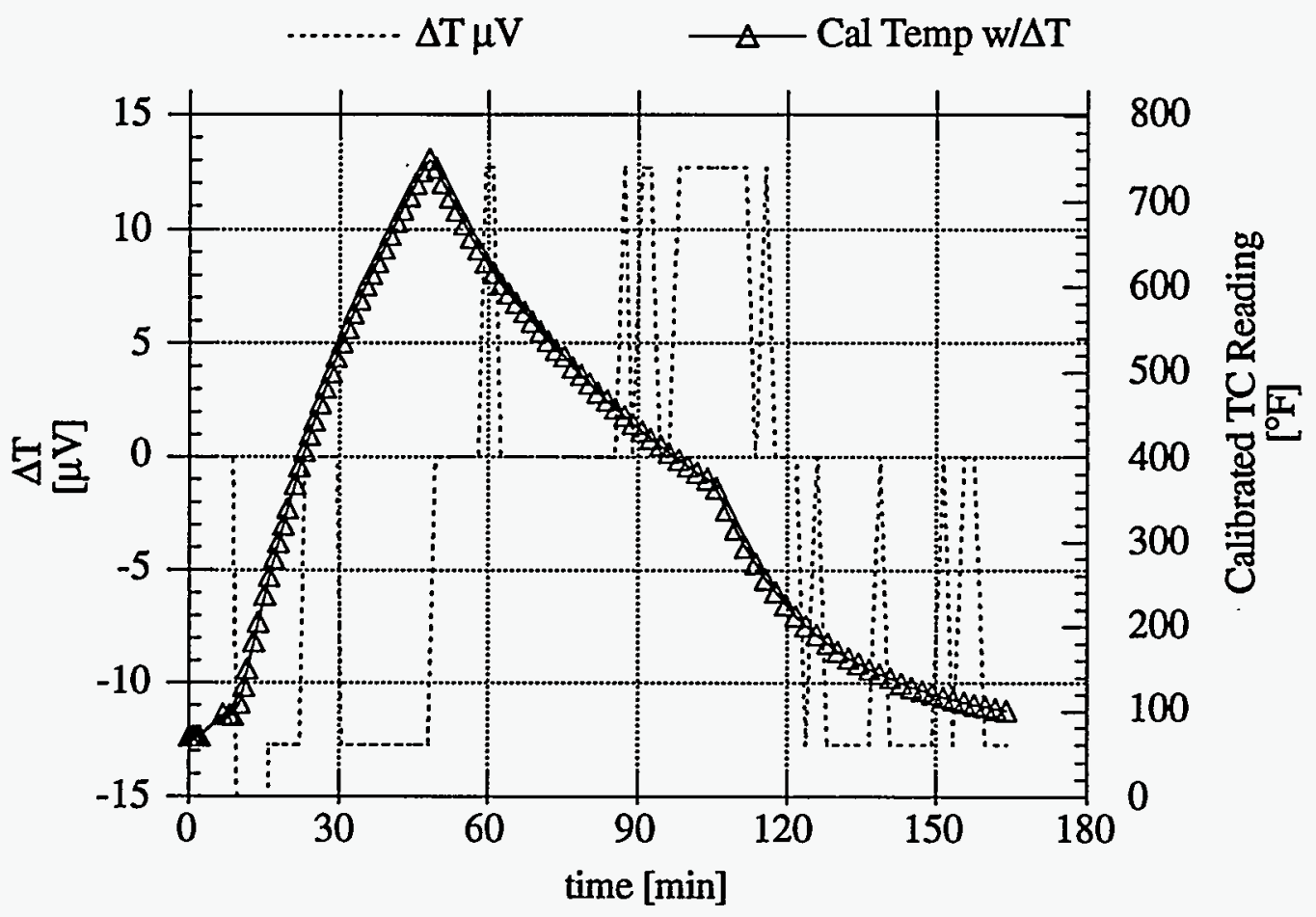

Figure 51. Differential thermocouple readings history 


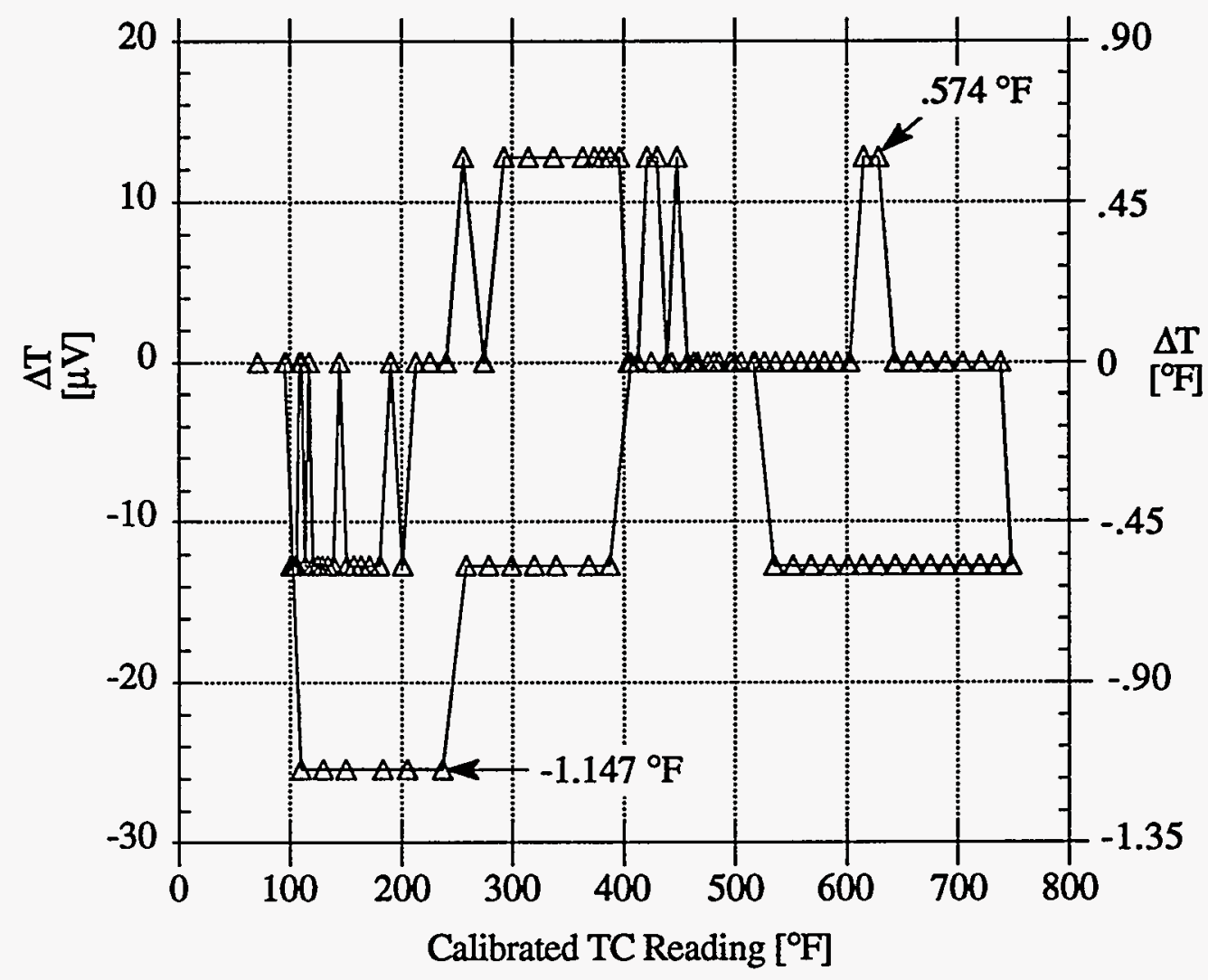

Figure 52. Differential thermocouple errors history

The absolute mean temperature must also be known to convert the millivolt output of the differential thermocouples into an equivalent temperature difference. The voltage to temperature difference conversion factor is determined from a polynomial function of the mean temperature (Fig. 53). The conversion factor polynomial was derived from the voltage-temperature tables for K-type thermocouples.(14)

No calibration of the differential thermocouples was performed with a difference in temperature at the junctions. 


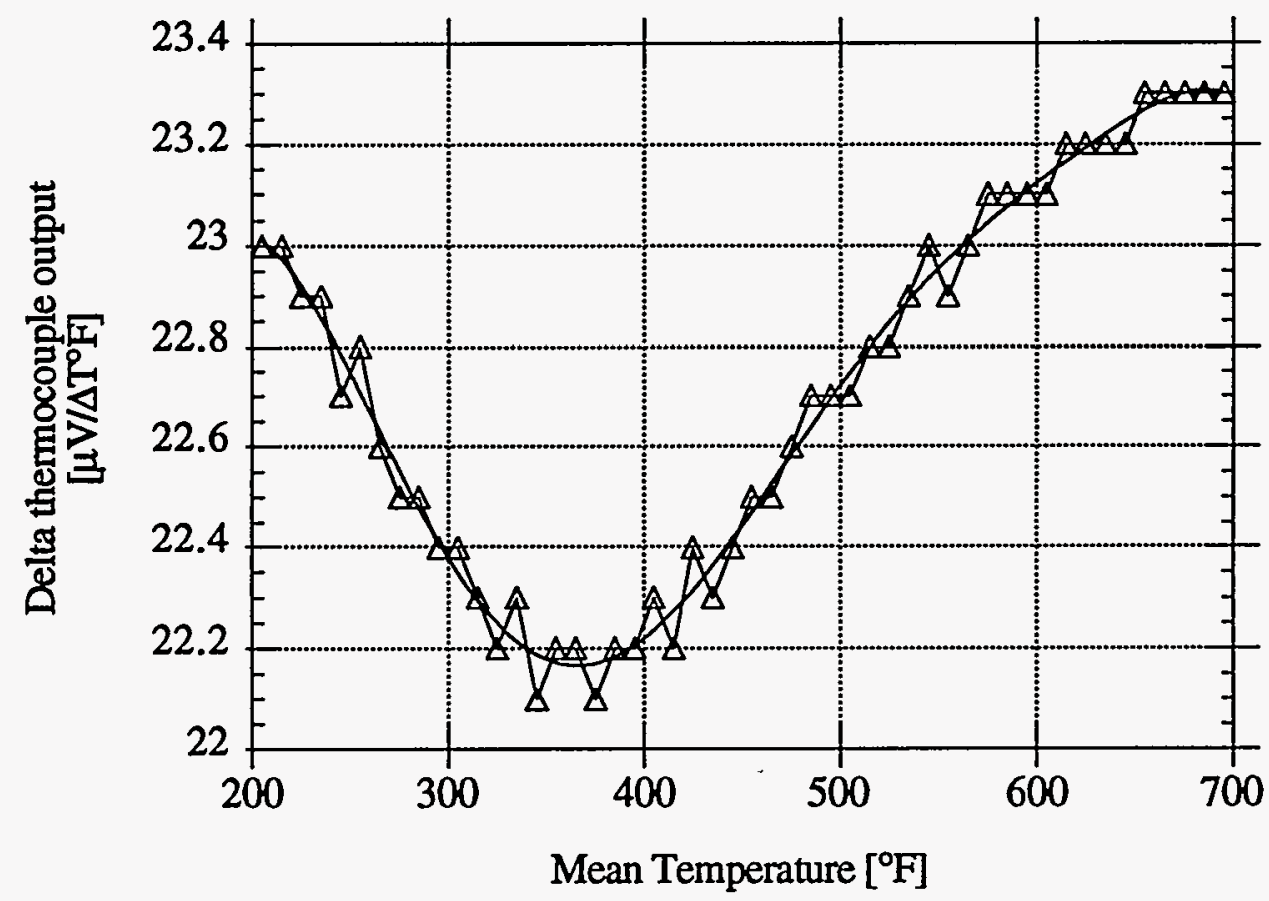

Figure 53. Differential thermocouple output versus mean temperature

\section{Radiometer Calibration}

The Hy-Cal ${ }^{\circledR}$ Hy-Therm ${ }^{\circledR}$ Pyrheliometer P-8400-B was used to measure the thermal radiative heat loss from the receiver cavity (Fig. 54). The spectral range of the radiometer without its quartz window is from 0.2 to 30 microns. The radiometer consists of a thermopile on top of a heat sink. The thermopile converts the temperature gradient across the pile to a proportional current signal. The heat sink is water cooled aluminum base. The exposed end of the thermopile is coated with fused colloidal graphite providing a minimum absorptivity of 0.9 . The radiometer outputs $5 \mathrm{mV}$ per solar constant $\left(0.13980 \mathrm{Watts} / \mathrm{cm}^{2}\right)$. The calibration specifications are provided in Appendix 19.

The radiometer was supplied with a bezel mounted quartz window. Because the radiative being measured is in the infra-red wave length region, preliminary testing showed that the 
quartz window excessively attenuated the heat flux to the radiometer resulting in an insufficient signal output. When the window was removed, the radiometer became overly sensitive to localized convective heating and cooling which resulted in a fluctuating output signal. For low heat flux level measurements, a window that is virtually transparent to the infrared radiative is desirable. Various widow materials were considered and tested for replacement of the quartz window.

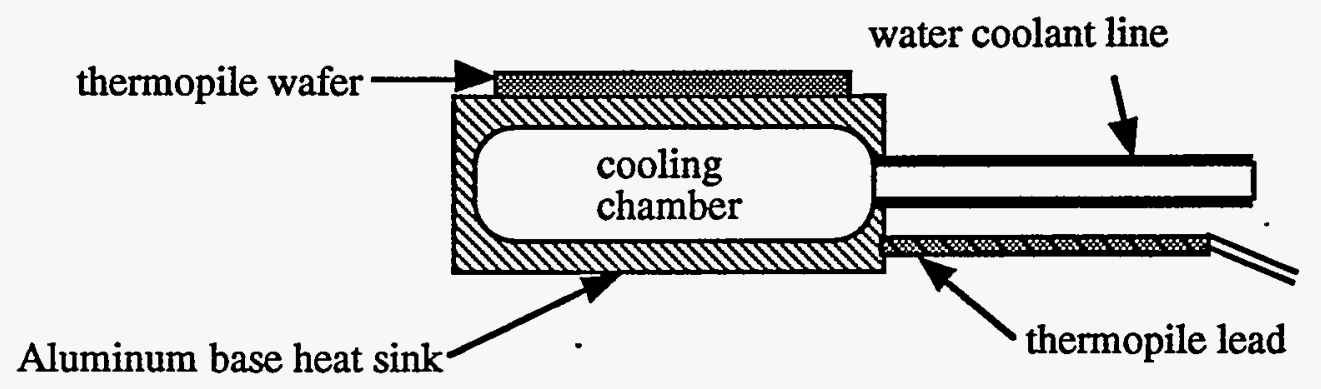

Figure 54. Radiometer section view

\section{Radiometer Window Evaluations}

A bezel was fabricated to accommodate various film windows for testing (Fig. 55). The film was pulled snugly over the bezel. The film was secured in place with a rubber band. The bezel fits over the radiometer. The film window is close enough to the thermopile wafer providing the thermopile with almost $180^{\circ}$ of view.

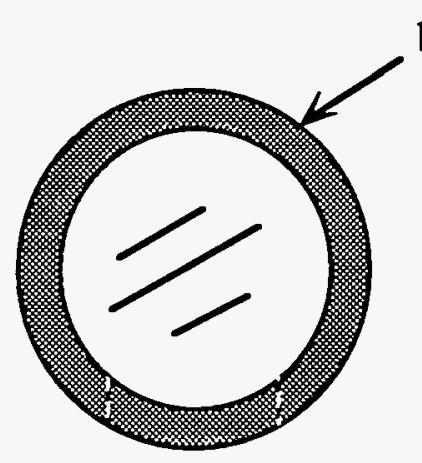

top view bezel mount

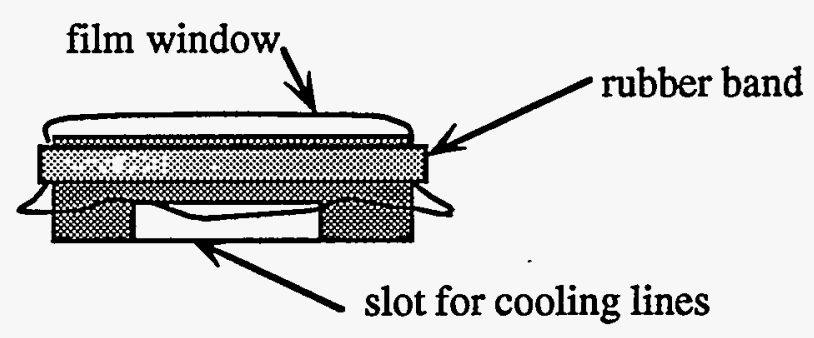

side view

Figure 55. Film window bezel 
The test stand consisted of an inverted hot plate positioned concentrically above and facing the radiometer (Fig. 56). A K-type thermocouple probe is immersed in the coolant return catch basin for the radiometer. The base of the radiometer is assumed to be at the same temperature as the water in the catch basin. The hot plate is inverted and positioned above the radiometer to prevent convective heating of the radiometer. The hot plate temperature is controlled using a variable AC power supply. The radiometer can be positioned at various vertical distances from the hot plate. The surface of the hot plate has nine K-type thermocouples welded to it.

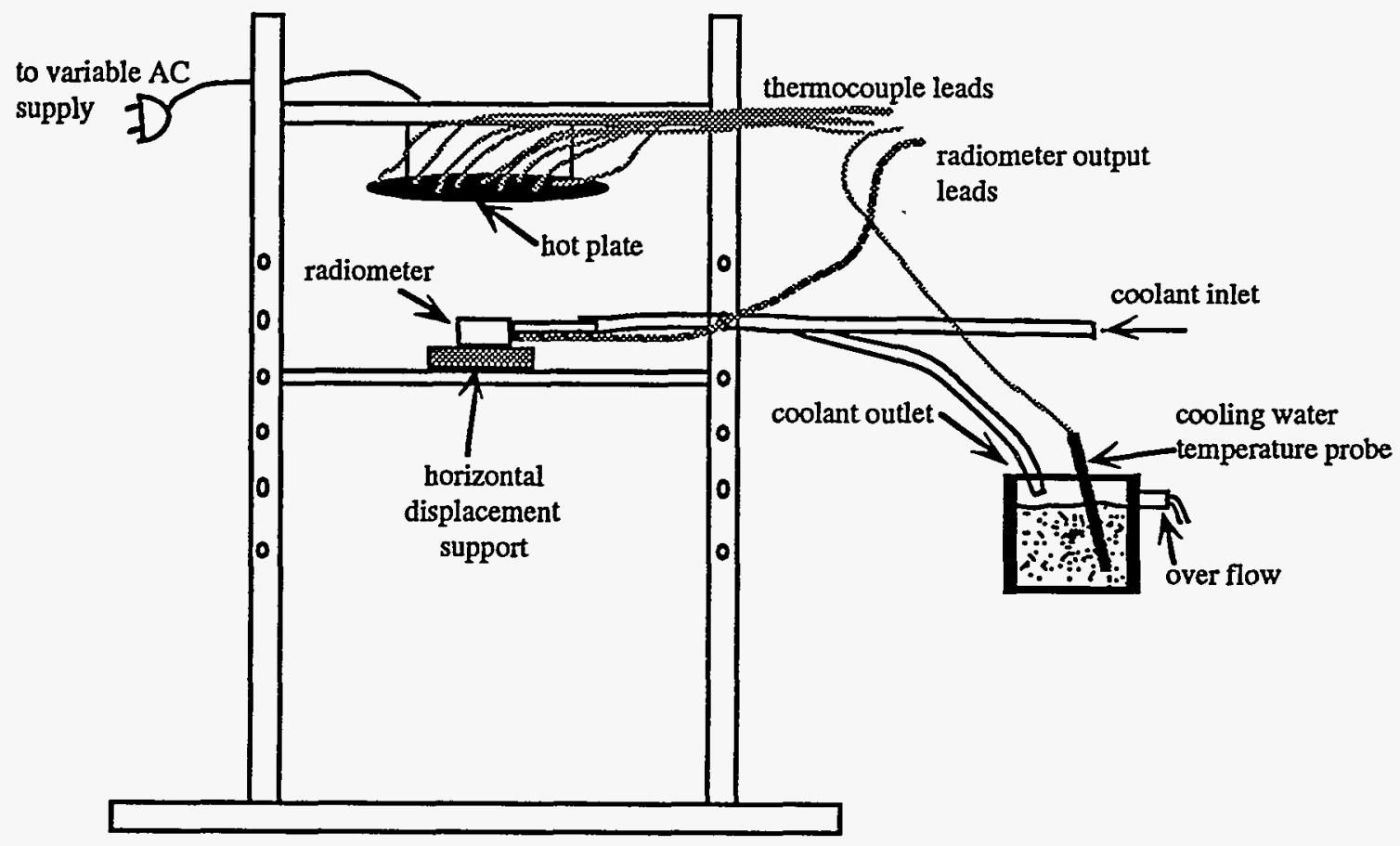

Figure 56. Radiometer calibration test stand

The hot plate surface was coated with high emissivity Pyromark ${ }^{\circledR}$ paint. The manufacturer's specifications for the Pyromark ${ }^{\circledR}$ paint are provided in Appendix 20. The average black-body normal emittance of the painted surface is a function of the surface temperature and can be as low as 0.867 at $600 \mathrm{~K}$ (Fig. 57). A fifth order polynomial curve fit provides an equation for paint surface emittance as a function of surface temperature. 


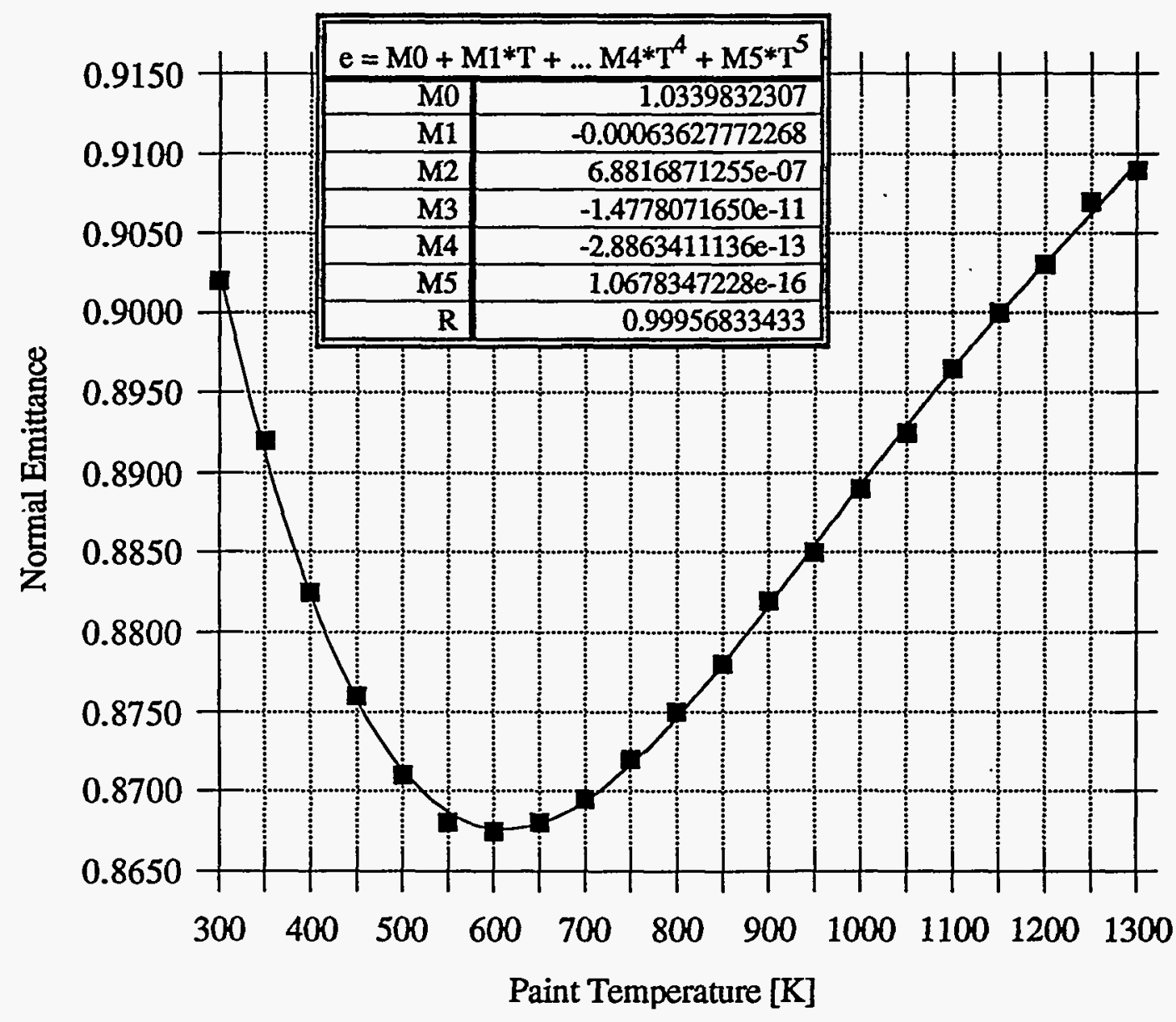

Figure 57. Pyromark paint emittance

The parameters for the window evaluation test plan are shown in Table 6. At the beginning and end of each test, background measurements were recorded by removing the radiometer from the test stand and placing it above the hot plate on an insulated pad. For each of the plate and background thermal radiative measurements the readings were recorded after a two minute stabilization period. The variable AC power supply was adjusted until the average plate temperature was close to the target temperature. The thermocouples were distributed over the plate surface (Fig. 58). 
Table 6

Radiometer window test parameters

\begin{tabular}{|c|c|c|}
\hline $\begin{array}{c}\text { Test } \\
\text { Window }\end{array}$ & $\begin{array}{c}\text { Target } \\
\text { Temperature }\end{array}$ & $\begin{array}{c}\text { Vertical } \\
\text { Displacement }\end{array}$ \\
\hline Saran Wrap & $300^{\circ} \mathrm{F}$ & $0.32 r$ \\
\hline quartz & $"$ & $"$ \\
\hline Glad Wrap & $"$ & $n$ \\
\hline none & $"$ & $n$ \\
\hline Saran Wrap & $400^{\circ} \mathrm{F}$ & $0.75 r$ \\
\hline guartz & $"$ & $"$ \\
\hline Glad Wrap & $"$ & $"$ \\
\hline none & $"$ & $"$ \\
\hline Saran Wrap & $500^{\circ} \mathrm{F}$ & $1.23 r$ \\
\hline quartz & $"$ & $"$ \\
\hline Glad Wrap & $n$ & $"$ \\
\hline none & 4 & $"$ \\
\hline Saran Wrap & $600^{\circ} \mathrm{F}$ & $1.80 \mathrm{r}$ \\
\hline quartz & $"$ & $"$ \\
\hline Glad Wrap & $"$ & $"$ \\
\hline none & $"$ & $"$ \\
\hline Saran Wrap & $700^{\circ} \mathrm{F}$ & $2.5 \mathrm{r}$ \\
\hline quartz & $"$ & $"$ \\
\hline Glad Wrap & $"$ & $"$ \\
\hline none & $"$ & $"$ \\
\hline
\end{tabular}

where

$$
r=\text { radius of the hot plate }
$$




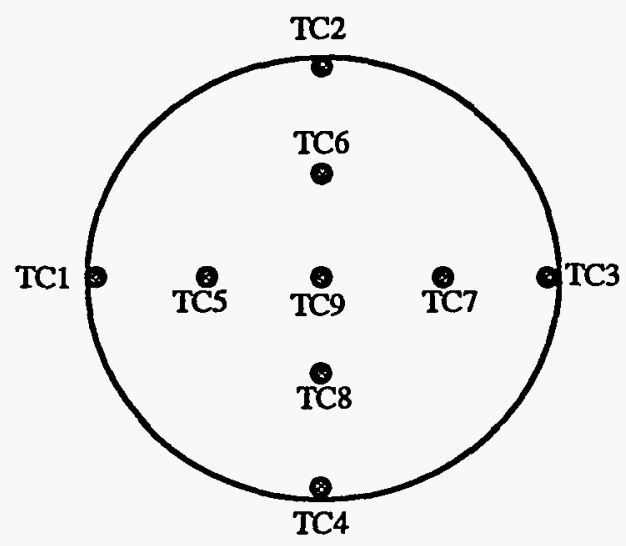

Figure 58. Hot plate thermocouple distribution

For an average area temperature only thermocouples five through nine were considered.

The average area temperature is given by:

$$
\mathrm{T}_{\text {average }}=\frac{\mathrm{T}_{5}+\mathrm{T}_{6}+\mathrm{T}_{7}+\mathrm{T}_{8}+\mathrm{T}_{9}}{5}
$$

The window transmittance, $\tau_{\text {window }}$ is given by:

$$
\tau_{\text {window }}=\frac{q_{\text {radio }}}{q_{\text {radio/plate }}}
$$

where

$$
\begin{aligned}
& \mathrm{q}_{\text {radio }}=\text { the thermal radiative heat flux read by the radiometer } \\
& \mathrm{q}_{\text {plate/radio }}=\text { the thermal radiative heat flux incident on the radiometer from the hot } \\
& \text { plate }
\end{aligned}
$$

The radiative leaving the hot plate and incident on the radiometer is given by:

$$
\mathrm{q}_{\mathrm{radio} / \mathrm{plate}}=\mathrm{q}_{\text {plate }} \mathrm{F}_{\text {plate-radio }}
$$

where

$$
\begin{aligned}
& \mathrm{q}_{\text {plate }}=\text { the thermal radiative heat flux leaving the hot plate } \\
& \mathrm{F}_{\text {plate -radio }}=\text { the shape factor from the hot plate to the radiometer }
\end{aligned}
$$

The radiative heat flux leaving the hot plate is given by: 


$$
\mathrm{q}_{\text {plate }}=\sigma \varepsilon\left(\overline{\mathrm{T}}_{\text {plate }}^{4}-\mathrm{T}_{\text {ambient }}^{4}\right) \pi \mathrm{r}_{\text {plate }}^{2}
$$

where

$B=5.729 \times 10-8\left[\mathrm{~W} /\left(\mathrm{m}^{2} \cdot \mathrm{K}^{4}\right)\right]$ Stefan-Boltzmann constant

$r_{\text {plate }}=8.9[\mathrm{~cm}]$ the radius of the hot plate

$\varepsilon=$ emissivity of the plate surface.

The shape factor from the hot plate to the radiometer is given by:

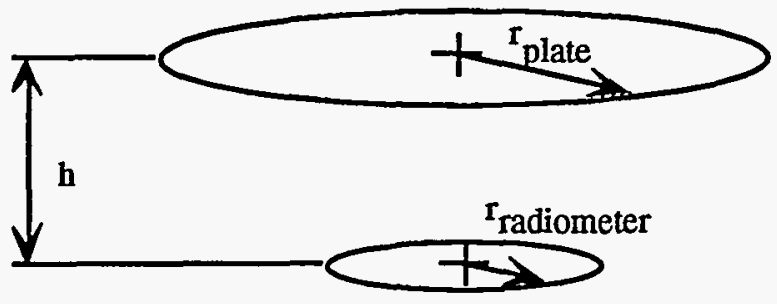

$$
F_{\text {plate-radio }}=\frac{1}{2}\left\{1+\frac{h^{2}+r_{\text {radio }}^{2}}{r_{\text {plate }}^{2}}-\sqrt{\left[1+\frac{h^{2}+r_{\text {radio }}^{2}}{r_{\text {plate }}^{2}}\right]^{2}-4\left[\frac{r_{\text {radio }}}{r_{\text {plate }}}\right]^{2}}\right\}
$$

where

$$
\begin{aligned}
& h=\text { vertical displacement of the hot plate and radiometer. } \\
& r_{\text {radio }}=\text { radius of the radiometer }=0.5625 \text { [in.] }
\end{aligned}
$$

When the diameter of the radiometer approaches one inch, as is the case here, a simplified formula may be used. The simplified shape factor formula is given as follows:

$$
\mathrm{F}_{\text {plate-radio }}=\frac{\mathrm{r}_{\text {radio }}^{2}}{\mathrm{~h}^{2}+\mathrm{r}_{\text {plate }}^{2}}
$$

All real gas effects have been ignored (absorption, scattering etc.).

The results of the test are in Appendix 21. The quartz window transmittance varies linearly with source temperature (Fig. 59). The transmittance for the Grad Wrap and Saran Wrap windows are nearly constant over the testing temperature range. The average transmittance for the no window condition is 0.99 . Ideally, the transmittance for the no window 
condition should be unity. The error in the no window transmittance is well within the instrument's error. Real gas effects may also account for a small loss in the incident flux on the radiometer from the hot plate.

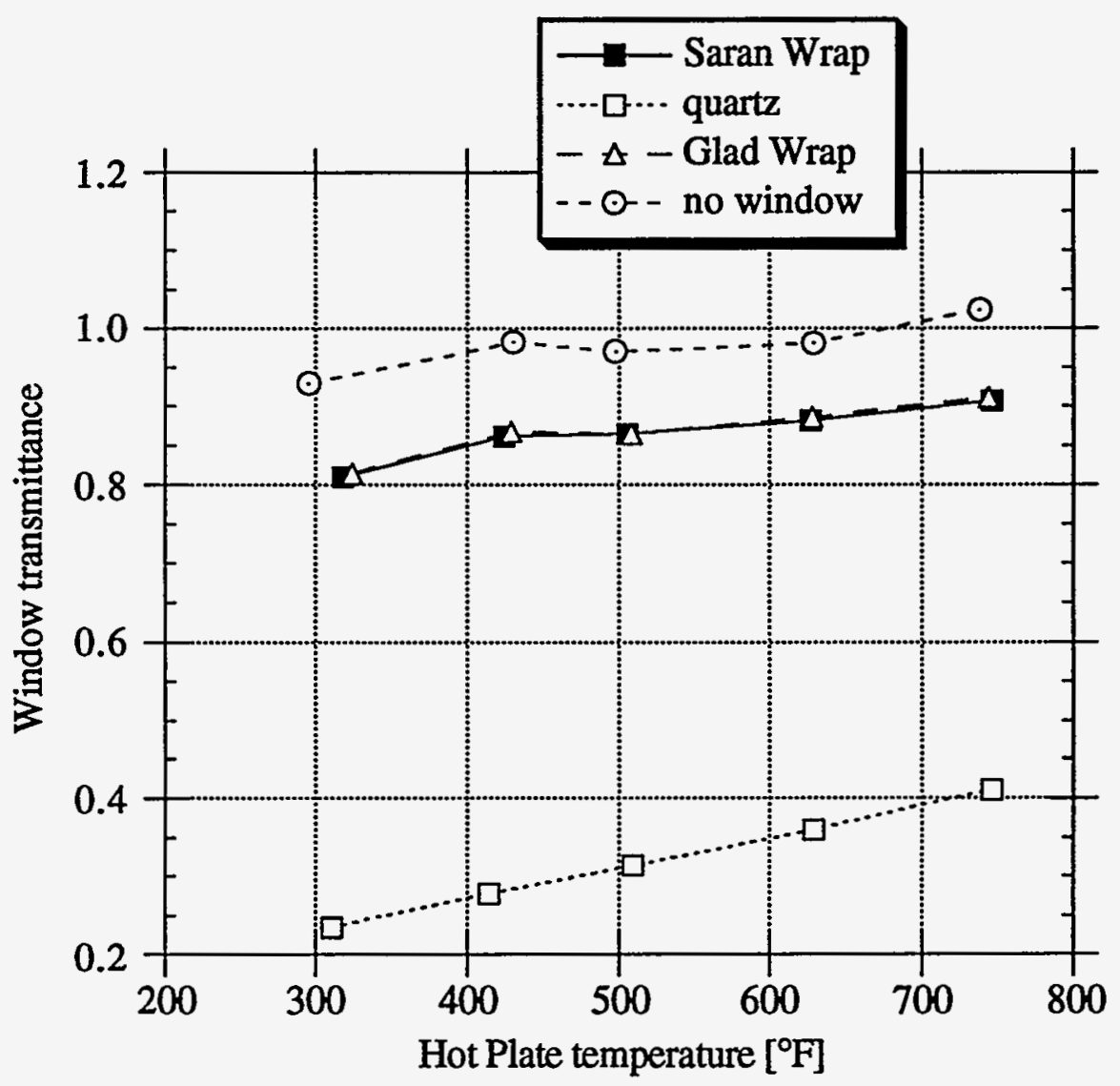

Figure 59. Radiometer windows transmittance

The average transmittance for the Saran Wrap window was determined to be 0.87 . The manufacturer specifies a transmittance of 0.88 for the infrared portion of the spectrum. Technical information for Saran Wrap® films is provided in Appendix 22. Although the Glad Wrap had similar transmission characteristics, the Saran Wrap was selected as the radiometer window, since no manufacturer specifications were available for the Glad Wrap. In addition to selecting a radiometer window, it was also necessary to determine effects of radiometer positioning relative to the heat source. 


\section{Radiometer Positioning}

The radiometer positioning sensitivity must be considered for accurate heat flux measurements. The parameters for the radiometer positioning sensitivity test plan are presented in Table 7. At the end of each test the background measurements were taken by removing the radiometer from the test stand and placing it above the hot plate on an insulated pad. For each of the plate and background thermal radiative measurements the radiometer readings were recorded after a two minute stabilization period.

Table 7

Radiometer position sensitivity test parameters

\begin{tabular}{|c|c|c|}
\hline Hot Plate Temp & Offset Distance & $\begin{array}{c}\text { Vertical } \\
\text { Displacement }\end{array}$ \\
\hline $400^{\circ} \mathrm{F}$ & 0 to $2 \mathrm{r}$ step $0.5 \mathrm{r}$ & $0.75 \mathrm{r}$ \\
\hline $700^{\circ} \mathrm{F}$ & 0 to $6 \mathrm{r}$ step $1 \mathrm{r}$ & $2.5 \mathrm{r}$ \\
\hline $400^{\circ} \mathrm{F}$ & 0 & 1 to $6 \mathrm{r}$ step $1 \mathrm{r}$ \\
\hline $700^{\circ} \mathrm{F}$ & 0 & 2 to $12 \mathrm{r}$ step $2 \mathrm{r}$ \\
\hline
\end{tabular}

where $\quad r=$ radius of the hot plate

The shape factor from the hot plate to the radiometer is given by:

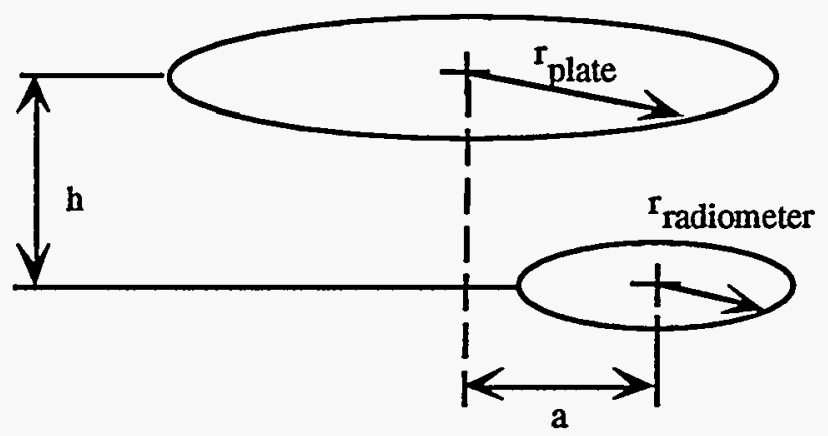




$$
\mathrm{F}_{\text {plate-radio }}=\frac{1}{2}\left\{1-\frac{1+\left(\frac{\mathrm{h}}{\mathrm{a}}\right)^{2}-\left(\frac{\mathrm{r}_{\text {plate }}}{\mathrm{a}}\right)^{2}}{\sqrt{\left[1+\left(\frac{\mathrm{h}}{\mathrm{a}}\right)^{2}-\left(\frac{\mathrm{r}_{\text {plate }}}{\mathrm{a}}\right)^{2}\right]^{2}-4\left[\frac{\mathrm{r}_{\text {plate }}}{\mathrm{a}}\right]^{2}}}\right\}\left(\frac{\mathrm{r}_{\text {radio }}}{\mathrm{r}_{\text {plate }}}\right)^{2}
$$

where

$$
\begin{aligned}
& \mathrm{h}=\text { vertical displacement of the hot plate and radiometer. } \\
& \mathrm{r}_{\text {radio }}=\text { radius of the radiometer }=1.43 \mathrm{~cm} \\
& \mathrm{r}_{\text {plate }}=\text { radius of the hot plate }=8.9 \mathrm{~cm} \\
& \mathrm{~h}=\text { vertical displacement [in.] } \\
& \mathrm{a}=\text { horizontal displacement [in.] }
\end{aligned}
$$

The results of the displacement sensitivity test are tabled in Appendix 23. The effects of vertical and horizontal displacement of the radiometer from the heat source are presented in Figure 60. Ideally, all values should be equal to one. The radiometer is especially sensitive to horizontal displacement (i.e. off axis readings).

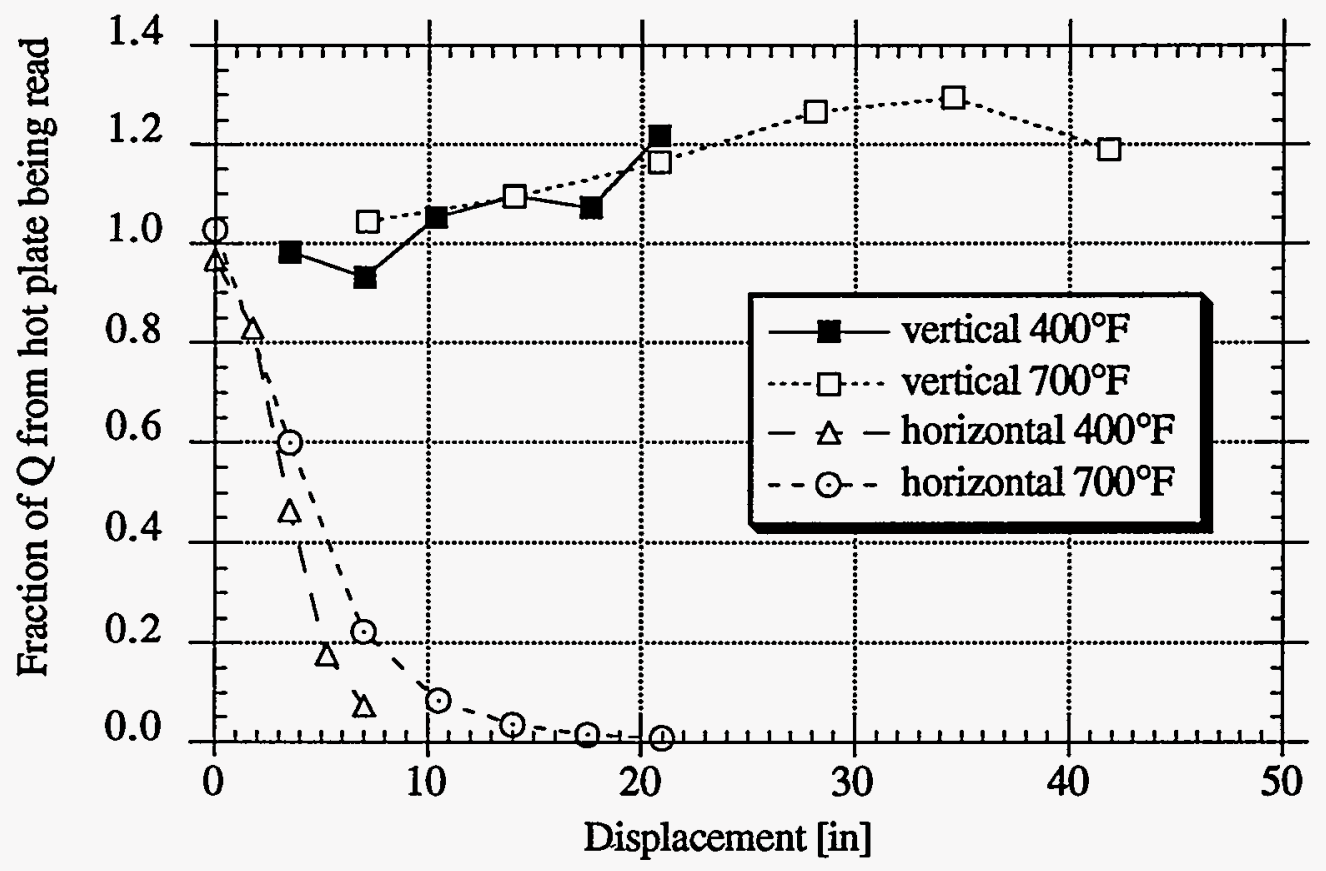

Figure 60. Radiometer displacement effects

The results indicate that the radiometer should be placed as close as possible and in line 
with the heat source. Extreme care was taken to assure the radiometer was centered on the receiver axis during the test phase. An elaborate string and plumb bob arrangement was used to center the radiometer.

\section{ERROR ANALYSIS}

This error analysis determines error in the results based on test method and instruments used. The error analysis also serves as one form of evaluating the test method. The error analysis does not account for human errors or systematic errors. The general form for the error analysis of a given function, $z$, where $z=z\left(x_{i}\right)$ is given as follows $(16)$ :

$$
\sigma_{z}=\sqrt{\sum_{i}\left[\left(\frac{\partial z}{\partial x_{i}}\right) \sigma_{x_{i}}\right]^{2}}
$$

The general formula for the total heat lost from the cavity is given by:

$$
Q_{\text {total }}=\rho \dot{v} c_{p} \Delta T
$$

The percent error in the total heat loss is given by:

$$
\frac{\sigma_{Q_{\text {total }}}}{Q_{\text {total }}}=\sqrt{\left(\frac{\sigma_{\rho}}{\rho}\right)^{2}+\left(\frac{\sigma_{\dot{\mathrm{v}}}}{\dot{\mathrm{v}}}\right)^{2}+\left(\frac{\sigma_{\mathrm{c}_{\mathrm{p}}}}{\mathrm{c}_{\mathrm{p}}}\right)^{2}+\left(\frac{\sigma_{\Delta \mathrm{T}}}{\Delta \mathrm{T}}\right)^{2}}
$$

The density of the heat transfer fluid is a function of the temperature and is approximated by(17):

$$
\rho=60.6-0.0324 \mathrm{~T}_{\text {inlet }}+9.84 \mathrm{e}-6 \mathrm{~T}_{\text {inlet }}^{2}-1.79 \mathrm{e}-8 \mathrm{~T}_{\text {inlet }}^{3}\left[\mathrm{lb} / \mathrm{ft}^{3}\right]
$$

The error in the heat transfer fluid density is approximated by: 


$$
\sigma_{\rho}=\sqrt{\left(-0.0324+1.968 \mathrm{e}-5 \mathrm{~T}_{\text {inlet }}-5.37 \mathrm{e}-8 \mathrm{~T}_{\text {inlet }}^{2}\right)^{2} \sigma_{\mathrm{T}_{\text {inlet }}}^{2}}
$$

The inlet temperature is used for density calculation. The inlet thermocouple used is the one closest to the flow meters.

The heat capacity of the heat transfer fluid is a function of the temperature and is approximated by(17):

$$
c_{p}=0.3690+2.267 e-4 T_{\text {mean }}\left[B t u / l b{ }^{\circ} \mathrm{F}\right]
$$

The error in the heat transfer fluid heat capacity is approximated by:

$$
\sigma_{c_{p}}=2.267 \mathrm{e}-4 \sigma_{T_{\text {mean }}}
$$

\section{A. Flow Measurement Error Analysis}

The HTF flow rate is given by:

$$
\dot{\mathrm{v}}=0.2978 \mathrm{E}
$$

where:

$$
\begin{aligned}
& \mathrm{E}=\text { is the output signal from the pulse rate converter (PRC) [volts] } \\
& \dot{\mathrm{v}}=\text { volumetric flow rate }[\mathrm{gpm}]
\end{aligned}
$$

The manufacturer's specified linearity of the PRC is $\pm 0.4 \%$ of full scale. The calibrated flow meter is accurate to within $\pm 0.5 \%$ of the reading in the flow rate range of 0.8 to 2.5 gallons per minute and with a fluid viscosity in the range of 0.4 to 2.0 centistokes. ${ }^{(18)}$

The output of the PRC to the computer is from 0 to 10 volts. The accuracy of the computer for the 10 volt input range is the larger of $\pm 1 \%$ of the reading or $\pm 0.2 \%$ of the range (the range is 11 volts for the -1 to 10 volt input ). ${ }^{(19)}$ The combined error for the factory calibrated flow meter reading is given by: 


$$
\begin{gathered}
\sigma_{\text {flow }}=\sqrt{b^{2} \sigma_{\mathrm{E}}^{2}} \\
\sigma_{\mathrm{E}}=\sqrt{\left(\sigma_{\mathrm{PRC}}\right)^{2}+\left(\sigma_{\text {flow meter }}\right)^{2}+\left(\sigma_{\text {computer }}\right)^{2}}
\end{gathered}
$$

where:

$$
\begin{aligned}
& \mathrm{b}=\text { the slope of the flow rate versus voltage output for the PRC-flow meter } \\
& \text { combination } \\
& \mathrm{b}=0.2978 \text { [gpm/volt] } \\
& B_{\text {PRC }}=\text { the error in the pulse rate converter } \\
& \frac{\sigma_{\mathrm{PRC}}}{\mathrm{E}_{\text {scale PRC }}}= \pm 0.4 \% \text { of full scale } \\
& \mathrm{E}_{\text {scale PRC }}=10 \text { volts } \\
& B_{\text {flow meter }}=\text { the error in the flow meter } \\
& \frac{\sigma_{\text {flow meter }}=0.5 \% \text { of reading }}{E_{\text {reading }}} \\
& B_{\text {computer }}=\text { the error in the voltage signal ADC } \\
& \quad \sigma_{\text {computer }}
\end{aligned}
$$

The maximum error on flow rate measurement is $1.6 \%$ or $0.0208 \mathrm{gpm}$.

\section{B. Temperature Measurement Error Analysis}

The accuracy of the computer must also be taken into consideration. The specified accuracy of the data acquisition system is given as $\pm 1.44^{\circ} \mathrm{F}\left( \pm 0.8^{\circ} \mathrm{C}\right)$ with a resolution of $0.18{ }^{\circ} \mathrm{F}$ $\left(0.1^{\circ} \mathrm{C}\right)$ for $\mathrm{K}$-type thermocouples. The accuracy of the differential thermocouple connection is specified as $\pm 20 \mu \mathrm{V}$ for the $\pm 25 \mathrm{mV}$ range setting. This corresponds to a 
temperature difference accuracy of $\pm 0.90^{\circ} \mathrm{F}\left( \pm 0.5^{\circ} \mathrm{C}\right)$. Calibration tests indicates an error of $\pm 25.45 \mu \mathrm{V}$ which corresponds to a temperature difference error of $\pm 1.147^{\circ} \mathrm{F}$.

The error of the temperature readings must include the combined effects of the error of the computer, calibrated probe, the absolute temperature probes, and the computer micro volt readings. The error of the absolute temperature thermocouples is given by:

$$
\sigma_{\text {Tin }}=\sqrt{\sigma_{\text {Tin/cal }}^{2}+\sigma_{\text {cal }}^{2}+\sigma_{\text {computer TC }}^{2}}
$$

and

$$
\sigma_{\text {Tout }}=\sqrt{\sigma_{\text {Tout } / \text { cal }}^{2}+\sigma_{\text {cal }}^{2}+\sigma_{\text {computer TC }}^{2}}
$$

where

$$
\begin{aligned}
& \sigma_{\mathrm{Tin} / \mathrm{cal}}=\text { error of the inlet probe as compared with the calibrated probe. } \\
& \sigma_{\mathrm{Tin} / \mathrm{cal}}= \pm 1.02^{\circ} \mathrm{F} \\
& \sigma_{\mathrm{Tout} / \mathrm{cal}}=\text { error of the outlet probe as compared with the calibrated probe. } \\
& \sigma_{\text {Tout/cal }}= \pm 1.44^{\circ} \mathrm{F} \\
& \sigma_{\text {computer TC }}=\text { error of the computer ADC thermocouple channels. } \\
& \sigma_{\text {computer TC }}= \pm 1.0^{\circ} \mathrm{F}
\end{aligned}
$$

The mean temperature is required in converting the micro volt signal from the differential thermocouple connection to an equivalent temperature difference. The mean temperature is calculated from the absolute temperature readings of the inlet and outlet thermocouples as follows:

$$
\mathrm{T}_{\text {mean }}=\frac{\mathrm{T}_{\text {in }}+\mathrm{T}_{\text {out }}}{2}
$$

The error in the mean temperature is given by:

$$
\sigma_{\text {Tmean }}=\sqrt{\sigma_{\text {Tin }}^{2}+\sigma_{\text {Tout }}^{2}}
$$

The temperature difference from the differential thermocouple reading is given by:

$$
\Delta \mathrm{T}=\frac{\mu \mathrm{V}}{\mathrm{k}}
$$


where $\mathrm{k}$ is the micro volt to temperature difference conversion factor.

The conversion factor, $\mathrm{k}$, is a function of the mean temperature (Fig. 49). The error in the measured temperature difference is given by:

$$
\sigma_{\Delta \mathrm{T}}=\sqrt{\left(\frac{\partial \Delta \mathrm{T}}{\partial \mu \mathrm{V}} \sigma_{\mu \mathrm{V}}\right)^{2}+\left(\frac{\partial \Delta \mathrm{T}}{\partial \mathrm{k}} \sigma_{\mathrm{k}}\right)^{2}}
$$

which reduces to:

$$
\sigma_{\Delta \mathrm{T}}=\sqrt{\left(\frac{\sigma_{\mu \mathrm{V}}}{\mathrm{k}}\right)^{2}+\left(\frac{\mu \mathrm{V}}{\mathrm{k}^{2}} \sigma_{\mathrm{k}}\right)^{2}}
$$

The error in the micro volt reading is dependent on the error in the differential thermocouple output as well as the error in the computer ADC. The error in the micro volt reading is given by:

$$
\sigma_{\mu \mathrm{V}}=\sqrt{\sigma_{\Delta \mathrm{T} \mu \mathrm{V}-\mathrm{cal}}+\sigma_{\mathrm{computer} \mu \mathrm{V}}}
$$

where

$\sigma_{\Delta \mathrm{T} \mu \mathrm{V} \text {-cal }}=$ error in differential thermocouple as compared with the calibrated thermocouple.

$\sigma_{\Delta \mathrm{T} \mu \mathrm{V} \text {-cal }}= \pm 25.45 \mu \mathrm{V}$

$\sigma_{\text {computer } \mu \mathrm{V}}=$ error in the computer microvolt reading.

$\sigma_{\text {computer } \mu \mathrm{V}}= \pm 20 \mu \mathrm{V}$

The micro volt to temperature difference conversion factor, $\mathrm{k}$, is determined from a ninth order polynomial of the mean temperature at the inlet and outlet junctions. The function for $\mathrm{k}$ is given as follows:

$$
\begin{gathered}
\mathrm{k}=(\dot{\mathrm{m}} 0)+(\mathrm{m} 1) \mathrm{T}_{\text {mean }}+(\mathrm{m} 2) \mathrm{T}_{\text {mean }}^{2}+(\mathrm{m} 3) \mathrm{T}_{\text {mean }}^{3}+(\mathrm{m} 4) \mathrm{T}_{\text {mean }}^{4}+(\mathrm{m} 5) \mathrm{T}_{\text {mean }}^{5} \\
+(\mathrm{m} 6) \mathrm{T}_{\text {mean }}^{6}+(\mathrm{m} 7) \mathrm{T}_{\text {mean }}^{7}+(\mathrm{m} 8) \mathrm{T}_{\text {mean }}^{8}+(\mathrm{m} 9) \mathrm{T}_{\text {mean }}^{9}
\end{gathered}
$$

where

$$
\begin{aligned}
& \mathrm{m} 0=-5.9996574248 \\
& \mathrm{~m} 1=0.57623140669 \\
& \mathrm{~m} 2=-0.0050328211032 \\
& \mathrm{~m} 3=2.6366840630 \mathrm{e}-5
\end{aligned}
$$




$$
\begin{aligned}
& \mathrm{m} 4=-9.2911149803 \mathrm{e}-8 \\
& \mathrm{~m} 5=2.2361762393 \mathrm{e}-10 \\
& \mathrm{~m} 6=-3.5624990721 \mathrm{e}-13 \\
& \mathrm{~m} 7=3.5424764505 \mathrm{e}-16 \\
& \mathrm{~m} 8=-1.9716587450 \mathrm{e}-19 \\
& \mathrm{~m} 9=4.6528339298 \mathrm{e}-23
\end{aligned}
$$

The error in $\mathrm{k}$ is given by:

$$
\sigma_{\mathbf{k}}=\sqrt{\left(\frac{\partial \mathrm{k}}{\partial \mathrm{T}_{\text {mean }}} \sigma_{\mathrm{T}_{\text {mean }}}\right)^{2}}
$$

where:

$$
\begin{aligned}
\frac{\partial \mathrm{k}}{\partial \mathrm{T}_{\text {mean }}} & =(\mathrm{m} 1)+2(\mathrm{~m} 2) \mathrm{T}_{\text {mean }}+3(\mathrm{~m} 3) \mathrm{T}_{\text {mean }}^{2}+4(\mathrm{~m} 4) \mathrm{T}_{\text {mean }}^{3}+5(\mathrm{~m} 5) \mathrm{T}_{\text {mean }}^{4} \\
& +6(\mathrm{~m} 6) \mathrm{T}_{\text {mean }}^{5}+7(\mathrm{~m} 7) \mathrm{T}_{\text {mean }}^{6}+8(\mathrm{~m} 8) \mathrm{T}_{\text {mean }}^{7}+9(\mathrm{~m} 9) \mathrm{T}_{\text {mean }}^{8}
\end{aligned}
$$

\section{Normalization Error Analysis}

The heat loss is normalized using the following formula:

$$
Q_{\text {normalized }}=Q_{\text {measured }}\left(\frac{T_{\text {target }}-T_{\text {ambient standard }}}{T_{\text {measured }}-T_{\text {ambient measured }}}\right)
$$

The percent error in the normalized heat loss is given by:

$$
\frac{\sigma_{\mathrm{Q}_{\text {normalized }}}}{\text { Qnormalized }}=\sqrt{\left(\frac{\sigma_{\mathrm{Q}_{\text {measured }}}}{\text { Qmeasured }^{2}}\right)^{2}+\left(\frac{\sigma_{\mathrm{N}}}{\mathrm{N}}\right)^{2}}
$$

where

$$
\mathrm{N}=\frac{\mathrm{T}_{\text {target }}-\mathrm{T}_{\text {ambient standart }}}{\mathrm{T}_{\text {measured }}-\mathrm{T}_{\text {ambient measured }}}
$$

and

$$
\frac{\sigma_{N}}{N}=\sqrt{\frac{\sigma_{T_{\text {mean }}}^{2}+\sigma_{T_{\text {ambent messured }}^{2}}^{2}}{\left(T_{\text {mean }}-T_{\text {ambiet messured }}\right)^{2}}}
$$


The convective heat loss is given by:

$$
\frac{\sigma_{N}}{N}=\sqrt{\frac{\sigma_{T_{\text {mexn }}}^{2}+\sigma_{T_{\text {mbeat mesured }}^{2}}^{2}}{\left(T_{\text {mean }}-T_{\text {mbleat mesured }}\right)^{2}}}
$$

The error in the convective heat loss is given by:

$$
Q_{\text {convective }}=Q_{\text {total }}-Q_{\text {total }} 0^{\circ}
$$

The conductive heat loss is given by:

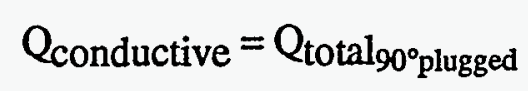

The error in the conductive heat loss is given by:

$$
\sigma_{\mathrm{Q}_{\text {conductive }}}=\sigma_{\mathrm{Q}_{\text {total } 90_{\text {ploggec }}}}
$$

The radiative heat loss is given by:

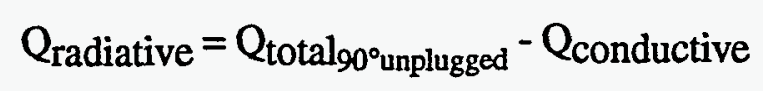

The error in the radiative heat loss is given by:

$$
\sigma_{\mathrm{Q}_{\text {radiative }}}=\sqrt{\sigma_{\mathrm{Q}_{\text {totalgoo apploged }}^{2}}^{2}+\sigma_{\mathrm{Q}_{\text {conductive }}^{2}}}
$$

The maximum error in the normalized total heat loss is $30.63 \%$. This error occurs with the aperture plugged and the receiver in the $+90^{\circ}$ position (Fig. 61). The total heat loss with the aperture plugged is equivalent to the conductive heat loss. 


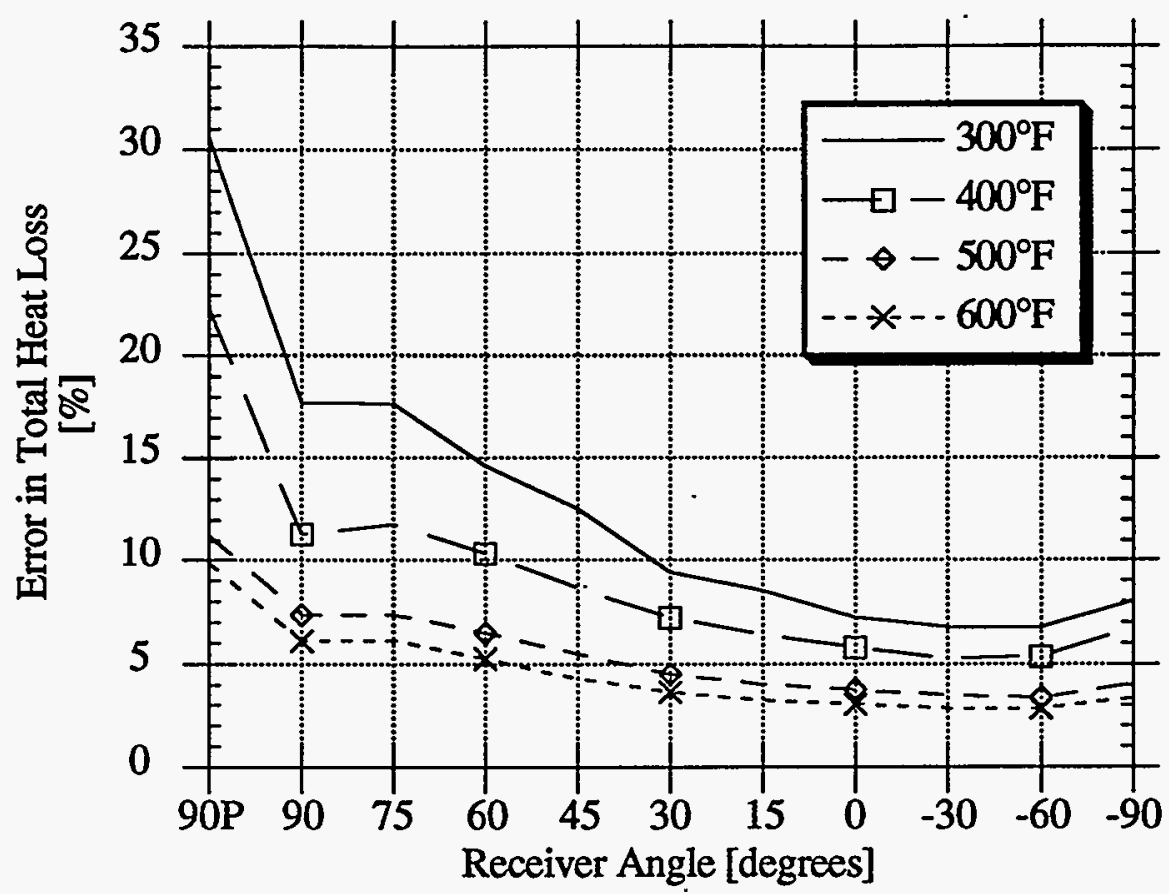

Figure 61. Error in total heat loss for various operating temperatures

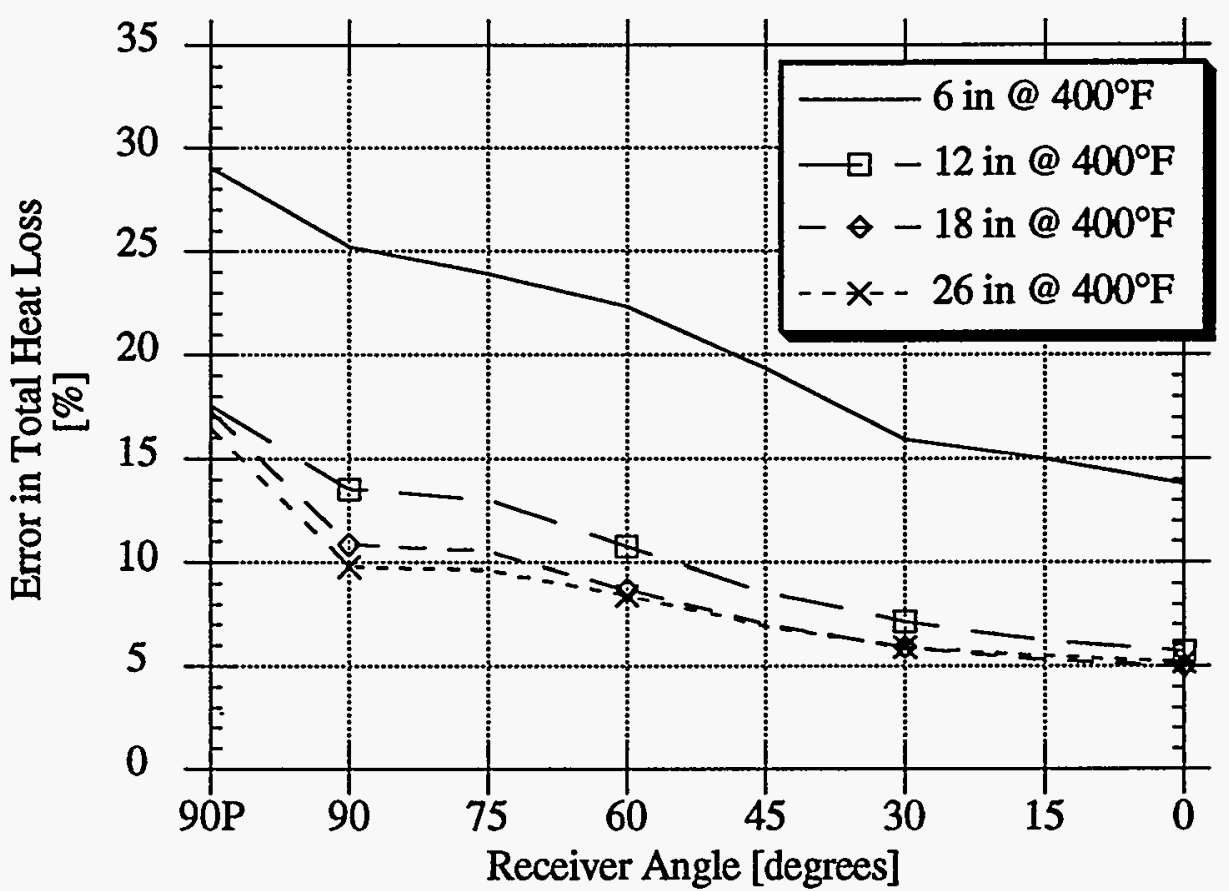

Figure 62. Error in total heat loss for various aperture diameter operating at $400^{\circ} \mathrm{F}$ 


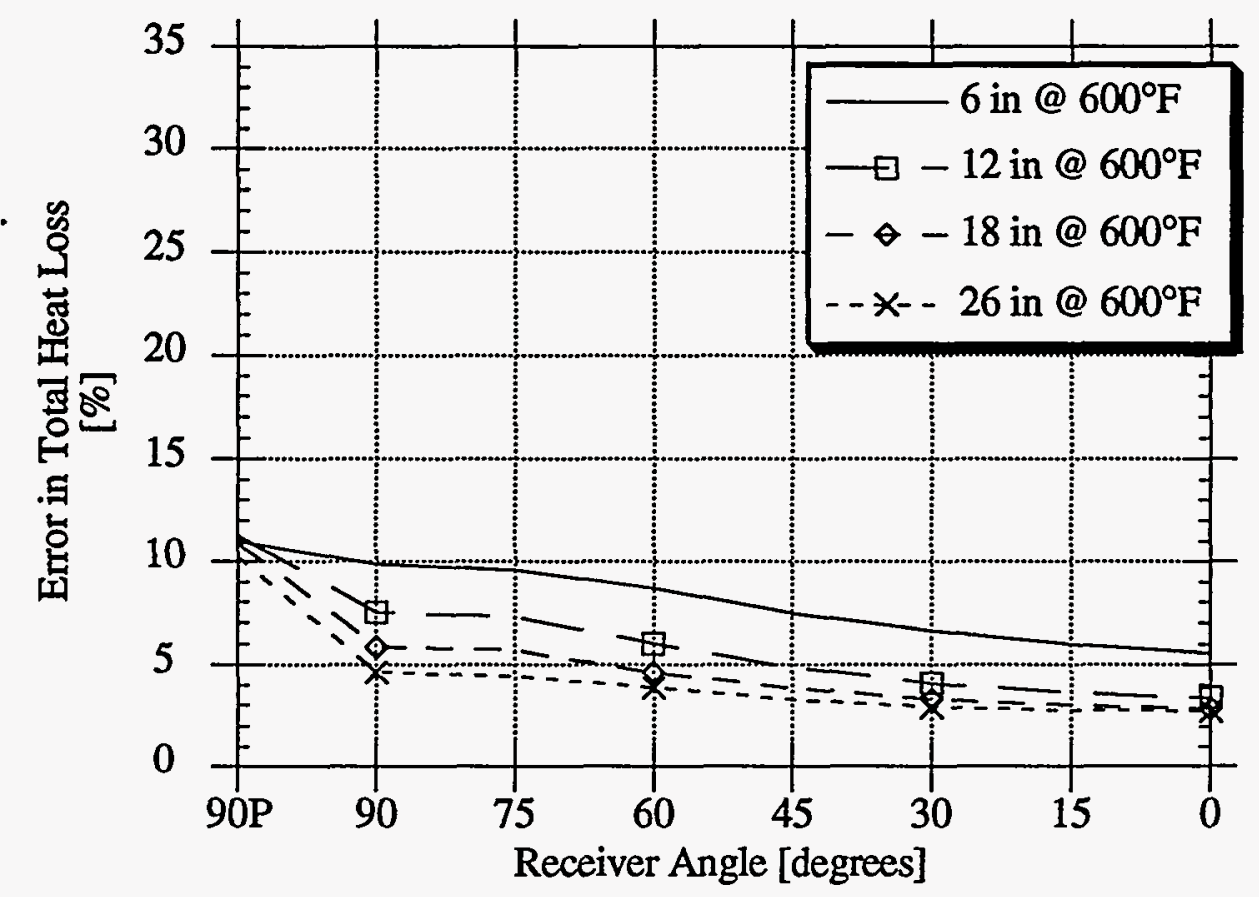

Figure 63. Error in total heat loss for various aperture diameter operating at $600^{\circ} \mathrm{F}$

The errors in the convective and radiative heat losses are higher due to summation variables, each of which contains an error (Equations 110,111, 113). The maximum error in the convective heat loss is $35.70 \%$. The maximum convective heat loss error occurs at a receiver operating temperature of $400^{\circ} \mathrm{F}$ with a 6 inch aperture and the receiver in the $+90^{\circ}$ position (Fig. 64). 


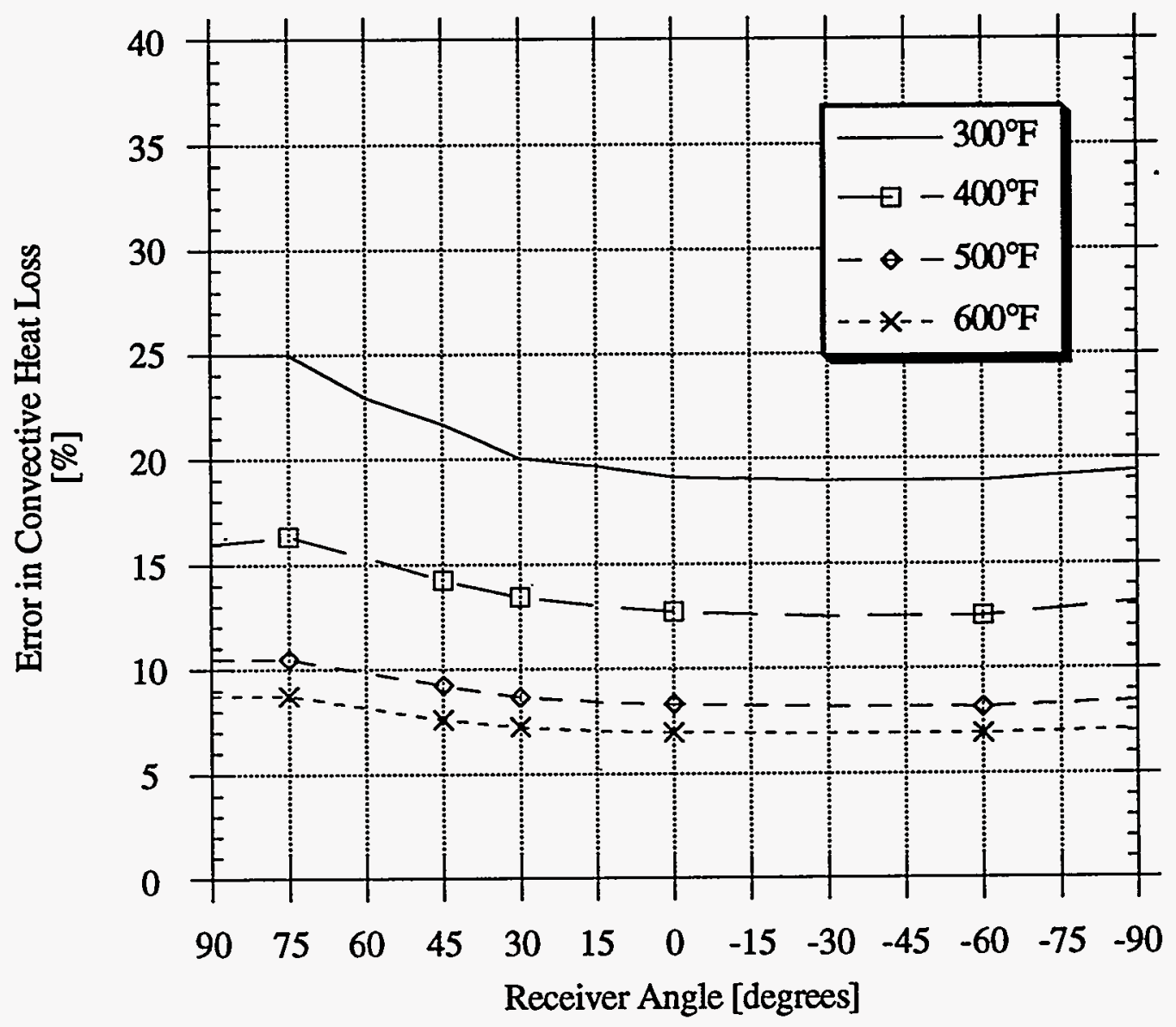

Figure 64. Error in convective heat loss for various operating temperatures 


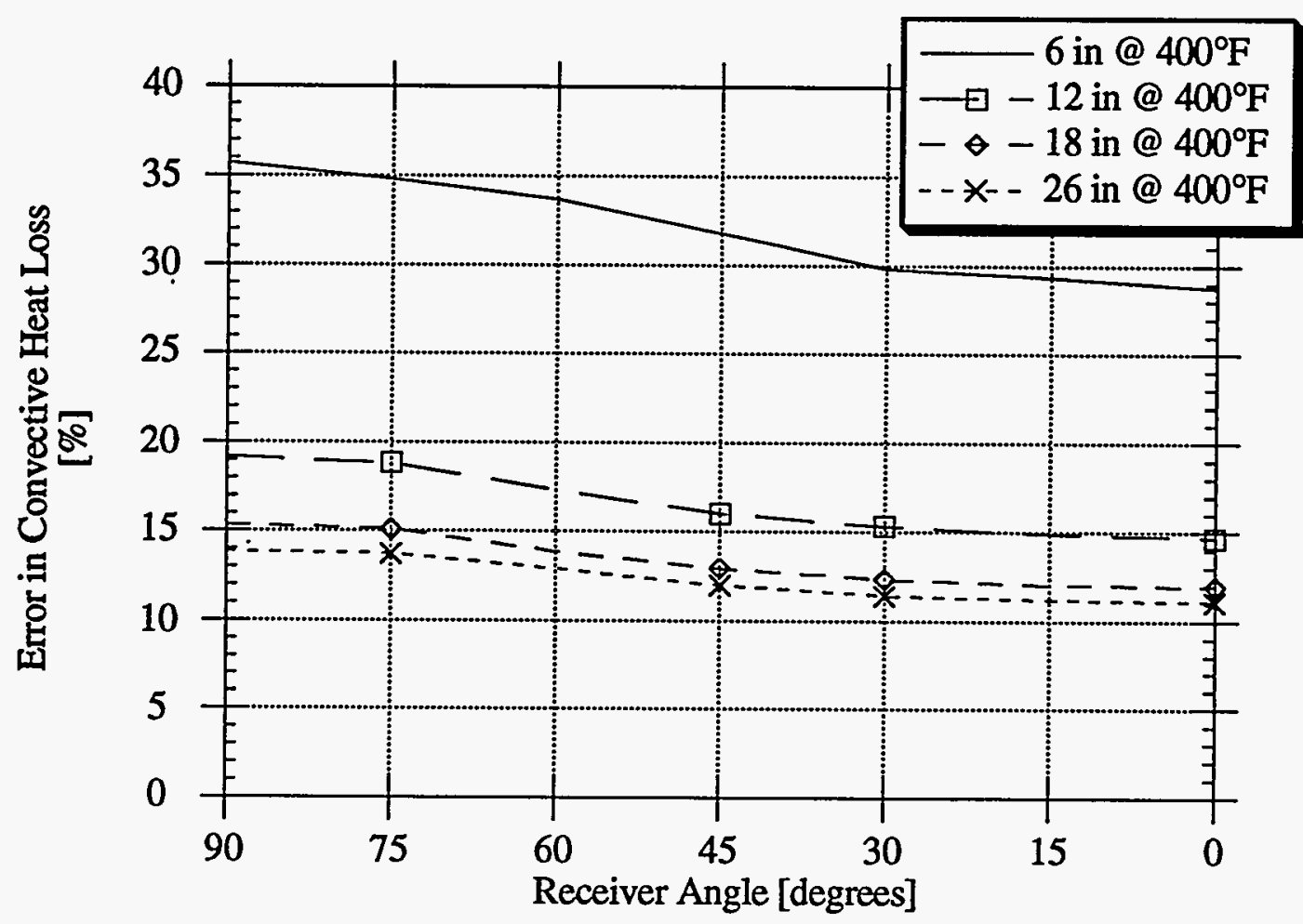

Figure 65. Error in convective heat loss for various aperture diameter operating at $400^{\circ} \mathrm{F}$

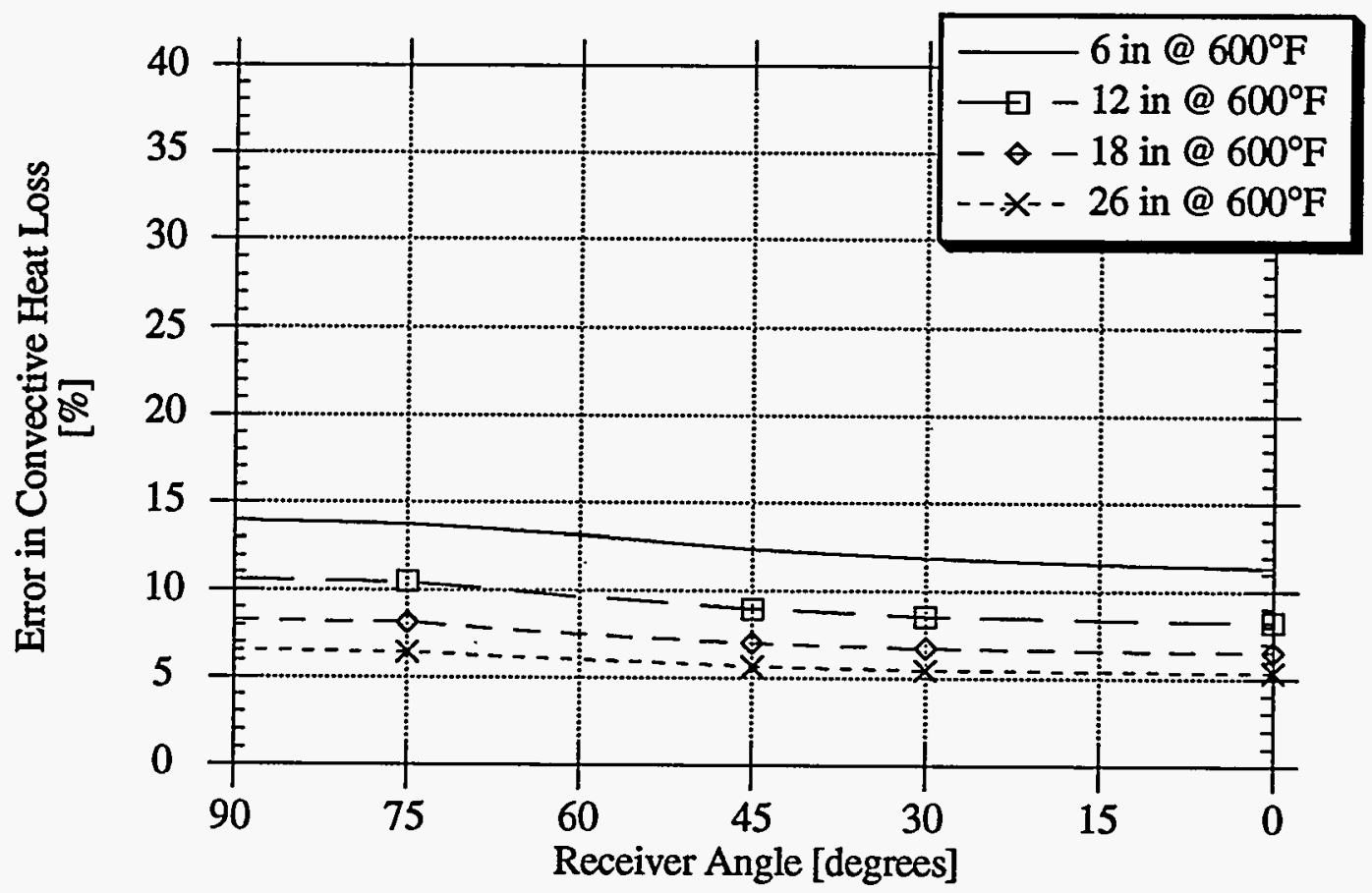

Figure 66. Error in convective heat loss for various aperture diameter operating at $600^{\circ} \mathrm{F}$ 


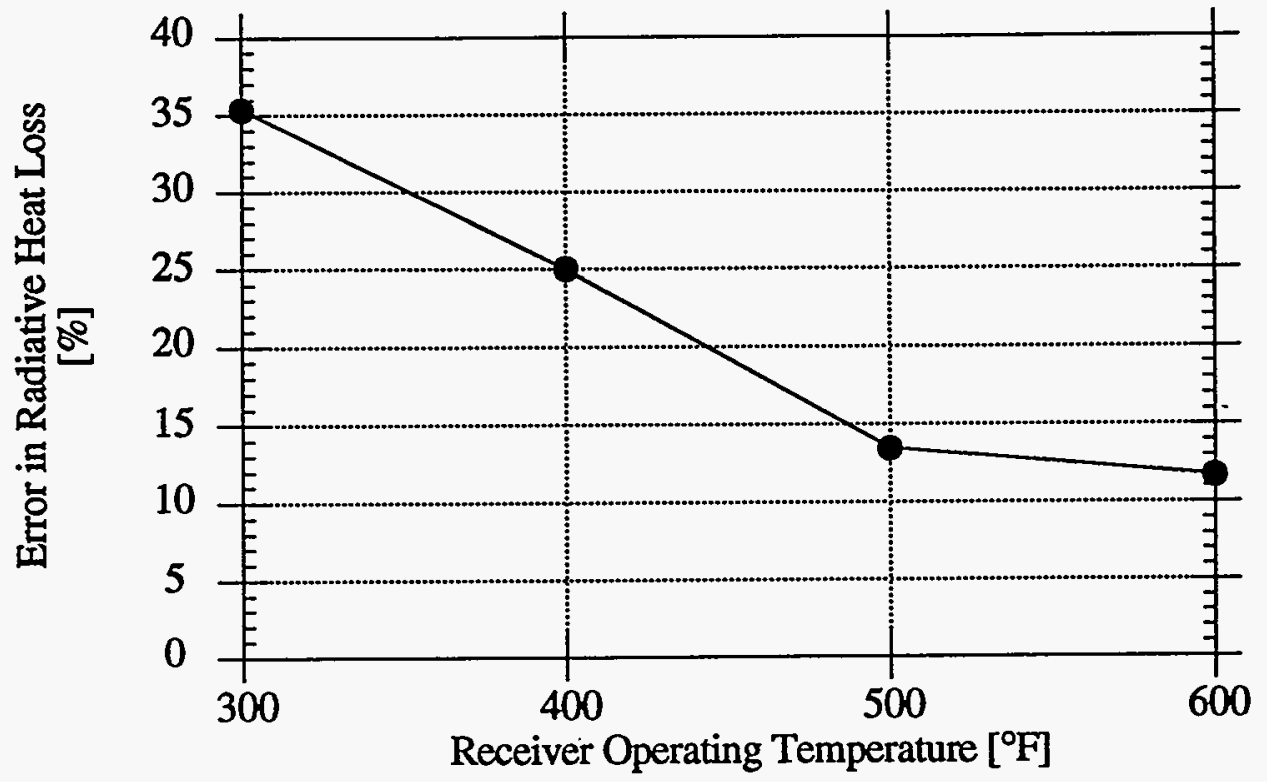

Figure 67. Error in radiative heat loss from Phase 1 test

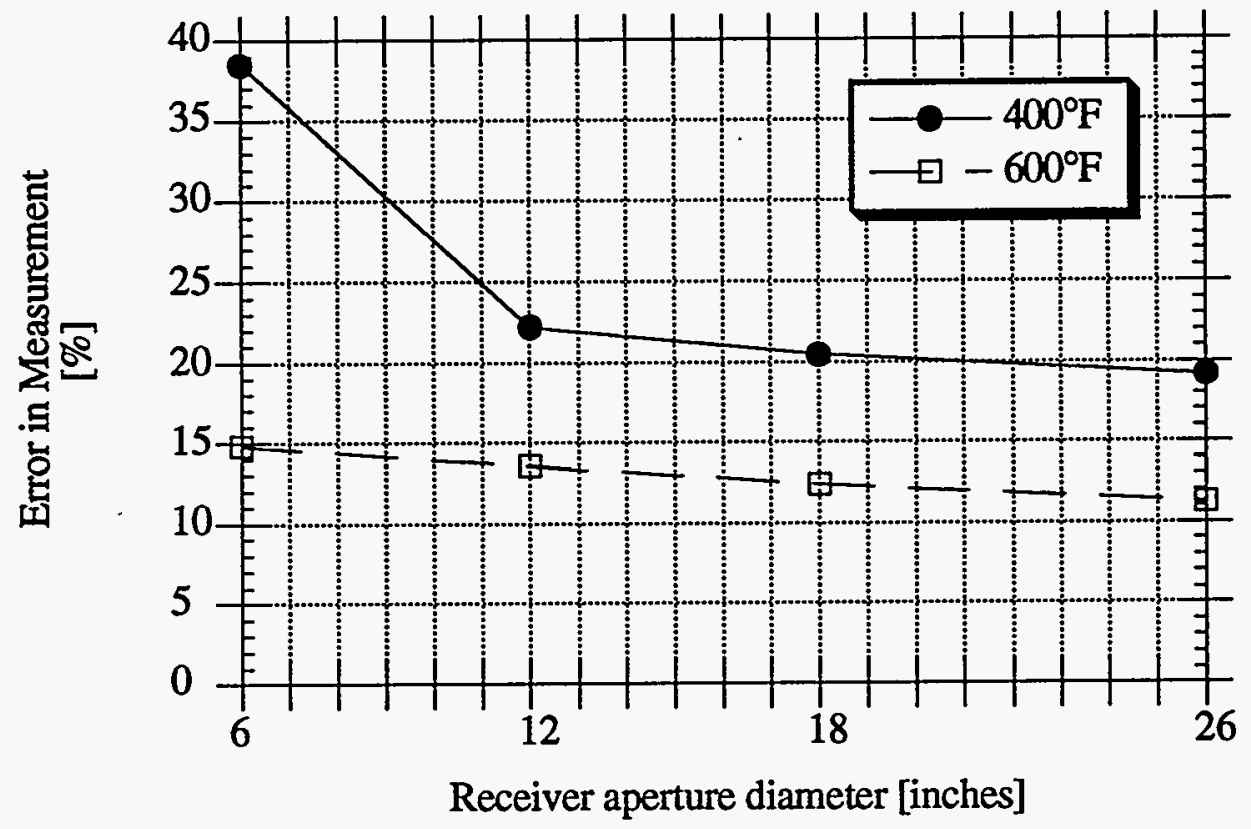

Figure 68. Error in radiative heat loss from Phase 2 test 
The error in the radiative heat loss measurement increases with decrease in receiver operating temperature and receiver aperture diameter (Fig. 67 \& 68). The maximum error in the radiative heat loss is $38.5 \%$ with a six inch aperture and a $400^{\circ} \mathrm{F}$ operating temperature.

\section{CONCLUSIONS:}

The results of experimental testing of the heat loss from a solar cavity receiver for various aperture diameters and operating temperatures have been presented. With an increase in aperture size there was an increase in the convective heat loss. The effect of aperture size on the convective heat loss decreased with increases in aperture size. Decreasing the aperture diameter from 18 inches to 6 inches, reduce the convective losses by $60 \%$. The 18 inch aperture presently used for this type of receiver has little or no effect on the free convective heat loss from the receiver.

Conduction was the primary mode of heat loss from the receiver for very small apertures (less than 12 inch diameter).

A low cost radiometer can be used to determine the radiative heat loss from a cavity within $\pm 20 \%$ of experimentally determined radiative heat loss.

\section{RECOMMENDATIONS}

Further investigation into cavity temperature distribution and internal surface emissivity and how each affects analytically determined radiative heat loss. Inquiries into convective heat loss from a cavity is necessary to consider how various wind condition will effect heat loss characteristics. 


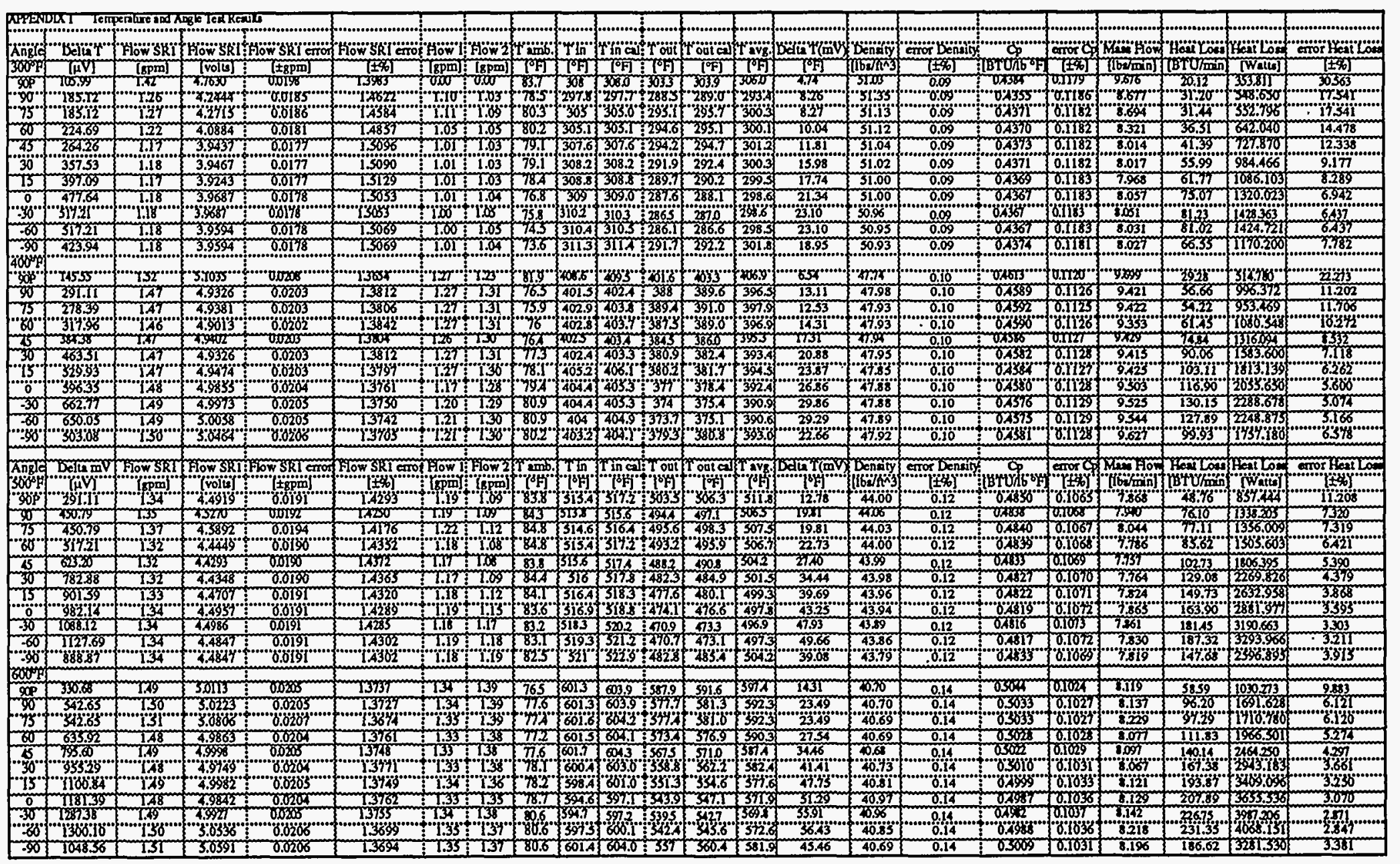




\begin{tabular}{|c|c|c|c|c|c|c|c|c|c|c|c|c|c|c|}
\hline & & & & & & & & & & & & & & \\
\hline & - & Coror HeitLost & & & & & & & & & & & & \\
\hline & (Whatis & 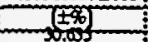 & (14:60] & 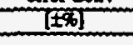 & 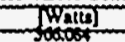 & 191 & [6] & $\frac{191}{101}$ & Por & tim & tat & TPi & 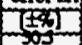 & entivat \\
\hline & -887.296 & 17.675 & & $34: 34$ & anor conde" & & & 37.7 & & & & .... & & 10.374 \\
\hline & 339 & -119.369 & 3.345 & 243 & 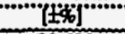 & 1.6 & 337 & 383 & 223786 & & 0.0101 & 17 & 173 & $1+0$ \\
\hline$\pi$ & 37570 & & $\begin{array}{r}8.143 \\
-163633 \\
\end{array}$ & -31350 & 30.635 & 年3 & $\frac{34.5}{48.6}$ & $\frac{32.8}{323}$ & 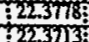 & 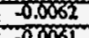 & (.0141 & 1.4 & 年, & 1.7981 \\
\hline & $\begin{array}{l}1.733 .799 \\
0.92 .98 \\
023.42\end{array}$ & 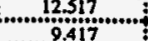 & 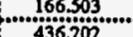 & 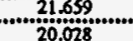 & & 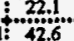 & $\begin{array}{l}48.6 .6 \\
35.8 \\
35.4\end{array}$ & 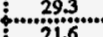 & : 22,3713 & 60061 & 0141 & 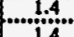 & 122. & 1756 \\
\hline & $\frac{10239.429}{1129.722}$ & & $\frac{436.222}{542.226}$ & س & Hathen Las Red & 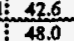 & 35.8. & $\frac{21.6}{19.6}$ & 22.37364 & 0052 & 然1414 & 年 & | & $\begin{array}{l}1.7665 \\
1.7604\end{array}$ \\
\hline & & & $\frac{24.520}{781.781}$ & $\frac{10.011}{19.106}$ & $\frac{1}{221.212}$ & $\frac{48.0}{57.1}$ & $\frac{3.4}{26.7}$ & & 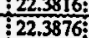 & 年 & 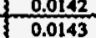 & $\frac{1.4}{1.4}$ & $\frac{8.1}{6.8}$ & \\
\hline 4 & $17+1.466^{\circ}$ & 8.70 & 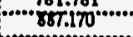 & raspras & 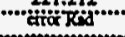 & 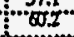 & 243 & $\cdots$ & 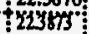 & . & 6 & H. & (3)" & 1.17384 \\
\hline 6253 & 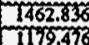 & $\frac{1.757}{8.047}$ & 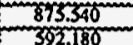 & $\frac{18}{98}$ & 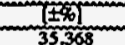 & 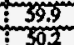 & 3. & 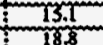 & 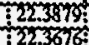 & 然, & 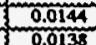 & $\sqrt[1.4]{1.4}$ & $\frac{63}{76}$ & $\frac{1.7 .743}{1.7353}$ \\
\hline & & & & & Hoitoon: & & & & & & & & & \\
\hline & 322635 & $\frac{2.320}{11.298}$ & & 155.976 & -352.635 & & 10080 & 80 & & $\begin{array}{ll}0.003 \\
0.002\end{array}$ & 60.0062 & 13 & min & 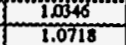 \\
\hline 2 & 977.075 & 1.1988 & 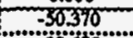 & & sortcond & 3.2 & 63.5 & & & & & & & \\
\hline 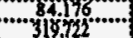 & 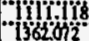 & $\ldots . . .18 .8747$ & 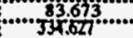 & 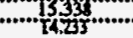 & 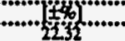 & $2 x \times 5$ & (37. & $\cdots$ & 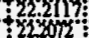 & 0.0028 & & 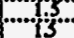 & & nation \\
\hline 387.2 & 1033.244 & 7.270 & 623.989 & 13. & Mentron $\mathrm{Kad}$ & 37.9 & 31.6 & 30.3 & 2.002 & $0.00 \mathrm{t}$ & & 1.5 & 7.0 & 1.000 \\
\hline $\begin{array}{l}816.767 \\
10630.340\end{array}$ & 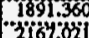 & 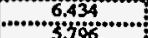 & 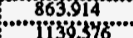 & ........133. & $\ldots$ & 43. & 27.6. & 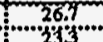 & 2035 & & 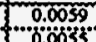 & & . & $\frac{1.0522}{1.021}$ \\
\hline 1292 & 2436.096 & 5.294 & 1408.651 & $\frac{1.20}{12.21}$ & croor Rad & 57. & & $\frac{20.7}{20.7}$ & & .0023 & & & $\frac{3.4}{4.9}$ & \\
\hline & & & & & & & & & & & & & & \\
\hline & 0.183933 & 6.74 & ...826.387. & .....13.138. & ....25.016. & . & 28. & iz? & & 0.002 & 年 & & 6 & 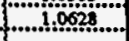 \\
\hline Emitontc & prentions & crror Test Loss & Hetito & & matin & $x \mathrm{C}$ & $x \operatorname{con}$ & का & aphin & dapta & sippham & & & 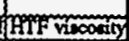 \\
\hline & 6037 & 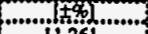 & ........ & 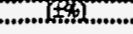 & $\ldots$ & & s. & T/ & & & (1) & $\ldots$ & क] & \\
\hline & & & 0.00 & & 80 & & & 58.2 & & & & & & \\
\hline & 99.399 & 7.408 & & 10. & & 1.2 & & & & 5.0032 & & & 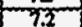 & \\
\hline 76790 & istos & $\cdots$ & ing & 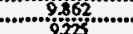 & & 1112 & & 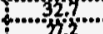 & 等 & & 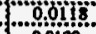 & .4. & & \\
\hline $931.6 \mathrm{Cl}$ & 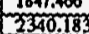 & The & & & 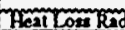 & 418 & 6.8 & 21.2 & $2 x$ & & & & & \\
\hline & & & $1363.692 \ldots$ & $\ldots$ & & & & $\ldots$ & & 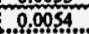 & & & & \\
\hline & (3) & $3 \pi$ & $\frac{1068.83}{103}$ & 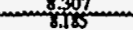 & - & & & & & & & & & \\
\hline 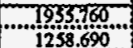 & 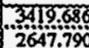 & $\frac{3.403}{4.060}$ & 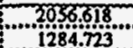 & 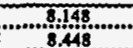 & 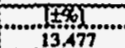 & $\begin{array}{l}60011 \\
485\end{array}$ & 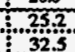 & 18.9 & 227785 & 0.0053 & 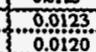 & .....4. & 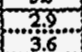 & 0.673 \\
\hline & & & & & & & 100 & & 159 & & 0.00 & & $g x$ & \\
\hline A & ons & ............ & 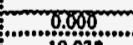 & 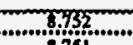 & $\frac{1188}{1088}$ & & & & & & & & & \\
\hline & 0.031 .461 & W. & | & -8.2 & $\frac{\operatorname{sos} c 1}{1+x}$ & מ. & $\begin{array}{l}5.5 \\
51.6 \\
5\end{array}$ & 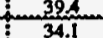 & 23.093 & & & 14 & & \\
\hline$m$ & 2061,75 & 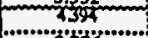 & $800 \mathrm{~m}$ & 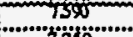 & & 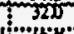 & 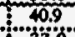 & 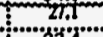 & 3048 & & 0 & 11. & . & \\
\hline 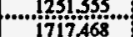 & {$\left[\begin{array}{l}\mathrm{B} .1 .1 \\
\end{array}\right.$} & 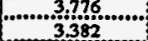 & $\left(\begin{array}{l}1831.60 \\
187631\end{array}\right.$ & $=. .7 .730$. & 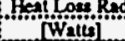 & 31. & \% & 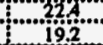 & & . & 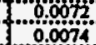 & 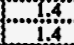 & 2.9 & 0.45 \\
\hline 1963.5 & 3027.963 & $\frac{3.213}{3026}$ & $-\frac{2186.103}{25003}$ & 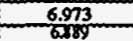 & 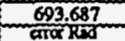 & $\begin{array}{l}55.7 \\
979.7\end{array}$ & $\frac{126.7}{243}$ & \begin{tabular}{|l|l}
17.7 \\
161
\end{tabular} & $\begin{array}{l}3.033 \\
3.02017 \\
3\end{array}$ & to.0034 & $\frac{0.0077}{0.0078}$ & $\begin{array}{c}\frac{1.4}{1 .} \\
\end{array}$ & $\frac{2.7}{23}$ & 0 \\
\hline 23 & & $(-1.30811$ & - 26601156 & (n) & 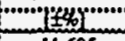 & $136 \%$ & & -115: & & & 800 & & & \\
\hline & & & & & & & & & & & & & & \\
\hline
\end{tabular}




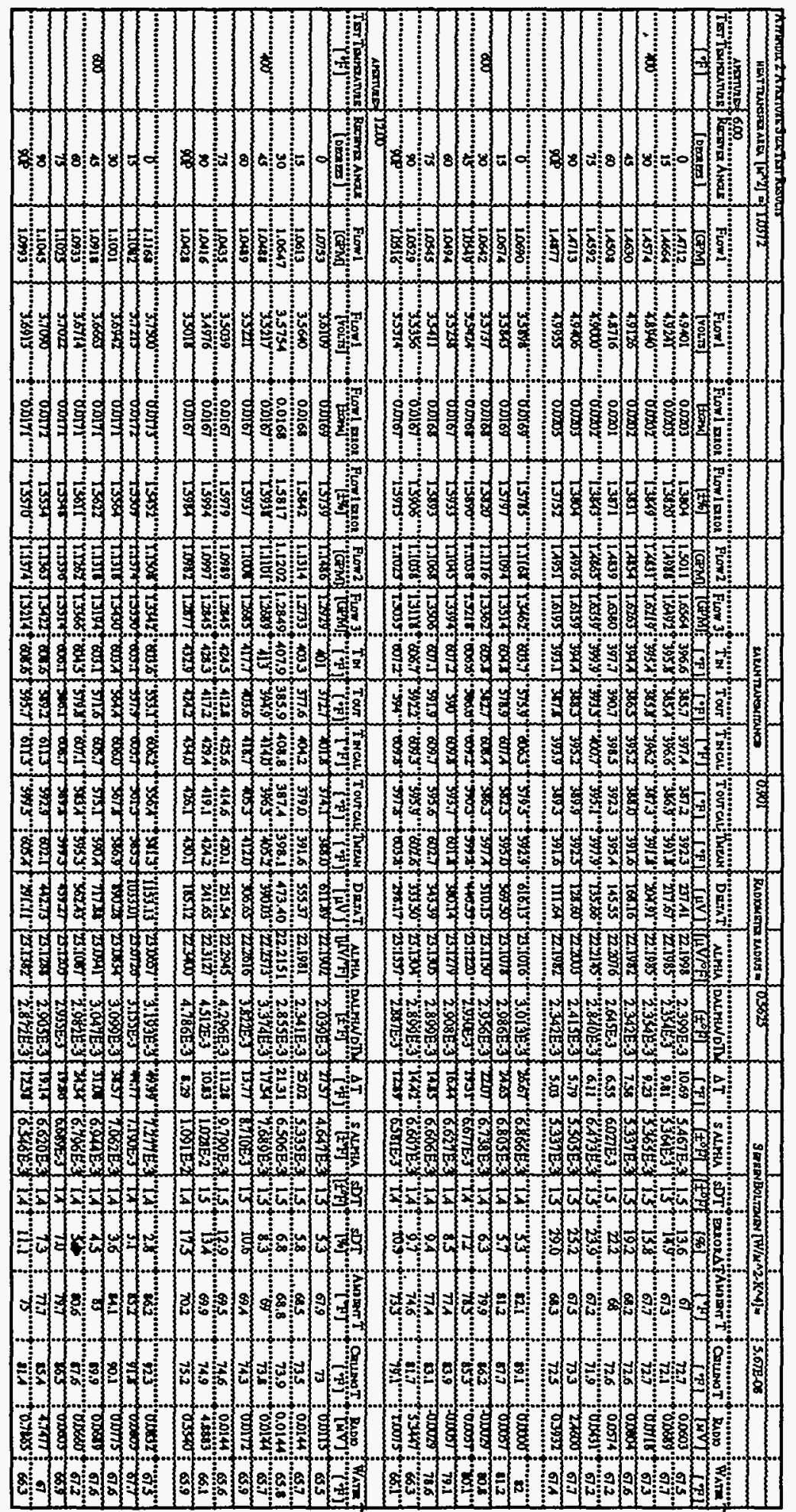

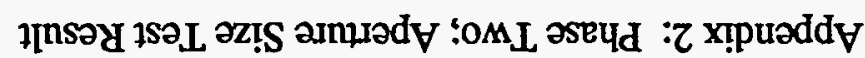


Appendix 2: Phase Two; Aperture Size Test Result

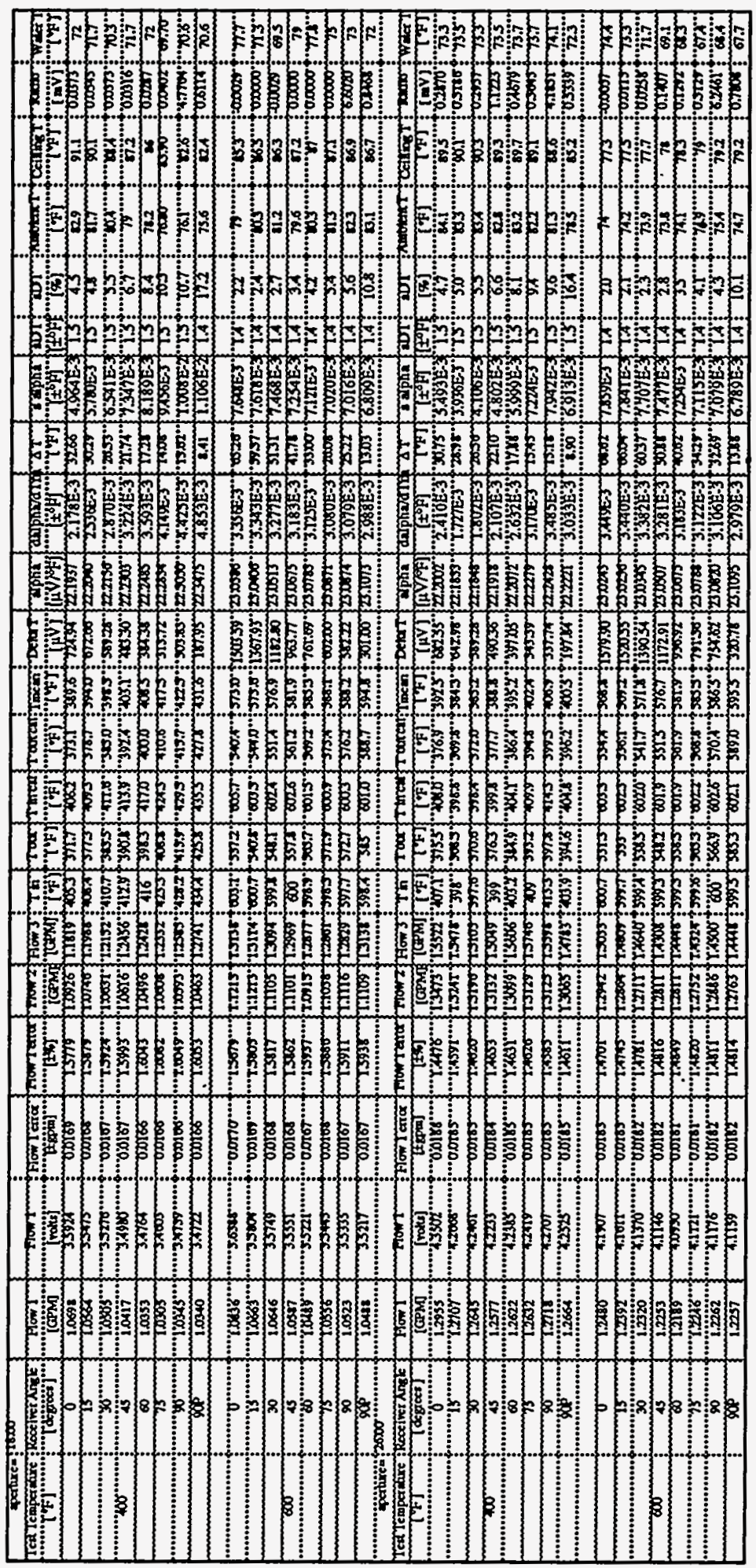


Appendix 2: Phase Two; Aperture Size Test Result

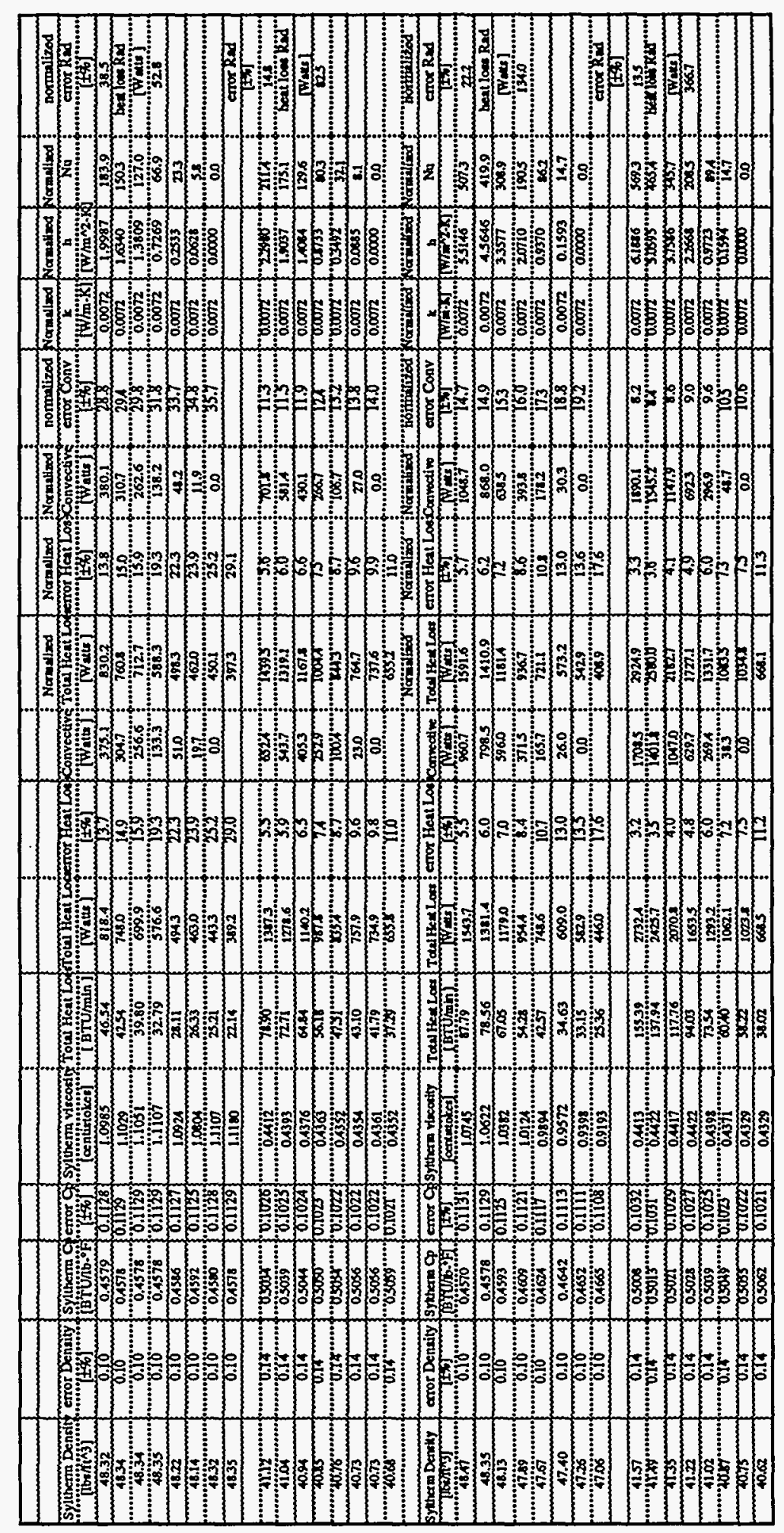


Appendix 2: Phase Two; Aperture Size Test Result

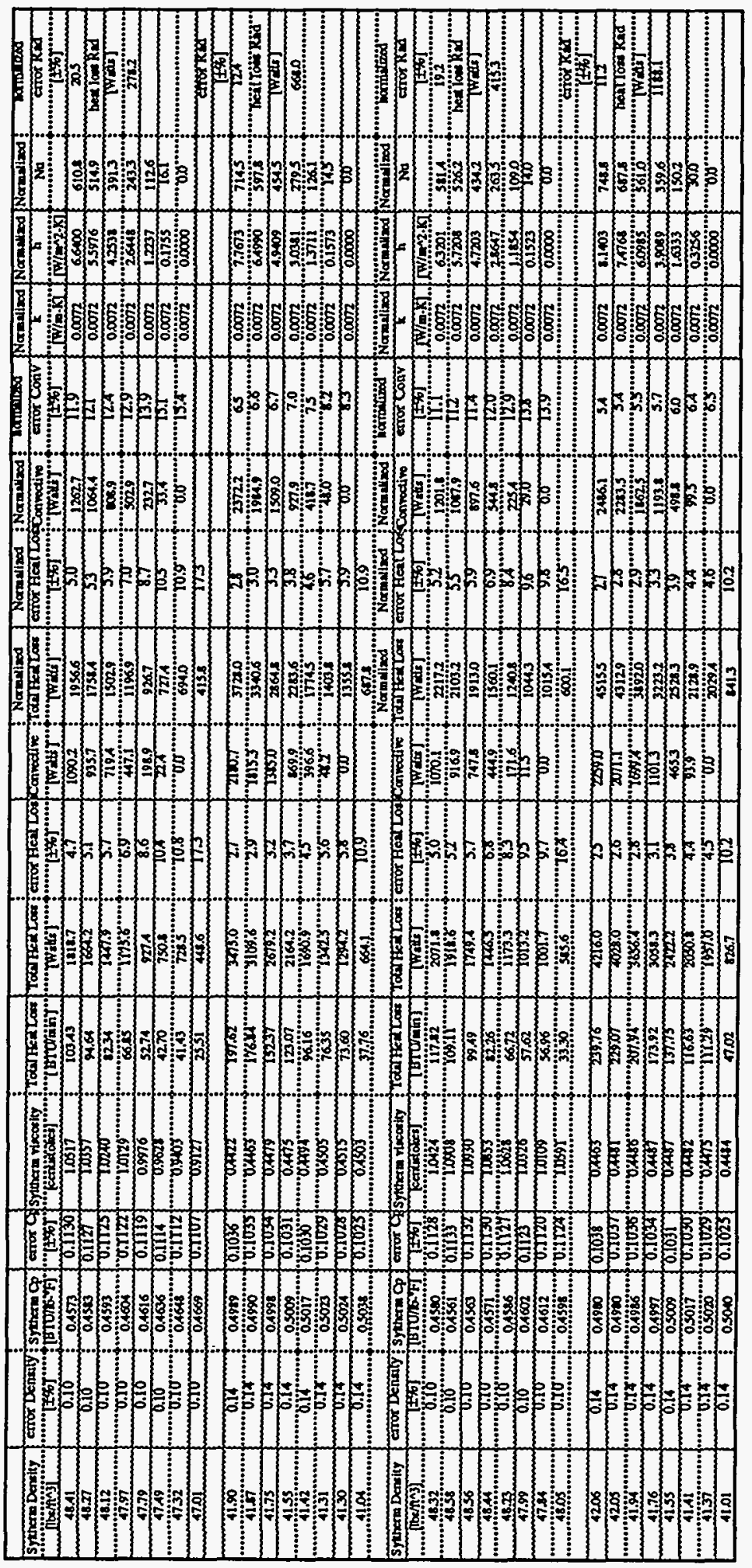


APPENDIX 3: LeQuere, Penot and Mirenayat Model Computer Program Listing

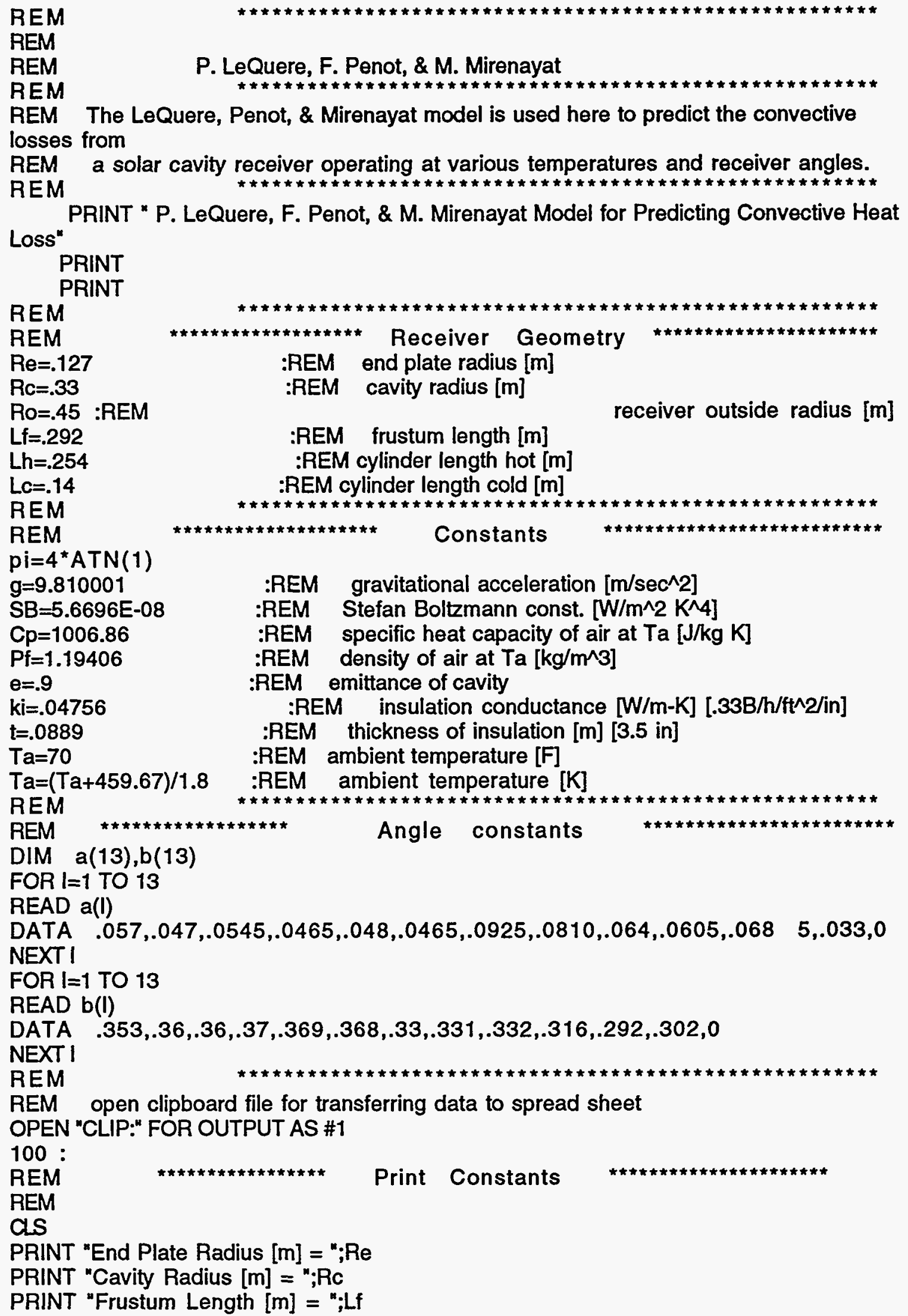


PRINT "Hot Cylindrical Section Length $[\mathrm{m}]=$ "; Lh

PRINT "Cold Cylindrical Section Length $[\mathrm{m}]=$ ";Lc

PRINT "Ambient Temperature $[\mathrm{K}]=$ ";

PRINT USING"\#\#\#\#.\#";Ta

PRINT

REM

Write to the clipboard

WRITE\#1," ",","End Plate Radius [m] = ",Re

WRITE\# 1," ",", "Cavity Radius [m] = ",Rc

WRITE\#1,"n","x", "Frustum Length [m] = ",Lf

WRITE\#1, "n" "n" "Hot Cylindrical Section Length [m] = "Lh

WRITE\#1, ""," "Cold Cylindrical Section Length [m] = "LC

WRITE\#1,"*," ", "Ambient Temperature $[K]=$ ",Ta

WRITE\#1,

REM Receiver Aperture Radius Loop

as

FOR I $=1$ TO 4

READ Ra

DATA $.0762, .1524, .2286, .329$

$\mathrm{Da}=2^{\star} \mathrm{Ra}$

$\mathrm{Aa}=\mathrm{pi}^{\star} \mathrm{Ra} \mathrm{a}^{\wedge} 2$

:REM aperture diameter [m]

:REM aperture area $\left[\mathrm{m}^{\wedge} 2\right]$

REM

REM

REM In the following section $\mathrm{Ah}$ and $\mathrm{Ar}$ are calculated.

REM Ah is the total interior heated cavity surface area based on the tube bundle geometry.

REM Ar is the total interior refractory cavity surface.

REM At is the total cavity area.

$A h=p^{*}(R e+R c)^{\star}\left(L f \wedge 2+(R c-R e)^{\wedge} 2\right)^{\wedge} .5+2^{*}{ }^{*} \mathrm{pi}^{\star} R c^{\star} L h$

$A r=p i^{\star} R e^{\wedge} 2+p i^{\star}\left(R c^{\wedge} 2-R a^{\wedge} 2\right)+2^{\star} p^{\star} R c^{\star} L c$

$A t=A h+A r$

REM

$A 0=\mathrm{pi}^{\star}((\mathrm{Rc}+\mathrm{Ro}) / 2)^{\wedge} 2+2^{*} \mathrm{pi}^{*}((\mathrm{Rc}+\mathrm{Ro}) / 2)+\mathrm{pi}^{\star}\left(R \mathrm{c}^{\wedge} 2-\mathrm{Ra} \mathrm{a}^{\wedge} 2\right)$

REM

REM

CS

PRINT "Aperture Radius $[\mathrm{m}]=$ "; Ra

PRINT " Total Cavity Area [m^2] = ";

PRINT USING "\#\#\#.\#\#\#\#";At

PRINT "Total Heated Cavity Area $\left[\mathrm{m}^{\wedge} 2\right]=$ ";

PRINT USING "\#\#\#.\#\#\#\#";Ah

PRINT " Total Refractory Cavity Area $\left[\mathrm{m}^{\wedge} 2\right\}=$ ";

PRINT USING "\#\#\#.\#\#\#";Ar

REM write header to clipboard

WRITE\#1, "," ", "Aperture Radius [m] = ",Ra

WRITE\#1, "n'," ", Total Cavity Area [m^2] = ",At

WRITE\#1, "" "," Total Heated Cavity Area [m^2] = ",Ah

WRITE\# 1 ," ," ", "Total Refractory Cavity Area $\left[m^{\wedge} 2\right\}=$ ",Ar

REM Operating Temperature Loop

REM

FOR $\operatorname{Tmf}=300$ TO 600 STEP 100

WRITE\#1,

REM The operating temperature is converted from $F$ to $K$

$T m=(T m f+459.67) / 1.8$

Twf $=$ Tmf -100 :REM The refractory surfaces are assumed to be $100^{\circ} \mathrm{F}$ cooler :REM than the heated tube surfaces. 

CLS

$T w=(T w f+459.67) / 1.8$

REM

REM

PRINT "T mean $[K]=$ ";

Print Table Header

PRINT USING "\#\#\#\#.\#";Tm;

PRINT " $\left[{ }^{\circ} \mathrm{F}\right]=$ ";

PRINT

PRINT USING "\#\#\#\#.";Tmf

PRINT ;TAB(3);" Angle";TAB(12);"Q conv";TAB(24);" Nu ";TAB(35);" Gr"

PRINT ;TAB(1);" [degrees]";TAB(13);"[Watts]"

PRINT

REM

REM

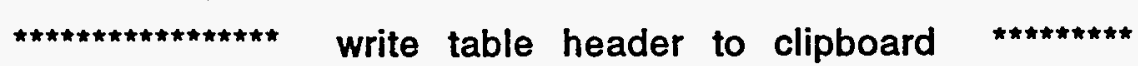

WRITE\#1,"", "T mean [K] = ",Tm

WRITE\# 1 ,

WRITE\#1, "*" ['F] = "Tmf

WRITE\#1," Angle","Q conv"," Nu "," Gr"

WRITE\#1," [degrees]","[Watts]"

WRITE\#1,

REM

$\star \star \star \star \star \star \star \star \star \star \star \star \star \star \star \star \star \star \star$ Beginning of Angle Loop

$\mathrm{n}=0$

FOR phi $=-90$ TO 90 STEP 15

$\mathrm{Z}=\mathrm{pi}{ }^{*} \mathrm{phi} / 180: \mathrm{REM}$ convert angle to radian measure

REM Angle Function

$n=n+1$

REM

$\mathrm{Tcav}=\left(\mathrm{Tm}^{\star} \mathrm{A} h+\mathrm{T} w^{\star} \mathrm{Ar}\right) / \mathrm{At}: \mathrm{REM}$ area average cavity temperature [K]

$\mathrm{L}=2^{\star} \mathrm{Ra}$

$\mathrm{C}=1.1547 \mathrm{E}+19^{\star} \mathrm{Ta}-4.4187$ :REM gB/v^2.

$k=.0071749261015 \#+.000064030639041 \#^{\star} \mathrm{Ta}$

REM Heat Loss Calculations

$\mathrm{Gr}=\mathrm{C}^{\star}(\mathrm{Tcav}-\mathrm{Ta})^{\star} \mathrm{L} \wedge 3 \quad: \mathrm{REM}$ Grashof number

$\mathrm{Pr}=.7814008749 \#-.00037306809395{ }^{*} \mathrm{Ta}+5.2131644352 \mathrm{D}-07^{*} \mathrm{~T} a^{\wedge} 2-2$.

$1272705278 \mathrm{D}-10 * \mathrm{Ta}{ }^{\wedge} 3$

REM $\mathrm{Pr}=$ Prandtl number

$\mathrm{Nu}=\mathrm{a}(\mathrm{n})^{\star} \mathrm{Gr} \wedge \mathrm{b}(\mathrm{n})$

$h=N u^{*} k /$

REM

REM

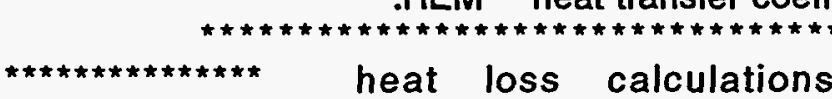

$\mathrm{QC}=\mathrm{h}^{\star} \mathrm{At} t^{\star}(\mathrm{Tcav}-\mathrm{Ta}) \quad$ :REM

REM Output Loop Results

-REM Nusselt number

PRINT ;TAB(3);phi;

PRINT TAB(12);

PRINT USING "\#\#\#\#.\#";Qc;

PRINT TAB(22);

PRINT USING "\#\#\#.\#\#";Nu;

PRINT TAB(32);

PRINT USING "\#\#.\#\#MM";Gr

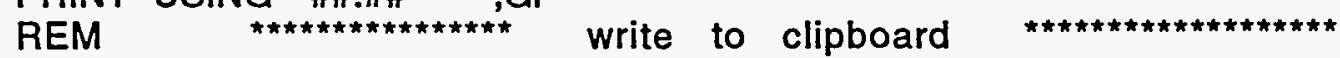

WRITE\# 1 ,phi,Qc,Nu,Gr

REM

REM

NEXT phi

REM 


REM
NEXT Tmf
REM
REM
NEXTI
REM
CLOSE\#1
END




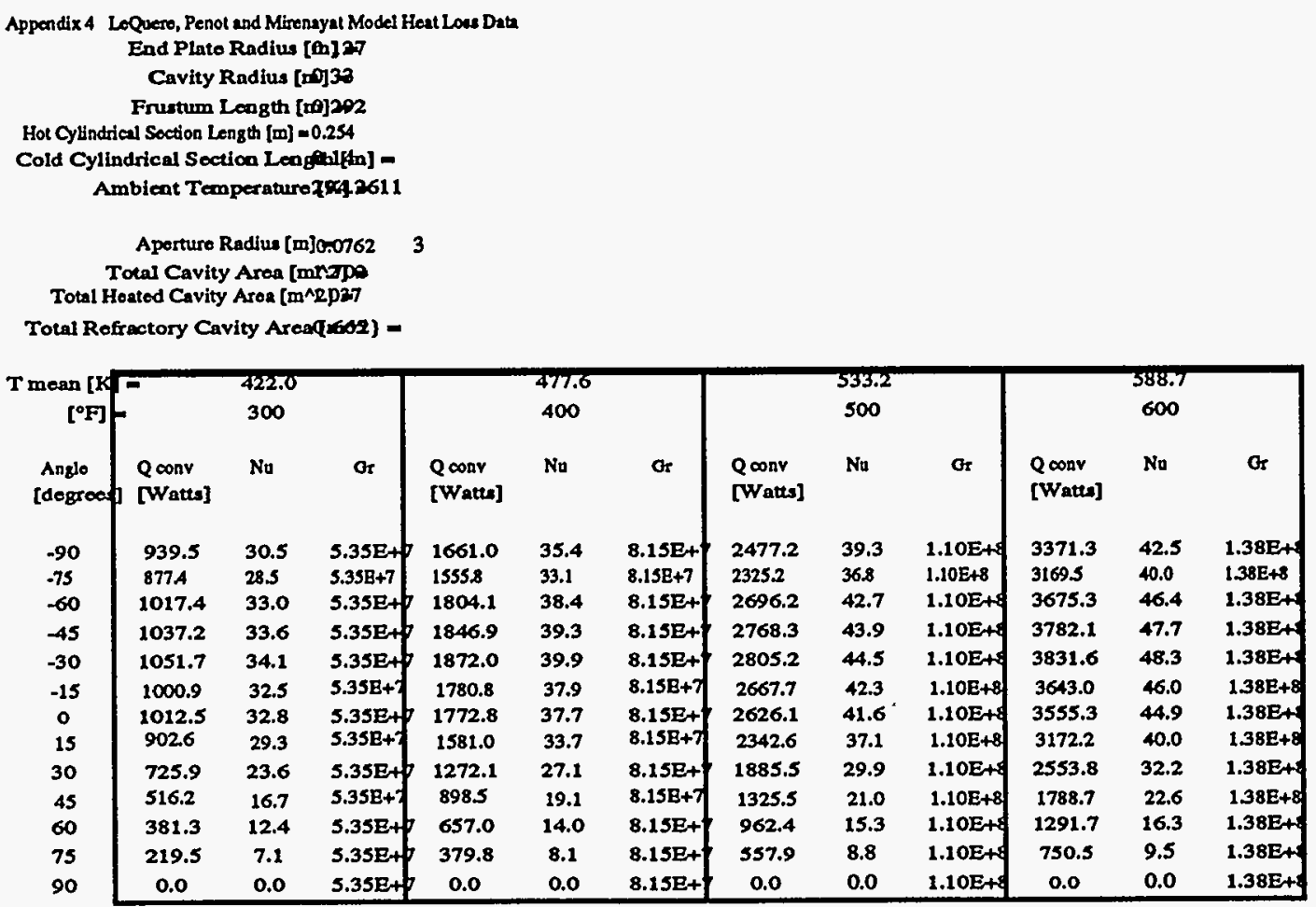

Aperture Radius [a] 504

Total Cavity Area [mngostan

Total Heated Cavity Area [m^₹p27

Total Refractory Cavity Area(q6ia) =

\begin{tabular}{|c|c|c|c|c|c|c|c|c|c|c|c|c|}
\hline $\begin{array}{l}T \operatorname{man}[K]-] \\
{\left[{ }^{\circ} \mathrm{F}\right]}\end{array}$ & & $\begin{array}{r}222.0 \\
300\end{array}$ & & & $\begin{array}{r}477.6 \\
400\end{array}$ & & & $\begin{array}{l}533.2 \\
500\end{array}$ & & & $\begin{array}{r}588.7 \\
600\end{array}$ & \\
\hline $\begin{array}{c}\text { Anglo } \\
\text { [dogroes }\end{array}$ & $\begin{array}{l}\text { Q conv } \\
\text { [Warts] }\end{array}$ & $\mathrm{Nu}$ & or & $\begin{array}{l}Q \operatorname{cons} \\
\text { [Wattu] }\end{array}$ & $\mathrm{Nu}$ & or & $\begin{array}{l}\text { Qconv } \\
\text { [Watte] }\end{array}$ & $\mathrm{Nu}$ & $O x$ & $\begin{array}{l}\text { Q conv } \\
\text { [Wartu] }\end{array}$ & $\mathrm{Nu}$ & $\theta r$ \\
\hline .90 & 960.8 & 63.7 & $4.33 \mathrm{~B}+8$ & 1690.5 & 73.9 & $6.578+8$ & 2515.1 & 81.9 & $8.81 \mathrm{E}+8$ & 3418.1 & 88.8 & $1.11 \mathrm{E}+9$ \\
\hline-75 & 910.6 & 60.4 & $4.33 E+$ & 1606.8 & 70.2 & $6.57 \mathrm{E}+$ & 2395.5 & 78.0 & $8.81 E+d$ & 3260.7 & 84.7 & $1.11 \mathrm{E}+$ \\
\hline$-\infty$ & 1055.9 & 70.0 & $4.33 \mathrm{E}+8$ & 1863.1 & 81.4 & $6.57 \mathrm{~B}+8$ & 2777.8 & 90.5 & $8.81 E+8$ & 3781.0 & 98.2 & $1.11 \mathrm{E}+9$ \\
\hline-45 & 1099.1 & 72.9 & $4.33 \mathrm{E}+$ & 1947.5 & 85.1 & 6.57E+ & 2912.1 & 94.9 & 8.81E+4 & 3972.8 & 103.2 & $1.11 \mathrm{E}+$ \\
\hline-30 & 1112.2 & 73.8 & $4.33 \mathrm{E}$ & 1969.9 & 86.1 & $6.57 \mathrm{E}+$ & 2944.8 & 95.9 & $8.81 \mathrm{E}+4$ & 4016.5 & 104.3 & $1.11 \mathrm{E}+8$ \\
\hline-15 & 1056.3 & 70.1 & $4.33 \mathrm{E}+$ & 1870.0 & 81.7 & $6.57 \mathrm{TE}$ & 2794.6 & 91.0 & $8.81 E+d$ & 3810.8 & 99.0 & $1.11 \mathrm{E}+$ \\
\hline 0 & 986.9 & 65.3 & $4.33 \mathrm{~B}+8$ & 17198 & 75.1 & $6.57 \mathrm{~B}+8$ & 2541.5 & 828 & $881 E+8$ & 3436.0 & 89.2 & $1.11 E+9$ \\
\hline 15 & 881.6 & 58.5 & $4.33 \mathrm{E}+$ & 1536.8 & 67.2 & 6.57E+ & 2271.9 & 74.0 & $8.81 \mathrm{E}+\mathrm{d}$ & 3072.1 & 79.8 & $1.11 \mathrm{E}+$ \\
\hline 30 & 710.6 & 47.1 & $4.33 \mathrm{E}+$ & 1239.2 & 54.1 & 6.57E+ & 1832.4 & 59.7 & $8.81 E+4$ & 2478.4 & 64.4 & $1.11 \mathrm{E}+$ \\
\hline 45 & 488.6 & 32.4 & $4.33 \mathrm{E}+$ & 846.5 & 37.0 & $6.57 \mathrm{E}+$ & 1245.9 & 40.6 & $8.81 \mathrm{E}+4$ & 1679.0 & 43.6 & $1.11 \mathrm{E}+$ \\
\hline 60 & 343.3 & 228 & $4.33 \mathrm{~B}+3$ & S888 & 25.7 & $6.57 \mathrm{~B}+8$ & 8603 & 28.0 & $881 E+8$ & $\mathbf{1 1 5 3 3}$ & 29.9 & $1.11 E+9$ \\
\hline 75 & 201.8 & 13.4 & $4.33 \mathrm{E}+$ & 347.5 & 15.2 & $6.57 \mathrm{E}+$ & 509.3 & 16.6 & $8.81 \mathrm{E}+$ & 684.2 & 17.8 & $1.11 E+$ \\
\hline 90 & 0.0 & 0.0 & 4.33E & 0.0 & 0.0 & $6.57 \mathrm{E}+$ & 0.0 & 0.0 & $8.81 \mathrm{E}+\mathrm{H}$ & 0.0 & 0.0 & $1.11 \mathrm{E}+$ \\
\hline
\end{tabular}


Apectar Redion (m) = 0.2256 Toul Hoted Cavity Area $\left[\mathrm{m}^{2}\right.$ 2] -1.556 Totw Refractory Cavity Area (m/2) - 0.519

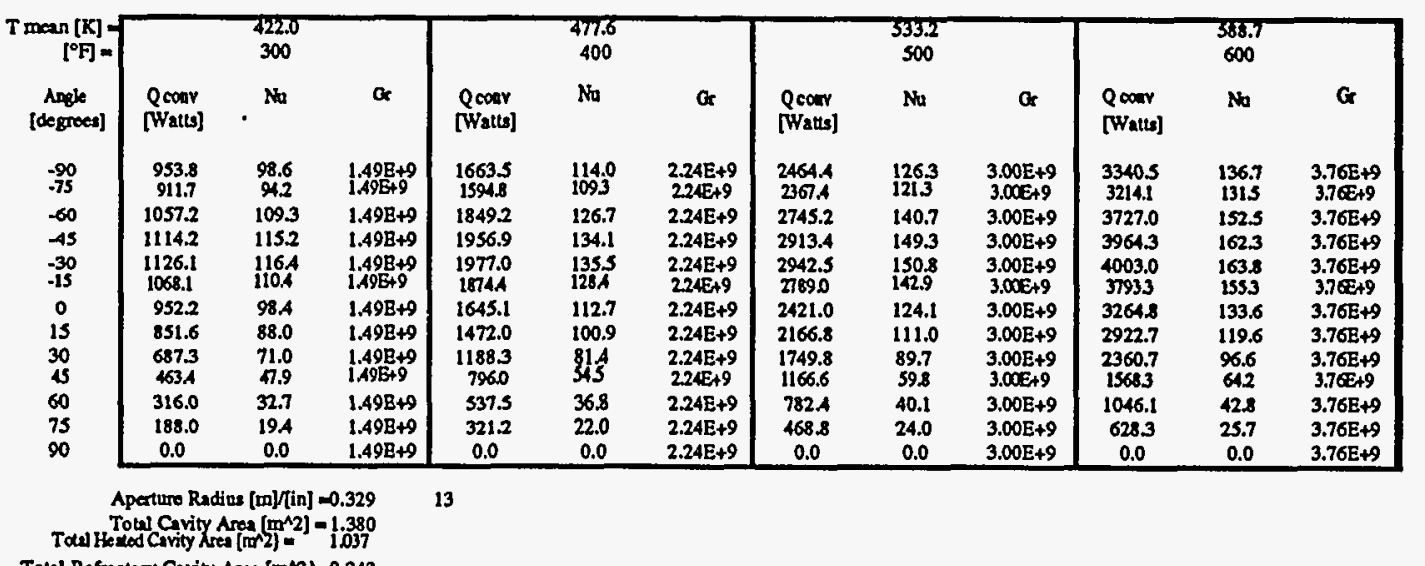

\begin{tabular}{|c|c|c|c|c|c|c|c|c|c|c|c|c|}
\hline$T$ mean $\left[{ }_{(\circ)}{ }^{\circ}\right)=$ & & 300 & & & 400 & & & $\begin{array}{l}4250 \\
300\end{array}$ & & & $\begin{array}{l}3647.1 \\
600\end{array}$ & \\
\hline $\begin{array}{c}\text { Angle } \\
\text { [degroes] }\end{array}$ & Q Qonp & $\mathrm{Na}$ & or & $\begin{array}{l}\text { Q cons } \\
\text { [Ny ats] }\end{array}$ & $\mathrm{Nu}$ & $\sigma_{r}$ & $\begin{array}{l}Q \operatorname{con} v \\
\text { [Wrots] }\end{array}$ & $\mathrm{Na}$ & $\sigma_{r}$ & 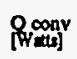 & $\mathrm{No}$ & Gr \\
\hline .90 & 915.2 & 147.1 & $4.63 \mathrm{E}+9$ & 1566.2 & 169.3 & $6.88 \mathrm{E}+9$ & 2298.3 & 187.1 & $9.14 E+09$ & 3097.6 & 202.3 & $1.14 \mathrm{E}+10$ \\
\hline $\begin{array}{l}.75 \\
. \infty\end{array}$ & $\begin{array}{r}882.9 \\
10226\end{array}$ & ${ }_{164 A}^{141.8}$ & $\begin{array}{l}4.63 \mathrm{3}+9 \\
4.63 \mathrm{~B}+9\end{array}$ & $\begin{array}{c}1513.3 \\
77548\end{array}$ & $\begin{array}{l}163.6 \\
189.7\end{array}$ & $\begin{array}{l}6.88 E+9+9 \\
688 E+9\end{array}$ & $\begin{array}{l}2225.1 \\
2580.2\end{array}$ & $\begin{array}{l}181.1 \\
210.0\end{array}$ & $9.14 \mathrm{E}+09$ & 3003.6 & 198.1 & $1.14 \mathrm{E}+10$ \\
\hline 45 & 1090.0 & 175.2 & $4.63 \mathrm{~B}+9$ & 1877.9 & 203.0 & $6.88 \mathrm{E}+9$ & 2768.9 & 225.4 & $\begin{array}{l}9.14 E+09 \\
9.14 E+0\end{array}$ & $\begin{array}{r}37629 \\
3746.0\end{array}$ & $\begin{array}{l}272 A \\
244.6\end{array}$ & $\begin{array}{l}1.1 .14 \mathrm{E}+10 \\
1.1 \mathrm{E}+10\end{array}$ \\
\hline-30 & 1100.4 & 176.9 & $4.63 \mathrm{E}+9$ & 1895.0 & 204.8 & $6.88 \mathrm{E}+9$ & 2793.4 & $227 \mathrm{~A}$ & $9.14 E+09$ & 3778.3 & 246.7 & $1.14 \mathrm{E}+10$ \\
\hline${ }_{0}^{-15}$ & $\begin{array}{r}1042.5 \\
8902.2\end{array}$ & $\begin{array}{l}167.6 \\
143 . i^{\circ}\end{array}$ & $\begin{array}{r}4.63 \mathrm{BE}+9 \\
4.63 \mathrm{E}+9\end{array}$ & $\begin{array}{c}1794.7 \\
15095\end{array}$ & 194.0 & $\begin{array}{l}6.88 \mathrm{E}+9 \\
688 \mathrm{BE}+9\end{array}$ & 2644.8 & $\begin{array}{l}215.3 \\
179.2\end{array}$ & $9.14 E+09$ & 3576.5 & 233.5 & $1.1<\mathrm{E}+10$ \\
\hline 15 & 797.1 & 128.1 & $4.63 \mathrm{E}+9$ & 1352.1 & 146.1 & $\begin{array}{l}6.88 \mathrm{E}+9 \\
6\end{array}$ & 1971.8 & 160.5 & $\begin{array}{l}9,1,14+29 \\
9,1 \mathrm{E}+0\end{array}$ & 2644.8 & $\begin{array}{l}1927 \\
172.7\end{array}$ & $\begin{array}{l}1.1 .14 \mathrm{E}+10 \\
\text { 1.10 }\end{array}$ \\
\hline 30 & 644.0 & 103.5 & $4.63 \mathrm{E}+9$ & 1092.8 & 118.1 & $6.88 \mathrm{E}+9$ & 1594.1 & 129.8 & $9.14 \mathrm{E}+09$ & 2138.6 & 139.6 & $1.14 \mathrm{E}+10$ \\
\hline $\begin{array}{l}45 \\
60\end{array}$ & 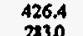 & $\begin{array}{l}68.5 \\
15.5\end{array}$ & $\begin{array}{l}4.63 \mathrm{z}+9 \\
1.65 \mathrm{E}+9\end{array}$ & 719.0 & 77.7 & $6.88 E+9$ & 1044.1 & 85.0 & $9.14 E+0 q$ & 1395.7 & 91.1 & 1.14E+10 \\
\hline $\begin{array}{l}00 \\
75\end{array}$ & 17030 & 275 & $4.63 \mathrm{~B}+9$ & $\begin{array}{r}727.7 \\
2856\end{array}$ & 30.9 & $\begin{array}{l}6.6885+9 \\
688 \mathrm{E}+9\end{array}$ & 608.7 & 35.5 & $9.14 \mathrm{E}+09$ & $\begin{array}{l}9065 \\
3805\end{array}$ & 59.2 & $\begin{array}{l}1.14 E+10 \\
1.14 E+10\end{array}$ \\
\hline 90 & 0.0 & 0.0 & $4.63 \mathrm{E}+9$ & 0.0 & 0.0 & $6.8 \mathrm{BE}+9$ & 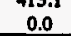 & 0.0 & $9.14 E+08$ & 0.0 & 0.0 & 1.14E+10 \\
\hline
\end{tabular}


APPENDIX 5: Koenig and Marvin Model Computer Program Listing

REM

REM

REM

REM

Koenig and Marvin Model

REM The Koenig and Marvin method is used here to predict the convective losses from

REM

REM

a cavity solar receiver operating at various temperatures and receiver angles.

PRINT " Koenig and Marvin Model for Predicting Convective Heat Loss"

PRINT

PRINT

REM

REM

$\mathrm{Re}=.127$

$\mathrm{Rc}=.33$

$\mathrm{Ro}=.45$ :REM

$\mathrm{Lf}=.292$

$\mathrm{Lh}=.254$

LC $=.14$

REM

REM

$\mathrm{pi}=4^{\star} \mathrm{ATN}(1)$

$g=9.810001$

$\mathrm{SB}=5.6696 \mathrm{E}-08$

$\mathrm{Cp}=1006.86$

$\mathrm{Pf}=1.19406$

$\theta=.9$

$\mathrm{ki}=.04756$

$t=.0889$

$\mathrm{Ta}=70$

$\mathrm{Ta}=(\mathrm{Ta}+459.67) / 1.8$

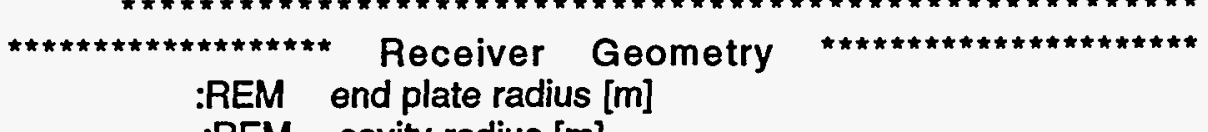

:REM end plate radius [m]

:REM cavity radius [m]

:REM frustum length [m]

receiver outside radius $[\mathrm{m}]$

:REM cylinder length hot [m]

:REM cylinder length cold [m]

REM

REM open clipboard file for transferring data to spread sheet

OPEN "CLIP:" FOR OUTPUT AS \#1

100 :

REM

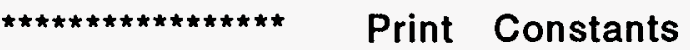

Constants

:REM gravitational acceleration [m/sec^2]

:REM Stefan Boltzmann const. [W/m^2 $\left.\mathrm{K}^{\wedge} 4\right]$

:REM specific heat capacity of air at Ta [J/kg K]

:REM density of air at $\mathrm{Ta}\left[\mathrm{kg} / \mathrm{m}^{\wedge} 3\right]$

:REM emittance of cavity

:REM insulation conductance $[\mathrm{W} / \mathrm{m}-\mathrm{K}][.33 \mathrm{~B} / \mathrm{h} / \mathrm{ft} \wedge 2 / \mathrm{in}]$

REM

:REM thickness of insulation [m] [3.5 in]

:REM ambient temperature [F]

:REM ambient temperature [K

CS

PRINT "End Plate Radius [m] $=$ "; Re

PRINT "Cavity Radius [m] $=$ ";Rc

PRINT "Frustum Length [m] = ";Lf

PRINT "Hot Cylindrical Section Length $[\mathrm{m}]=$ ";Lh

PRINT "Cold Cylindrical Section Length [m] = ";c

PRINT "Ambient Temperature [K] = ";

PRINT USING"\#\#\#\#.\#";Ta

PRINT

REM Write to the clipboard

WRITE\#1," ",","End Plate Radius [m] = ",Re

WRITE\#1," "," "Cavity Radius [m] = ",Rc

WRITE\#1," ",", "Frustum Length [m] = "Lf

WRITE\#1, "x"," "Hot Cylindrical Section Length [m] = ",Lh

WRITE\#1, "n"," ",Cold Cylindrical Section Length [m] = ",Lc

WRITE\#1,""," "Ambient Temperature $[\mathrm{K}]=$ ",Ta

WRITE\#1, 
as

FOR $I=1$ TO 4

READRa

DATA $.0762, .1524, .2286, .329$

$\mathrm{Da}=2^{*} \mathrm{Ra}$

$A a=p^{\star} R^{\wedge} 2$

REM

:REM aperture diameter [m]

:REM aperture area [ $\left.\mathrm{m}^{\wedge} 2\right]$

REM Area Constants

REM In the following section Ah and Ar are calculated.

REM Ah is the total interior heated cavity surface area based on the tube bundle geometry.

REM Ar is the total interior refractory cavity surface.

REM At is the total cavity area.

$A h=\mathrm{pi}^{\star}(R e+R c)^{\star}\left(L f^{\wedge} 2+(R c-R e)^{\wedge} 2\right)^{\wedge} .5+2 \quad{ }^{*} \mathrm{pi}^{\star} R c^{\star} L h$

$A r=p i^{\star} R e^{\wedge} 2+p^{*}\left(R c^{\wedge} 2-R a^{\wedge} 2\right)+2^{\star} p i^{\star} R c^{\star} L c$

$A t=A h+A r$

REM

$A O=\mathrm{pi}^{*}((R c+R o) / 2)^{\wedge} 2+2^{*} \mathrm{pi}^{\star}((R c+R o) / 2)+\mathrm{pi}^{\bullet}\left(R c^{\wedge} 2-R \mathrm{a}^{\wedge} 2\right)$

REM

REM

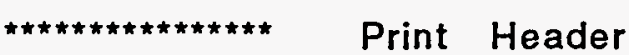

CS

PRINT "Aperture Radius [m] = ";Ra

PRINT " Total Cavity Area [m^2] = ";

PRINT USING "\#\#\#.\#\#\#\#";At

PRINT " Total Heated Cavity Area $\left[m^{\wedge} 2\right\}=$ ";

PRINT USING "\#\#\#.\#\#\#\#";Ah

PRINT " Total Refractory Cavity Area $\left[\mathrm{m}^{\wedge} 2\right\}=$ ";

PRINT USING "\#\#\#.\#\#\#";Ar

REM

write header to clipboard

WRITE\#1, "n," ", "Aperture Radius [m] = ",Ra

WRITE\#1, "," "," Total Cavity Area [m^2] = ",At

WRITE\#1, "," "," Total Heated Cavity Area [m^2] = ",Ah

WRITE\#1,"n" $" *$ " "Total Refractory Cavity Area $\left[m^{\wedge} 2\right\}="$,Ar

REM

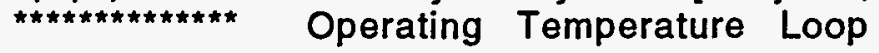

REM

FOR Tmf $=300$ TO 600 STEP 100

WRITE\#1,

REM The operating temperature is converted from $\mathrm{F}$ to $\mathrm{K}$

$T m=(T m f+459.67) / 1.8$

Twf $=$ Tmf-100 :REM The refractory surfaces are assumed to be $100^{\circ} \mathrm{F}$ cooler :REM than the heated tube surfaces.

$T w=(T w f+459.67) / 1.8$

CS

REM

REM

PRINT "T mean $[\mathrm{K}]=$ ";

PRINT USING "\#\#\#\#.\#";Tm;

PRINT " $\left[{ }^{\circ} \mathrm{F}\right]=$ ";

PRINT

PRINT USING "\#\#\#\#.";Tmf

PRINT ;TAB(3);" Angle";TAB(12);"Q conv";TAB(24);"Q total";TAB(34);"\% Conv";

PRINT TAB(45);" Nu ";TAB(56);"

$\mathrm{Gr}^{n} ; \mathrm{TAB}(66) ;{ }^{*} \mathrm{P}(\varnothing)^{n} ; \mathrm{TAB}(76) ; " k^{n} ; \operatorname{TAB}(86) ; " g B / v^{\wedge} 2^{n} ; \mathrm{TAB}(96) ; " \mathrm{Pr}$

"TAB(106);"Tp" 


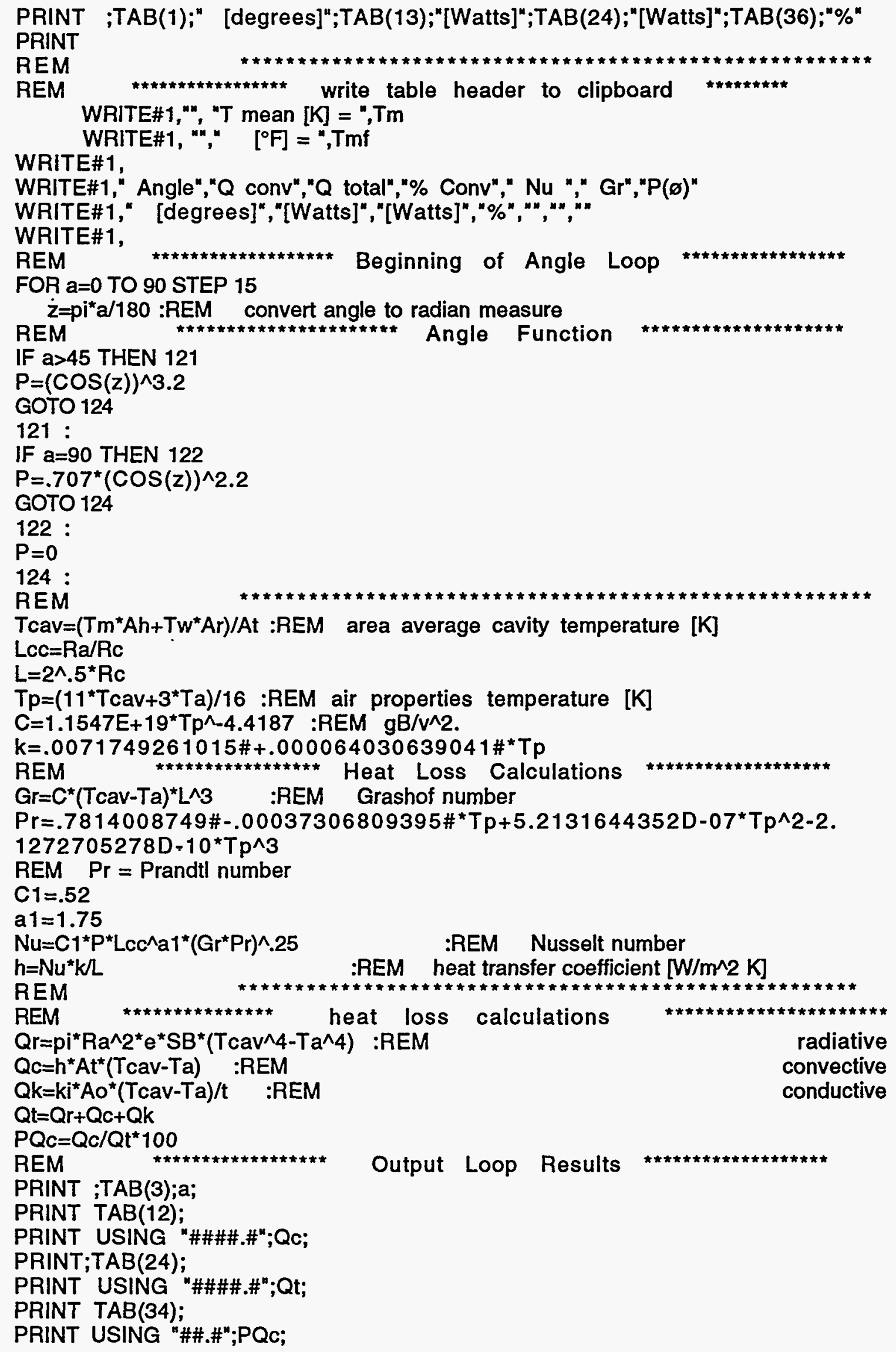




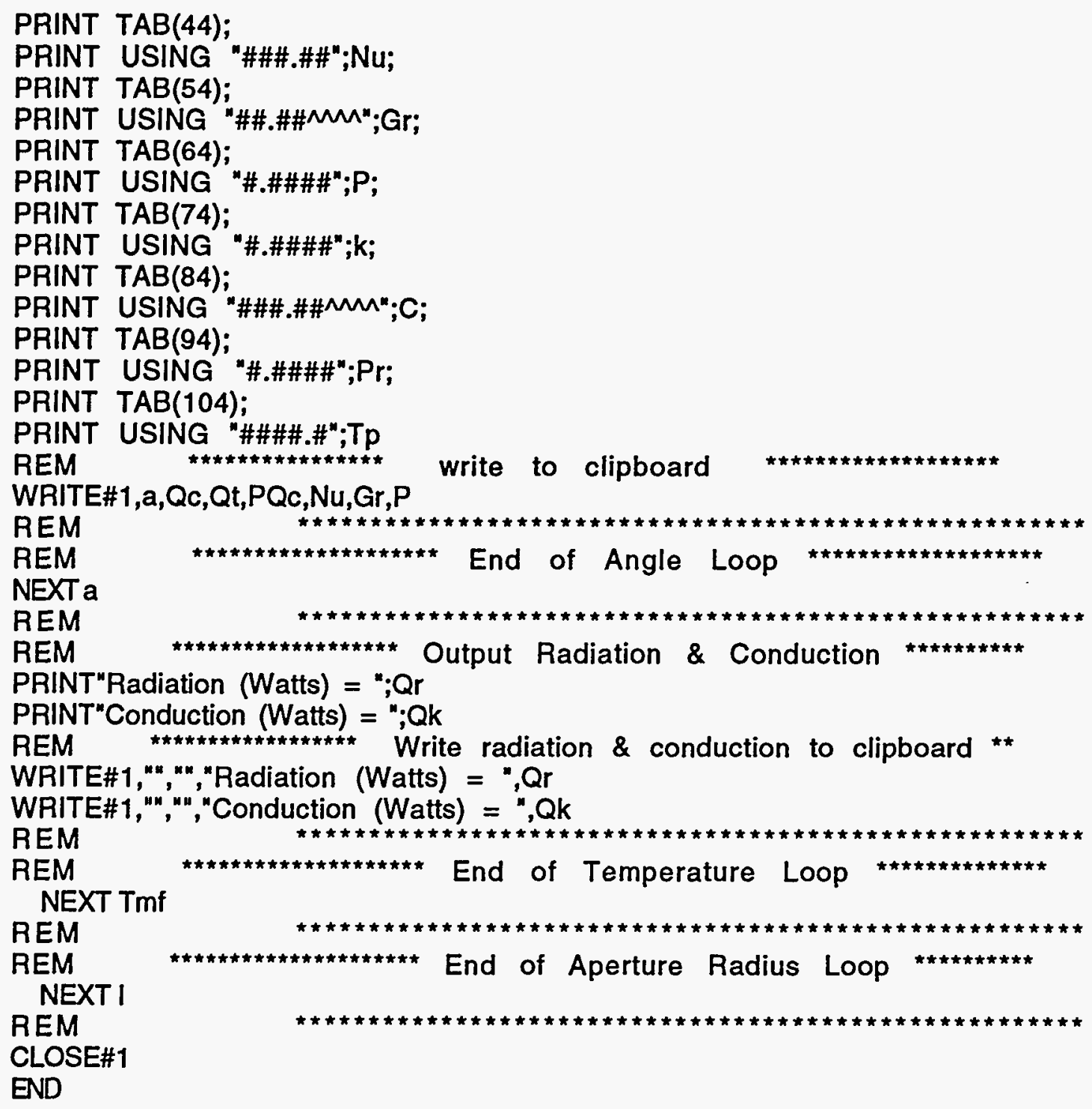




\section{Appendix 6: Koenig and Marvin Model Heat Loss}

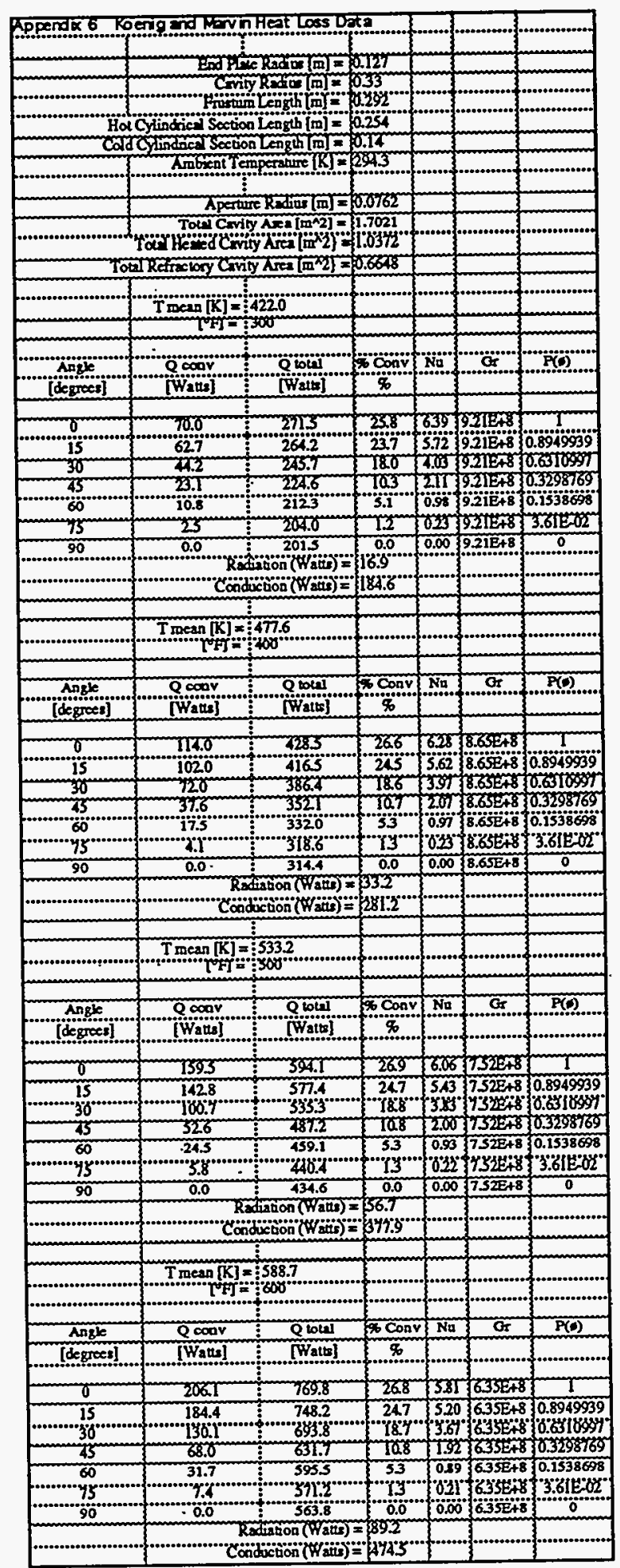




\section{Appendix 6: Koenig and Marvin Model Heat Loss}

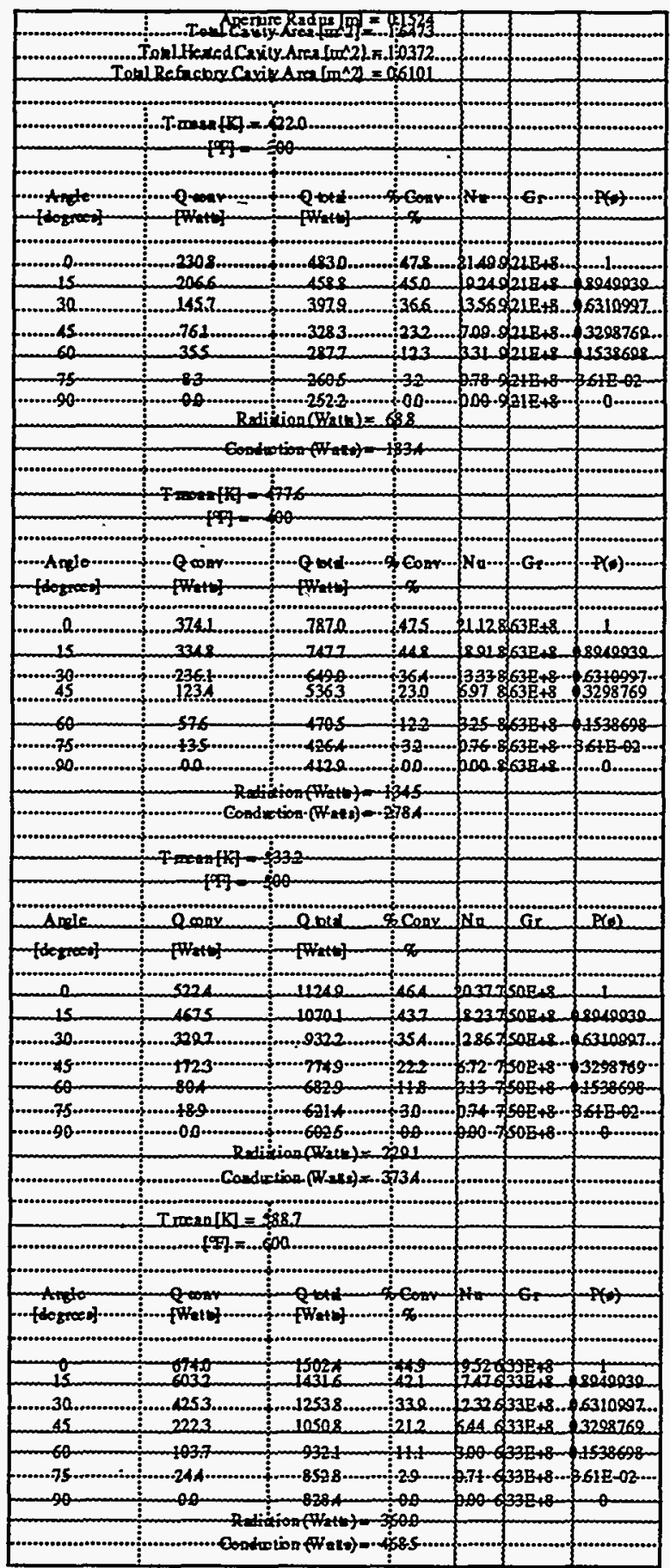


Appendix 6: Koenig and Marvin Model Heat Loss

\begin{tabular}{|c|c|c|c|c|c|}
\hline & Apartie Radus[mal = & 92236 & & & \\
\hline & 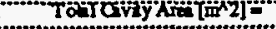 & 15351 & & & \\
\hline & 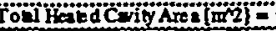 & 10332 & & & \\
\hline & 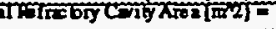 & passos & & & \\
\hline & & & & & \\
\hline & T些㛭 & & & & \\
\hline & $\mathrm{PF}=\$ 00$ & & & & \\
\hline & & & & & \\
\hline Angle & Qioioi & poin & Ni & (it) & ici \\
\hline 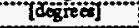 & [wice" & 6 & & & \\
\hline & & & & & \\
\hline$\sigma^{\circ}$ & $79 \times 11^{\circ}$ & "צr.x" & 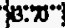 & 21 218 & $\mathbf{I}^{*}$ \\
\hline "i3" & 4036 & 3.3 & G.ii & BiE +8 & 408939 \\
\hline 30 & 2860 & 6.6 & p.s. & $821 E+8$ & 0631099 \\
\hline$\times 5$ & $1495^{\circ}$ & $30: 5$ & $\operatorname{kcos}$ & I2TE+8 & 0325869 \\
\hline $60^{\circ}$ & $4106 \cdots$ & $m .0^{\prime \cdots}$ & $\mid 672-1$ & 2 LE+78 & 01588698 \\
\hline 75 & 337.2 & 46 & 138 & 21E+8 & $361 E-02$ \\
\hline 90 & $360^{\circ} 8^{\circ}$ & " & $0000^{\circ}$ & [2LE+8: & $\sigma^{\circ}$ \\
\hline & 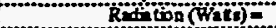 & 393 & & & \\
\hline & 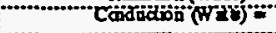 & min. & & & \\
\hline & & & & & \\
\hline & 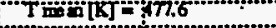 & & & & \\
\hline & $\mathrm{Pr}$ & & & & \\
\hline & & & & & \\
\hline Angie & Qcon & 策 Oonv & Nio & Gt & Pio \\
\hline [dégréa] & [wati]" & $-\infty \infty^{\infty}$ & & & \\
\hline & & & & & \\
\hline "0* & rand & 55.6 & 20 & $6 C E+8^{\circ}$ & 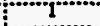 \\
\hline iis" & i230i & 38 & 6.0 & 860 & : \\
\hline 30 & 108.1 & Hii & a.6 & $860+8$ & 0631097 \\
\hline 75 & $8276^{\circ}$ & ঋ:Z & $4: 5$ & $3600+8$ & $03288760^{\circ}$ \\
\hline $60^{\circ}$ & 6553 & "4.5. & $6560^{\circ}$ & $860+8+8$ & 40198698 \\
\hline 73 & 6003 & $\because 3$ & 135 & $860 \%+8$ & 3610 \\
\hline 90 & 3851 & 00 & 000 & SORE+ & 0 \\
\hline & Riviono & 0093 & & & \\
\hline & 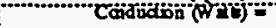 & p & $\cdots$ & & \\
\hline & & & & & \\
\hline & T前尚[R]" & & & & \\
\hline & $\mathrm{PF}]=300$ & & & & \\
\hline & & & & & \\
\hline Angle & Qcoin & önv & Nï & at & 80 \\
\hline [agicici] & [Wait] & 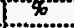 & & & \\
\hline & & & & & \\
\hline$\sigma$ & TOE. 9 & 30.2 & 11.50 & TASE+8 & $\mathbf{T}$ \\
\hline 133 & 1738 & 30.5 & 官" & $74 x+3$ & 089939 \\
\hline $30^{\circ}$ & $1350 \%$ & 48 & 6.0 & $348+8$ & $0639099^{\circ}$ \\
\hline & 7225 & 2.3 & 5.4 & T्रSE+8 & 03388769 \\
\hline $60^{\circ}$ & roons & "r:y.” & 636. & TXSE +8 & (4198698 \\
\hline$" 73$ & 927.6 & 20 & 149 & 7436 & 360102 \\
\hline 90 & 8910 & 00 & 000 & $245 E+8$ & 0 \\
\hline & 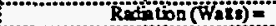 & 648 & & & \\
\hline & 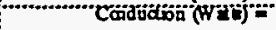 & $\$ 663^{\circ}$ & & & \\
\hline & & & & & \\
\hline$m$ & $T=5887$ & & & & \\
\hline 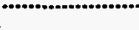 & pF $=\$ 000$ & & & & \\
\hline & & & & & \\
\hline Angle & Qcon & 6ong & Ka & $G$ & $P(4)$ \\
\hline 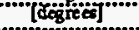 & [Wity] & \% & & & \\
\hline & & & & & \\
\hline & $\mathrm{T} 30.2$ & 305 & 9.02 & $\$ 24 E+8$ & 1 \\
\hline "i33” & 113.2 & 4.7 & 80 & +320 & 0899939 \\
\hline 30 & $210 \% 8$ & 3.1 & 8. & 62 每+8 & 06310997 \\
\hline 75 & I7II. & 2.2 & 3.W & $629 E+8$ & 03328769 \\
\hline${ }^{6} 60^{\circ}$ & $148 D^{\circ}$ & 15.6” & 610 & $5296+8^{\circ}$ & 0158658 \\
\hline & 13233 & 36 & 143 & 82 宅+8 & $361 \mathrm{E}-02$ \\
\hline $990 "$ & 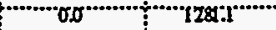 & $\infty 0^{2} \cdots$ & $6000^{\circ}$ & $629+8$ & " \\
\hline & Retiono (Wats): & 626 & & & \\
\hline & 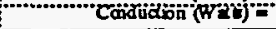 & $883^{\circ}$ & & & \\
\hline
\end{tabular}




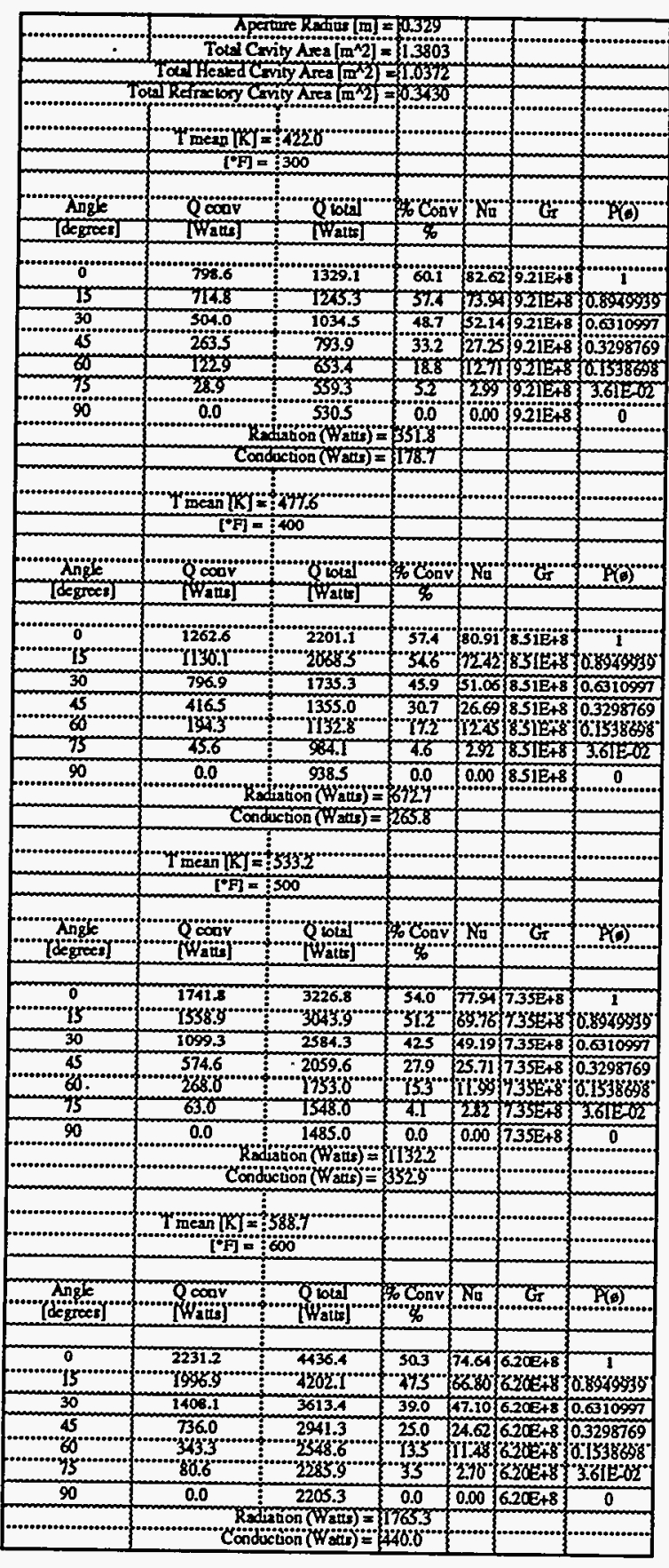




\section{Zone Area Formulas}

The receiver cavity is divided into two zones (Fig. 23). The boundary between the zones is formed by a horizontal plane cutting through the cavity at the upper lip of the aperture. The upper zone is assumed stagnate while the lower zone has active convective currents. Zone 1 area represents the internal surface area of the receiver above the horizontal plane. The zone 2 area represents the internal surface area of the receiver below the horizontal plane. The zone 1 and zone 2 areas vary with receiver angle for a given receiver geometry. The following formulas describe the zone 1 and zone 2 surface areas of the receiver cavity

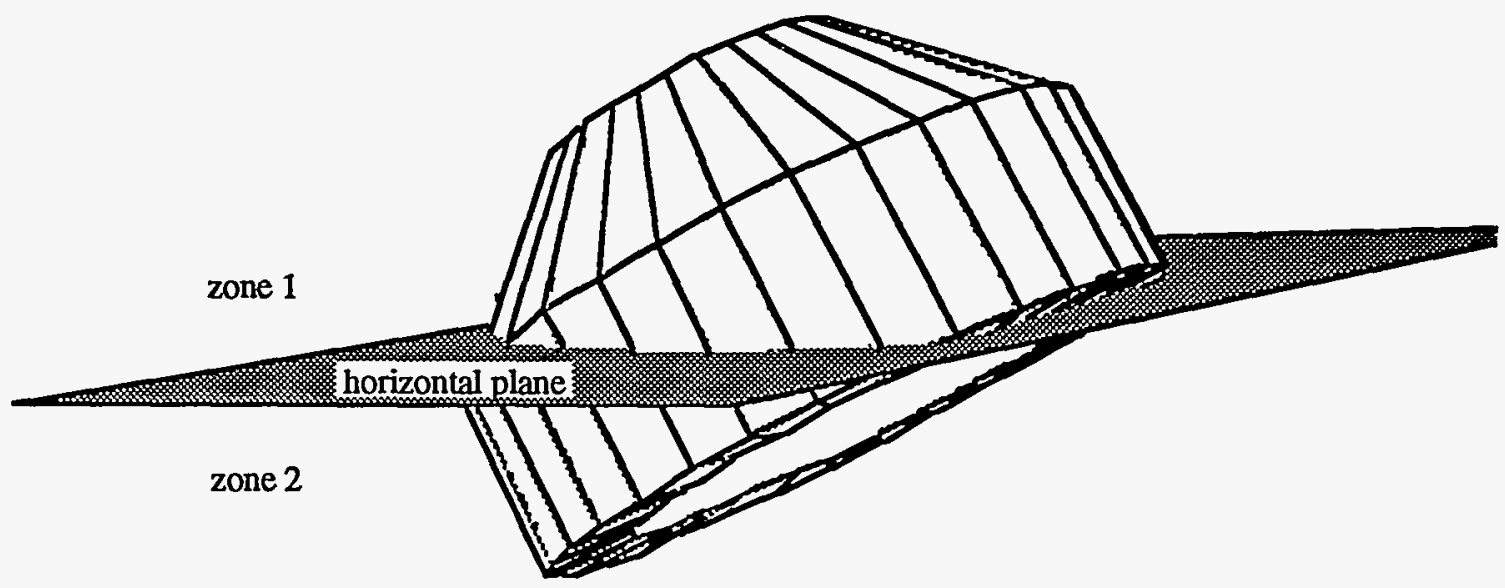

Figure 23. Cavity zones areas. 
The receiver internal geometry is divided into five sections representing the hot and cold surfaces in the receiver (Fig. 24). The hot surfaces are actively heated. The cold surfaces represent the refractory surfaces. Section 1 is the circular plate at the end of the frustum. Section 2 is the frustum portion of the tube bundle. Section 3 is the cylindrical portion of the tube bundle. Section 4 is the short refractory portion of the cylindrical section. Section 5 is the refractory ring that forms the aperture.

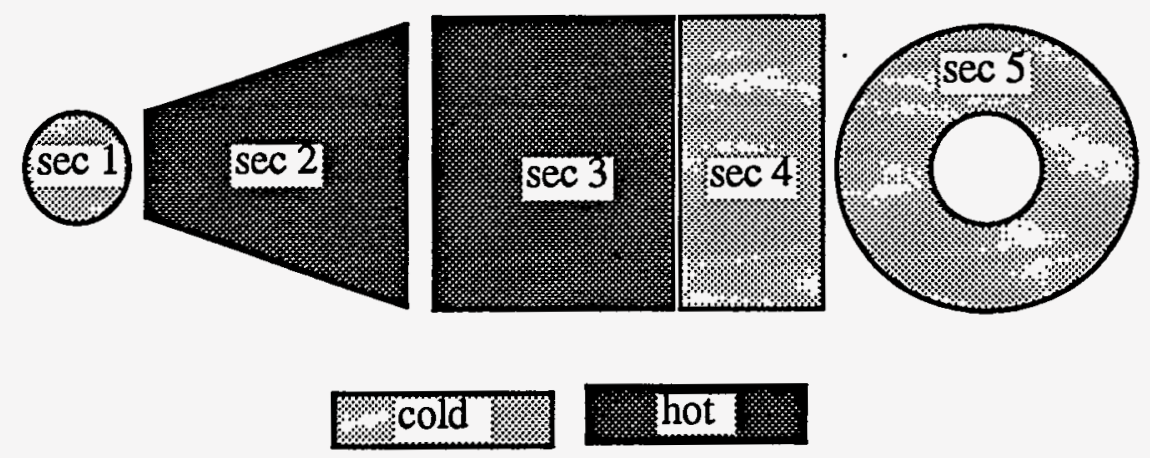

Figure 24. Cavity sections.

As the receiver is rotated through various angles, each section of the internal receiver geometry may be divided by the horizontal plane that cuts through the upper inside edge of section 5 . The critical angles represent limits for the various algebraic expression of the zone areas (Fig. 69). The following formulas define the portion of the area of each section that is in zone 1 for a given receiver angle range. The remaining surface area of each section in zone 2 is determined by subtracting the zone 1 area from the total surface area for that section. 


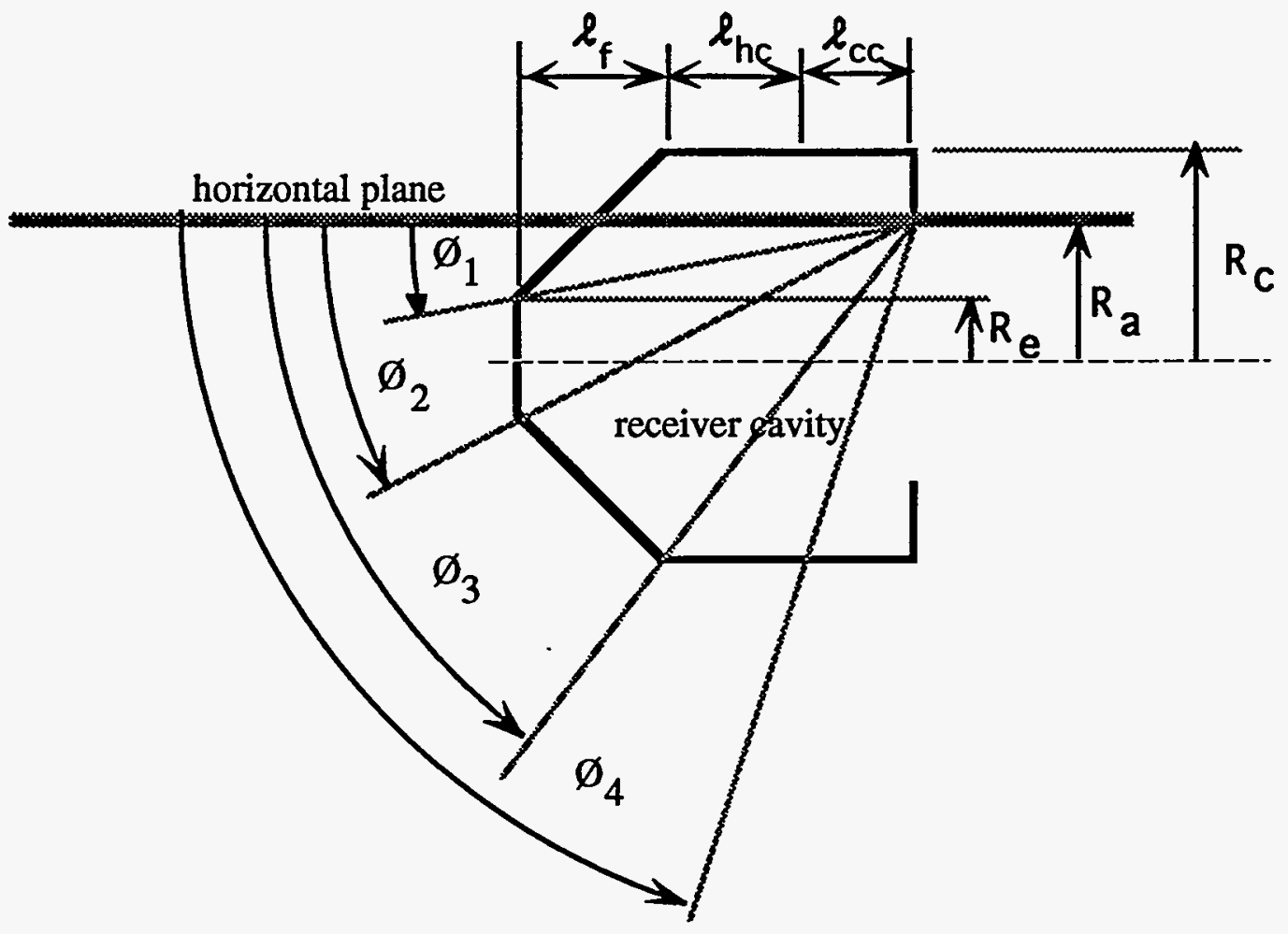

Figure 69. Critical angles.

where:

$$
\begin{gathered}
\emptyset_{1}=\tan ^{-1}\left[\frac{R_{\mathrm{a}}-R_{\mathrm{e}}}{\ell_{\mathrm{cc}}+\ell_{\mathrm{hc}}+\ell_{\mathrm{f}}}\right] \\
\emptyset_{2}=\tan ^{-1}\left[\frac{\mathrm{R}_{\mathrm{a}}+\mathrm{R}_{\mathrm{e}}}{\ell_{\mathrm{cc}}+\ell_{\mathrm{hc}}+\ell_{\mathrm{f}}}\right] \\
\emptyset_{3}=\tan ^{-1}\left[\frac{\mathrm{R}_{\mathrm{a}}+\mathrm{R}_{\mathrm{c}}}{\ell_{\mathrm{cc}}+\ell_{\mathrm{hc}}}\right] \\
\emptyset_{4}=\tan ^{-1}\left[\frac{\mathrm{R}_{\mathrm{a}}+\mathrm{R}_{\mathrm{c}}}{\ell_{\mathrm{cc}}}\right]
\end{gathered}
$$

where:

$$
R_{e}=\text { radius of the end plate }
$$


(a) section 1

Range $\quad 0 \leq \emptyset \leq \emptyset_{1}$

$$
\text { Area }=0
$$

Range $\emptyset_{1} \leq \emptyset \leq \emptyset_{2}$

$$
\begin{gathered}
\text { Area }=R_{e}^{2} \cos ^{-1}\left[\frac{R_{a}-\left(\ell_{c c}+\ell_{h c}+\ell_{f}\right) \tan \emptyset}{R_{e}}\right]+\left[\left(\ell_{c c}+\ell_{h c}+\ell_{f}\right) \tan \emptyset-R_{a}\right] \\
\left\{2 R_{e}\left[\left(\ell_{c c}+\ell_{h c}+\ell_{f}\right) \tan \emptyset-R_{a}+R_{e}\right]-\left[\left(\ell_{c c}+\ell_{h c}+\ell_{f}\right) \tan \emptyset-R_{a}+R_{e}\right]^{2}\right\}^{1 / 2}
\end{gathered}
$$

Range $\quad \emptyset_{2} \leq \varnothing \leq \frac{\pi}{2}$

$$
\text { Area }=\pi \mathrm{R}_{\mathrm{e}}^{2}
$$

(b) section 2

$$
\begin{aligned}
& \text { Range } \quad 0 \leq \emptyset \emptyset_{1} \\
& \text { Area }=\left\{\frac{\left[\left(\frac{\mathrm{R}_{\mathrm{c}}-\mathrm{R}_{\mathrm{e}}}{\ell_{\mathrm{f}}}\right)\left(\mathrm{R}_{\mathrm{c}}-\mathrm{R}_{\mathrm{a}}\right)+\left(\ell_{\mathrm{cc}}+\ell_{\mathrm{hc}}\right)\right] \sin \emptyset}{\sin \left[\frac{\pi}{2}-\emptyset-\tan ^{-1}\left(\frac{\mathrm{R}_{\mathrm{c}}-\mathrm{R}_{\mathrm{e}}}{\ell_{\mathrm{f}}}\right)\right]}+\frac{\left(\mathrm{R}_{\mathrm{c}}-\mathrm{R}_{\mathrm{a}}\right)}{\sin \left[\tan ^{-1}\left(\frac{\mathrm{R}_{\mathrm{c}}-\mathrm{R}_{\mathrm{e}}}{\ell_{\mathrm{f}}}\right)\right]}\right\}
\end{aligned}
$$




$$
R_{c} \cos ^{-1}\left[\frac{R_{a}-\left(\ell_{c c}+\ell_{h c}\right) \tan \emptyset}{R_{c}}\right]
$$

Range $\emptyset_{1} \leq \emptyset \leq \emptyset_{2}$

$$
\begin{gathered}
\text { Area }=\sqrt{\ell_{\mathrm{f}}^{2}+\left(R_{\mathrm{c}}-R_{\mathrm{e}}\right)^{2}}\left\{\mathrm{R}_{\mathrm{e}} \cos ^{-1}\left[\frac{\mathrm{R}_{\mathrm{a}}-\left(\ell_{c \mathrm{c}}+\ell_{\mathrm{hc}}+\ell_{\mathrm{f}}\right) \tan \emptyset}{\mathrm{R}_{\mathrm{e}}}\right]\right. \\
\left.+\mathrm{R}_{\mathrm{c}} \cos ^{-1}\left[\frac{\mathrm{R}_{\mathrm{a}}-\left(\ell_{\mathrm{cc}}+\ell_{\mathrm{hc}}\right) \tan \emptyset}{\mathrm{R}_{\mathrm{c}}}\right]\right\}
\end{gathered}
$$

Range $\quad \emptyset_{2} \leq \emptyset \leq \emptyset_{3}$

$$
\begin{gathered}
\text { Area }=\left\{\pi R_{e}+\pi\left\{R_{e}+a \sin \left[\tan ^{-1}\left(\frac{R_{c}-R_{e}}{\ell_{f}}\right)\right]\right\}\right\} a \\
+\left\{R_{c} \cos ^{-1}\left[\frac{R_{a}-\left(\ell_{c c}+\ell_{h c}\right) \tan \emptyset}{R_{c}}\right]+\pi\left\{R_{e}+a \sin \left[\tan ^{-1}\left(\frac{R_{c}-R_{e}}{\ell_{f}}\right)\right]\right\}\right\} \\
{\left[\sqrt{\left(R_{c}-R_{e}\right)^{2}+\ell_{f}^{2}}-a\right]}
\end{gathered}
$$

where:

$$
a=\left\{\frac{\sqrt{\left(R_{e}+R_{a}\right)^{2}+\left(\ell_{c c}+\ell_{h c}+\ell_{f}\right)^{2}} \sin \left[\varnothing-\tan ^{-1}\left(\frac{R_{a}+R_{e}}{\ell_{c c}+\ell_{b c}+\ell_{f}}\right)\right]}{\sin \left[\pi-\emptyset-\tan ^{-1}\left(\frac{R_{c}-R_{e}}{\ell_{f}}\right)\right]}\right.
$$

Range

$$
\begin{aligned}
& \emptyset_{3} \leq \emptyset \leq \frac{\pi}{2} \\
& \quad \text { Area }=\pi\left(R_{c}+R_{e}\right) \sqrt{\left(R_{c}-R_{e}\right)^{2}+\ell_{\mathrm{f}}^{2}}
\end{aligned}
$$

(c) section 3

Range $\quad 0 \leq \emptyset \leq \emptyset_{3}$ 


$$
\text { Area }=R_{c} \ell_{b c}\left\{\cos ^{-1}\left[\frac{R_{a}-\ell_{c c} \tan \emptyset}{R_{c}}\right]+\cos ^{-1}\left[\frac{R_{a}-\left(\ell_{c c}+\ell_{h c}\right) \tan \emptyset}{R_{c}}\right]\right\}
$$

Range $\quad \emptyset_{3} \leq \emptyset \leq \emptyset_{4}$

$$
\begin{gathered}
\text { Area }=2 \pi R_{c}\left[\ell_{c c}+\ell_{b c}-\frac{\left(R_{a}+R_{c}\right)}{\tan \emptyset}\right] \\
+R_{c}\left[\frac{\left(R_{a}+R_{c}\right)}{\tan \emptyset}-\ell_{c c}\right]\left\{\pi+\cos ^{-1}\left[\frac{R_{a}-\ell_{c c} \tan \emptyset}{R_{c}}\right]\right\}
\end{gathered}
$$

Range $\quad \emptyset_{4} \leq \varnothing \leq \frac{\pi}{2}$

$$
\text { Area }=2 \pi R_{c} \ell_{\mathrm{hc}}
$$

(d) section 4

Range $\quad 0 \leq \varnothing \leq \emptyset_{4}$

$$
\text { Area }=R_{c} \ell_{c c}\left\{\cos ^{-1}\left[\frac{R_{a}}{R_{c}}\right]+\cos ^{-1}\left[\frac{R_{a}-\ell_{c c} \tan \emptyset}{R_{c}}\right]\right\}
$$

Range

$$
\emptyset_{4} \leq \varnothing \leq \frac{\pi}{2}
$$

$$
\text { Area }=2 \pi R_{c}\left[\ell_{c c}-\frac{\left(R_{a}+R_{c}\right)}{\tan \emptyset}\right]+R_{c}\left\{\pi+\cos ^{-1}\left[\frac{R_{a}}{R_{c}}\right]\right\} \frac{\left(R_{a}+R_{c}\right)}{\tan \emptyset}
$$

\section{(e) section 5}

Range

$$
0 \leq \varnothing \leq \frac{\pi}{2}
$$

$$
\text { Area }=R_{c}^{2} \cos ^{-1}\left[\frac{R_{a}}{R_{c}}\right]-R_{a} \sqrt{R_{c}^{2}-R_{a}^{2}}
$$

Range

$$
\varnothing=\frac{\pi}{2}
$$




$$
\text { Area }=\pi\left(R_{c}^{2}-R_{a}^{2}\right)
$$

\section{Shear Plane Area}

The shear plane area is the area of the horizontal plane within the cavity (Fig. 25). The shear plane area is divided into two sections. The first section is formed by the horizontal plane cutting through the cylindrical portion of the receiver cavity. Not all of the horizontal plane in the cylindrical portion participates in the convective heat loss. The sides of the aperture reduce the effective shear plane area by restricting flow along the horizontal plane at the sides of the cavity near the aperture. The shear plane expands parabolically from the upper lip of the aperture in the horizontal plane. The second section is formed where the horizontal plane cuts the frustum portion of the receiver cavity. The following formulas describe the shear plane area in the specified portion of the cavity for a given receiver angle

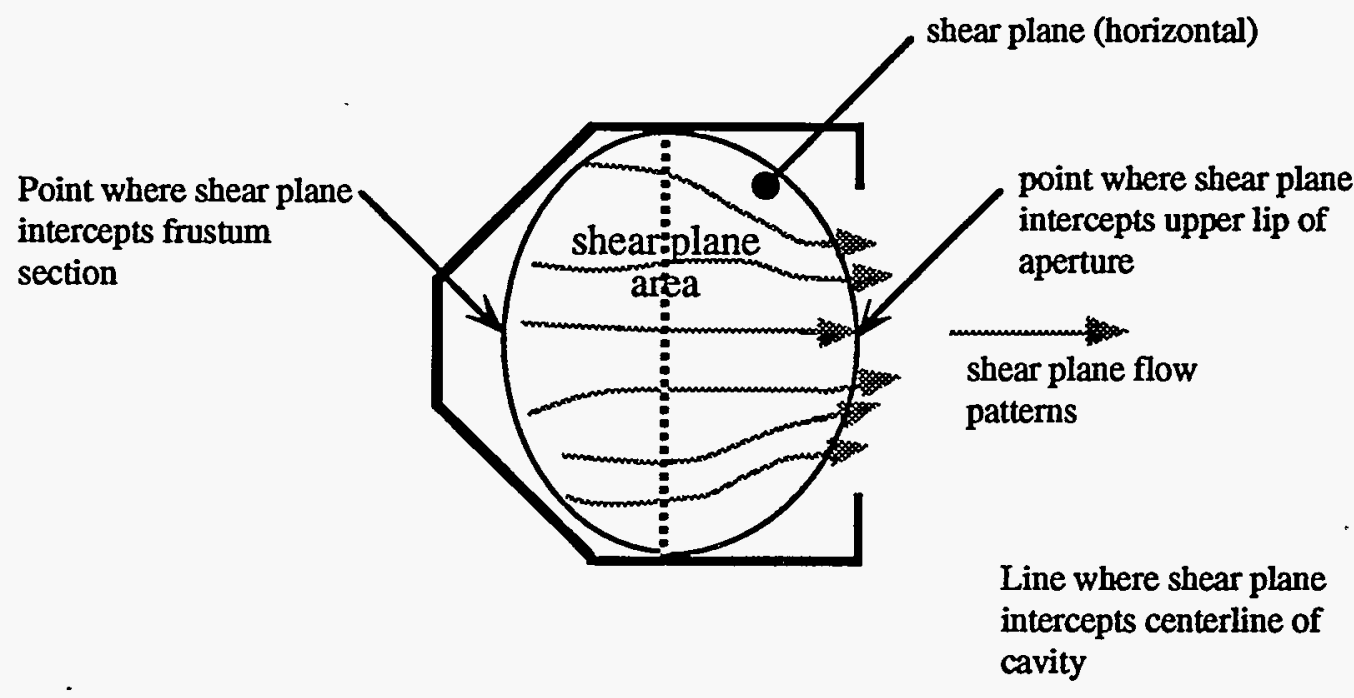

Figure 25. View looking down showing the effective shear plane area. 
(a) Shear Plane Area -cylindrical section

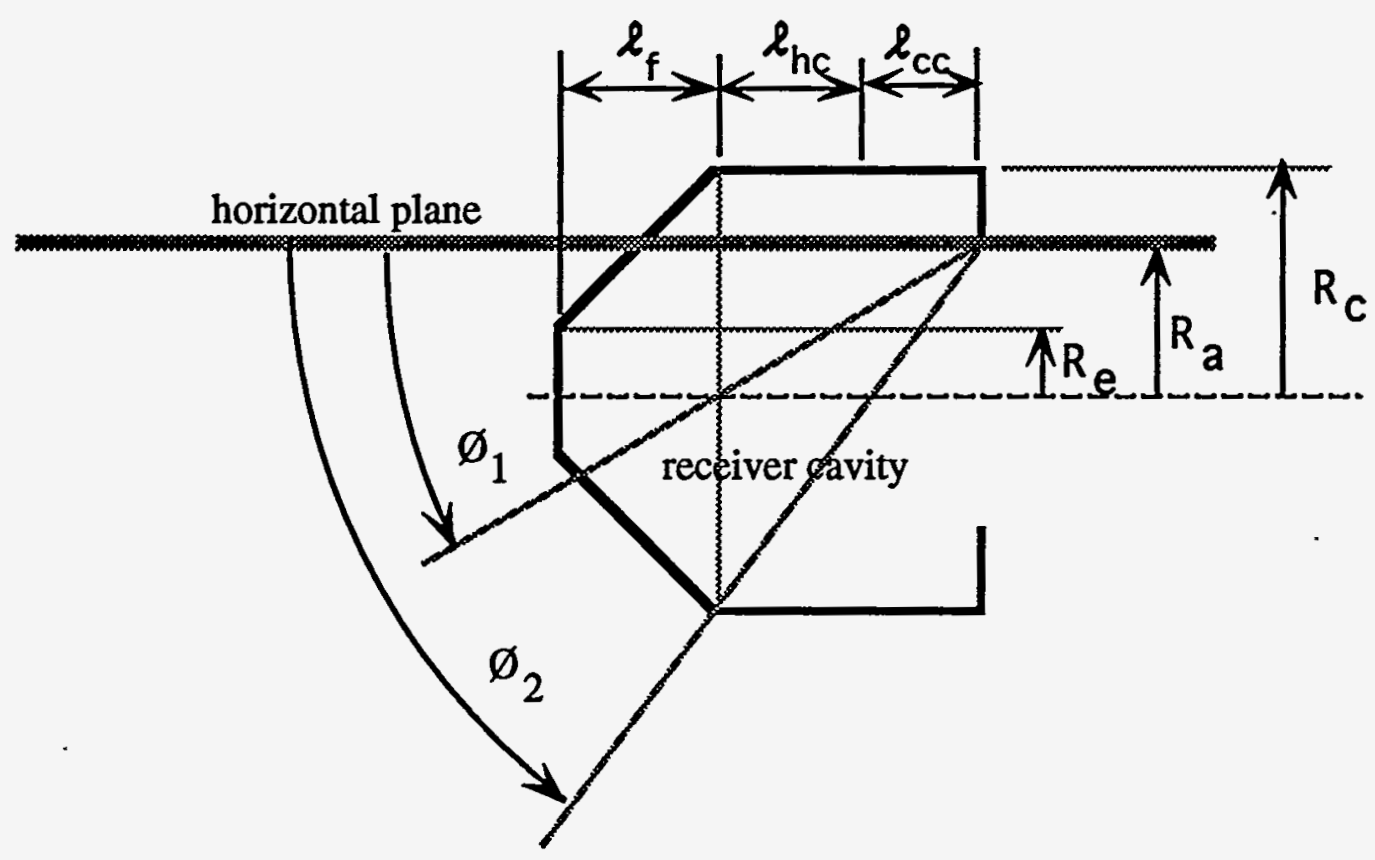

Figure 70. Cylindrical section shear plane angles.

The angles in figure 70 are defined as follows:

$$
\begin{aligned}
& \emptyset_{1}=\tan ^{-1}\left[\frac{\mathrm{R}_{\mathrm{a}}}{\ell_{\mathrm{cc}}+\ell_{\mathrm{hc}}}\right] \\
& \emptyset_{2}=\tan ^{-1}\left[\frac{\mathrm{R}_{\mathrm{a}}+\mathrm{R}_{\mathrm{c}}}{\ell_{\mathrm{cc}}+\ell_{\mathrm{hc}}}\right]
\end{aligned}
$$

Range $\quad 0 \leq \emptyset \leq \emptyset_{1}$

$$
\begin{gathered}
\mathrm{D}=\frac{\left(\ell_{\mathrm{cc}}+\ell_{\mathrm{hc}}\right)}{\cos \emptyset} \\
\mathrm{L}=2 \sqrt{\mathrm{R}_{\mathrm{c}}^{2}-\mathrm{R}_{\mathrm{a}}^{2}} \\
\mathrm{~L}_{\mathrm{e}}=2 \sqrt{\mathrm{R}_{\mathrm{c}}^{2}-\left[\mathrm{R}_{\mathrm{a}}-\left(\ell_{\mathrm{cc}}+\ell_{\mathrm{hc}}\right) \tan \emptyset\right]^{2}}
\end{gathered}
$$


（ISI）

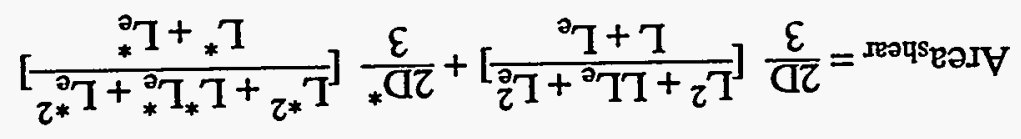

(OSI)

$$
\frac{\emptyset \text { u!s }}{{ }^{\mathrm{D}} \mathrm{y}}={ }_{*} \sigma
$$

(6tI)

$$
0={ }_{*}^{2} T
$$

$(8+1)$

$$
{ }^{3} \mathrm{~d} z={ }_{*} \mathrm{~T}
$$

$(L t I)$

$$
\frac{\emptyset \mathrm{uts}}{{ }^{\mathrm{E}} \mathrm{d}}=\alpha
$$

(9tr)

$$
{ }^{2} \mathrm{~d} z={ }^{2} \mathrm{~T}
$$

(stI)

$$
i z-i z \mu z=1
$$

$$
\frac{\tau}{\iota}>\varnothing>^{\tau} \emptyset
$$

วริน์บ

（ttI）

$(\varepsilon \not l)$

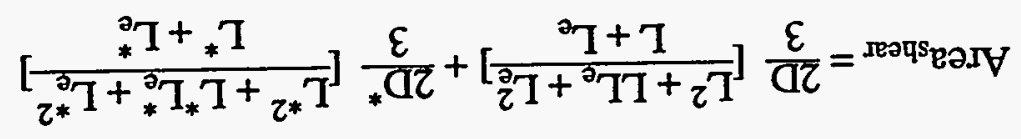

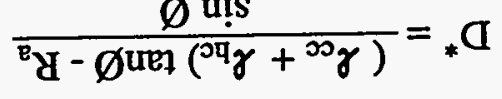

(z力I)

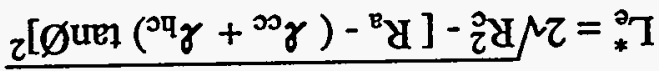

$$
\begin{aligned}
& { }^{\circ} \mathrm{y} z={ }_{*} \mathrm{I} \\
& \frac{\emptyset \text { u!̣s }}{{ }^{8} \mathrm{~d}}=a \\
& { }^{2} \mathrm{y} z={ }^{2} \mathrm{~T}
\end{aligned}
$$

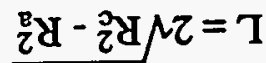

(ItI)

(OtI)

(6عI)

¿

(8EI)

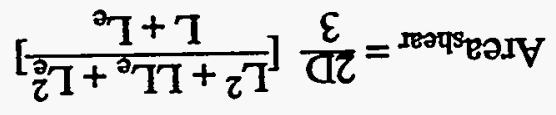




\section{Shear Plane Area -frustum section}

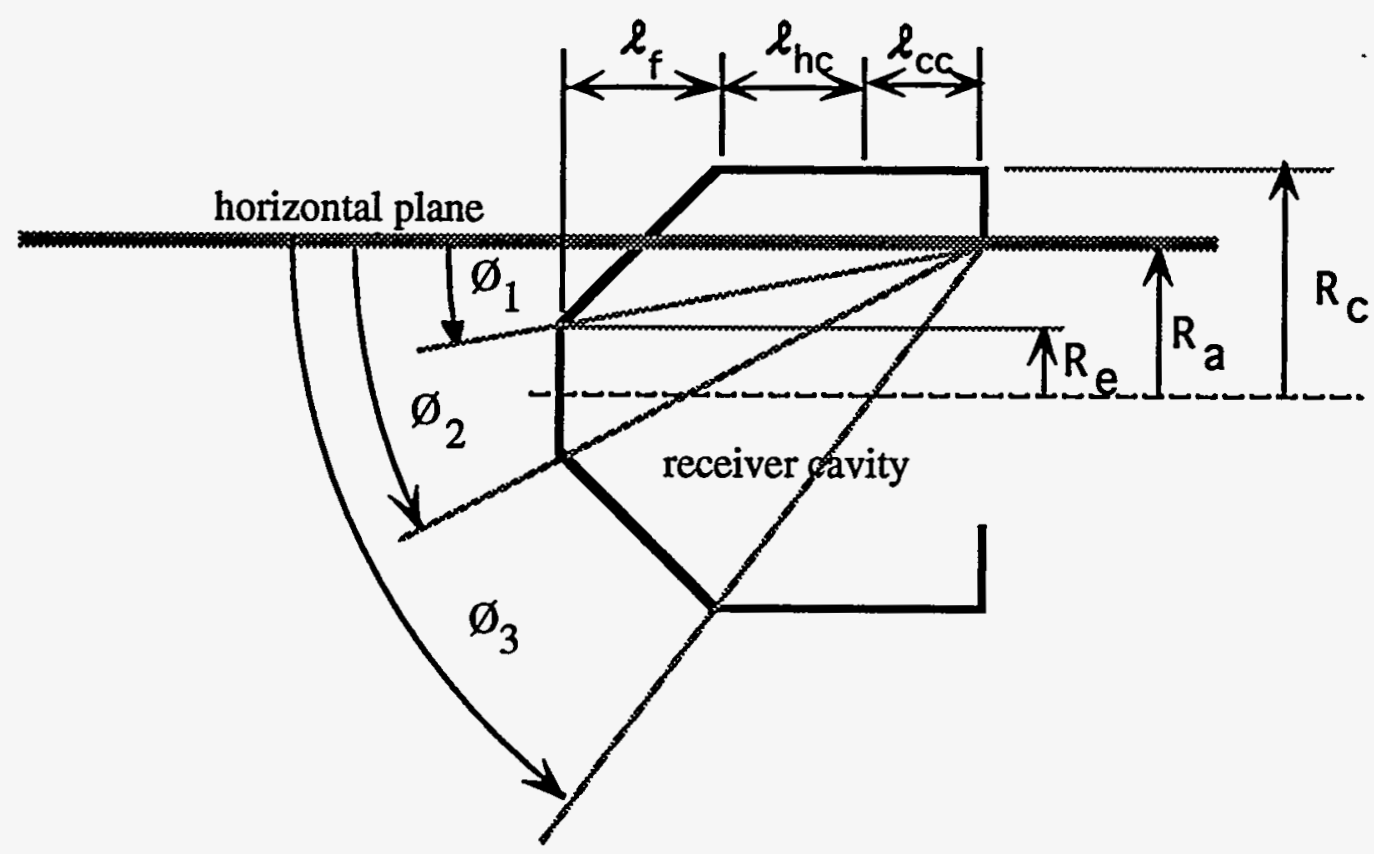

Figure 71. Frustum section shear plane angles.

The angles in figure 71 are defined as follows:

$$
\begin{gathered}
\emptyset_{1}=\tan ^{-1}\left[\frac{R_{\mathrm{a}}-\mathrm{R}_{\mathrm{e}}}{\ell_{\mathrm{cc}}+\ell_{\mathrm{hc}}+\ell_{\mathrm{f}}}\right] \\
\emptyset_{2}=\tan ^{-1}\left[\frac{\mathrm{R}_{\mathrm{a}}+\mathrm{R}_{\mathrm{e}}}{\ell_{\mathrm{cc}}+\ell_{\mathrm{bc}}+\ell_{\mathrm{f}}}\right] \\
\emptyset_{3}=\tan ^{-1}\left[\frac{\mathrm{R}_{\mathrm{a}}+\mathrm{R}_{\mathrm{c}}}{\ell_{\mathrm{cc}}+\ell_{\mathrm{hc}}}\right]
\end{gathered}
$$

Range $\quad 0 \leq \varnothing \leq \emptyset_{1}$

$$
\text { . } \mathrm{L}_{\mathrm{e}}=0
$$

$$
\begin{aligned}
& \mathrm{L}=2 \sqrt{\mathrm{R}_{\mathrm{c}}^{2}-\left[\mathrm{R}_{\mathrm{a}}-\left(\ell_{\mathrm{cc}}+\ell_{\mathrm{hc}}\right) \tan \varnothing\right]^{2}} \\
& \mathrm{D}=\frac{\ell_{\mathrm{f}}\left[\mathrm{R}_{\mathrm{c}}+\left(\ell_{\mathrm{cc}}+\ell_{\mathrm{hc}}\right) \tan \emptyset-\mathrm{R}_{\mathrm{a}}\right]}{\left(\mathrm{R}_{\mathrm{c}}-\mathrm{R}_{\mathrm{c}}\right) \cos \varnothing-\ell_{\mathrm{f}} \sin \emptyset}
\end{aligned}
$$




$$
\text { Area }_{\text {shear }}=\frac{2 D}{3}\left[\frac{L^{2}+L_{L}+L_{e}^{2}}{L+L_{e}}\right]
$$

Range $\emptyset_{1} \leq \emptyset \leq \emptyset_{2}$

$$
\begin{gathered}
L=2 \sqrt{R_{c}^{2}-\left[R_{a}-\left(l_{c c}+l_{h c}\right) \tan \emptyset\right]^{2}} \\
L_{e}=2 \sqrt{R_{e}^{2}-\left[R_{a}-\left(l_{c c}+l_{h c}+\ell_{f}\right) \tan \emptyset\right]^{2}} \\
D=\frac{l_{f}}{\cos \emptyset} \\
\text { Area }{ }_{\text {shear }}=\frac{2 D}{3}\left[\frac{L^{2}+L L_{e}+L_{e}^{2}}{L+L_{e}}\right]
\end{gathered}
$$

Range $\quad \emptyset_{2} \leq \emptyset \leq \emptyset_{3}$

$$
L=2 \sqrt{R_{c}^{2}-\left[R_{a}-\left(\ell_{c c}+\ell_{b c}\right) \tan \emptyset\right]^{2}}
$$

$\mathrm{L}_{\mathrm{e}}=0$

Range

$$
\begin{gathered}
D=\frac{\ell_{f}\left[R_{c}-\left(\ell_{c c}+\ell_{b c}\right) \tan \emptyset+R_{a}\right]}{\left(R_{c}-R_{e}\right) \cos \emptyset+\ell_{f} \sin \emptyset} \\
\text { Area }_{\text {shear }}=\frac{2 D}{3}\left[\frac{L^{2}+L L_{e}+L_{e}^{2}}{L+L_{e}}\right]
\end{gathered}
$$

$$
\emptyset_{3} \leq \emptyset \leq \frac{\pi}{2}
$$

$$
\text { Area }_{\text {shear }}=0
$$

The total shear area in the cavity at any one angle is the sum of the shear areas of the cylindrical section and the frustum section. 
Appendix 8: Clausing's Model Computer Program Listing

REM

REM

REM

REM

REM

REM

REM

REM

5 sections program $w /$ shear plane area

REM

The Clausing method is used here to predict the convective, radiative,

and conductive losses from a cavity solar receiver operating at various

temperatures and receiver angles.

PRINT " Clausing's Method of Predicting Heat Losses"

PRINT

REM

PRINT

REM The program allows some variations in receiver geometry. These

REM variables are inputted in this section of the program.

REM

REM

$\mathrm{Re}=.127$

$\mathrm{Rc}=.33$

$L f=.292$

$\mathrm{Lh}=.254$

$\mathrm{LC}=.14$

REM

REM

$\mathrm{pi}=4^{\star} \mathrm{ATN}(1)$

$\mathrm{g}=9.810001$

$\mathrm{SB}=5.6696 \mathrm{E}-08$

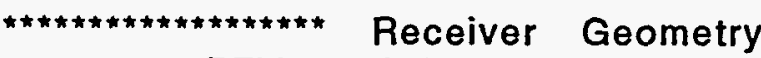

:REM end plate radius [m]

:REM cavity radius [m]

:REM frustum length [m]

:REM cylinder length hot [m]

$\mathrm{Cp}=1006.86$

:REM cylinder length cold [m]

$\mathrm{Pf}=1.19406$

$\mathrm{e}=1$

$k i=.04756$

$t=.0889$

$\mathrm{Ta}=70$

$\mathrm{Ta}=(\mathrm{Ta}+459.67) / 1.8$

REM

Constants

:REM gravitational acceleration [m/sec^^2]

:REM Stefan Boltzmann const. [W/m^2 K^4]

:REM specific heat capacity of air at Ta $[\mathrm{J} / \mathrm{kg} \mathrm{K}]$

:REM density of air at $\mathrm{Ta}\left[\mathrm{kg} / \mathrm{m}^{\wedge} 3\right]$

:REM emittance of cavity

:REM insulation conductance $[\mathrm{W} / \mathrm{m}-\mathrm{K}][.33 \mathrm{~B} / \mathrm{h} / \mathrm{ft} / 2 / \mathrm{in}]$

:REM thickness of insulation [m] [3.5 in]

:REM ambient temperature [F]

:REM ambient temperature [K]

Pflag $=0$

INPUT "Do you want a hard copy ";Q\$

IF LEFT\$(Q\$,1)="y" THEN 50

IF LEFT $\$(Q \$, 1)=" Y^{n}$ THEN 50

Pflag $=1$

50:

REM open clipboard file for transferring data to spread sheet

OPEN "CLIP:" FOR OUTPUT AS \#1

100 :

IF Pflag=1 THEN 55

REM Print Constants

REM

CS

LPRINT "End Plate Radius [m] = ";Re

LPRINT "Cavity Radius [m] = ";Rc

LPRINT "Frustum Length $[\mathrm{m}]=$ "; Lf

LPRINT "Hot Cylindrical Section Length $[\mathrm{m}]=$ "; Lh

LPRINT "Cold Cylindrical Section Length $[\mathrm{m}]=$ ";LC 


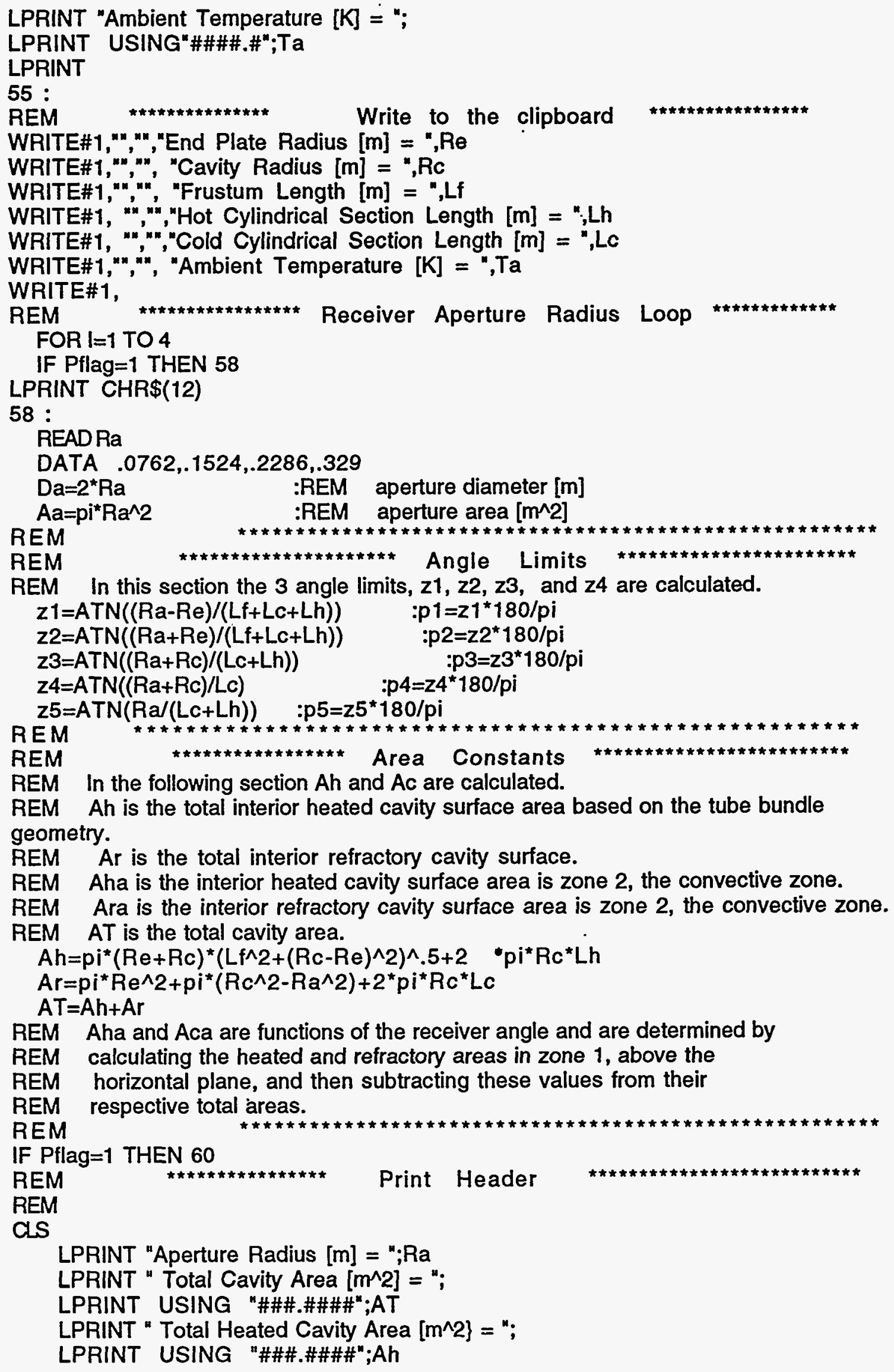




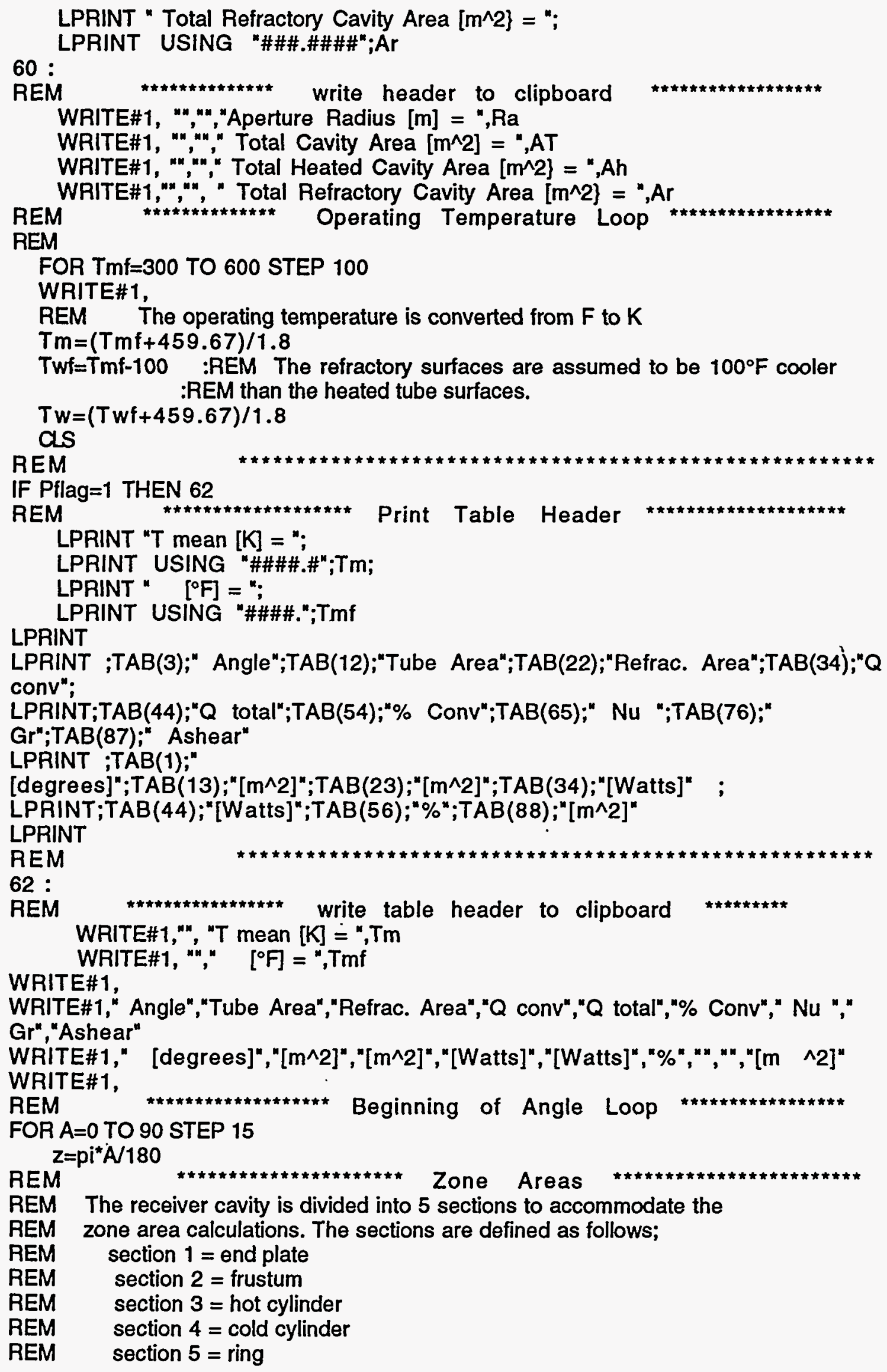




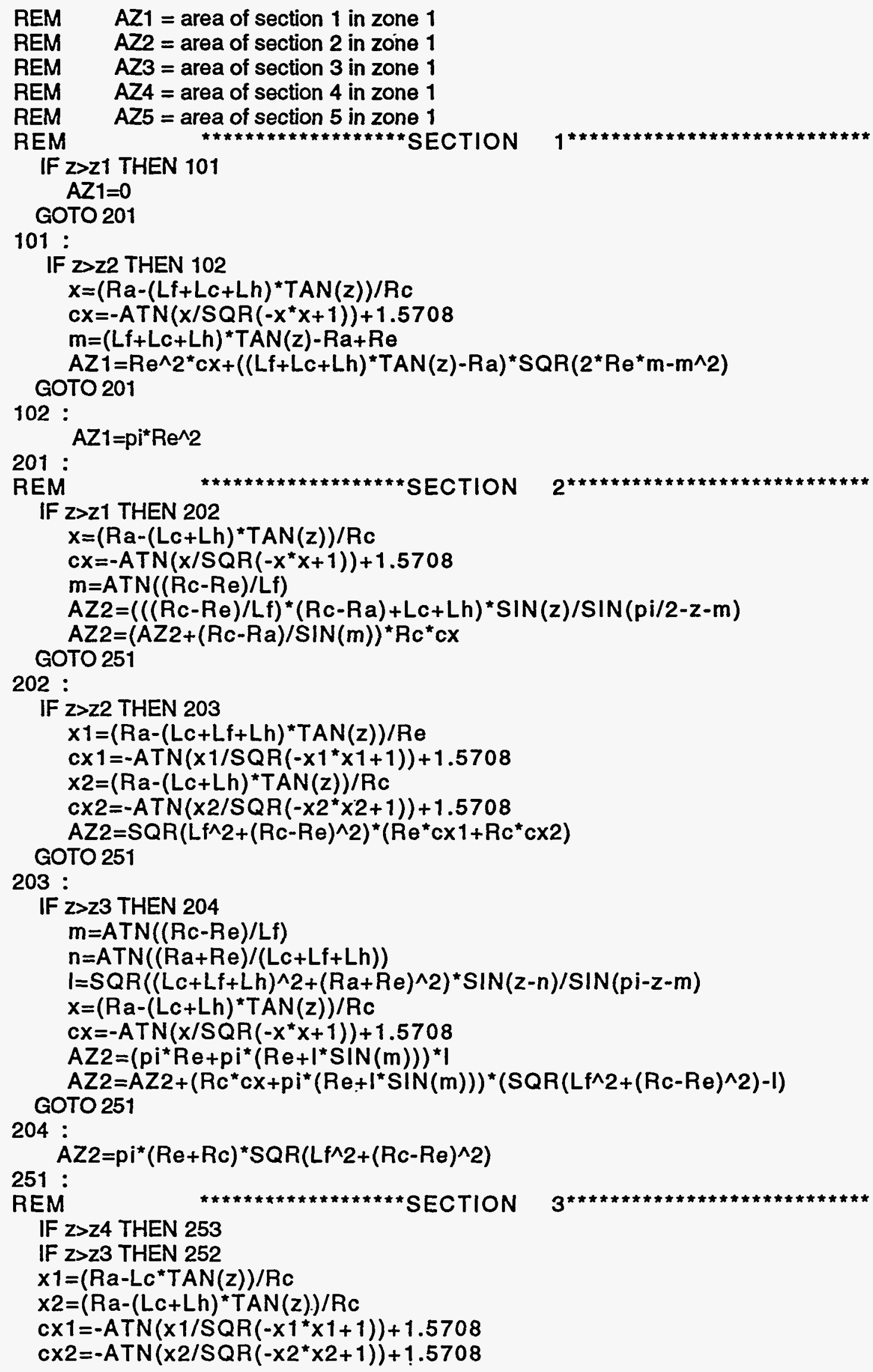




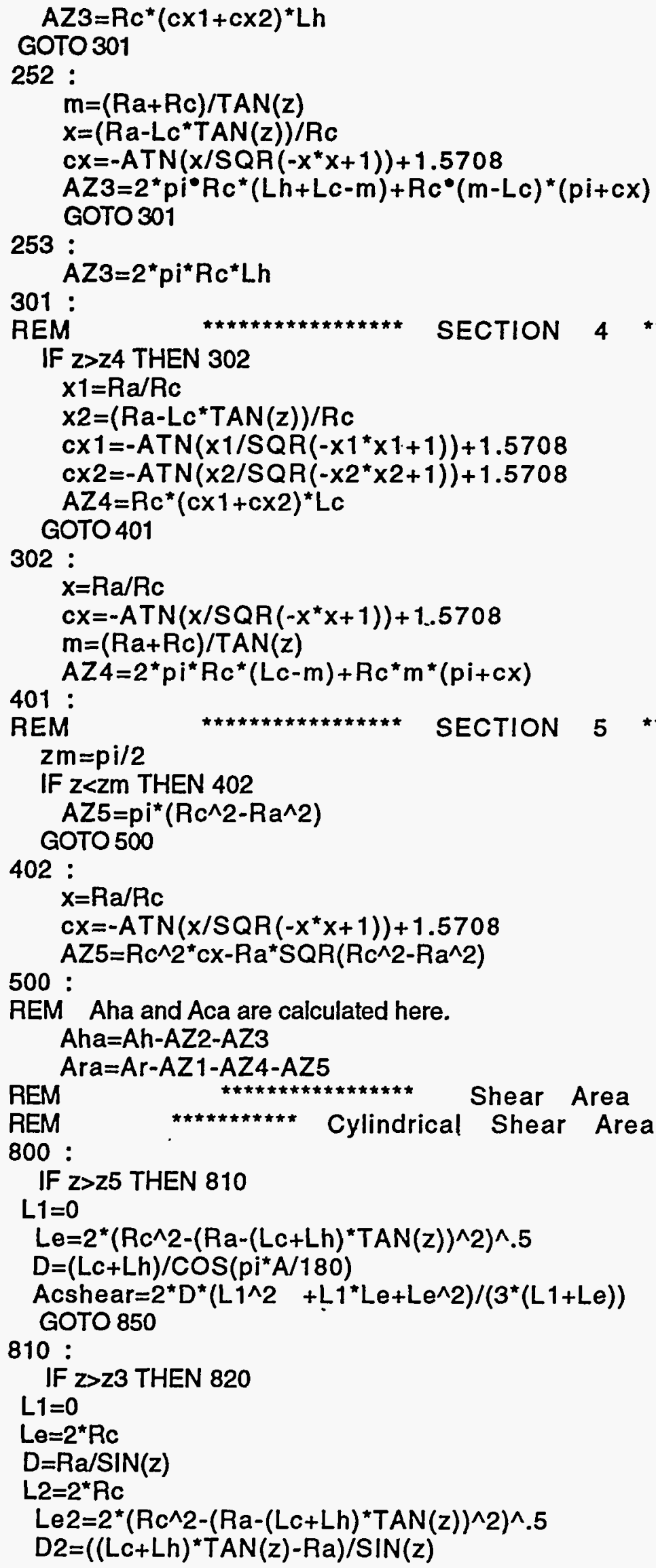




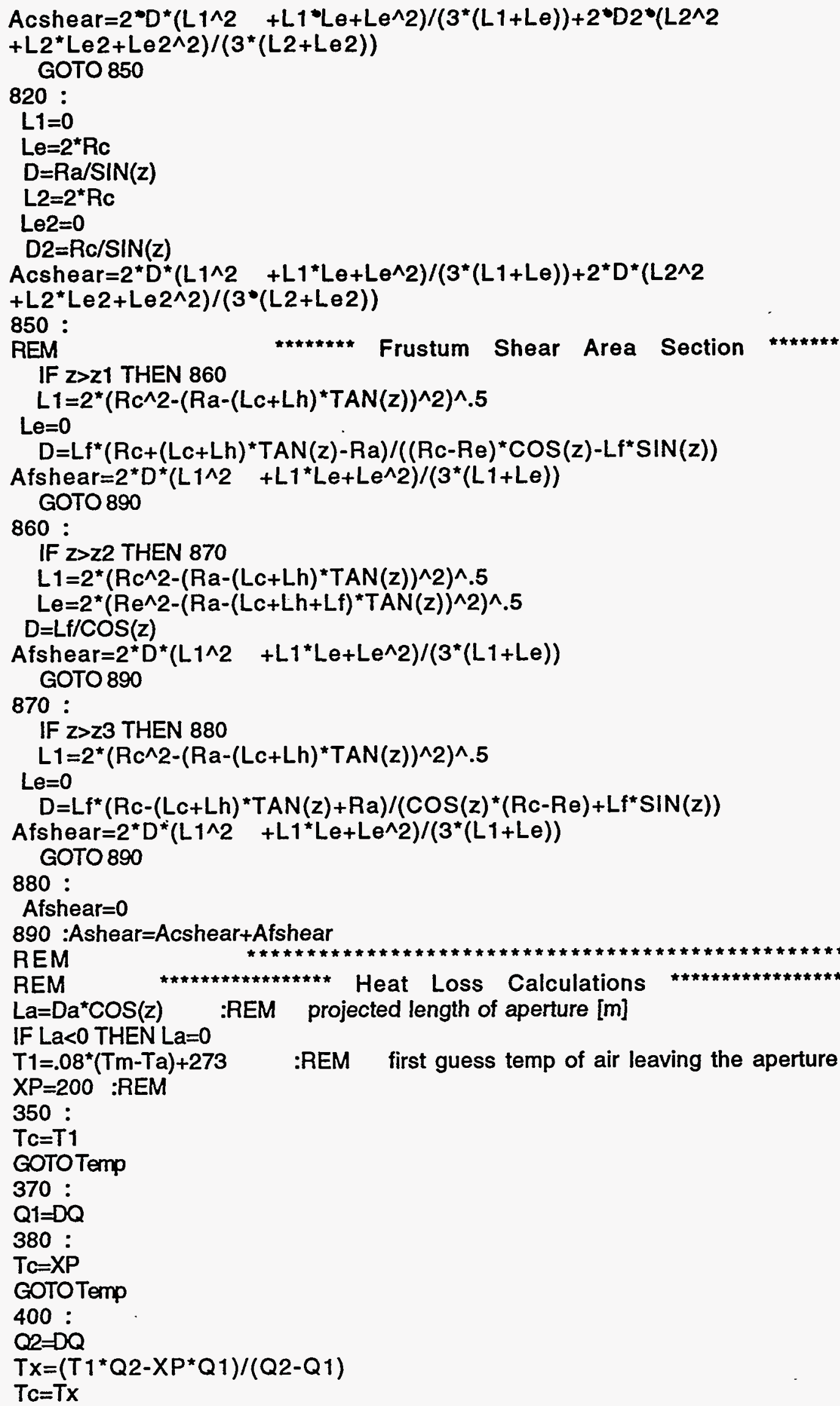


Temp:

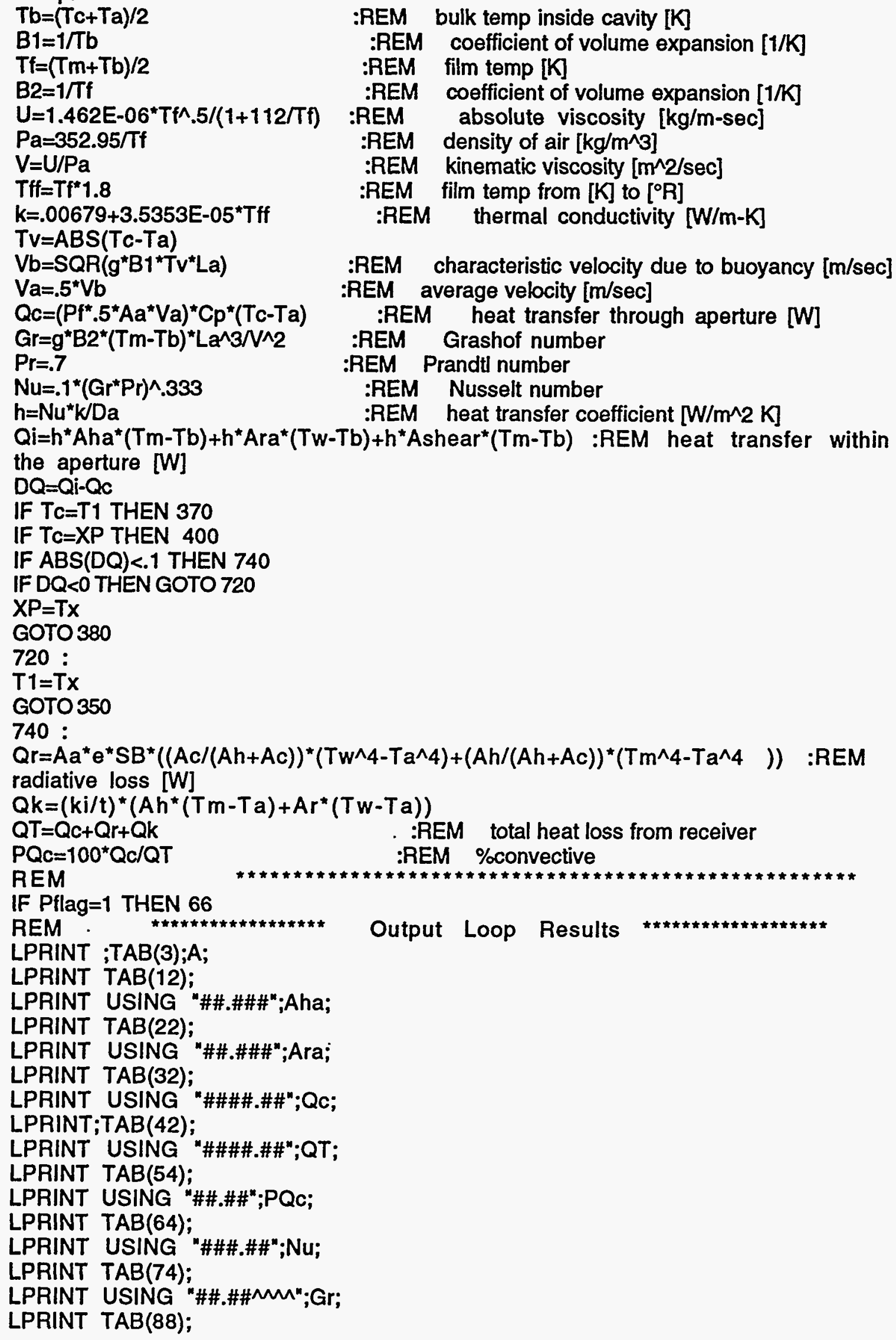


LPRINT USING "\#\#.\#\#";Ashear

66 :

REM Write to clipboard

WRITE\#1,A,Aha,Ara,Qc,QT,PQc,Nu,Gr,Ashear

REM

REM

NEXT A

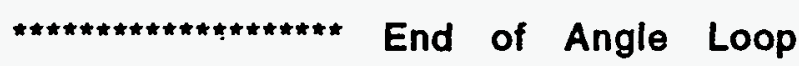

REM

IF Pflag=1 THEN 68

REM

$\star \star \star \star \star \star \star \star \star \star \star \star * * * \pi$

LPRINT"Radiation (Watts) = ";Qr

LPRINT"Conduction (Watts) = ";Qk

68:

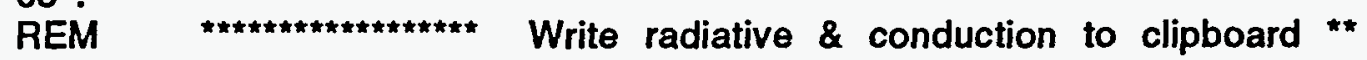

WRITE\#1," ",","Radiation (Watts) = "Qr

WRITE\#1," "," "Conduction (Watts) = ",Qk

REM

REM

NEXT Tmf

REM

REM

NEXT I

REM

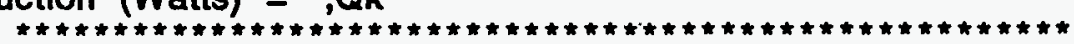

CLOSE\#1

END 
Appendix 9: Clausing Model Heat Loss Data

\begin{tabular}{|c|c|c|c|c|c|c|c|c|}
\hline \multicolumn{9}{|c|}{ ppendix 9 Claussag Mode Heat Loss Daq } \\
\hline & & \multicolumn{3}{|c|}{ EndPIn Radim $[\mathrm{m}=$} & tor.2\% & & & \\
\hline & & \multirow{2}{*}{\multicolumn{3}{|c|}{$\begin{array}{l}\text { Cavity Rodiue }[\mathrm{m}]= \\
\text { FutumLenth }[\mathrm{m}]=\end{array}$}} & 0330 & & & \\
\hline & & & & & 0292 & & & \\
\hline & \multicolumn{4}{|c|}{ Hot Cylindricalsection $L \mathrm{en}$ gth $[\mathrm{m}]=$} & 0254 & & & \\
\hline & \multicolumn{4}{|c|}{ Codd Cylindrical Section Length (m) = } & 0.140 & & & \\
\hline & & \multicolumn{3}{|c|}{ Ambien Temperature $[\mathrm{K}]=$} & 294.251 & & & \\
\hline & & & & & & & & \\
\hline & & \multicolumn{3}{|c|}{ Aperture Radius $[3]=$} & 10076 & & & \\
\hline & & \multicolumn{3}{|c|}{ Toul Cavity Area[m 2$]=$} & 11.702 & & & \\
\hline & \multirow{2}{*}{\multicolumn{4}{|c|}{$\begin{array}{l}\text { Toul Heated Guvit Area }\left[\mathrm{m}^{2} 2\right]= \\
\text { in Refractory Ovity Area }[\mathrm{m} 2]=\end{array}$}} & 1.037 & & & \\
\hline & & & & & 0665 & & & \\
\hline & (1) & & & & & & & \\
\hline Tin & $\operatorname{mean}[R]=$ & 220 & & & & & & \\
\hline & {$[\mathbf{F}]=$} & 30000 & & & & & & \\
\hline Angle & Nibèxiea & 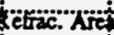 & Q⿻ón & Qtö̀ar. & 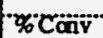 & $\mathrm{Nü}$ & Gri & Asliear \\
\hline [de gecis] & 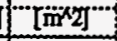 & {$\left[\ddot{u}^{x} 2\right]$} & IWatia'" & [Waft] ] & \%" & & & {$[\operatorname{lin} x 2]^{-}$} \\
\hline & & & & & & & & \\
\hline 15 & 0.614 & 0.406 & 355 & 467.1 & 74.0 & 205 & $126+07$ & 030 \\
\hline 15 & 0 & 037 & 313 & 434.2 & 720 & 202 & $1198+07$ & 034 \\
\hline 30 & 0284 & 0358 & 2441 & 365.7 & 667 & 187 & $948 \mathrm{E}+06$ & 032 \\
\hline 45 & 0 & $0350^{\circ}$ & 164.7 & 285.4 & $57.5^{\circ}$ & 15.9 & $\$ 534 \mathrm{E}+06$ & 026 \\
\hline${ }^{6} 60^{\circ}$ & 0.033 & 0334 & 69.4 & "ryl:1" & 36.3 & 120 & $231 \mathrm{~T}+06$ & OD8 \\
\hline 75 & 00000 & 0267 & 29.5 & 131.2 & 19.5 & 67 & $3282 E+15$ & oxt \\
\hline 90 & 0000 & 00000 & 00 & 121:6 & $0 \%$ & 60 & $000 \mathrm{E}+00$ & \%07 \\
\hline & Räàätiònín & (Watis $)=$ & $25 . I^{*}$ & & & & & \\
\hline & Conduction & $($ Walt $)=$ & 96.6 & & & & & \\
\hline & & & & & & & & \\
\hline$T$ & $\operatorname{mean}[\mathrm{X}]=$ & 476 & & & & & & \\
\hline & PF]= & 4000 & & & & & & \\
\hline Angle & ITUbe Are & Efrec-Are & $0 \operatorname{conv}$ & Qtoal & $\%$ Canv & $\mathrm{Nu}$ & Gr & Astear \\
\hline [degses] & {$\left[m^{2}\right]$} & {$[\mathrm{m} 2]$} & IWatts & IHatts] & g & & & {$\left[\mathrm{m}^{2}\right]$} \\
\hline 6 & 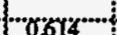 & $6 \neq 0$ & $57 \%$ & 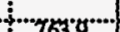 & yor" & & Towingel & \\
\hline 15 & 0.465 & $03 \pi$ & 516.1 & 709.9 & 728 & 108 & iIJ3E+0 & $\frac{030}{034}$ \\
\hline $30^{\circ}$ & 0.284 & 0358 & 4085 & 399.8 & 6T.8 & 184 & $907 E+05$ & 632 \\
\hline 45 & 0.139 & 0330 & 2786 & 471.8 & 59.0 & 15.7 & $\$ 563 \mathrm{E}+06$ & 026 \\
\hline 60 & 0.033 & 0334 & 1246 & 317.8 & 39.2 & 11.9 & $2 A 5 E+06$ & 0.08 \\
\hline 75 & 0000 & 0267 & 334 & 2466 & 21.6 & $6 A$ & $3.78 \mathrm{E}+05$ & 007 \\
\hline 90 & 0000 & 0000 & 0.0 & 193.2 & 00 & 00 & $0000+00$ & 007 \\
\hline & Radiation & (Watts) $=$ & 46.1 & & & & & \\
\hline & Conduction & $($ watts $)=$ & 1472 & & & & & \\
\hline & & & & & & & & \\
\hline$T m$ & $\operatorname{ean}[K]=3$ & 5332 & & & & & & \\
\hline & $([\mathrm{F}]=$ & $50000^{\circ}$ & & & & & & \\
\hline & & & & & & & & \\
\hline Angle & Inube Areas & efface. Arei & $Q \operatorname{con} v$ & $Q_{\text {tolal }}$ & $\%$ Canv & $\mathrm{Nu}$ & $\mathrm{Gr}$ & Ashear \\
\hline deferess] & . & {$\left[m^{2}\right]$} & W. Warts. & Wats]. & . & & & {$[m \mid$} \\
\hline 0 & 0.614 & $0 A 06$ & 8089 & $1082 A$ & 74.7 & 19.5 & $10 \pi \bar{k}+07$ & \\
\hline 15 & $0 A 65$ & 037 & $732 A$ & 10060 & 728 & 19.2 & $102 \mathrm{E}+07$ & 034 \\
\hline 30 & 0284 & 0358 & 5780 & 851.6 & 67.9 & 17.8 & $6+06$ & 032 \\
\hline 45 & & 0350 & 398 & 6723 & 59.3 & 15.3 & $515 \mathrm{DE}+06$ & 026 \\
\hline 60 & 0033 & 0334 & 1829 & 456 & 401 & 11.6 & $2266+06$ & 008 \\
\hline 75 & 00000 & 0267 & 78.4 & 3320 & 223 & 62 & $353 \mathrm{E}+05$ & 007 \\
\hline 90 & 0000 & 0000 & 00 & 273.6 & 00 & 00 & $000 E+\infty$ & D.DT \\
\hline & Radation & $\left(W_{a t t s}\right)=$ & 75.8 & & & & & \\
\hline & Conaution & (Watts)= & 1978 & & & & & \\
\hline & & & & & & & & \\
\hline$T m$ & $\tan [\mathrm{K}]=\mathrm{i}$ & 588.7 & & & & & & \\
\hline & {$[0 \mathrm{~F}]=$} & 6000 & & & & & & \\
\hline Angle & Tube Areas & & & & Q Conv: & & & Astear \\
\hline [degees] & {$\left[m^{2} 2\right]$} & efres. Ara & $\begin{array}{l}Q \text { cong } \\
\text { [Watts] }\end{array}$ & [Wates & : & No & Gr & Ashear \\
\hline & & & & & & & & \\
\hline 0 & 6614 & 0705 & "ro55.r" & 1arg9" & 74.3 & $18 \%$ & $9 A 5 E+06^{\circ}$ & 030 \\
\hline 15 & $0 A 65$ & $03 \pi$ & 9533 & 13201 & 724 & 184 & $905 \mathrm{E}+06$ & 034 \\
\hline 30 & 0.284 & 0358 & 7550 & 11198 & 67.4 & 17.2 & $734 \mathrm{E}+06$ & 032 \\
\hline 45 & 0139 & 0350 & 326 & 887.5 & 589 & 14.7 & $451 E+06$ & 026 \\
\hline 60 & 0.033 & 0334 & 2430 & 607.9 & 400 & 11.2 & $204 \mathrm{E}+06$ & 008 \\
\hline 75 & 0.000 & 026 & 1042 & 469.1 & 222 & 61 & $321 E+05$ & 0,07 \\
\hline 90 & 0000 & 0000 & 00 & 364.8 & 00 & 00 & $000 E+00$ & 007 \\
\hline & Radiati & (Watts) $=$ & 1165 & & & & & \\
\hline & Cand & & & & & & & \\
\hline
\end{tabular}




\section{Appendix 9 Clausing Model Heat Loss Data}

\begin{tabular}{|c|c|c|c|c|c|c|c|c|}
\hline & \multicolumn{4}{|c|}{ Aperure Radius $[\mathrm{m}]=: 0.132$} & & & & \\
\hline & Totai & Caviy Area & {$\left[m{ }^{2} \mathrm{z}\right]=$} & :1647 & & & & \\
\hline & Total Ḧ Heat & Oavity Are & {$[m-2]=$} & 1037 & & & & \\
\hline Tot & I Refractay & Cavity Area & $2\left[\mathrm{~m}^{2}\right)=$ & 0610 & & & & \\
\hline & & & & & & & & \\
\hline Tn & $\operatorname{men}[\bar{X}]=$ & 220 & & & & & & \\
\hline & {$[\mathrm{F}]=$} & 300.0 & & & & & & \\
\hline & & & & & & & & \\
\hline Ange & Mube Areas & Ketrac.Arat & Qcant & Qtar & \%Canv & $\mathrm{Na}$ & $G$ & Xaliear \\
\hline [degraes] & 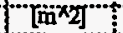 & {$[\mathrm{m} \times 2]$} & [watrib] & [Wrattis] & "\%" & & & {$[\mathrm{m} \times 2]$} \\
\hline & & & & & & & & \\
\hline 0 & 0.742 & 0735 & 605.0 & 799.7 & 75.7 & 77.7 & $1586+08$ & 025 \\
\hline 15 & 0356 & 0398" & 335.8 & 7305 & 73.3 & 464 & $11758+08$ & 032 \\
\hline 30 & 0320 & 0372 & 4084 & 603.1 & 67.7 & 422 & $1098+08$ & 033 \\
\hline 45 & 0213 & 0364 & 277.0 & 471.7 & 587 & 35.0 & $6238+07$ & 031 \\
\hline 60 & 0059 & 0350 & 118.2 & 3129 & 37.8 & 25.4 & $2386+07$ & 0.15 \\
\hline 75 & " & 028 & $46 \%$ & 241.1 & 19.2 & 13.3 & $373 E+C 6$ & 014 \\
\hline 90 & 0000 & ర000 & ov & Tar.T & 00 & 00 & $0006+00$ & 0.13 \\
\hline & Radiuriä́l' & $($ Wais $)=$ & $100.2^{-1}$ & & & & & \\
\hline & Cañöutiä & (Waitis) $=$ & 94.5 & & & & & \\
\hline & & & & & & & & \\
\hline Ti & tean $[1]=$ & $7 \pi .6$ & & & & & & \\
\hline & {$[\mathrm{F}]=$} & $x+0.0$ & & & & & & \\
\hline & & & & & & & & \\
\hline Angie & TuBe Arts & efrac Are & Q conv & ôtotal & $\%$ Canv & $\mathrm{Nu}$ & $G$ & Ashear \\
\hline [degrees] & {$[m \times 2]$} & {$[m \times 2]$} & [Wets] & [Wate] & 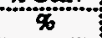 & & & {$[m \times 2]$} \\
\hline & & & & & & & & \\
\hline$\sigma$ & $0.742^{\circ}$ & 0735 & 984.4 & 131200 & $75.0^{\circ}$ & 47.6 & $1578+08^{\circ}$ & 025 \\
\hline 13 & 0356 & roysy & 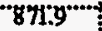 & 11956 & 727 & 462 & IASE+X8 & 032 \\
\hline 30 & 0370 & 0372 & 667.8 & 955.5 & 67.1 & 722 & $1098+108$ & 033 \\
\hline 45 & 0213 & 0364 & 457.6 & 7853 & 38.3 & $350^{\circ}$ & $6264+41$ & 031 \\
\hline $.60^{\circ}$ & 6059" & 6350 & 2013.2 & $53088^{\circ}$ & 383 & $25.5^{\circ}$ & $2 A 0 B+0 T$ & $015^{\circ}$ \\
\hline 75 & 0000 & 0282 & 80.5 & 7082 & 19.7 & 13.4 & $3508+06$ & 0.14 \\
\hline $90^{\circ}$ & 00000 & 0000 & 00 & 327.7 & ชัก๊ & 00 & 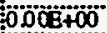 & 0013 \\
\hline & Radiation & $(\hat{W} a+t)=$ & 184.2 & & & & & \\
\hline & Conduction & (Watts) $=$ & 143,4 & & & & & \\
\hline & & & & & & & & \\
\hline$T$ & $\operatorname{mean}[\overline{\mathrm{K}}]=$ & 533.2 & & & & & & \\
\hline & {$\left[{ }^{\circ} \mathrm{F}\right]=$} & 300.0 & & & & & & \\
\hline & & & & & & & & \\
\hline Angige" & hube $A$ rea & 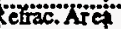 & $Q$ cotion & "Qtääal" & $" \%$ Cärv" & Nit" & Gr & “xishëär \\
\hline [degrees] & {$\left[\bar{m}^{x} 2\right]$} & {$\left[\mathrm{m}^{x}\right]$} & [Wats] & [Wats] & $\%$ & & & {$\left[\bar{m}^{2}\right]$} \\
\hline \% & 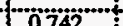 & "م35\% & 13\% & 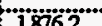 & 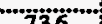 & 186 & 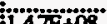 & 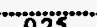 \\
\hline 15 & 0566 & 0399 & 1202.7 & $\frac{10104}{17183}$ & 71.2 & $\frac{400}{45.4}$ & $1136+08$ & $\frac{423}{032}$ \\
\hline 30 & 0370 & 037 & 938.5 & 14341 & 65.4 & 41.3 & $1038+08$ & 033 \\
\hline 45 & 0213 & 0364 & 645.9 & 11416 & 566 & 34.4 & $589 \mathrm{~s}+07$ & 031 \\
\hline 60 & 0059 & 0350 & 2921 & 787.7 & 37.1 & 25.0 & $227 \mathrm{E}+07$ & 0.15 \\
\hline 75 & $0000 \%$ & 6282 & 1162 & 611.8 & Y9.0 & 13.2 & $3328+26$ & $0 Y 4^{\ldots \ldots .}$ \\
\hline $90^{\circ-0}$ & 00000 & 0000 & 00 & 4956 & $60^{\circ}$ & $0 \%$ & toDOE+00 & 013 \\
\hline & Radiation & (Wars $)=$ & 303.2 & & & & & \\
\hline & Cänütiañ & $($ Watts) $=$ & 1924 & & & & & \\
\hline & & & & & & & & \\
\hline Tn & $\operatorname{mean}[\mathrm{K}]=$ & 58.7 & & & & & & \\
\hline & {$[p]=$} & 6000 & & & & & & \\
\hline & & & & & & & & \\
\hline Angle & Tube AlcaR & efrac.Arei & $Q \operatorname{conv}$ & $\bar{Q}$ lotal & GCany & Nu & $\overline{G t}$ & Ashear \\
\hline [degrees] & {$\left[\mathrm{m}^{\mathrm{N}} \mathrm{z}\right]$} & {$\left[m{ }^{*}\right]$} & [Wits] & [Wats] & \% & & & {$\left[\mathrm{m}_{2}\right]$} \\
\hline & & & & & & & & \\
\hline 0 & 0.742 & $0 A 33$ & 1786.1 & 24933 & 71.6 & $25 \pi$ & $1348+08$ & 025 \\
\hline 15 & 0326 & 0399 & $138 \mathrm{r}^{\circ} \mathrm{S}^{\circ-1}$ & 225888 & ६\%:1..... & $44.0^{\circ}$ & I24E+08 & "0332" \\
\hline 30 & $037 \%$ & $0372 \cdots$ & Y215.1. & 19227 & 63.2 & $\times 01^{-1}$ & $938 E+077^{\circ}$ & 033 \\
\hline 45 & 0213 & 0364 & 838.3 & 13455 & 34.2 & 33.3 & $5398+07$ & 031 \\
\hline 60 & 0059 & 0350 & 389 & 10901 & 35.1 & 24.3 & $2085+07$ & 0.15 \\
\hline 75 & 0000 & 0282 & 1525 & 859.8 & 17.7 & 128 & $305 E+06$ & 0.14 \\
\hline 90 & 0000 & 0000 & 00 & 707.2 & 00 & 00 & $000 \mathrm{E}+\infty 0$ & 0.13 \\
\hline & Radiation & (wats) $=4$ & 765.9 & & & & & \\
\hline & Canduction & (Watts) $=2$ & 241.4 & & & & & \\
\hline
\end{tabular}




\section{Appendix 9 Clausing Model Heat Loss Data}

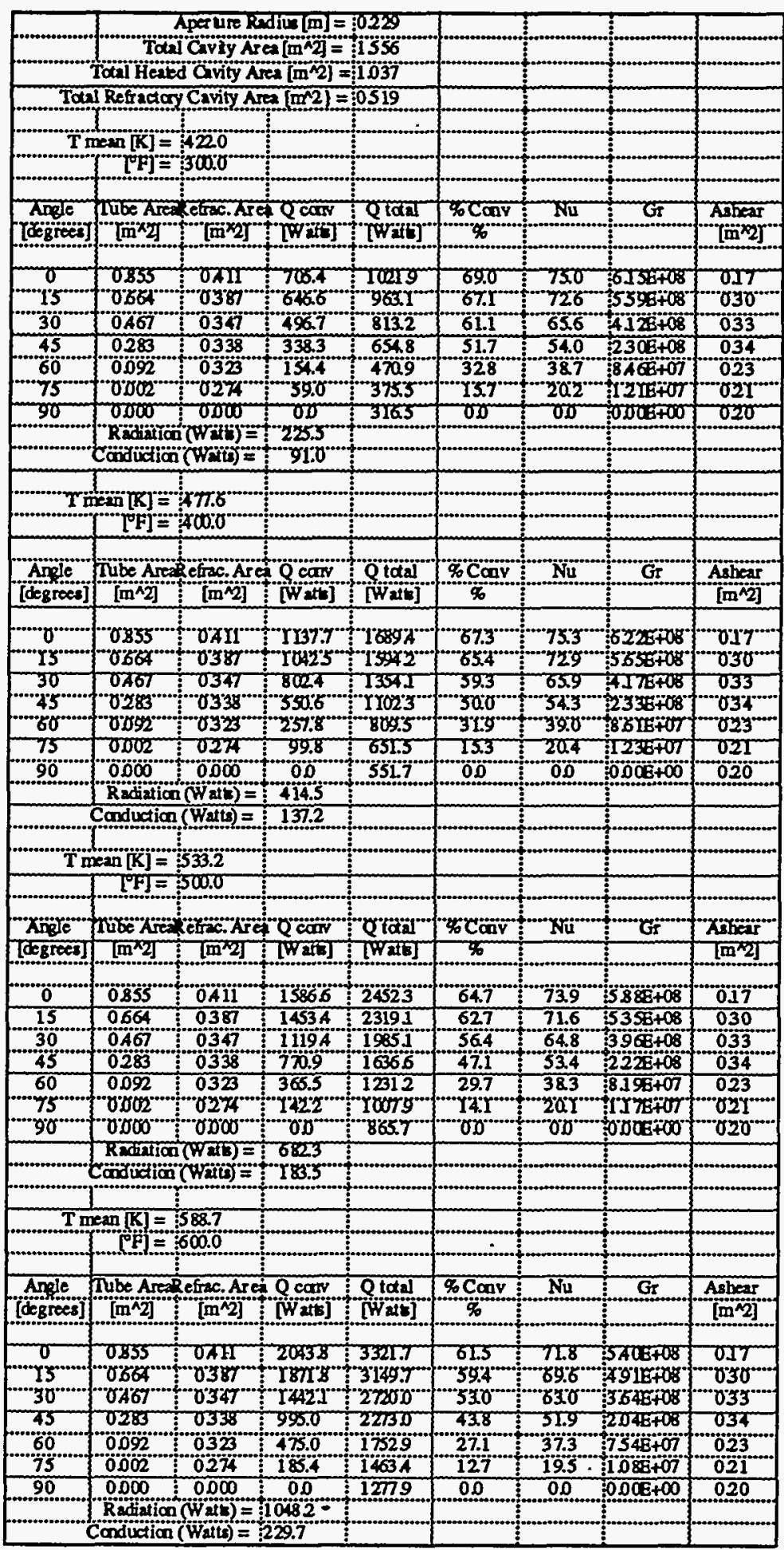




\section{Appendix 9 Clausing Model Heat Loss Data}

\begin{tabular}{|c|c|c|c|c|c|c|c|c|}
\hline & \multicolumn{4}{|c|}{ Aperure Radiu $[\mathrm{m}]=: 0320$} & & & 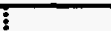 & \\
\hline & \multicolumn{4}{|c|}{ Total Caviy Area $\left[\mathrm{m}^{\wedge} 2\right]=1380$} & & & & \\
\hline & \multicolumn{4}{|c|}{ Iotal Heated Cavity Aren $[\mathrm{m} \times 2]=\mathrm{i}_{1037}$} & & & & \\
\hline \multicolumn{5}{|c|}{ Total Refractoy Cavity Ara $\left(\mathrm{m}^{2} 2\right)=0343$} & & & & \\
\hline & & & & & & & & \\
\hline & 20 & & & & & & \\
\hline \multicolumn{2}{|c|}{ (F) } & $300: 0^{\circ}$ & & & & & & \\
\hline & & & & & & & & \\
\hline Ariplè & Tribexara: & \multirow{2}{*}{ 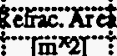 } & \multirow{2}{*}{$Q \operatorname{con}$} & Qtătă" & \multirow{2}{*}{ "\%Canv" } & \multirow[t]{2}{*}{ Nî́ } & Ft & 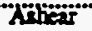 \\
\hline 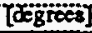 & 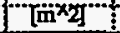 & & & [Warte] & & & & {$[\bar{m} \times 2]$} \\
\hline & 'rare & & & & & & & \\
\hline 0 & 1024 & 0336 & 740.0 & 12912 & 37.3 & 110.7 & $1988+09$ & 601 \\
\hline 15 & 0883 & 0311 & 723.7" & Y20505 & $37 . x^{\cdots \cdots \cdots}$ & $100 \%$ & $1.788+29$ & 022 \\
\hline 30 & 0.628 & 0270 & 592.6 & 11438 & 51.8 & 962 & $130 \mathrm{~B}+09$ & 034 \\
\hline 45 & 0384 & 0244 & 385.3 & 9366 & 41.1 & 79.0 & $1196+08$ & 036 \\
\hline 60 & 0.146 & 0228 & 191.5 & 7427 & 258 & 563 & $26 \alpha \hat{s}+08$ & 033 \\
\hline 75 & 0011 & 0.181 & 69.0 & 6202 & TI & 29.3 & $367 \mathrm{E}+0 \mathrm{~T}$ & 030 \\
\hline $90^{* \prime}$ & 000000 & 00000 & $6 \%$ & S51.3. & 0 & 60 & 0000 & $029^{\circ}$ \\
\hline & Radiatión & $($ Watt $)=$ & $767 . Y^{\prime}$ & & & & & \\
\hline & Conduation & (watts $)=$ & 87.2 & & & & & \\
\hline & & & & & & & & \\
\hline$T_{i}$ & 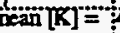 & 7.6 & & & & & & \\
\hline & $T F]=$ & 100.0 & & & & & & \\
\hline & & & & & & & & \\
\hline Angle & THBe Ara & efrac. Area & $Q \mathrm{cosv}$ & Qtatai & ocanv & $\mathrm{Nui}$ & Gr & Ainear \\
\hline [degrees] & {$\left[\mathrm{m}^{\wedge} 2\right]$} & {$\left[\mathrm{m}^{\mathrm{N}} \mathrm{2}\right]$} & [Watte] & [Watt] & $\%$ & & & {$\left[\mathrm{~m}^{\mathrm{N} 2}\right]$} \\
\hline$\sigma$ & Frax" & $0,3 \times 5$ & Tror"3. & 27650 & $5 \times 6$ & IrIO; & $2025+0 \%$ & Dor \\
\hline 13 & OB83 & o3I7 & $T 183$ & 21672 & 34.6 & 107.6 & $1828+09$ & 022 \\
\hline $30^{\circ}$ & 0.528 & $02 \times 0^{\circ}$ & 9:41.6. & Yygs3 & $489^{\circ}$ & 968 & $11328+109$ & 034 \\
\hline $45^{\circ}$ & 0384 & 0224 & 614.8 & I $3983^{\circ}$ & 38.5 & $79.6^{\circ}$ & $173386+08$ & 036 \\
\hline 60 & 0146 & 0228 & 309.0 & $T 222 . T$ & 23.9 & 35.7 & $2566 E+08$ & 033 \\
\hline $75^{\circ}$ & oDYr & $0187^{\circ}$ & rYz3" & 10565 & raz" & $29.6^{\circ}$ & $3.766+07^{\circ}$ & 030 \\
\hline 90 & "0ొ000" & 0ூ0̈0̈ & ö & 9837 & 00 & 00 & $000 \bar{B}+00$ & 029 \\
\hline & Radiation & (Watts) $=$ & 858.5 & & & & & \\
\hline & Canduction & $($ Watts $)=$ & 135.2 & & & & & \\
\hline & & & & & & & & \\
\hline T I & nean $[\mathrm{K}]=$ & 533.2 & & & & & & \\
\hline & {$[P]=$} & $500.0^{\circ}$ & & & & & & \\
\hline & & & & & & & & \\
\hline Xnge & Trab Atel: & frime.tre & Qcaiv & Qtan & $\%$ Canv & $\mathrm{Nu}$ & Gr & Thear \\
\hline [agrecs] & {$\left[\mathrm{m}^{*} \times 2\right]$} & {$[\mathrm{m} \times 2]$} & [wains] & [Wafte & $\%$ & & 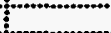 & {$\left[\mathrm{iin}_{2}\right]^{-}$} \\
\hline & & & & & & & & \\
\hline 0 & 1024 & 0336 & 1677 & 3217.1 & 509 & 109.6 & $1928+09$ & 0.01 \\
\hline 15 & 083 & 0317 & 1630 & $3217 A$ & 509 & 100.8 & $1733+09$ & 022 \\
\hline 30 & 0628 & 0270 & 13021 & $2881 A$ & 452 & 953 & $1268+09$ & 034 \\
\hline 45 & 0384 & 024 & 851.7 & 24311 & 35.0 & 78.3 & $7005+08$ & 036 \\
\hline 60 & 0.146 & 0228 & 430.5 & 20099 & 21.4 & 558 & $2538+08$ & 033 \\
\hline 75 & odm & 0181 & 157.0 & T736A & 90 & 29.1 & $\$ 3598+01$ & 030 \\
\hline 90 & 0000 & 0700 & 00 & $1579 A^{\circ}$ & 00 & $00^{\circ}$ & $000 E+W$ & $029^{\circ}$ \\
\hline & Radiation & $(W a t t)=$ & $14132^{\circ}$ & & & & & \\
\hline & Canduan & $(W a 15)=$ & 165.2 & & & & & \\
\hline & & & & & & & & \\
\hline$T$ & $\operatorname{man} \mid \mathrm{K}]=$ & 5887 & & & & & & \\
\hline & {$[\mathrm{F}]=$} & 600.0 & & & & & & \\
\hline & & & & & & & & \\
\hline Angle & Tüe Aтеa & efrac. Are & $Q \mathrm{conv}$ & Q̈talal & $\% \mathrm{Canv}$ & Nü & $\mathrm{G}$ & Ashear \\
\hline [degrees] & {$\left[m^{\wedge} 2\right]$} & {$\left[\mathrm{m}^{\mathrm{n}} \mathbf{2 ]}\right.$} & [Watte] & [Watt] & $\%$ & & 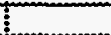 & {$\left[m^{1} 2\right]$} \\
\hline$\sigma^{*}$ & Trana" & $0335^{\circ}$ & zYor:- & 27795 & $469^{\circ}$ & rob.6 & IT778+09 & ozr \\
\hline T3 & 08883 & 0317 & 20997 & 74718 & 769 & Tos.0 & $1398+09$ & 022 \\
\hline $30^{\circ}$ & 0528 & $62 \times$ & 18679" & 40763 & $41: 2$ & 927 & Iryestog & 034 \\
\hline 45 & 0384 & $0244^{\circ}$ & $\operatorname{Tos} 2 I^{\circ}$ & $34 \pi A^{-\cdots}$ & $31: 5$ & 762 & $66468+00^{\circ}$ & 036 \\
\hline 60 & 0.146 & 0228 & 553.7 & 2932.1 & 18.9 & 54.4 & $2346+08$ & 033 \\
\hline 75 & öôi & 0.187 & 2025 & 25809 & 78 & 284 & 331 & 030 \\
\hline 90 & 0000 & 0000 & 00 & $2378 A$ & 00 & 00 & $000 \bar{Q}+\infty 0$ & $029^{\circ}$ \\
\hline & Radiation & (Watt) $=$ & 21712 & & & & 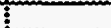 & \\
\hline & Conduction & (Waits) $=$ & 200.2 & & & & & \\
\hline
\end{tabular}


Appendix 10 Siebers and Kraabel Computer Program Listing

REM

REM

REM

REM

REM

REM

REM

REM

REM
Siebers \& Kraabel Method

\section{PRINT "Siebers \& Kraabel Method of Predicting Convective Losses"}

\section{PRINT}

REM PRINT

REM The program allows some variations in receiver geometry. These

REM variables are inputted in this section of the program. The characteristic

REM length, as called for in the reference, is simply the cavity diameter

REM given here as ' $\mathrm{Cl}$ '.

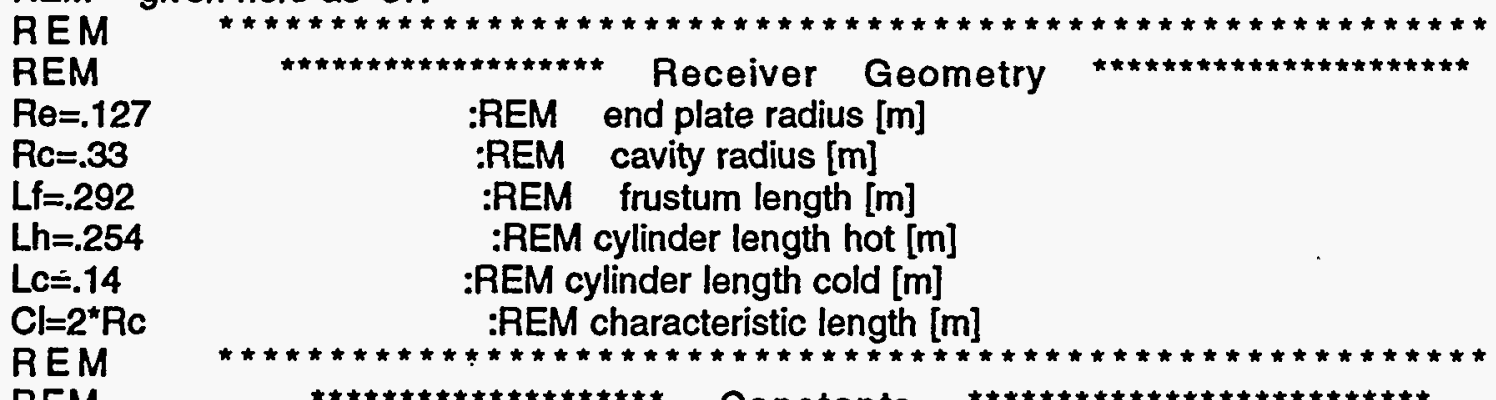

REM $\mathrm{pi}=4^{*} \mathrm{ATN}(1)$

$\mathrm{Ta}=70$

:REM ambient temperature [ ${ }^{\circ} \mathrm{F}$

REM

OPEN "CLIP:" FOR OUTPUT AS \#1

REM write header to clipboard

WRITE\#1, " Siebers \& Kraabel Method"

WRITE\#1,

WRITE\#1," "," ","End Plate Radius [m] = ",Re

WRITE\#1,","," Cavity Radius [m] = ",Rc

WRITE\#1,""," ","Frustum Length $[\mathrm{m}]=$ ",Lf

WRITE\#1,","n,"Hot Cylindrical Section Length $[\mathrm{m}]=$ ",Lh

WRITE\#1," "," "Cold Cylindrical Section Length $[\mathrm{m}]=$ ",Lc

WRITE\#1," "," ","T amb $\left[{ }^{\circ} \mathrm{F}\right]=$ ",Ta

WRITE\#1,

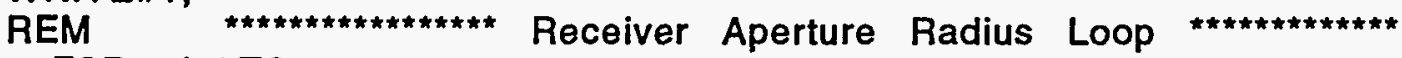

FOR $\mathrm{rad}=1$ TO 4

READRa

DATA .0762, .1524, .2286, .329

$\mathrm{Da}=2^{*} \mathrm{Ra}$

REM

REM

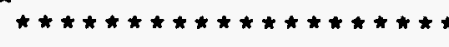

REM In this section the 4 angle limits, $z 1, z 2, z 3$, and $z 4$ are calculated.

$z 1=A T N((R a-R e) /(L f+L c+L h)) \quad: p 1=z 1 * 180 / p i$

$z 2=A T N((R a+R e) /(L f+L C+L h)) \quad$ :p2=z2*180/pi

Z3=ATN $((R a+R c) /(L c+L h))$

$Z 4=A T N((R a+R c) / L c)$

:p4=z4*180/pi

:p3 $=z 3^{*} 180 / p i$ 
REM $A 1$ is the total interior cavity surface area.

REM A2 is the total interior cavity surface area minus the lower lip.

REM $A 3$ is the interior cavity surface area below the horizontal plane

REM cutting through the receiver at the top of the aperture.

REM

$A h=p^{\bullet}(R e+R c)^{\bullet}\left(L f^{\wedge} 2+(R c-R e)^{\wedge} 2\right)^{\wedge} .5+2^{\star} p^{\star}{ }^{\star} R c^{\star} L h$

$A r=p i^{\bullet} R e^{\wedge} 2+p^{\star}\left(R c^{\wedge} 2-R a^{\wedge} 2\right)+2 * p i \bullet R c \bullet L c$

$\mathrm{A} 1=\mathrm{Ah}+\mathrm{Ar}$

$A 2=A 1-R c^{\wedge} 2^{*}(-A T N((R a / R c) / S Q R(-(R a / R c) *(R a / R c)+1))+1.5708)+R a$

${ }^{*} \operatorname{SQR}\left(R c^{\wedge} 2-\operatorname{Ra}{ }^{\wedge} 2\right)$

REM Area 3 is a function of the receiver angle and is determined by

REM calculating the total area in zone 1, above the horizontal

REM plane, and then subtracting this value from the total area.

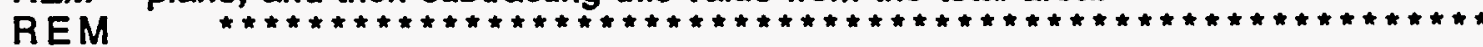

REM Print Header

PRINT " Siebers \& Kraabel Method"

PRINT

PRINT "End Plate Radius [m] = ";Re

PRINT "Cavity Radius [m] = ";Rc

PRINT "Aperture Radius [m] = ";Ra

PRINT "Frustum Length [m] = ";Lf

PRINT "Hot Cylindrical Section Length $[\mathrm{m}]=$ ";Lh

PRINT "Cold Cylindrical Section Length [m] = ";Lc

PRINT "T amb = ";Ta

PRINT

PRINT " Total Area [m^2] = ";A1

REM

REM

WRITE\#1,

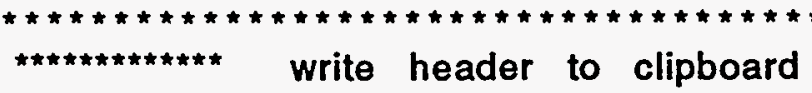

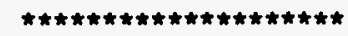

WRITE\#1,"",","Aperture Radius [m] = ",Ra

WRITE\#1,"n,"n"," Total Area [m^2] = "A1

REM Operating Temperature Loop

REM

FOR $T h=300$ TO 600 STEP 100

REM mean system operating temperature of receiver $\left[{ }^{\circ} \mathrm{F}\right]$

$\operatorname{Tr}=T h-100$

$T w=\left(T h^{\star} A h+T r^{\star} A r\right) / A 1$

CS

REM

REM

REM

REM

REM REM equation for ' $k$ ' is based on data from Table A-1, p. 388, Kays \& Crawford,

REM "Convective Heat and Mass Transfer ", second edition, McGraw-Hill.

PRINT

$k=2.651 E+08-2186000 l^{\star} T a+7935.4726 \#^{*} T a^{\wedge} 2-13.3076^{\star} T a^{\wedge} 3+.0082^{*} T \quad a^{\wedge} 4$

$\mathrm{Gr}=k^{*}(\mathrm{Tw}-\mathrm{Ta}) / 1.8^{*} \mathrm{Cl} \wedge 3 \quad:$ REM Grashoff number

$\mathrm{Nu}=.088^{\star} \mathrm{Gr}^{\wedge}(1 / 3)^{\star}((\mathrm{T} w+459.67) /(\mathrm{Ta}+459.67))^{\wedge} .18 \quad: R E M$ Nusselt number

hc $=.81^{\star}((\mathrm{Tw}-\mathrm{Ta}) / 1.8)^{\wedge} .426$

REM hc=natural convection no lip heat transfer coefficient REM

The value of ' $k$ ' calculated here is the product of the gravitational constant times the coefficient of volumetric expansion divided by the kinematic viscosity squared (i.e. $B / v^{\wedge} 2\left[1 / K-m^{\wedge} 3\right]$ ) The 
PRINT "Nusselt Number =";Nu

PRINT "Grashoff Number $=" ; G r$

PRINT "T mean $\left[{ }^{\circ} \mathrm{F}\right]=$ ";Th

PRINT ;TAB(3);" Angle";TAB(11);"Sec 1";TAB(19);"Sec 2";TAB(27);"Sec 3";

PRINT;TAB(35);"Sec 4";TAB(43);"Sec 5";TAB(50);"Heat Loss";TAB(61);" $h$ ";

PRINT;TAB(72);"Total Zone 1"

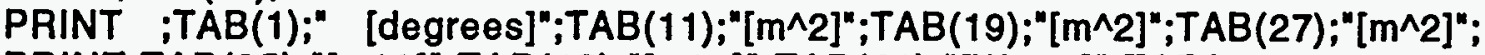

PRINT;TAB(35);"[m^2]";TAB(43);"[m^2]" ;TAB(51);"[Watts]";TAB(

60); "[Watts/K-m^2]";

PRINT;TAB(73);"[m^2]"

PRINT

REM

REM

*********** WRITE HEADER TO CLIPBOARD

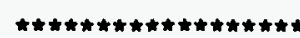

WRITE\#1," "Nusselt Number =",Nu

WRITE\#1," "',"Grashoff Number $=", G r$

WRITE\# $1, " T$ mean $=$ ",Th

WRITE\#1,

WRITE\#1,"Angle","Sec 1","Sec 2","Sec 3","Sec 4","Sec 5","Heat Loss","h","Total Zone $1^{\text {" }}$

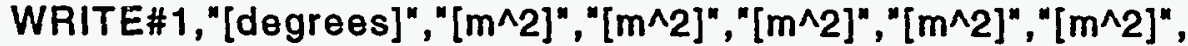

"[Watts]","[Watts/K-m^2]","[m^^2]"

WRITE\#1,

REM

FOR $A=0$ TO 90 STEP 15

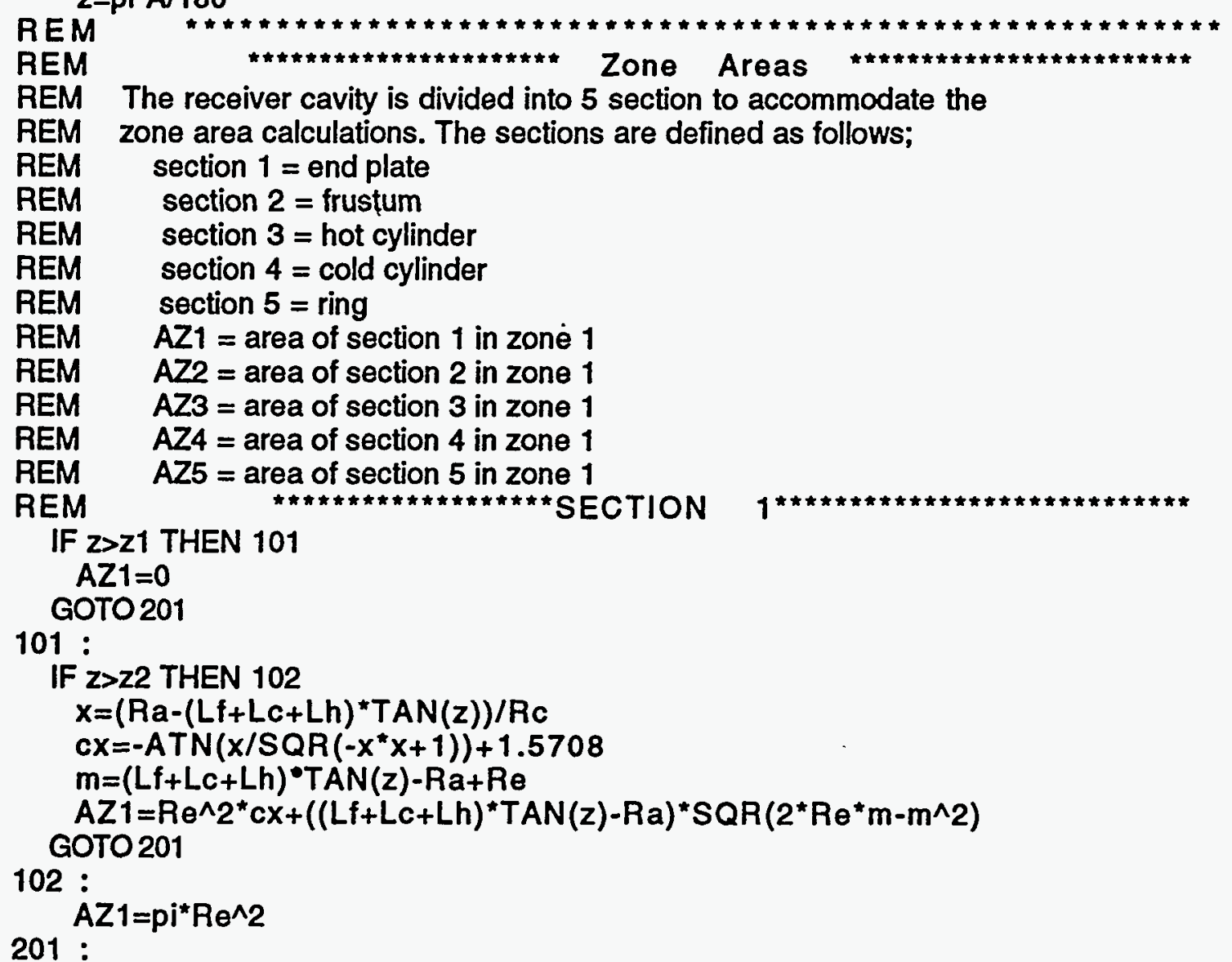


REM

IF $z>Z 1$ THEN 202

$x=(R a-(L c+L h) * T A N(z)) / R c$

$c x=-A T N\left(x / \operatorname{SQR}\left(-x^{*} x+1\right)\right)+1.5708$

$m=A T N((R c-R e) / L f)$

$A Z 2=\left(((R c-R e) / L f)^{\star}(R c-R a)+L c+L h\right){ }^{\star} \operatorname{SIN}(z) / S I N(p i / 2-z-m)$

$A Z 2=(A Z 2+(R c-R a) / S I N(m)){ }^{*} c^{*} c x$

GOTO 301

202 :

IF $Z>Z 2$ THEN 203

$x 1=\left(R a-(L c+L f+L h){ }^{\star} T A N(z)\right) / R e$

cx1 $=-A T N\left(x 1 /\right.$ SQR $\left.\left(-x 1^{*} \times 1+1\right)\right)+1.5708$

$\times 2=($ Ra $-(L C+L h) * T A N(z)) / R c$

$\operatorname{cx2}=-A T N\left(\times 2 / S Q R\left(-\times 2^{\star} \times 2+1\right)\right)+1.5708$

$A Z 2=S Q R\left(L f \wedge 2+(R c-R e)^{\wedge} 2\right)^{\star}\left(R e^{\star} c \times 1+R c^{\star} c \times 2\right)$

GOTO 301

203 :

IF $Z>Z 3$ THEN 204

$m=A T N((R c-R e) / L f)$

$n=A T N((R a+R e) /(L c+L f+L h))$

$I=S Q R\left((L c+L f+L h)^{\wedge} 2+(R a+R e)^{\wedge} 2\right)^{\star} \operatorname{SIN}(z-n) / S I N(p i-z-m)$

$x=\left(R a-(L c+L h){ }^{*} T A N(z)\right) / R c$

$c x=-A T N\left(x / S Q R\left(-x^{\star} x+1\right)\right)+1.5708$

$A Z 2=\left(p^{\star} R e+p^{\star}\left(R e+l^{\star} \operatorname{SiN}(m)\right)\right)^{\star} \mid$

$A Z 2=A Z 2+\left(R c^{*} c x+p^{*}\left(R e+l^{\star} \operatorname{SIN}(m)\right)\right)^{*}\left(S Q R\left(L f^{\wedge} 2+(R c-R e)^{\wedge} 2\right)-I\right)$

GOTO 301

204 :

$A Z 2=p^{\star}(R e+R c)^{\star} S Q R\left(L f \wedge 2+(R c-R e)^{\wedge} 2\right)$

$301:$

REM

IF $Z>23$ THEN 302

$x 1=(R a-L c * T A N(z)) / R c$

$\times 2=(\operatorname{Ra}-(L c+L h) \star T A N(z)) / R c$

$\operatorname{cx1}=-A T N\left(x 1 / S Q R\left(-x 1^{*} \times 1+1\right)\right)+1.5708$

$\operatorname{cx} 2=-A T N(\times 2 / S Q R(-\times 2 * \times 2+1))+1.5708$

$A Z 3=R c^{*}(c \times 1+c \times 2)^{\star} L h$

GOTO 401

302 :

IF $Z>Z 4$ THEN 303

$m=(R a+R c) / T A N(z)$

$x=($ Ra-Lc*TAN $(z)) / R c$

$c x=-A T N\left(x / S Q R\left(-x^{*} x+1\right)\right)+1.5708$

$A Z 3=2^{*} p^{*} R c^{\star}(L h+L c-m)+R c^{\star}(m-L c){ }^{\star}(p i+c x)$

GOTO 401

303 :

$A Z 3=2^{\star} \mathrm{pi}^{\star} \mathrm{Rc} \mathrm{c}^{\star} \mathrm{Lh}$

401:

REM

IF $z>Z 4$ THEN 402

$x 1=R a / R c$

$\times 2=\left(\operatorname{Ra}-\operatorname{Lc}^{*} \mathrm{TAN}(\mathrm{z})\right) / \mathrm{Rc}$

cx1 $=-A T N\left(x 1 / S Q R\left(-x 1^{*} \times 1+1\right)\right)+1.5708$

$\operatorname{cx} 2=-A T N\left(x 2 / S Q R\left(-x 2^{*} \times 2+1\right)\right)+1.5708$

$A Z 4=R c^{*}(c \times 1+c \times 2) * L c$

GOTO 501 
402 :

$x=R a / R c$

$c x=-A T N\left(x / \operatorname{SQR}\left(-x^{*} x+1\right)\right)+1.5708$

$m=(R a+R c) / T A N(z)$

501 :

$A Z 4=2^{*} p^{*} R c^{*}(L c-m)+R c^{*} m^{*}(p i+c x)$

REM

SECTION 5

$\mathrm{zm}=\mathrm{pi} / 2$

IF $z<Z$ Zm THEN 502

$A Z 5=\mathrm{pi}^{\star}\left(\mathrm{Rc} \mathrm{c}^{\wedge} 2-\mathrm{Ra} \mathrm{a}^{\wedge} 2\right)$

GOTO 600

502 :

$x=R a / R c$

$c x=-A T N\left(x / S Q R\left(-x^{*} x+1\right)\right)+1.5708$

$A Z 5=R c^{\wedge} 2^{\star} c x-R a^{*} S Q R\left(R c^{\wedge} 2-R a^{\wedge} 2\right)$

600 :

REM

$A Z T=A Z 1+A Z 2+A Z 3+A Z 4+A Z 5$

$A 3=A 1-A Z T$

REM

REM

$z z=p^{\star} 30 / 180$

IF $z>Z Z$ THEN 601

$\mathrm{n}=.63$

GOTO 700

601 :

$n=.8$

700 :

$h=h c^{*}(A 1 / A 2)^{\star}(A 3 / A 1)^{\wedge} n$

$q=h^{\star} A 1^{*}(T w-T a) / 1.8$

REM

$\star \star \star \star \star \star \star \star \star \star \star \star \star \star \star \star \star \star \star$ PRINTER Output

REM

PRINT;TAB(4);

PRINT USING"\#\#\#.";A;

PRINT;TAB(9);

PRINT USING "\#\#\#.\#\#\#\#";AZ1;

PRINT;TAB(17);

PRINT USING "\#\#\#.\#\#\#\#";AZ2;

PRINT;TAB(25);

PRINT USING "\#\#\#.\#\#\#";AZ3;

PRINT;TAB(33);

PRINT USING "\#\#\#.\#\#\#\#";AZ4;

PRINT;TAB(41);

PRINT USING "\#\#\#.\#\#\#\#";AZ5;

PRINT;TAB(50);

PRINT USING "\#\#\#\#.\#";q;

PRINT;TAB(60);

PRINT USING "\#\#\#.\#\#\#\#";h;

PRINT;TAB(70);

PRINT USING "\#\#\#.\#\#\#\#";AZT

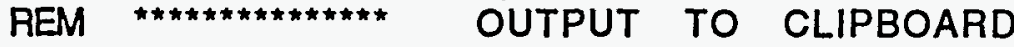

WRITE \#1,A,AZ1,AZ2,AZ3,AZ4,AZ5, q,h,AZT

NEXT A

NEXT Th

NEXT rad 
PRINT "bye!"

CLOSE \#1

EN 
Appendix 11 Siebers and Kraabel Model Heat Loss

\begin{tabular}{|c|c|c|c|c|c|c|c|c|}
\hline \multicolumn{9}{|c|}{ 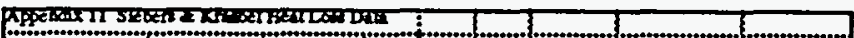 } \\
\hline & Hölliti & 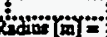 & 30.127 & & & & & \\
\hline & Conty & $\operatorname{con}]=$ & 0.33 & & & & & \\
\hline & Trutent & S(m) $=$ & 0.292 & & & & & \\
\hline Ratçitio: & hicu Secteotal & 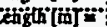 & $0.25 \%$ & & $\ldots$ & & & \\
\hline Coddcyind & mensecton & 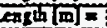 & 0.14 & & & & & \\
\hline & & $-\mathrm{ab} T^{6} \mathrm{~F}=$ & $370^{\circ}$ & & & & & \\
\hline 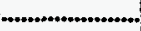 & 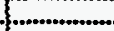 & & & & .... $>$ > > & & & \\
\hline & Aperture & $\log (m)=$ & 0.076 & & & & & \\
\hline & 10:5 & $\operatorname{cea}\left[\bar{\pi}^{3}\right)=$ & 1.702 & & & & & \\
\hline$\cdots \cdots \cdots$ & 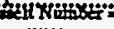 & $23^{\circ}$ & & & & & & \\
\hline Gire & mar winber & XXTE+9 & & & & & & \\
\hline Twen= & 300 & & & & & & & \\
\hline$\cdots x$ & " & sack & fsects: & $|\sec 4|$ & $\{\sin x\}$ & 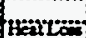 & $\sigma^{\infty}$ & tratroto \\
\hline 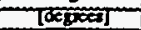 & Tा"2 2 & 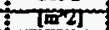 & 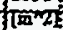 & (5) 2 & {$\left[\lim ^{\prime} 2\right.$} & Trast & 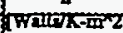 & {$\left[\begin{array}{ll}20 \\
2]\end{array}\right.$} \\
\hline ט* & 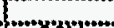 & Eet & 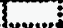 & & & & & \\
\hline 8 & 8.012 & 0.189 & $10334:$ & 0.128 & 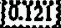 & 8311.9 & $4.2607^{\circ}$ & $8.68 \%$ \\
\hline 15 & 0.035 & 83m & $0.261:$ & 0.129 & 0.121 & 73629 & 7.001 & $0.8580^{\circ}$ \\
\hline 30 & DI & Taxy & fosor: & :.135 & D.T.21 & 6213 & 3.47 & $\operatorname{TaS}$ \\
\hline 25 & 0.831 & $" 0316 "$ & 0.388 & 0.143 & $\{0.121\}$ & $423 I^{\circ}$ & 2343 & 1313 \\
\hline 60 & 2.051 & 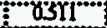 & 10.24: & 0.139 & $\{0.121\}$ & 3363 & 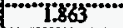 & $\cdots 1333$ \\
\hline 73 & 0.051 & o3m & fo3:327: & 0.225 & (0.121 & 2513 & 1.47 & TA35 \\
\hline प्रo & Oxp & $03 \pi$ & toset: & 0.290 & 0.324 & 0.0 & 0,000 & T.7.12 \\
\hline $\mathrm{Na}$ & Melixtobers & 180 & & & & & & \\
\hline Gn: & hoth Kanbers & $68 \mathrm{BE}+9$ & & & & & & \\
\hline $\operatorname{tac} n=$ & 400 & & & & & & & \\
\hline$\cdots$ onite & "Ser. & $\sec 2$ & $\log 3:$ & (2) & $\{s ; 0\}$ & Heition & $\cdots \infty$ & tarstot \\
\hline (xipger & Thent & Tax? & $\left\{\left[\sin ^{x} 2\right\}\right.$ & $\operatorname{tin} 2 \mid$ & $\left\{x x^{2}\right\}$ & Twat & 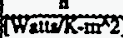 & [ats \\
\hline & & & $\operatorname{sog}:$ & :07z\} & noizit & 7565 & $\ldots$ & \\
\hline is" & 0.038 & "63IY" & $30.261:$ & 60.129 & \{0.121\} & .1340 & $\ldots+\cdots$ & 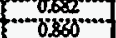 \\
\hline 30 & $0.03 \pi$ & 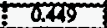 & $6.30 \%$ & 0.135 & \{0.121 & $T 327$ & $7.17 \%$ & 1035 \\
\hline 75 & 0005 & 03510 & 0.308 & 0.1243 & 0.121 & $m \pi$ & 2800 & T213 \\
\hline 60 & "u. 0 & USit & foxpr: & 0.759 & 0.121 & \%13.2 & $2.229^{\circ}$ & $1335^{\circ}$ \\
\hline 75 & 0.051 & 0311 & to.325: & 0.225 & $0.121\}$ & 7763 & T.73I & 1735 \\
\hline 90 & 2.031 & USII & $0327:$ & 0.250 & 0.324 & 0.0 & 0.000 & 1.702 \\
\hline 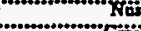 & an & 203.3 & & & & & & \\
\hline 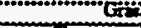 & 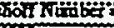 & 9.158+9 & & & & & & \\
\hline Tren $=$ & 300 & & & & & & & \\
\hline 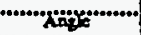 & "sectl" l" & $2=2$ & צ:eะs? & 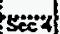 & sacs & 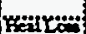 & $\mathbf{2}$ & tratrosion \\
\hline 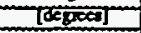 & [men & TRT2 & III. & Tine & {$\left[\operatorname{mat}^{2}\right.$} & TWan & 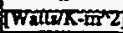 & Tिय \\
\hline & & & tom: & (im) & 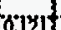 & $4311 \cdots$ & & $0 \times 0$ \\
\hline Yss" & ross.... & 8.3ri & $8261^{4}$ & $0.12 y$ & O.YYYY & 20173 & 3338 ..... & yxos" \\
\hline 30 & D.0T & TA49 & tosor: & 0.135 & 0,21 & $1725 \mathrm{~L}$ & 7.669 & $\mathrm{~T} 0000$ \\
\hline 75 & 0.051 & 0310 & $0.388:$ & 0.143 & 0.121 & T175.6 & 3.180 & TIIS \\
\hline $66^{\circ}$ & 0.631 & 6311 & $0.640:$ & 0.159 & $0.131\}$ & $\$ 34 \%$ & 43328 & $1343^{\circ}$ \\
\hline 75 & T.03T & osm & 0.327 & 0.223 & [O.ren? & 725.5 & 104 & $\tan$ \\
\hline प्रo & 0.001 & क्SIr & 0.227 & 0.290 & 0.34 & 0.0 & 0,000 & $T .70 L$ \\
\hline "Xistion & EIR & 32346 & & & & & & \\
\hline $\mathrm{Grm}$ & doolf Nutumer & $1.13 E \div 10$ & & & & & & \\
\hline$T$ Tren & 1000 & & & & & & & \\
\hline Angle & Seci & $\sec 2$ & $\{\sec \}^{+}$ & $5 \sec 4$ & 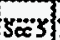 & Heitiroit & b"* & 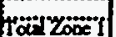 \\
\hline 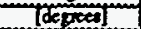 & $\tan \times 2$ & $\operatorname{man} 2$ & $\left(\mathrm{~m}^{x}\right)$ & $(\pi+2)$ & $\left(m^{2} \times 2\right.$ & matrit & 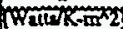 & (1진 \\
\hline 0 & o.ors & 0.799 & lomat & $\cos x$ & 070 & $\boldsymbol{p} \cdot$ & $\cdots$ & $\cdots$ \\
\hline "YS"* & $8.038^{\circ}$ & 6.311.... & $0.261^{+}$ & 0.129 & 0.121 & .28328. & . & $\ldots$ \\
\hline 30 & 0.051 & 0,109 & $0.30 \%$ & 0.135 & 0.1211 & 2388.6 & 3.125 & 1.080 \\
\hline 25 & 0.001 & OSTIO & $0.388:$ & 0.143 & 0.121 & T6267 & उ39 & T213 \\
\hline$" \infty$ & 0.051 & ostr... & 0.498 & corss & a.T21 & T293.0" & $2755^{\circ}$ & $\cdots 1335 \cdots$ \\
\hline 775 & "8.051" & 2035I & $0.5324:$ & 0.223 & U.t21 & $=1000+3$ & 2130 & $\cdots 1 \times 35 \cdots$ \\
\hline$\$ 0$ & 0.051 & 0,35 & $0.327 ?$ & 0.290 & 0.3321 & 0.0 & 0.0000 & 1.702 \\
\hline
\end{tabular}


Appendix 11 Siebers and Kraabel Model Heat Loss

\begin{tabular}{|c|c|c|c|c|c|c|c|c|}
\hline & $A$ & & $0.152 \div$ & & & & $\ldots$ & \\
\hline & Tarr & स्या= & 1.007 & & & & & \\
\hline & andomber & 5.85 & & & & & & \\
\hline to & far woin & 30 & & & & & & \\
\hline 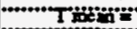 & $1800^{\circ}$ & & & & & & & \\
\hline & & & & & & & & \\
\hline Rnge & 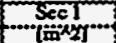 & 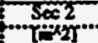 & 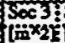 & 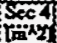 & secs & FEALA & mate $=1$ & 10420001 \\
\hline & & & & & & & & \\
\hline 0 & 0.000 & aाr2 & $0.165:$ & renor & $10.07 \pi$ & 868.2 & 3.029 & $6 \times 7 \%$ \\
\hline IS & $203 \pi$ & 8.235 & $0.228 \div$ & 0.107 & 0.074 & 783.2 & 2735 & 0.685 \\
\hline $38^{\circ}$ & $8.65 \%$ & $6205^{\circ}$ & $102364:$ & o.:14 & $0.07 x$ & 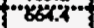 & $3.762^{\circ}$ & "85865" \\
\hline 20 & प.05 & Was & fo329: & comen & $0.07 x$ & $+77 \times 3$ & $26 \times 5$ & 1070 \\
\hline $60^{\circ}$ & 0.881 & ब.SII & $0.467 \%$ & 0.136 & 0.074 & 359.8 & 2037 & 1249 \\
\hline $75^{\circ}$ & 8.031 & asil & X3537! & 0.2003 & 0.074 & $267: 4$ & 1316 & 1353 \\
\hline$\cdots$ & $0.05 \%$ & $031 r^{\circ}$ & foserisi & 0.250 & 0.268 & 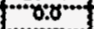 & 2.600 & 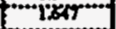 \\
\hline I & orromats & Tous9 & & & & & & \\
\hline Gre & Eofinmber & $6.868+09$ & & & & & & \\
\hline$\tau$ ines: & $1460^{\circ}$ & & & & & & & \\
\hline$x=2$ & 50 & $\cos$ & xess & cदा & $\infty x$ & Th & & 7 \\
\hline [oreace] & (im-2in & 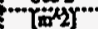 & {$[1 \times 2$} & $F_{n}^{2} \times 2$ & Yien & WHAT & Wiiiik-aris & $\left|\div x^{2}+2\right|$ \\
\hline & & & & & & & & \\
\hline$\sigma$ & 0.000 & $8 \mathrm{rr2}$ & 0.005 & oror & 0.074 & Toros & 62008 & dx7\% \\
\hline 15 & 0.031 & 0.250 & 502209 & 0.107 & \{0.074 & 192005 & $3.295^{\circ}$ & 0.085 \\
\hline $30^{\circ}$ & $0.0 \leqslant 1$ & 2003 & 03262 & ชo:ins & \{0.074 & "1205.1." & $4785^{\circ}$ & $\cdots$ \\
\hline t5 & 0.031 & 0.795 & $0.328:$ & $m$ & 60.074 & 830.3 & 3.265 & $1.070^{\circ}$ \\
\hline$\infty$ & a.05T & 0.311 & 02067 & 0.136 & 0.074 & 652.6 & 2434 & 1259 \\
\hline $75^{\circ}$ & 0.005 & 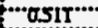 & 0.527 & 0.203 & $0,07 x$ & $\because 405.6 \%$ & $T 217^{\prime \cdots}$ & r.o.s. \\
\hline $30^{\circ}$ & 0.681 & osir & 0.356 & $0.2 \% 0$ & 0.269 & 6.6 & $8.000 \%$ & 16640 \\
\hline $\mathrm{Kar}$ & bell Nerber & 203.77 & & & & & & \\
\hline ts & han Nonser? & $9.200+09$ & & & & & & \\
\hline$T$ The & $m$ & & & & & & & \\
\hline & & & & & & & & \\
\hline Xnge & SecI & $3 \times 2$ & Sece $3:$ & $\sec 4$ & Sec 3 & SHEail Lom & $\mathbf{L}$ & torrzonel \\
\hline 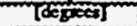 & 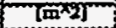 & {$\left[x^{2} 2\right]$} & $\tan \times 2 y$ & $\left(\pi \pi^{*}\right)$ & t=x/2] & TW:at & Watmo-ma & $7(10 \times 2)$ \\
\hline & & & & & & & & \\
\hline 0 & 0.000 & 0.12 & Dores: & DII & 00.074 & 3488 & 6809 & $0 \times 7 \%$ \\
\hline I5 & 0.031 & 0.250 & $50.202:$ & 0.107 & 0.071 & $2139 x$ & 6.007 & 0.683 \\
\hline & $0.051^{\circ}$ & $0.2653^{\circ}$ & 30.28t: & o.r.ns & forts & WHYX & $3.09 \%$ & 8305 \\
\hline $45^{\circ}$ & $0.00 r^{\circ}$ & axys. & to.385: & o.t21 & 0,074 & $7307 \times$ & 3.656 & 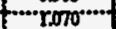 \\
\hline 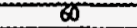 & 0.0051 & 03ाI & $0.267 !$ & & 10.072 & 992.0 & 2.738 & 1239 \\
\hline 73 & 2081 & aSII & fosm?: & 0.203 & 0.074 & $736 \pi$ & 2052 & 1336 \\
\hline 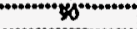 & $8.881^{\circ}$ & tasti" & U.3.327: & 0.285 & (6.269 & 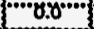 & 0.06000 & YвaY" \\
\hline Ko & a dIN & 222385 & & & & & & \\
\hline Gra & Wof Number & 1.13E+10 & & & & & & \\
\hline$T=$ & 300 & & & & & & & \\
\hline & & & & & & & & \\
\hline xnge & $\sec 1$ & $\sec 2$ & sec $3:$ & $\sec 4$ & $\sec 5$ & HEation & n & Tor20001 \\
\hline [deges] & [m²] & {$\left[\bar{x}^{2} 2\right]$} & $\mid\left[\mathbf{m}^{x} 2\right]$ & T血弪 & {$\left[m^{x} 2\right.$} & TWatt & Watur $=\mathrm{m}^{\mathrm{K}} \mathbf{2}$ & {$\left[\mathbf{m}^{2} 2\right]$} \\
\hline 8 & 8.0000 & $2 \pi r^{2}$ & b.18si & oror & to.87t & $3483 x^{2}$ & $7 \times 99$ & Ox\% \\
\hline IS & V.03I & 0.250 & $10222 \div$ & 0.07 & votus & 29835 & 6.615 & 08855 \\
\hline $30^{\circ}$ & $0.031^{\circ}$ & $8.2633^{\circ}$ & $62.281 ?$ & a.113 & 6.074 & 2531.80 & $3.610^{\circ}$ & $0.505^{\circ}$ \\
\hline $20 . \cdots$ & 0.651 & $6.495^{\circ}$ & $\{0.325 \%\}$ & 6.121 & 0.074 & "180ro" & $4.06 \%$ & $1.070 \cdots$ \\
\hline$\infty$ & 0.035 & vism & 0.467 & 0.136 & 0.074 & 737016 & 3.035 & 1259 \\
\hline & 4051 & OSII & $0.327:$ & 0.203 & 0.074 & I015: & 2265 & 135 \\
\hline 30 & ".03t" & "rost1" & 10.3327 & 0.290 & 0.268 & $6.0^{\circ}$ & $0.0600^{\circ}$ & $134 y^{\circ}$ \\
\hline
\end{tabular}




\begin{tabular}{|c|c|c|c|c|c|c|c|c|}
\hline & Aprition & 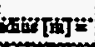 & 0.229 & 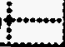 & & $\ldots$ & & \\
\hline & Torrex & $x+1+2]=$ & IDS: & & & & & \\
\hline $\mathrm{Nu}$ & entrombet & & & & & & & \\
\hline 0 & 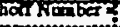 & 105 & & & & & & \\
\hline 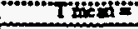 & $300^{\circ}$ & & & & & & & \\
\hline Angle & sect & $\operatorname{Sec} 2$ & $\sec 3:$ & $\operatorname{Sec} 4$ & $\{\sec 5\}$ & Heal Los & $\mathbf{h}$ & \\
\hline 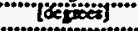 & [iiik) & 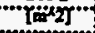 & {$[3 \times 2$} & Tin & (nin & Toticis & 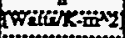 & " \\
\hline & & & & & & & & \\
\hline 0 & 0.000 & 0.047 & 0.135 & 0.074 & 0.033 & 9127 & 3.368 & 03390 \\
\hline IS & 0.018 & प्रा9 & 0.180 & 0881 & 0.033 & 811.2 & 7.771 & $\sigma 566$ \\
\hline 30 & "z.ture" & $6.346^{\circ}$ & $f 020$ & 0.068 & 0.033 & $890.8^{\circ}$ & $4.0553^{\circ}$ & 6.742 \\
\hline 0 & $0.05 r$ & 0.470 & $10205:$ & 0.097 & 0.033 & 790.1 & 2530 & 0.935 \\
\hline 60 & 0.031 & 0 SII & 0.735 & 10112 & 0.033 & 361.2 & 2135 & T.TRT \\
\hline 75 & 8.05[ & $63 \mathrm{TI}^{*}$ & 103325: & (b.,161) & \{.033\} & $260 \% 4$ & 13332 & $1380^{\circ}$ \\
\hline "30" & $0.03 \mathrm{Y}$ & r31Y" & $0.32 \%$ & 0.250 & 0.178 & 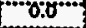 & 8.060 & 11356 \\
\hline No & WIINuber & T1.90 & & & & & & \\
\hline Gn: & Wof Nonber & S3E+0\% & & & & & & \\
\hline$f$ men= & 800 & & & & & & & \\
\hline Aftige & & 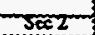 & 503 & & 5005 & Heat Lot & & $\operatorname{tatzODE}$ \\
\hline 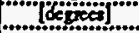 & & 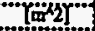 & $(\because \ddot{n}<2)$ & $\left\{x_{2} x_{2}\right.$ & [0] & Watis] & 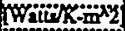 & 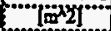 \\
\hline & & & & & & & & \\
\hline 25 & 0.000 & 0.047 & 0.135 & 0.074 & $0.033\}$ & 18103 & 6.396 & 0230 \\
\hline 15 & O.018 & 0.194 & T.100: & 0.081 & U.05s & $7 \times 578$ & 5.685 & 0,505 \\
\hline 30 & 0.031 & 6346 & 30.324 & 0.088 & 0.033 & 13215 & $7841^{\circ}$ & 0.742 \\
\hline 35 & 0.031 & 0770 & 10283 & 0.097 & 0.0331 & 835.3 & 3.291 & 0.936 \\
\hline 80 & 0.051 & 0.311 & 0,435 & 0.112 & 0.0335 & 699.2 & 23331 & T19! \\
\hline $75^{*}$ & "0.6s & "0sit" & $0.525:$ & 0.761 & $0: 033\}$ & 468.00 & 7.825 & 12800 \\
\hline "9x" & b.031" & 8319 & $0.32 \%$ & 0.250 & $0.178\}$ & $=0.0$ & $0.060^{\prime \cdots \cdots}$ & $1355^{\circ}$ \\
\hline Ka & ald Numbers & 200.36 & & & & & & \\
\hline Fis & 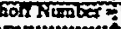 & प्र.29EFOS & & & & & & \\
\hline Theritis: & 1500 & & & & & & ....... & \\
\hline Xngle & Sect & $3 e x 2$ & $3 \sec 3:$ & $\sec 4$ & $\sec 3\}$ & Heatcont & b & TOE LODeI \\
\hline [REter] & {$\left[\mathrm{m}^{2} 2\right]$} & {$\left[\begin{array}{ll}x^{2} \\
2\end{array}\right.$} & 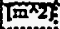 & $\ln \operatorname{mon}^{x}$ & T. & TWeTET & (Wallek- & Tw口2 \\
\hline 0 & 0.0000 & 20.047 & $60735:$ & :007nt & 80033 & 27821 & 1238 & 0,000 \\
\hline 15 & 0.018 & 0.19 & 0.180 & 0.081 & 0.033 & 28061 & 6.433 & 0306 \\
\hline $30^{\circ}$ & $8.051^{\circ}$ & $0: 345^{\circ}$ & (0)2201: & $\$ 0.088$ & $0.033\}$ & "18787'" & $3 x+5$ & " \\
\hline $45^{\circ}$ & 0.005 & $0.470^{\circ}$ & 0285 & 0.097 & $0: 033$ & $1351.5^{\circ}$ & $3.951^{\cdots}$ & $0.936^{\circ}$ \\
\hline 60 & 0.051 & O3II & 0,035 & 0.112 & 0.033 & 98233 & 2865 & 1.14 \\
\hline 75 & 0.031 & 0311 & 0.325 & 0.167 & 0.033 & 708.2 & 2065 & 12850 \\
\hline $40^{\circ}-1$ & 8.03!" & $8.3 Y_{1}{ }^{\circ}$ & 383527 & $0: 296$ & X.Y\% & 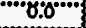 & 0.06000 & "Y358\%" \\
\hline Kut & sell Nuraber & 2225.98 & & & & & & \\
\hline Grat & Noptest & I.16Et & & & & & & \\
\hline 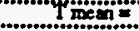 & 608 & & & & & & & \\
\hline & & & & & & & & \\
\hline Ange & Sect & 3 & $\sec 3:$ & $\sec 4$ & $\sec 2$ & FealLam & $\frac{\mathrm{h}}{\mathrm{n}}$ & Iotacost \\
\hline Tdefest & a.2] & {$\left[\pi^{2} 2\right]$} & $\mid \mathbb{m}^{\lambda} 2{ }_{2}$ & {$\left[m^{2} x^{2}\right.$} & {$\left[m^{2} 2\right.$} & TWx: & Watw & {$\left[\pi^{2}\right) !$} \\
\hline 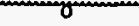 & 0.000 & 0.004 & s.135: & 0.074 & 0.035 & 4203 & 1.985 & 82960 \\
\hline & 0.015 & 0.194 & TOTEO: & 0051 & 0.053 & 3035.94 & 7.080 & USO5 \\
\hline $30^{\circ}$ & $8.031^{\circ}$ & 6345 & 0.323 & 0.088 & (6.033\} & 25888 & $6029^{\circ}$ & 0.742 \\
\hline 230 & 0.031 & $67 \%$ & 00335 & 0.0931 & $0.033\}$ & 186688 & $7348 \cdots$ & $0.336 \cdots$ \\
\hline$\infty$ & 0.081 & $03 m$ & 00335 & 0.17 & 0.035 & 13536 & 3.133 & mx1 \\
\hline 75 & ows & ostr & 0.325 & 0.161 & 0.033 & 975.9 & 2273 & 12300 \\
\hline 80 & 0.051 & 8391 & 0.3327 & 0.290 & 0.178 & $8.0^{\circ}$ & $0.0060^{\circ}$ & $135 \%$ \\
\hline
\end{tabular}




\begin{tabular}{|c|c|c|c|c|c|c|c|c|}
\hline & & & & & & & & \\
\hline & xpertist & 的] & 0.325 & & & & & \\
\hline & $\operatorname{Ian}$ & 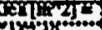 & 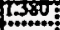 & & & & & \\
\hline "Naiz & Xinane & & & & & & & \\
\hline trin & 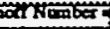 & $8+5$ & & & & & & \\
\hline Ines: & 300 & & & & & & & \\
\hline$x_{n}$ & secr & $\operatorname{loc} 2$ & 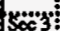 & $\sec 2$ & $3 \sec ^{3}$ & Lattoan & G & 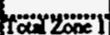 \\
\hline$(x, \mathrm{~g} x \mathrm{x})$ & $\mid(x+2)$ & (2x) & $\{=2$ & (ख. & |rinest & $T$ wat & 1 wallok-m & $\left(x^{2}\right)_{2}$ \\
\hline 80 & 8006 & & $0 \mathbf{3}$ & $m 71$ & trrest & $0783 \%$ & 6030 & 8706 \\
\hline 15 & 0,000 & tom & 0.10 & 0.026 & $\{0.000\}$ & (3) & 3378 & mog \\
\hline 30 & 0.035 & 0.24 & $0.16 \%$ & 0.037 & 0.000 & 750.9 & 7.046 & \% \\
\hline$\times 5$ & $0.051^{\circ}$ & $0 \times 2 x$ & 30289 & 0.045 & $\{0,000\}$ & "3ro:6" & 3.245 & $0.75 z$ \\
\hline$" 60$ & "xist & 8.311 & $8.381:$ & 0.03 & $\{0.008\}$ & 3372,2 & 21143 & $" 100 \%$ \\
\hline 75 & 0.0051 & 0311 & jost5: & 0.108 & $00.000\}$ & 2063.2 & 1.292 & 1.182 \\
\hline 90 & 0.051 & osm & $\{0.387$ & 0.290 & 0.002 & 0.0 & 0.000 & 1350 \\
\hline Rij: & 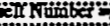 & 83.96 & & & & & & \\
\hline $\mathrm{Giz}$ & bot Ninber. & $10140+0 y^{\circ}$ & & & & & & \\
\hline$T$ men $=$ & 200 & & & & & & & \\
\hline Xing & Sëc1 & $x 2$ & (5ë3! & $\sec 4$ & 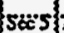 & Fétlä & $b^{*}$ & TULIZABT \\
\hline Togeres & |min & {$\left[\begin{array}{l}x \\
2\end{array}\right.$} & {$\left[m^{x} \mid\right.$} & $n^{\times 2}$ & {$\left[n^{\alpha} 2\right.$} & [Hate] & Waturk-In & {$\left[\omega^{x} 2\right]$} \\
\hline & & & & & & & & \\
\hline & & & $00.013 \%$ & 8.007 & 0.000 & 16722 & $7 \times 176$ & 8026 \\
\hline 15s" & 0,000 & 0.004 & 0.7104 & 0.026 & 0.000 & 1345,6 & $\cdots \cdots, 005$ & $0.780^{\circ}$ \\
\hline 30 & 0.036 & $0.24 \pi$ & 0.166 & 0.037 & 0.0000 & 72873 & 53302 & $0 \pi 82$ \\
\hline $\boldsymbol{B}$ & 6.051 & $822 \pi$ & 0.258 & 80.048 & 10.0000 & 839,4 & $3.8 \pi$ & 0.732 \\
\hline "ש⿱一⿻上丨 & $0.05)^{\circ}$ & "6.51Y" & $\left\{0.311^{\prime}\right\}$ & $0.0 \% 4$ & $\{0.060\}$ & "395.0" & "23539" & 1005 \\
\hline 75 & 0.051 & OSII & fosts & 0.100 & 0.000 of & 357.9 & 1530 & 1.102 \\
\hline 90 & 0.031 & ख्या & 10327 & 0.290 & 0.002 & 0.0 & 0.000 & 13800 \\
\hline Kus & eli Nunber & 2063 & & & & & & \\
\hline 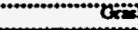 & 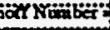 & 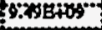 & & & & & & \\
\hline IDesen= & 500 & & & & & & & \\
\hline & & & & & & & & \\
\hline$x$ inge & $\mathrm{secil}$ & $\mathrm{Sec} 2$ & \{Seats: & Sect & $18 \times 3$ & Leitoon & $\mathrm{b}$ & Tod $20 x$ \\
\hline 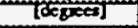 & {$\left[\mathbf{m}^{x} \mathbf{z}\right]$} & 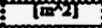 & [n] & $?\left[\frac{13}{2} \times 2\right)$ & 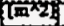 & Trais? & 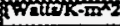 & tक्ष" \\
\hline 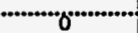 & $a$ & $0.60 \%$ & 0.013 & 0.007 & $\{0.000\}$ & 25053. & $8.081^{\circ}$ & $0.020^{\circ}$ \\
\hline 15 & $8.0060^{\circ}$ & 601 & 0.110 & 0.026 & $\{0.000\}$ & $23133^{\circ}$ & $\cdots \times 1 \times 33$ & 8.185 \\
\hline 30 & 0.038 & $0.24 x$ & fo.186! & 0.037 & $000000\}$ & 192888 & 6,209 & 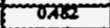 \\
\hline 75 & वर्का & A & togn: & 0.048 & 00000 & $7377 x$ & 7331 & 0722 \\
\hline $60^{\circ}$ & 0.031 & 8311 & $\$ 0.381:$ & 80.061 & $00.000 \%$ & "889.9" & 2884 & $1.005^{\circ}$ \\
\hline 75 & 0.031 & 0311 & $0 \leq 513$ & 0.105 & 100000 & 336.2 & 1.726 & 1.182 \\
\hline . & 0.031 & & $30.32 \%$ & 0.2 & 00.002 & 0.0 & 0.0 & 1300 \\
\hline Nivi & Elltaineat & 22515 & & & $\ldots$ & $6 .$. & & $\ldots$ \\
\hline G & Hof Ninber & iset & & & & & & \\
\hline 1 mean $=$ & 6000 & & & & & & & \\
\hline 'xäğgé & & & $\operatorname{sen} 3$ & sectu & $\sec 3\}$ & Hentas & 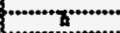 & (TаRZÖ) I \\
\hline 'anges] & 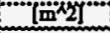 & 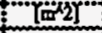 & 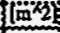 & {$\left[i^{*} \times 2\right]$} & 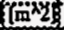 & W Writ & 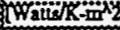 & 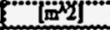 \\
\hline & & & & & & & & \\
\hline 0 & $0 x$ & 0.000 & 0.013 & 0.007 & $0.000\}$ & $34313^{3}$ & 8.16 & 0.020 \\
\hline 15 & $0.000^{\circ}$ & $0.07 x$ & fo.no: & 0.026 & $0.000\}$ & 31715 & $8.768^{\circ}$ & $\cdots 0.180$ \\
\hline 30 & 0.036 & $0.2 \times 4$ & 0.168 & 0.037 & 0.000 & 261.9 & 28280 & 0782 \\
\hline 25 & 0.051 & $0.42 \pi$ & $0 \times 229$ & 0.048 & 0.000 & 18453 & 4.764 & 0.732 \\
\hline$\infty$ & 8 & $0.3 Y$ & 0.360 & 0.068 & $\{0.000\}$ & "1218x" & $3: 14$ & $1000 \%$ \\
\hline $75 \cdots$ & $\cos 0$ & $051 T^{\circ}$ & 0.575 & 0.105 & $0: 000\}$ & -7374 & "T.896..... & $+\cdots=1.182 \cdots$ \\
\hline 90 & 0.031 & ग3ाI & 0.327 & 0.290 & $(0.002$ & 0.0 & 0.0000 & 1330 \\
\hline
\end{tabular}


APPENDIX 12: Stine and McDonald Model Computer Program Listing

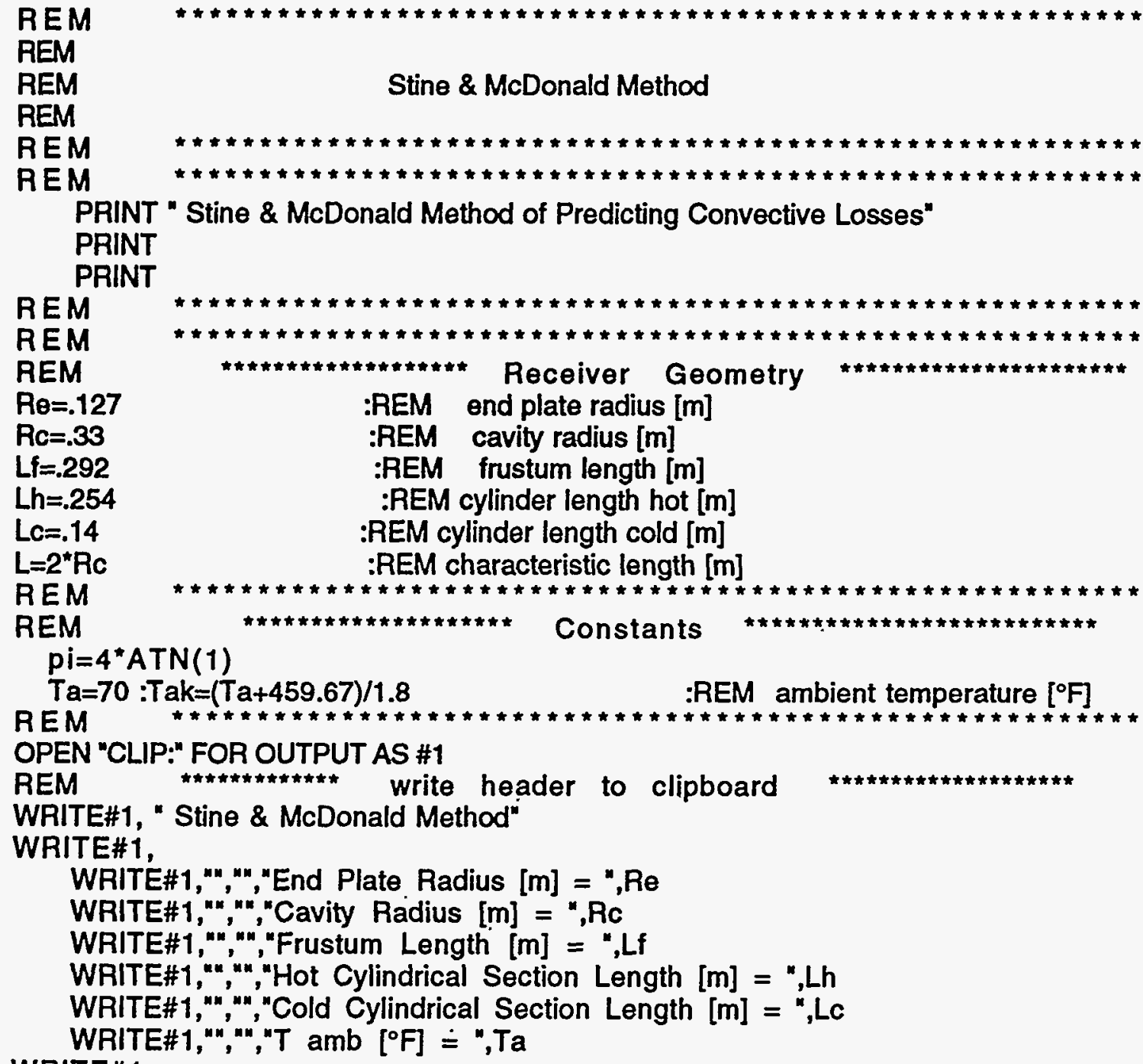

REM In the following section area 1, area 2 , and area 3 are calculated.

REM At is the total interior cavity surface area.

REM Ah is the simplified cavity tube surface area

REM Ar is the simplified refractory cavity surface area

$A h=p^{\star}(R e+R c)^{\star}\left(L^{\wedge} 2+(R c-R \theta)^{\wedge} 2\right)^{\wedge} .5+2^{\star} p^{*} R c^{\star} L h$

$A r=p i^{\star} R_{\theta} \wedge 2+p i^{\star}\left(R c^{\wedge} 2-R a^{\wedge} 2\right)+2^{\star} p^{\star}{ }^{\star} R c^{\star} L c$

$A t=A h+A r$

REM

REM Print Header

PRINT " Stine \& McDonald Method"

PRINT

PRINT "End Plate Radius [m] = ";Re 
PRINT "Cavity Radius [m] = ";Rc

PRINT "Aperture Radius [m] = ";Ra

PRINT "Frustum Length [m] = "if

PRINT "Hot Cylindrical Section Length [m] = ";Lh

PRINT "Cold Cylindrical Section Length [m] = ";LC

PRINT "T amb $\left[{ }^{\circ} \mathrm{F}\right]=$ ";Ta; " $[k]=$ ";Tak

PRINT

PRINT " Total Area [m^2] = ";At

REM

REM

WRITE\#1,

write header to clipboard

WRITE\#1,"","","Aperture Radius [m] = ",Ra

WRITE\#1,""," "," Total Area [m^2] = ",At

REM Operating Temperature Loop

REM

FOR Th $=300$ TO 600 STEP 100

REM mean system operating temperature of receiver $\left[{ }^{\circ} \mathrm{F}\right]$

$T r=T h-100$

$T w=\left(T h * A h+T r^{*} A r\right) / A t$

as

REM

REM

REM

REM

REM

REM equation for ' $k$ ' is based on data from Table A-1, p. 388, Kays \& Crawford,

REM "Convective Heat and Mass Transfer ", second edition, McGraw-Hill.

PRINT

$g B v=1.1547 E+19^{\star} T a k^{\wedge}-4.4187$

$\mathrm{Gr}=\mathrm{gBv}(\mathrm{Th}-\mathrm{Ta}) / 1.8^{*} \mathrm{~L} \wedge \mathrm{3} \quad$ :REM Grashoff number

$k=.0071749261015 \#+.000064030639041 \#^{*} T a k: R E M$ thermal conductivity of air

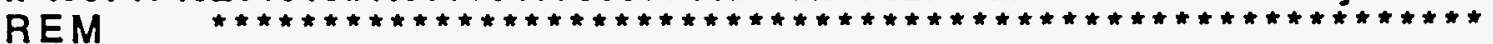

REM Print Table Header

PRINT "Grashoff Number $=" ; G r$

PRINT "T mean $\left[{ }^{\circ} \mathrm{F}\right]=$ ";Th

PRINT ;TAB(3);" Angle";TAB(11);"Nu";TAB(19);"Heat Loss";TAB(27);" $h \quad$ "

PRINT .;TAB(1);". [degrees] "TTA(1.1);" "TTAB(19);"[Watts]";TAB(27);"[Watts/K-m^

2]"

PRINT

REM

REM

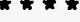

WRITE HEADER TO CLIPBOARD

WRITE\#1," ", "Grashoff Number $=", \mathrm{Gr}$

WRITE\#1,"T mean $=$ ",Th

WRITE\#1,

WRITE\#1,"Angle","Nu","Heat Loss"," $h "$

WRITE\# 1,"[degrees]"," ","[Watts]","[Watts/K-m^2]"

REM Beginning of Angle Loop

FOR $a=-90$ TO 90 STEP 15

REM $\mathrm{z}=\mathrm{pi}{ }^{\star} \mathrm{a} / 180$

REM

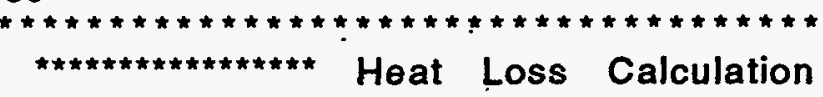

Heat Loss Calculation

$s=-.982^{*}(\mathrm{Da} / \mathrm{L})+1.12$

IF $a=90$ THEN 200

$\mathrm{Nu}=.088^{\star} \mathrm{Gr}^{\wedge}(1 / 3)^{\star}((\mathrm{Tw}+459.67) /(\mathrm{Ta}+459.67))^{\wedge} .18^{\star}(\operatorname{COS}(\mathrm{z}))^{\wedge} 2.47 \quad{ }^{*}(\mathrm{Da} / \mathrm{L})^{\wedge} \mathrm{s}$ GOTO 300 
200 :

$\mathrm{Nu}=0$.

300 :

:REM Nusselt number

$h=N u^{\star} k / L$

$q=h * A t^{*}(T w-T a) / 1.8$

REM

REM

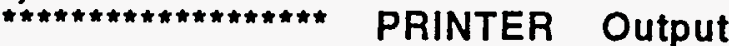

PRINT;TAB(4);

PRINT USING"\#\#\#.";a;

PRINT;TAB(9);

PRINT USING "\#\#\#.\#\#";Nu;

PRINT;TAB(17);

PRINT USING "\#\#\#\#\#.\#";q;

PRINT;TAB(25);

PRINT USING "\#\#\#.\#\#\#\#";h

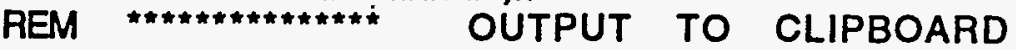

WRITE \#1,a,Nu,q,h

NEXT a

NEXT Th

NEXT rad

PRINT "bye!"

CLOSE \#1

END 


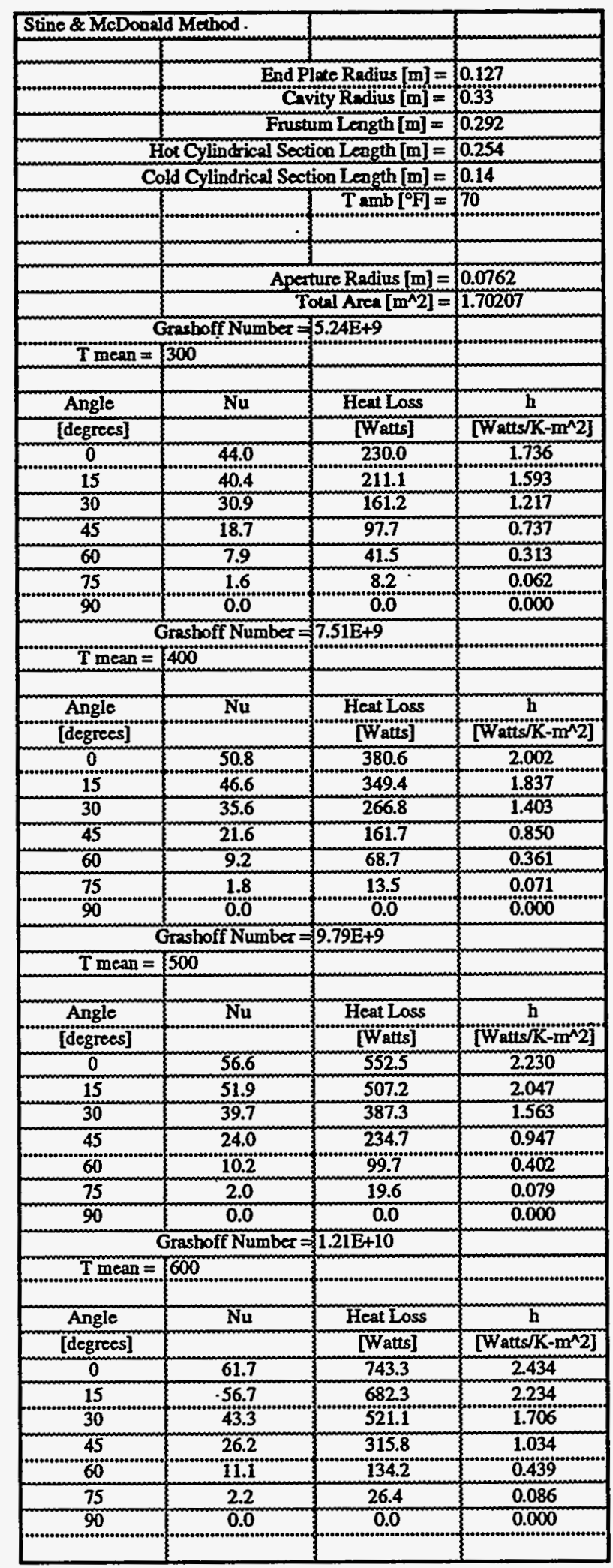




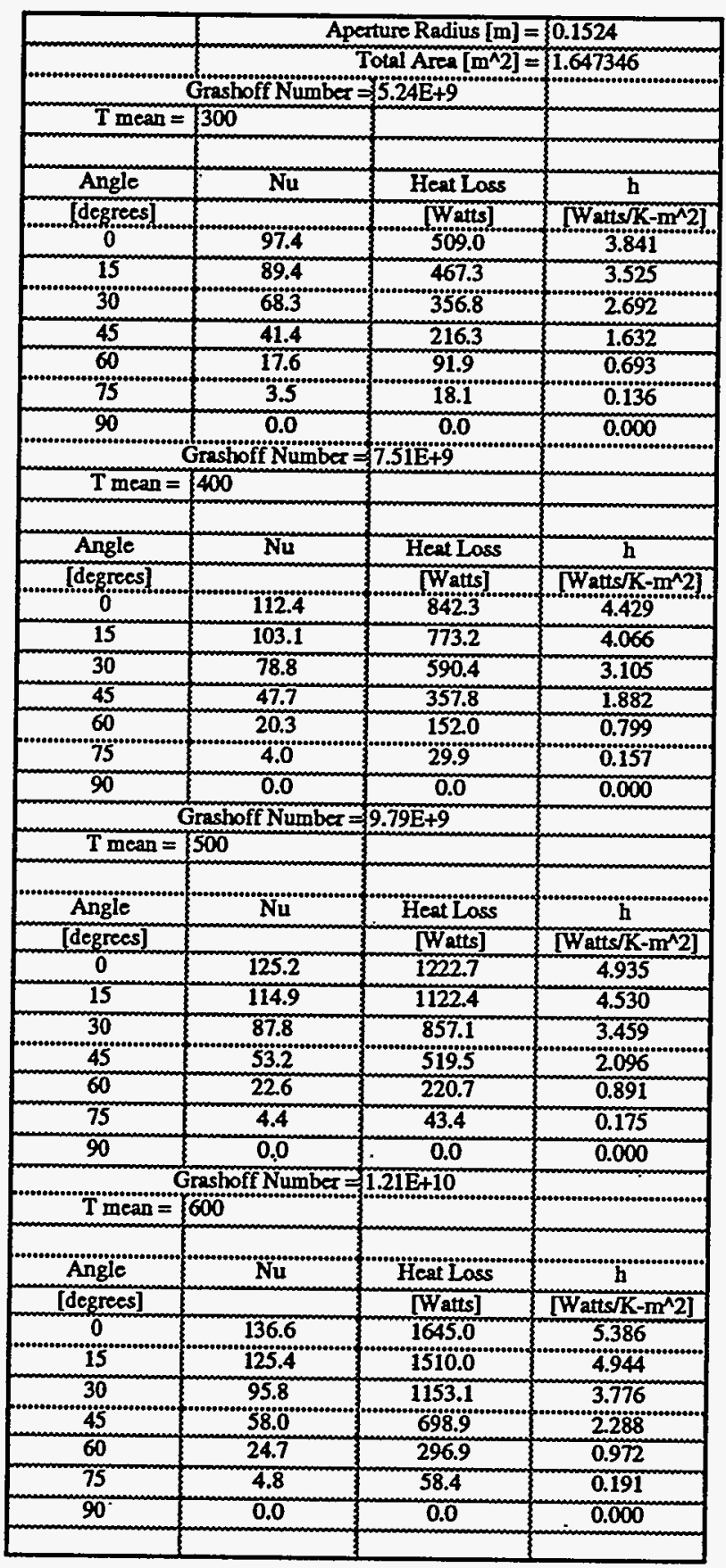




\begin{tabular}{|c|c|c|c|}
\hline - & Aper & fure Radius $[\mathrm{m}]=$ & 0.2286 \\
\hline & & otal Area $\left[\mathrm{m}^{\wedge} 2\right]=$ & 1.556138 \\
\hline \multicolumn{4}{|c|}{ Groshoff Number $=5.24 \mathrm{E}+9$} \\
\hline \multicolumn{4}{|c|}{$\mathrm{T}$ mean $=\int 300$} \\
\hline Angle & $\mathrm{Nu}$ & Heat Loss & h \\
\hline [degrees] & & [Watts] & {$\left[W a t t s / \mathrm{K}-\mathrm{m}^{\mathrm{N}} 2\right]$} \\
\hline 0 & 138.7 & 724.9 & 5.469 \\
\hline 15 & 127.4 & 665.4 & "5.030" \\
\hline 30 & 97.3 & 308.1 & 3.834 \\
\hline 45 & 58.9 & 308.0 & 2.324 \\
\hline 60 & 25.0 & 130.8 & 0.987 \\
\hline 75 & 4.9 & 25.7 & 0.194 \\
\hline 90 & 0.0 & 0.0 & 0.0000 \\
\hline \multicolumn{4}{|c|}{ Grashoff Number $=7.51 E+9$} \\
\hline \multicolumn{4}{|c|}{$T$ mean $=400$} \\
\hline Angle & $\mathrm{Nu}$ & Heat Loss & Th \\
\hline [degrees] & & [Watts] & {$\left[W_{a t t s} / \mathbf{K}-m^{*} 2\right]$} \\
\hline 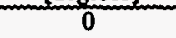 & 160.0 & 1199.4 & 6.307 \\
\hline 15 & 146.9 & 1101.0 & 5.790 \\
\hline 30 & 112.2 & 840.8 & 4.421 \\
\hline 45 & 68.0 & 509.6 & 2.680 \\
\hline 60 & 28.9 & 216.5 & 1.138 \\
\hline 75 & 5.7 & 42.6 & 0.224 \\
\hline 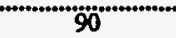 & $0.0 \%$ & 0.0 & 0.0̈0̈0” \\
\hline \multicolumn{4}{|c|}{ Grashoff Number $=9.79 \mathrm{E}+9$} \\
\hline \multicolumn{4}{|c|}{$\mathrm{T}$ mean $=500$} \\
\hline & & & \\
\hline Angle & Num & Heat Loss & h \\
\hline [degrees] & & [W"Watts] & 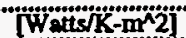 \\
\hline 0 & $\overline{178.3}$ & 1741.2 & 7.027 \\
\hline 15 & 163.6 & 1598.3 & 6.450 \\
\hline 30 & 125.0 & 1220.5 & 4.926 \\
\hline 45 & 75.7 & 739.7 & 2.985 \\
\hline 60 & 32.2 & 314.3 & 1.268 \\
\hline 75 & 6.3 & 61.8 & 0.249 \\
\hline 90 & 0.0 & 0.0 & 0.000 \\
\hline \multicolumn{4}{|c|}{ Grashoff Number $=1.21 E+10$} \\
\hline \multicolumn{4}{|c|}{$T_{\text {mean }}=600$} \\
\hline Angle & $\mathrm{Nu}$ & Heat Loss & h \\
\hline [degrees] & & [Watts] & [Watts $\left.\bar{K}-m^{\wedge} 2\right]$ \\
\hline 0 & 194.6 & 2342.5 & 7.670 \\
\hline 15 & 178.6 & 2150.2 & 7.041 \\
\hline 30 & 136.4 & 1642.0 & 5.376 \\
\hline 45 & 82.7 & 995.2 & 3.259 \\
\hline 60 & 35.1 & 422.8 & 1.384 \\
\hline 75 & 6.9 & 83.1 & 0.272 \\
\hline 90 & 0.0 & 0.0 & 0.000 \\
\hline & & & \\
\hline
\end{tabular}


Appendix 13: Stein and McDonald Model Heat Loss

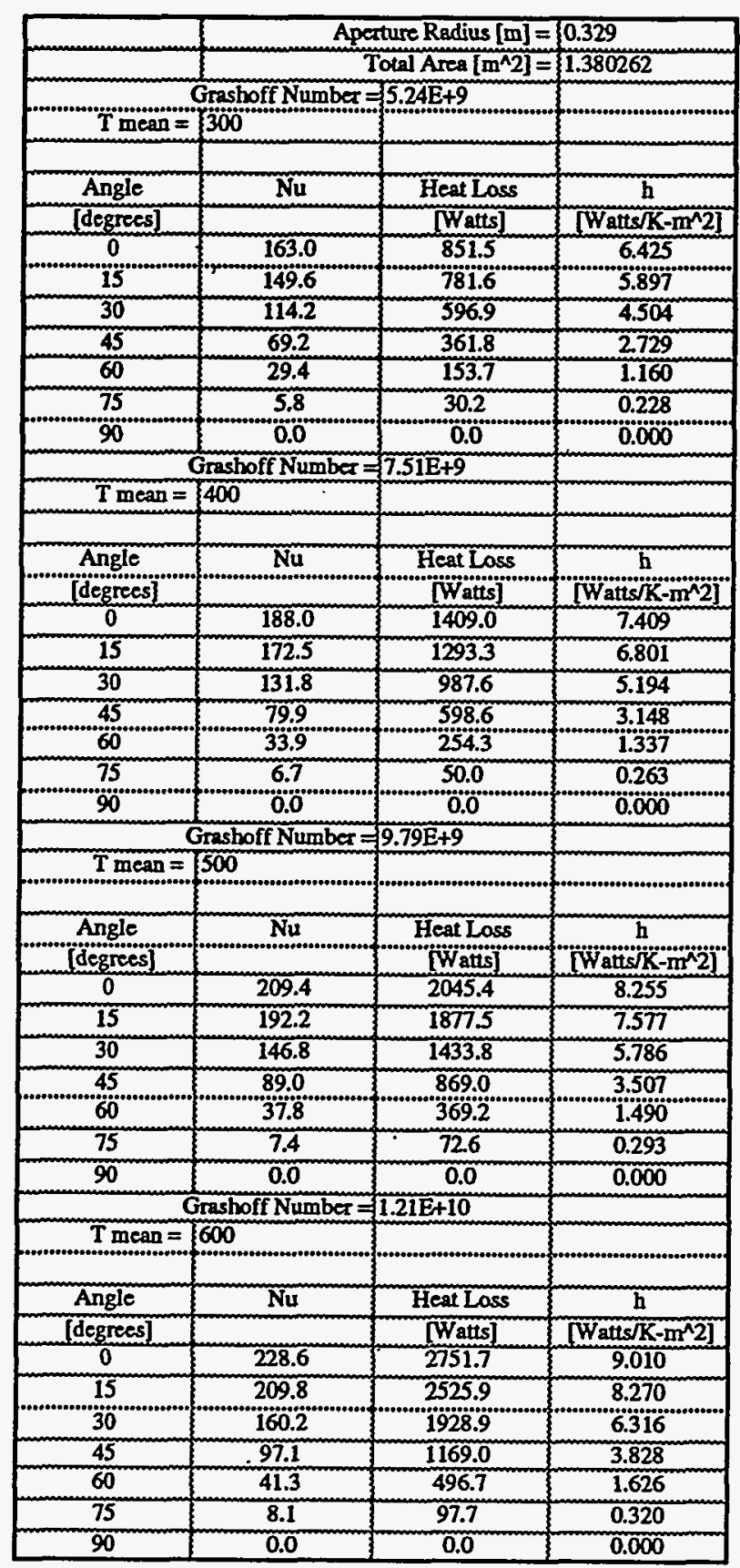




\section{Appendix 14: Shape Factors Formulas}

All formulas are developed from the basic disc-to-disc shape factor formula (20). The $\mathrm{N}$ by $\mathrm{N}$ coefficient matrix of the heat loss equation requires $\mathrm{N}^{2}$ shape factor equations (Eqn. 1). The shape factor equations are solved using a digital computer. The following section shows the development of the shape factor formulas used in the coefficient matrix.

(a) End Plate (section $1 \leftrightarrow$ aperture);

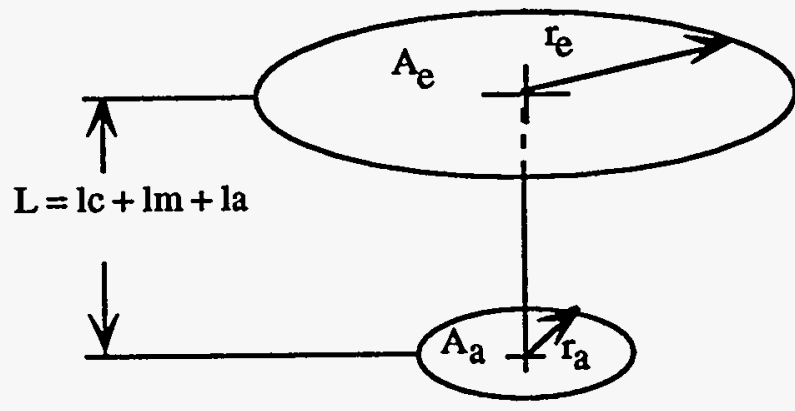

$$
\begin{aligned}
& \text { let } R_{e}=\frac{r_{e}}{L}, R_{a}=\frac{r_{a}}{L} \text {, and } X=1+\frac{1+R_{e}^{2}}{R_{a}^{2}} \\
& F_{A_{e}-A_{a}}=\frac{A_{a}}{A_{e}} F_{A_{a}-A_{e}} \\
& F_{A_{e}-A_{a}}=\frac{A_{a}}{2 A_{e}}\left[X-\sqrt{X^{2}-4\left(R_{e} / R_{a}\right)^{2}}\right] \\
& F_{A_{e}-A_{a}}=\frac{r_{a}^{2}}{2 r_{e}^{2}}\left[1+\frac{L^{2}+r_{e}^{2}}{r_{a}^{2}}-\sqrt{\left(1+\frac{L^{2}+r_{e}^{2}}{r_{a}^{2}}\right)^{2}-4\left(\frac{r_{e}}{r_{a}}\right)^{2}}\right] \\
& F_{A_{e}-A_{a}}=\frac{1}{2 r_{e}^{2}}\left\{\left(1_{c}+1_{m}+1_{a}\right)^{2}+r_{a}^{2}+r_{e}^{2}-\sqrt{\left[\left(1_{c}+l_{m}+l_{a}\right)^{2}+r_{a}^{2}+r_{e}^{2}\right]^{2}-4\left(r_{e} r_{a}\right)^{2}}\right\}
\end{aligned}
$$


(b) Center Cylinder (section $3 \leftrightarrow$ aperture):

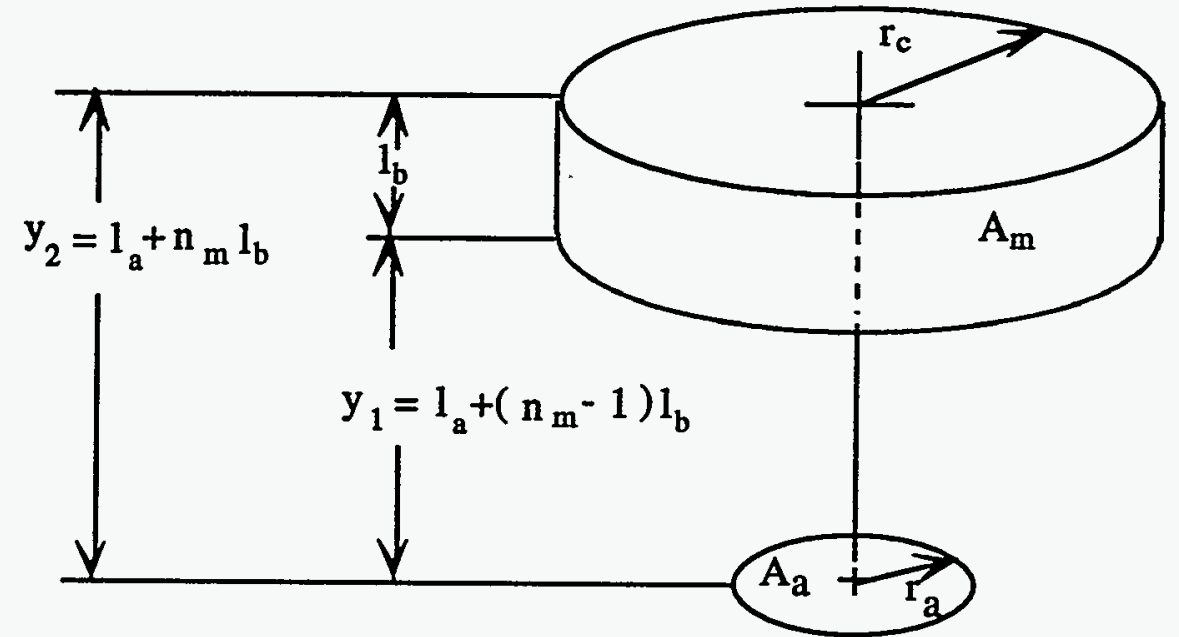

$$
\begin{aligned}
& F_{A_{a}-A_{\text {section }}}=F_{A_{a}-x-\text { section }_{1}}-F_{A_{a}-x \text {-section }} \\
& A_{a} F_{A_{a}-A_{\text {section }}}=A_{\text {section }} F_{A_{\text {section }}-A_{a}} \\
& \mathrm{~F}_{\mathrm{A}_{\text {section }}-\mathrm{A}_{\mathrm{a}}}=\frac{\mathrm{A}_{\mathrm{a}}}{\mathrm{A}_{\text {section }}} \mathrm{F}_{\mathrm{A}_{\mathrm{a}}-A_{\text {section }}} \\
& F_{A_{\text {section }}-A_{a}}=\frac{A_{a}}{A_{\text {section }}}\left[F_{A_{a}-\text { x-section }}-F_{A_{a}-\text { x-section }}\right] \\
& F_{A_{\text {section }}-A_{a}}=\frac{A_{a}}{A_{\text {section }}}\left[\frac{A_{c}}{A_{a}} F_{x \text {-section } 1}-A_{a}-\frac{A_{c}}{A_{a}} F_{x-\text { section }_{2}-A_{d}}\right] \\
& F_{A_{\text {section }}-A_{a}}=\frac{A_{c}}{A_{\text {section }}}\left[F_{x-\text { section }_{1}-A_{a}}-F_{x-\text { section }_{2}-A_{d}}\right] \\
& F_{A_{\text {section }}-A_{a}}=\frac{r_{c}}{2 I_{b}}\left[F_{x-\text { section }_{1}-A_{a}}-F_{x-\text { section }_{2}-A_{a}}\right] \\
& \text { let } \quad R_{1}=\frac{r_{c}}{y}, \quad R_{2}=\frac{r_{a}}{y}, \quad X=1+\frac{1+R_{2}^{2}}{R_{1}^{2}} \\
& \text { then } F_{A_{X-\text { section }-A_{a}}}=\frac{1}{2}\left[X-\sqrt{X^{2}-4\left(\frac{R_{2}}{R_{1}}\right)^{2}}\right]
\end{aligned}
$$

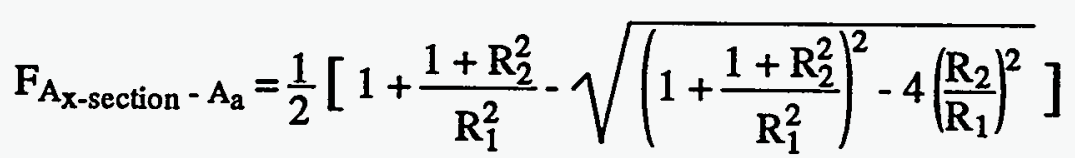




$$
\begin{aligned}
& \mathrm{F}_{\mathrm{A}_{\mathrm{x}-\operatorname{section}_{2}}-\mathrm{A}_{\mathrm{a}}}=\frac{1}{2}\left[1+\frac{1+\mathrm{r}_{\mathrm{a}}^{2} / \mathrm{y}_{2}^{2}}{\mathrm{r}_{\mathrm{r}}^{2} / \mathrm{y}_{2}^{2}}-\sqrt{\left(1+\frac{1+\mathrm{r}_{\mathrm{a}}^{2} / \mathrm{y}_{2}^{2}}{\mathrm{r}_{\mathrm{z}}^{2} / \mathrm{y}_{2}^{2}}\right)^{2}-4\left(\frac{\mathrm{r}_{\mathrm{a}}}{\mathrm{r}_{\mathrm{c}}}\right)^{2}}\right] \\
& \mathrm{F}_{\mathrm{A}_{\mathrm{x}-\mathrm{Section}}-\mathrm{A}_{\mathrm{a}}}=\frac{1}{2}\left[1+\frac{\mathrm{y}_{2}^{2}+\mathrm{r}_{\mathrm{a}}^{2}}{\mathrm{r}_{\mathrm{c}}^{2}}-\sqrt{\left(1+\frac{\mathrm{y}_{2}^{2}+\mathrm{r}_{\mathrm{a}}^{2}}{\mathrm{r}_{\mathrm{c}}^{2}}\right)^{2}-4\left(\frac{\mathrm{r}_{\mathrm{a}}{ }^{2}}{\mathrm{r}_{\mathrm{c}}}\right)^{2}}\right]
\end{aligned}
$$

and similarly:

$$
\begin{aligned}
& \mathrm{F}_{\mathrm{A}_{\mathrm{x}-\mathrm{section}}-\mathrm{A}_{\mathrm{a}}}=\frac{1}{2}\left[1+\frac{\mathrm{y}_{1}^{2}+\mathrm{r}_{\mathrm{a}}^{2}}{\mathrm{r}_{\mathrm{c}}^{2}}-\sqrt{\left(1+\frac{\mathrm{y}_{1}^{2}+\mathrm{r}_{\mathrm{a}}^{2}}{\mathrm{r}_{\mathrm{c}}^{2}}\right)^{2}-4\left(\frac{\mathrm{r}_{\mathrm{a}}}{\mathrm{r}_{\mathrm{c}}}\right)^{2}}\right] \\
& F_{A_{\text {section }}-A_{a}}=\frac{r_{c}}{4 l_{b}}\left[\frac{y_{1}^{2}+r_{a}^{2}}{r_{c}^{2}}-\sqrt{\left(1+\frac{y_{1}^{2}+r_{a}^{2}}{r_{c}^{2}}\right)^{2}-4\left(\frac{r_{a}}{r_{c}}\right)^{2}}-\frac{y_{2}^{2}+r_{a}^{2}}{r_{c}^{2}}\right. \\
& \left.+\sqrt{\left(1+\frac{y_{2}^{2}+r_{a}^{2}}{r_{c}^{2}}\right)^{2}-4\left(\frac{r_{a}}{r_{c}}\right)^{2}}\right] \\
& F_{A_{\text {section }}-A_{a}}=\frac{1}{4 r_{d} d_{b}}\left[y_{1}^{2}-y_{2}^{2}-\sqrt{\left(r_{a}^{2}+y_{1}^{2}+r_{c}^{2}\right)^{2}-4\left(r_{c} r_{a}\right)^{2}}+\sqrt{\left(r_{a}^{2}+y_{2}^{2}+r_{c}^{2}\right)^{2}-4\left(r_{c} r_{a}\right)^{2}}\right] \\
& F_{A_{\text {section }}-A_{a}}=\frac{1}{4 r_{c} l_{b}}\left[\left(l_{a}+\left(n_{m}-1\right) l_{b}\right)^{2}-\left(l_{a}+n_{m} l_{b}\right)^{2}-\sqrt{\left[\left(l_{a}+\left(n_{m}-1\right) l_{b}\right)^{2}+r_{a}^{2}+r_{c}^{2}\right]^{2}-4\left(r_{c} r_{a}\right)^{2}}\right. \\
& \left.+\sqrt{\left[\left(a_{a}+n_{m} l_{b}\right)^{2}+r_{a}^{2}+r_{c}^{2}\right]^{2}-4\left(r_{c} r_{a}^{2}\right.}\right]
\end{aligned}
$$

(c) Frustum (section $2 \leftrightarrow$ aperture):

The view factor for a section of the frustum from $A_{a}$ is equal to the view factor from $A_{a}$ to the circular cross-sectional area on the bottom of the frustum section minus the view factor from $A_{a}$ to the circular cross-section on the top of the frustum section. 


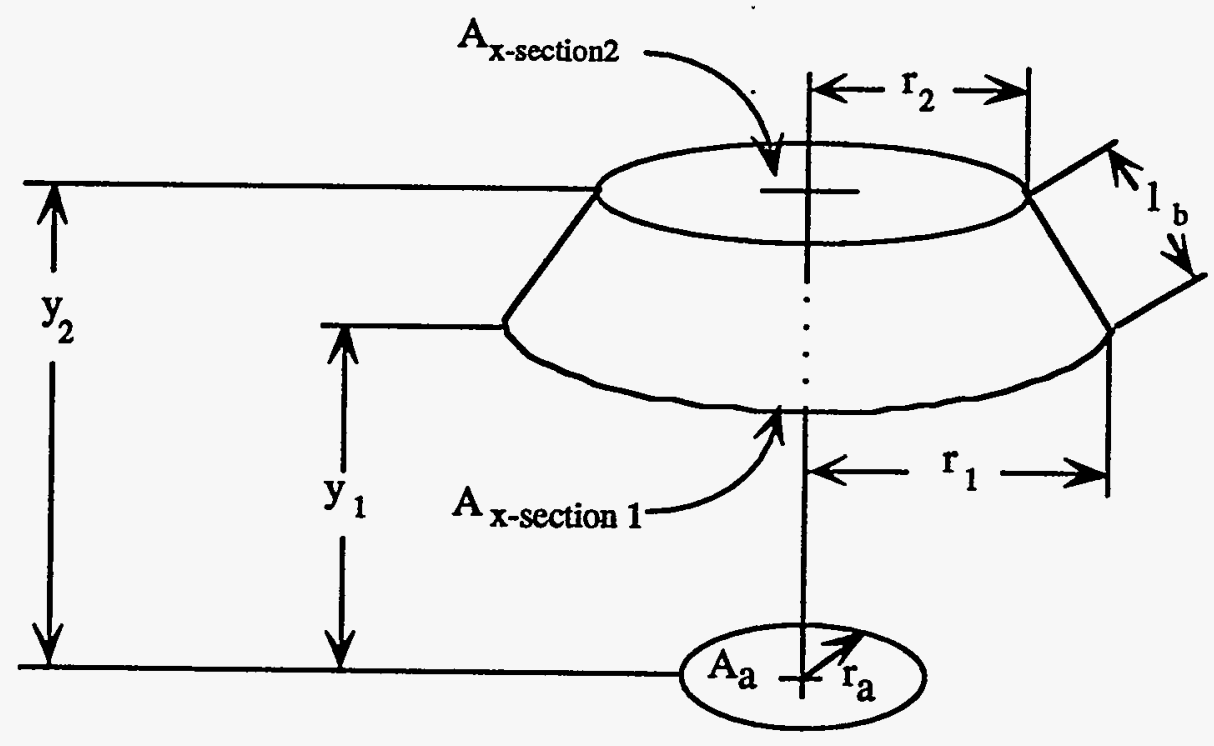

$$
\begin{aligned}
& F_{A_{a}-A_{\text {section }}}=F_{A_{a}-x \text {-section } 1}-F_{A_{a}-x-\text { section }_{2}} \\
& A_{a} F_{A_{a}}-A_{\text {section }}=A_{\text {section }} F_{A_{\text {section }}-A_{a}} \\
& F_{A_{\text {section }}-A_{a}}=\frac{A_{a}}{A_{\text {section }}} F_{A_{a}-A_{\text {section }}} \\
& F_{A_{\text {section }}-A_{a}}=\frac{A_{a_{a}}}{A_{c}}\left[F_{A_{a}-x-\text { section }_{1}}-F_{A_{a}-x-\text { section }_{2}}\right] \\
& F_{A_{\text {section }}-A_{a}}=\frac{A_{a}}{A_{\text {section }}}\left[\frac{A_{x-\text { section }_{1}}}{A_{a}} F_{x-\text { section }_{1}-A_{a}}-\frac{A_{x-\text { section }_{2}}}{A_{a}} F_{x-\text { section }_{2}-A_{a}}\right] \\
& F_{A_{\text {section }}-A_{a}}=\frac{1}{A_{\text {section }}}\left[A_{x-\text { section }_{1}} F_{x-\text { section }_{1}-A_{a}}-A_{x-\text { section }_{2}} F_{x-\text { section }_{2}-A_{a}}\right] \\
& F_{A_{\text {section }}-A_{a}}=\frac{1}{\left(r_{1}+r_{2}\right) l_{b}}\left[r_{1}^{2} F_{x-\text { section }_{1}-A_{a}}-r_{2}^{2} F_{x-\text { section }_{2}-A_{a}}\right] \\
& \text { let } \quad R_{1}=\frac{r_{x-s e c t i o n}}{y}, \quad R_{2}=\frac{r_{a}}{y}, \quad X=1+\frac{1+R_{2}^{2}}{R_{1}^{2}}
\end{aligned}
$$




$$
\begin{aligned}
& \text { then } F_{A_{X-S e c t i o n}-A_{a}}=\frac{1}{2}\left[X-\sqrt{X^{2}-4\left(\frac{R_{2}}{R_{1}}\right)^{2}}\right] \\
& \mathrm{F}_{\mathrm{A}_{\mathrm{x}-\text { section }}-\mathrm{A}_{\mathrm{a}}}=\frac{1}{2}\left[1+\frac{1+\mathrm{R}_{2}^{2}}{\mathrm{R}_{1}^{2}}-\sqrt{\left(1+\frac{1+\mathrm{R}_{2}^{2}}{\mathrm{R}_{1}^{2}}\right)^{2}-4\left(\frac{\mathrm{R}_{2}}{\mathrm{R}_{1}}\right)^{2}}\right]
\end{aligned}
$$

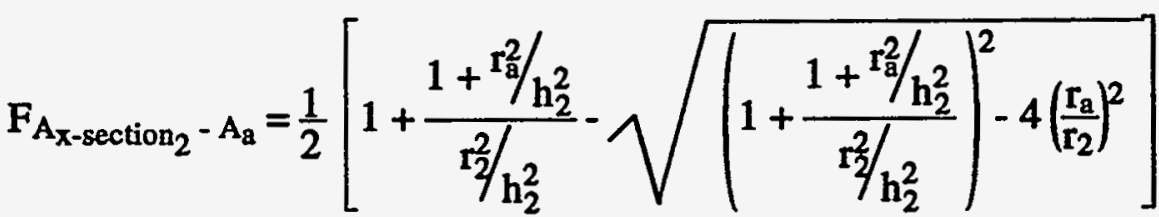

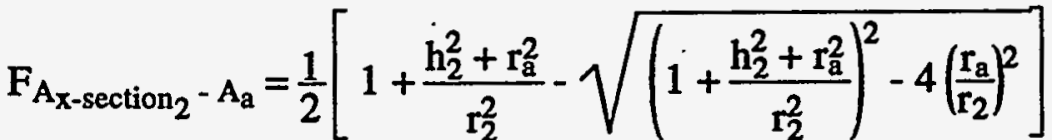

and similarly:

$$
\begin{aligned}
& F_{A_{x-\text { section }_{1}}-A_{a}}=\frac{1}{2}\left[1+\frac{h_{1}^{2}+r_{a}^{2}}{r_{1}^{2}}-\sqrt{\left(1+\frac{h_{1}^{2}+r_{a}^{2}}{r_{1}^{2}}\right)^{2}-4\left(\frac{r_{a}}{r_{1}}\right)^{2}}\right] \\
& F_{A_{\text {section }}-A_{a}}=\frac{1}{2 l_{b}\left(r_{1}+r_{2}\right)}\left[r_{1}^{2}-r_{2}^{2}+h_{1}^{2}-h_{2}^{2}-\sqrt{\left(r_{1}^{2}+h_{1}^{2}+r_{a}^{2}\right)^{2}-4\left(r_{1} r_{a}\right)^{2}}\right. \\
& \left.+\sqrt{\left(r_{2}^{2}+h_{2}^{2}+r_{a}^{2}\right)^{2}-4\left(r_{2} r_{a}\right)^{2}}\right] \\
& h_{1}=1_{a}+1_{m}+\left(n_{m}-1\right) \frac{1_{c}}{N_{c}} \quad h_{2}=1_{a}+l_{m}+n_{m} \frac{l_{c}}{N_{c}}
\end{aligned}
$$

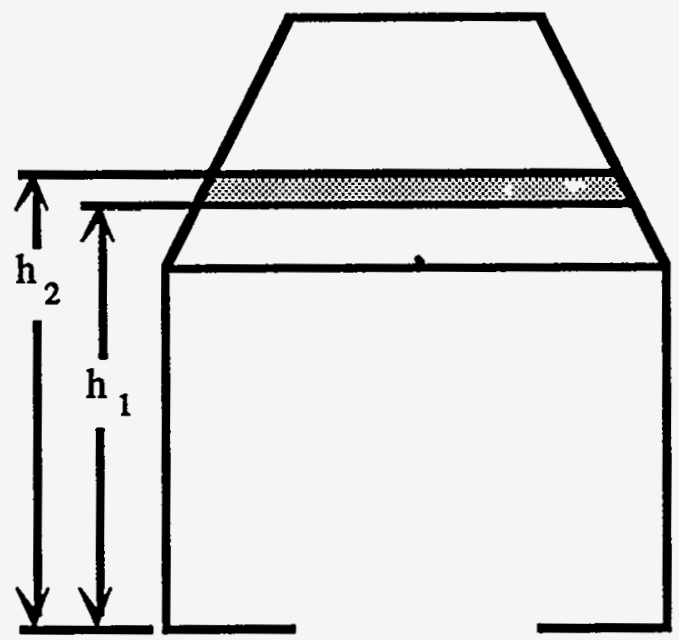




$$
\begin{gathered}
F_{n_{m}-A_{a}}=\frac{r_{2}=r_{c}-n_{m} \frac{r_{c}-r_{e}}{N_{c}} \quad r_{1}=r_{c}-\left(n_{m}-1\right) \frac{r_{c}-r_{e}}{N_{c}}}{2 l_{b}\left[2 r_{c}-\left(2 n_{m}-1\right) \frac{\left(r_{c}-r_{e}\right)}{N_{c}}\right]}\left\{\left[r_{c}-\left(n_{m}-1\right)\left(\frac{r_{c}-r_{e}}{N_{c}}\right)\right]^{2}-\left[r_{c}-n_{m}\left(\frac{r_{c}-r_{e}}{N_{c}}\right)\right]^{2}\right. \\
+\left[l_{a}+l_{m}+\left(n_{m}-1\right) \frac{l_{c}}{N_{c}}\right]^{2}-\left[l_{a}+l_{m}+n_{m} \frac{l_{c}}{N_{c}}\right]^{2} \\
-\sqrt{\left\{\left[r_{c}-\left(n_{m}-1\right)\left(\frac{r_{c}-r_{e}}{N_{c}}\right)\right]^{2}+\left(l_{a}+l_{m}+\left(n_{m}-1\right) \frac{l_{c}}{N_{c}}\right)^{2}+r_{a}^{2}\right\}^{2}-4\left\{\left[r_{c}-\left(n_{m}-1\right)\left(\frac{r_{c}-r_{e}}{N_{c}}\right)\right] r_{a}\right)^{2}} \\
+\sqrt{\left(\left[r_{c}-n_{m}\left(\frac{r_{c}-r_{e}}{N_{c}}\right)\right]^{2}+\left(l_{a}+l_{m}+n_{m} \frac{l_{c}}{N_{c}}\right)^{2}+r_{a}^{2}\right\}^{2}-4\left\{\left[r_{c}-n_{m}\left(\frac{r_{c}-r_{e}}{N_{c}}\right)\right] r_{a}\right)^{2}}
\end{gathered}
$$

(d) Spacer Ring (section $4 \leftrightarrow$ aperture):

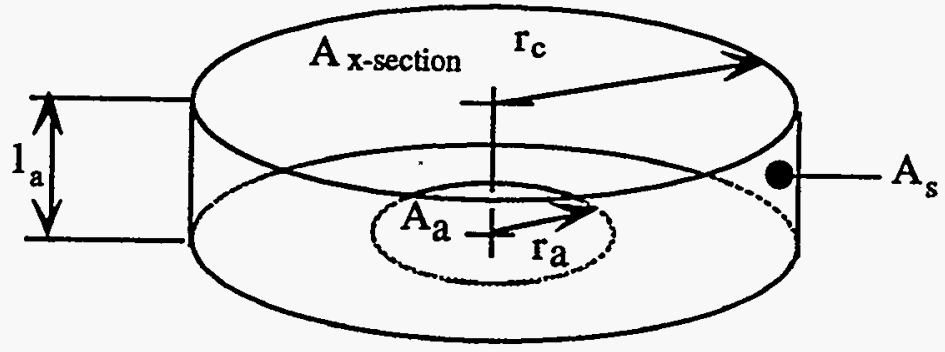

$$
\begin{gathered}
F_{A_{a}-A_{s}}=1-F_{A_{a}-A_{x-\text { section }}} \\
F_{A_{s}-A_{a}}=\frac{A_{a}}{A_{s}} F_{A_{a}-A_{s}} \\
F_{A_{a}-A_{x-\text { section }}}=\frac{A_{x-\text { section }}}{A_{a}} F_{A_{x-\text { section }}-A_{a}} \\
F_{A_{s}-A_{a}}=\frac{A_{a}}{A_{s}}\left[1-\frac{A_{x-\text { section }}}{A_{a}} F_{A_{x-\text { section }}-A_{a}}\right] \\
F_{A_{x-\text { section }}-A_{a}}=\frac{1}{2}\left[X-\sqrt{X^{2}-4\left(\frac{R_{a}}{R_{c}}\right)^{2}}\right] \\
F_{A_{s}-A_{a}}=\frac{r_{a}^{2}}{2 r_{c} l_{a}}\left\langle 1-\frac{r_{c}^{2}}{2 r_{a}^{2}}\left[X-\sqrt{X^{2}-4\left(\frac{R_{a}}{R_{c}}\right)^{2}}\right]\right)
\end{gathered}
$$




$$
\text { where } \begin{gathered}
\quad R_{a}=\frac{r_{a}}{l_{a}}, \quad R_{c}=\frac{r_{c}}{l_{a}} \\
X=1+\frac{1+\left(\frac{\left.r_{a} / l_{a}\right)^{2}}{\left(r_{1} /\right)^{2}}\right.}{X=1+\frac{1_{a}^{2}+r_{a}^{2}}{r_{c}^{2}}}
\end{gathered}
$$

therefore:

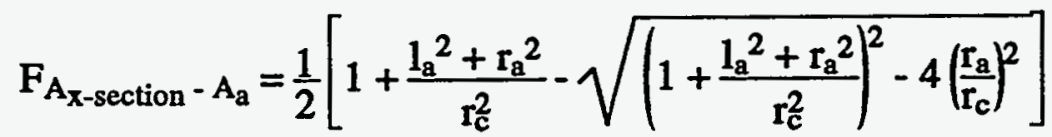

$$
\begin{aligned}
& F_{A_{s}-A_{a}}=\frac{r_{a}^{2}}{2 r_{c} d_{a}}\left\{1-\frac{r_{c}^{2}}{2 r_{a}^{2}}\left[1+\frac{l_{a}^{2}+r_{a}^{2}}{r_{c}^{2}}-\sqrt{\left(1+\frac{l_{a}^{2}+r_{a}^{2}}{r_{c}^{2}}\right)^{2}-4\left(\frac{r_{a}}{r_{c}}\right)^{2}}\right]\right\} \\
& F_{A_{s}-A_{a}}=\frac{r_{a}^{2}}{2 r_{c} d_{a}}\left\{1-\frac{1}{2 r_{a}^{2}}\left[\left(r_{c}^{2}+l_{a}^{2}+r_{a}^{2}\right)-\sqrt{\left(r_{c}^{2}+l_{a}^{2}+r_{a}^{2}\right)^{2}-4\left(r_{a} r^{2}\right)^{2}}\right]\right\}
\end{aligned}
$$

(e)(section iband $j \leftrightarrow$ section $i$ band $j$ : Shape Factors from a Surface Onte Itself

For the flat surfaces (aperture, annulus, and end plate) $F_{i-i}=0$

For the cylindrical and frustum sections:

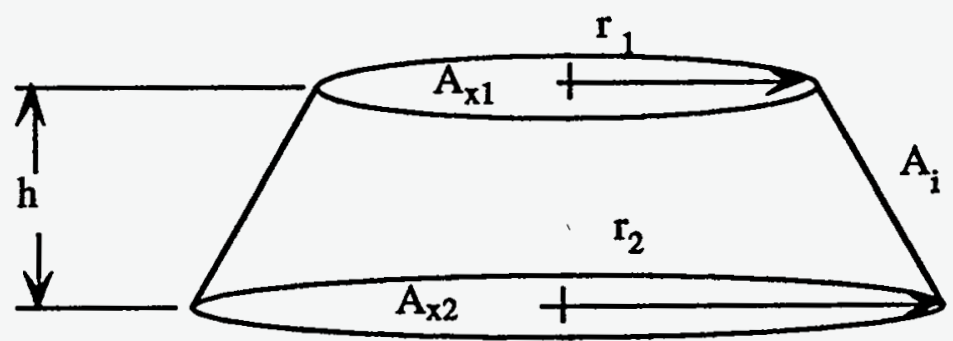

$$
\begin{gathered}
F_{i-i}=1-F_{i-\times 1}-F_{i-x 2} \\
F_{i=x 1}=\frac{A_{x 1}}{A_{i}} F_{x 1-i} \text { and } F_{i-x 2}=\frac{A_{x 2}}{A_{i}} F_{x 2-i}
\end{gathered}
$$

therefore

$$
F_{i-x 1}=\frac{A_{x 1}}{A_{i}} F_{x 1-i} \text { and } F_{i-x 2}=\frac{A_{x 2}}{A_{i}} F_{x 2-i}
$$


and

$$
\begin{aligned}
& F_{x 1-i}=1-F_{x 1-x 2} \text { and } F_{x 2-i}=1-F_{x 2-x 1} \\
& F_{x 2-x 1}=\frac{A_{x 1}}{A_{x 2}} F_{x 1-x 2} \\
& F_{i-i}=1-\frac{A_{x 1}}{A_{i}}\left[1-F_{x 1-x 2}\right]-\frac{A_{x 2}}{A_{i}}\left[1-\frac{A_{x 1}}{A_{x 2}} F_{x 1-x 2}\right] \\
& F_{i-i}=1-\frac{A_{x 1}}{A_{i}}-\frac{A_{x 2}}{A_{i}}+2 \frac{A_{x 1}}{A_{i}} F_{x 1-x 2} \\
& F_{x 1-x 2}=\frac{1}{2}\left[x-\sqrt{x^{2}-4\left[\frac{R_{2}}{R_{2}}\right]^{2}}\right] \\
& \text { where } R_{1}=\frac{r_{1}}{h}, \quad R_{2}=\frac{r_{2}}{h}, \quad \text { and } X=1+\frac{h^{2}+r_{2}^{2}}{r_{1}^{2}} \\
& F_{x 1-x 2}=\frac{1}{2}\left[1+\frac{h^{2}+r_{2}^{2}}{r_{1}^{2}}-\sqrt{\left[1+\frac{h^{2}+r_{2}^{2}}{r_{1}^{2}}\right]^{2}-4\left[\frac{r_{2}}{r_{1}}\right]^{2}}\right] \\
& F_{i-i}=1-\frac{A_{x 1}}{A_{i}}-\frac{A_{x 2}}{A_{i}}+\frac{A_{x 1}}{A_{i}}\left[1+\frac{h^{2}+r_{2}^{2}}{r_{1}^{2}}-\sqrt{\left[1+\frac{h^{2}+r_{2}^{2}}{r_{1}^{2}}\right]^{2}-4\left[\frac{r_{2}}{r_{1}}\right]^{2}}\right] \\
& \mathrm{F}_{\mathrm{i}-\mathrm{i}}=1-\frac{\mathrm{r}_{2}^{2}}{\left(\mathrm{r}_{1}+\mathrm{r}_{2}\right) \mathrm{l}_{\mathrm{b}}}+\frac{\mathrm{r}_{1}^{2}}{\left(\mathrm{r}_{1}+\mathrm{r}_{2}\right) \mathrm{l}_{\mathrm{b}}}\left[\frac{\mathrm{h}^{2}+\mathrm{r}_{2}^{2}}{\mathrm{r}_{1}^{2}}-\sqrt{\left[1+\frac{\mathrm{h}^{2}+\mathrm{r}_{2}^{2}}{\mathrm{r}_{1}^{2}}\right]^{2}-4\left[\frac{\mathrm{r}_{2}}{\mathrm{r}_{1}}\right]^{2}}\right]
\end{aligned}
$$

For the spacer ring (section $4 \leftrightarrow$ section 4 ):

$$
r_{1}=r_{2}=r_{c} \text { and } h=l_{a}
$$

For the hot cylinder (section $3_{\text {band } i} \leftrightarrow$ section 3 band $\mathrm{i}$ ):

$$
r_{1}=r_{2}=r_{c} \text { and } h=l_{b}
$$


For the frustum (section 2 band $\mathrm{i} \leftrightarrow$ section 2 band $\mathrm{i}$ ):

$$
r_{1}=r_{c}-\left(r_{c}-r_{e}\right) \frac{\left(n_{c}-1\right)}{N_{c}}, r_{2}=r_{c}-\left(r_{c}-r_{e}\right) \frac{n_{c}}{N_{c}}, \quad \text { and } h=\frac{1 d_{b}}{\sqrt{1_{c}^{2}+\left(r_{c}-r_{e}\right)^{2}}}
$$

Shape Factors from Bands of the Cylindrical and Frustum Sections to other Bands of the Cylindrical and Frustum Sections (section $i$ band $j \leftrightarrow$ section $i_{\text {band }} k$ )

The following shape factor formulas are used between different bands of the frustum section, between different bands of the hot cylindrical section, between bands of the hot cylindrical section and bands of the frustum section, between the spacer ring and bands of the hot cylindrical section, and between the spacer ring and bands of the frustum section.

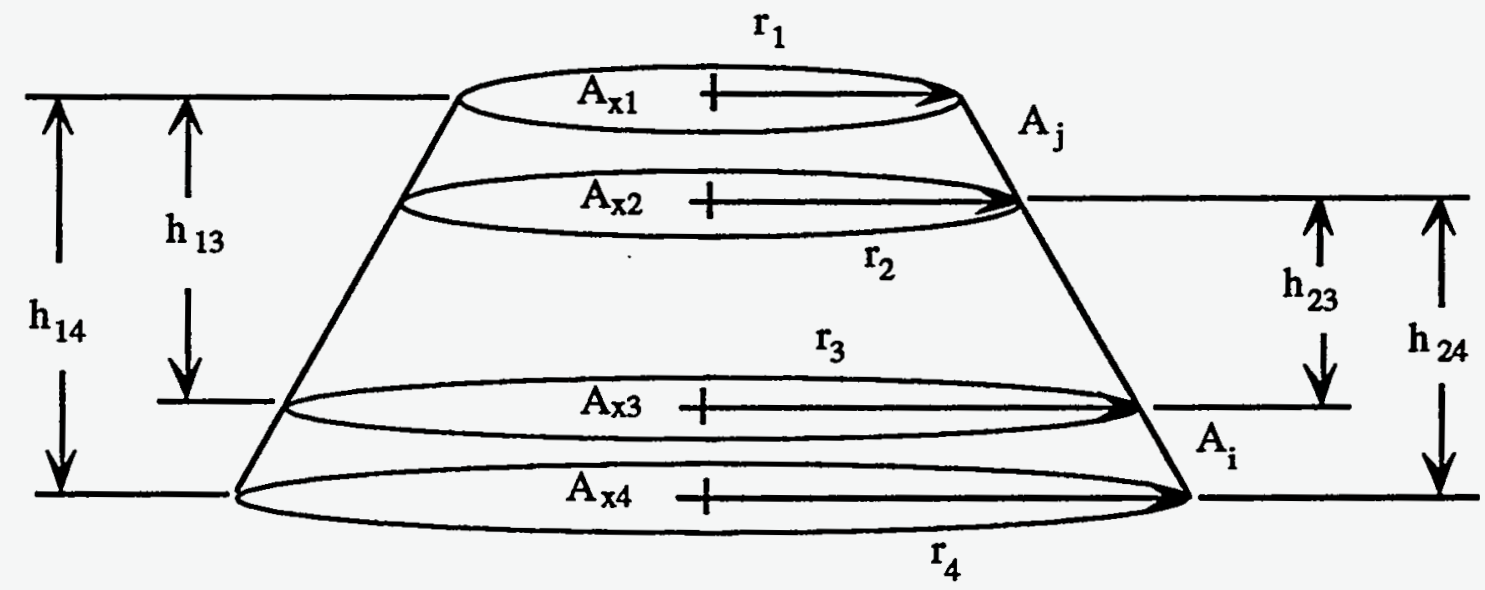

$$
\begin{gathered}
F_{i-j}=F_{i-x 2}-F_{i-x 1} \\
F_{x 1-i}=F_{x i-x 3}-F_{x 1-x 4} \\
F_{x 2-i}=F_{x 2}-x 3-F_{x 2-x 4} \\
F_{i-x 1}=\frac{A_{x 1}}{A_{i}} F_{x 1-i} \text { and } F_{i-x 2}=\frac{A_{x 2}}{A_{i}} F_{x 2-i}
\end{gathered}
$$




$$
\begin{gathered}
F_{i-j}=\frac{A_{x 2}}{A_{i}}\left[F_{x 2-x 3}-F_{x 2-x 4}\right]-\frac{A_{x 1}}{A_{i}}\left[F_{x 1-x 3}-F_{x 1-x 4}\right] \\
F_{i-j}=\frac{r_{2}^{2}}{\left(r_{3}+r_{4}\right) l_{b}}\left[F_{x 2-x 3}-F_{x 2-x 4}\right]-\frac{r_{1}^{2}}{\left(r_{3}+r_{4}\right) l_{b}}\left[F_{x 1-x 3}-F_{x 1-x 4}\right] \\
F_{x n-x m}=\frac{1}{2}\left[1+\frac{h_{n m}^{2}+r_{m}^{2}}{r_{n}^{2}}-\sqrt{\left[1+\frac{h_{n m}^{2}+r_{m}^{2}}{r_{n}^{2}}\right]^{2}-4\left[\frac{r_{m}}{r_{n}}\right]^{2}}\right]
\end{gathered}
$$

between different bands of the frustum section (section 2 band $i \leftrightarrow \operatorname{section} 2$ band j):

$$
\begin{gathered}
r_{1}=r_{c}-\left(r_{c}-r_{e}\right) \frac{n_{j}}{N_{c}} \\
r_{2}=r_{c}-\left(r_{c}-r_{e}\right) \frac{\left(n_{j}-1\right)}{N_{c}} \\
r_{3}=r_{c}-\left(r_{c}-r_{e}\right) \frac{n_{i}}{N_{c}} \\
r_{4}=r_{c}-\left(r_{c}-r_{e}\right) \frac{\left(n_{i}-1\right)}{N_{c}} \\
h=\frac{1 d_{b}}{\sqrt{1_{c}^{2}+\left(r_{c}-r_{e}\right)^{2}}} \\
h_{13}=h_{24}=\left(n_{j}-n_{j}\right) h \\
h_{14}=\left(n_{j}-n_{i}+1\right) h \\
h_{23}=\left(n_{j}-n_{i}-1\right) h
\end{gathered}
$$

between different bands of the hot cylindrical section (section $3_{\text {band } i} \leftrightarrow$ section $3_{\text {band }}$ ) :

$$
\begin{aligned}
& r_{1}=r_{2}=r_{3}=r_{4}=r_{c} \\
& h_{13}=h_{24}=\left(n_{j}-n_{j}\right) l_{b} \\
& h_{14}=\left(n_{j}-n_{i}+1\right) l_{b} \\
& h_{23}=\left(n_{j}-n_{i}-1\right) l_{b}
\end{aligned}
$$


between bands of the hot cylindrical section and bands of the frustum section (section 2 band $\mathrm{i} \leftrightarrow$ section $3_{\text {band }}$ ):

$$
\begin{gathered}
r_{1}=r_{c}-\left(r_{c}-r_{\partial}\right) \frac{n_{j}}{N_{c}} \\
r_{2}=r_{c}-\left(r_{c}-r_{\partial}\right) \frac{\left(n_{j}-1\right)}{N_{c}} \\
r_{3}=r_{4}=r_{c} \\
h=\frac{1 l_{b}}{\sqrt{l_{c}^{2}+\left(r_{c}-r_{\partial}\right)^{2}}} \\
h_{13}=h_{24}=l_{m}-n_{i} l_{b}+n_{j} h \\
h_{14}=l_{m}-\left(n_{i}-1\right) l_{b}+n_{j} h \\
h_{23}=l_{m}-n_{i} l_{b}+\left(n_{j}-1\right) h
\end{gathered}
$$

between the spacer ring and bands of the hot cylindrical section (section $4 \leftrightarrow$ section 3 band i):

$$
\begin{gathered}
F_{\text {spacer }-j}=\frac{r_{2}^{2}}{\left(r_{3}+r_{4}\right) l_{a}}\left[F_{x 2-x 3}-F_{x 21-x 4}\right]-\frac{r_{1}^{2}}{\left(r_{3}+r_{4}\right) l_{a}}\left[F_{x 1-x 3}-F_{x 1-x 4}\right] \\
F_{x n-x m}=\frac{1}{2}\left[1+\frac{h_{n m}^{2}+r_{m}^{2}}{r_{n}^{2}}-\sqrt{\left[1+\frac{h_{n m}^{2}+r_{m}^{2}}{r_{n}^{2}}\right]^{2}-4\left[\frac{r_{m}}{r_{n}}\right]^{2}}\right] \\
r_{1}=r_{2}=r_{3}=r_{4}=r_{c} \\
h_{13}=n_{j} l_{b} \\
h_{14}=n_{j} l_{b}+l_{a} \\
h_{23}=\left(n_{j}-1\right) l_{b} \\
h_{24}=\left(n_{j}-1\right) l_{b}+l_{a}
\end{gathered}
$$

between the spacer ring and bands of the frustum section (section $4 \leftrightarrow$ section 2 band i): 


$$
\begin{gathered}
r_{1}=r_{c}-\left(r_{c}-r_{\partial}\right) \frac{n_{j}}{N_{c}} \\
r_{2}=r_{c}-\left(r_{c}-r_{e}\right) \frac{\left(n_{j}-1\right)}{N_{c}} \\
r_{3}=r_{4}=r_{c} \\
h=\frac{l_{c} l_{b}}{\sqrt{l_{c}^{2}+\left(r_{c}-r_{e}\right)^{2}}} \\
h_{13}=l_{m}+n_{j} h \\
h_{14}=1_{m}+n_{j} h+l_{a} \\
h_{23}=l_{m}+\left(n_{j}-1\right) h \\
h_{24}=1_{m}+\left(n_{j}-1\right) h+l_{a}
\end{gathered}
$$

\section{Shape Factors from Circular Sections to Bands of the Cylindrical and Frustum Sections:}

The following shape factor formulas are used between the end plate and bands of the hot cylindrical section, bands of the frustum section, and the spacer section, between the aperture and the bands of the hot cylindrical section, bands of the frustum section, and the spacer section, and between the annulus and aperture combined and bands of the hot cylindrical section, bands of the frustum section, and the spacer section.

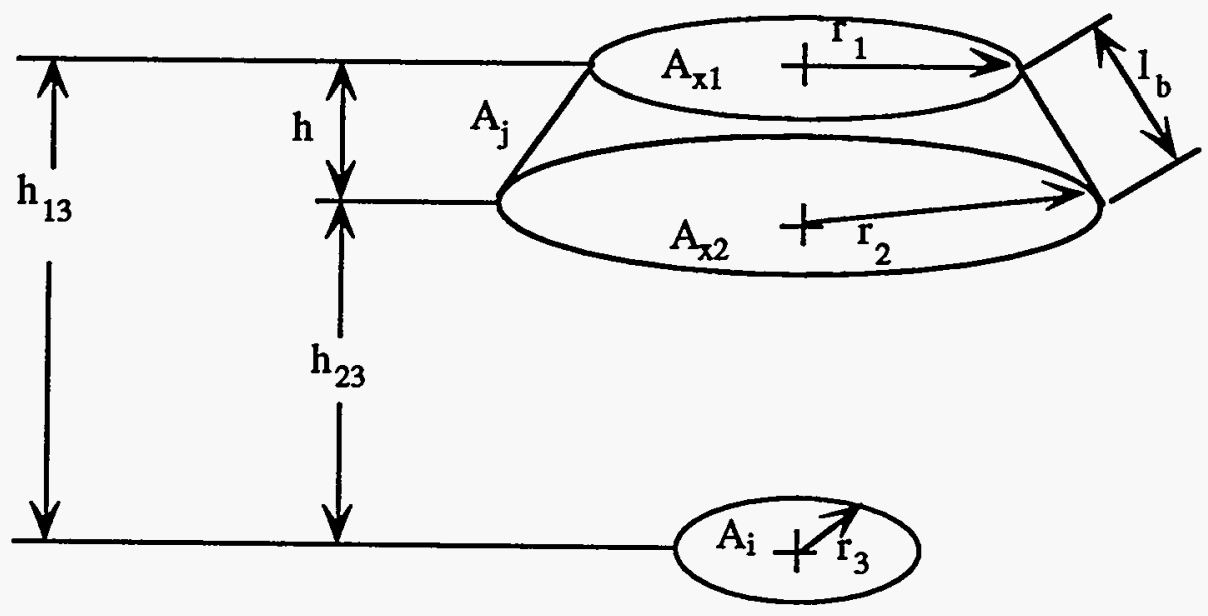




$$
F_{i-j}=F_{i}-x 2-F_{i}-x 1
$$

$F_{i-11}=\frac{1}{2}\left[1+\frac{h_{13}^{2}+r_{1}^{2}}{r_{3}^{2}}-\sqrt{\left[1+\frac{h_{13}^{2}+r_{1}^{2}}{r_{3}^{2}}\right]^{2}-4 \cdot\left[\frac{r_{1}}{r_{3}}\right]^{2}}\right]$

$F_{i-\times 2}=\frac{1}{2}\left[1+\frac{h_{23}^{2}+r_{2}^{2}}{r_{3}^{2}}-\sqrt{\left[1+\frac{h_{23}^{2}+r_{2}^{2}}{r_{3}^{2}}\right]^{2}-4\left[\frac{r_{2}}{r_{3}}\right]^{2}}\right]$

$F_{i-j}=\frac{1}{2}\left[\frac{h_{23}^{2}+r_{2}^{2}}{r_{3}^{2}}-\sqrt{\left[1+\frac{h_{23}^{2}+r_{2}^{2}}{r_{3}^{2}}\right]^{2}-4\left[\frac{r_{2}}{r_{3}}\right]^{2}}\right]-\frac{1}{2}\left[\frac{h_{13}^{2}+r_{1}^{2}}{r_{3}^{2}}-\sqrt{\left[1+\frac{h_{13}^{2}+r_{1}^{2}}{r_{3}^{2}}\right]^{2}}-\right.$

between the end plate and bands of the hot cylindrical section (section $1 \leftrightarrow$ section 3 band i):

$$
\begin{gathered}
r_{1}=r_{2}=r_{c} \\
r_{3}=r_{e} \\
h_{23}=1_{c}+\left(N_{m}-n_{j}\right) l_{b} \\
h_{13}=l_{c}+\left(N_{m}-n_{j}+1\right) l_{b}
\end{gathered}
$$

between the end plate and bands of the frustum section (section $1 \leftrightarrow$ section 2 band i):

$$
\begin{gathered}
r_{1}=r_{e}+\left(r_{c}-r_{e}\right)\left[1-\frac{n_{j}-1}{N_{c}}\right] \\
r_{2}=r_{e}+\left(r_{c}-r_{e}\right)\left[1-\frac{n_{j}}{N_{c}}\right] \\
r_{3}=r_{e}
\end{gathered}
$$




$$
\begin{gathered}
h=\frac{1 l_{b}}{\sqrt{l_{c}^{2}+\left(r_{c}-r_{e}\right)^{2}}} \\
h_{23}=\left(N_{c}-n_{j}\right) h \\
h_{13}=\left(N_{c}-n_{j}+1\right) h
\end{gathered}
$$

between the end plate and the spacer section (section $1 \leftrightarrow$ section 4 ):

$$
\begin{gathered}
\mathrm{r}_{1}=\mathrm{r}_{2}=\mathrm{r}_{\mathrm{c}} \\
\mathrm{r}_{3}=\mathrm{r}_{\mathrm{e}} \\
\mathrm{h}_{23}=\mathrm{l}_{\mathrm{c}}+\mathrm{l}_{\mathrm{m}} \\
\mathrm{h}_{13}=\mathrm{l}_{\mathrm{c}}+\mathrm{l}_{\mathrm{m}}+\mathrm{l}_{\mathrm{a}}
\end{gathered}
$$

between the annulus and aperture combined and bands of the hot cylindrical section (section $5+$ aperture $\leftrightarrow$ section 3 band i):

$$
\begin{gathered}
r_{1}=r_{2}=r_{3}=r_{c} \\
h_{23}=l_{a}+\left(n_{j}-1\right) l_{b} \\
h_{13}=l_{a}+n_{j} l_{b}
\end{gathered}
$$

between the annulus and aperture combined and bands of the frustum section (section $5+$ aperture $\leftrightarrow$ section 2 band i):

$$
\begin{gathered}
r_{1}=r_{c}-n_{j} \frac{\left(r_{c}-r_{e}\right)}{N_{c}} \\
r_{2}=r_{c}-\left(n_{j}-1\right) \frac{\left(r_{c}-r_{e}\right)}{N_{c}} \\
h=\frac{1_{c} l_{b}}{\sqrt{1_{c}^{2}+\left(r_{c}-r_{j}\right)^{2}}} \\
h_{23}=1_{a}+1_{m}+\left(n_{j}-1\right) h \\
h_{13}=l_{a}+l_{m}+n_{j} h
\end{gathered}
$$

between the annulus and aperture combined and the spacer section (section $5+$ aperture $\leftrightarrow$ section 4 ): 


$$
\begin{gathered}
r_{1}=r_{2}=r_{3}=r_{c} \\
h_{23}=0 \\
h_{13}=1_{a}
\end{gathered}
$$

between the aperture and bands of the hot cylindrical section (aperture $\leftrightarrow$ section 3 bands i):

$$
\begin{gathered}
r_{1}=r_{2}=r_{c} \\
r_{3}=r_{a} \\
h_{23}=1_{a}+\left(n_{j}-1\right) l_{b} \\
h_{13}=1_{a}+n_{j} l_{b}
\end{gathered}
$$

between the aperture and bands of the frustum section (aperture $\leftrightarrow$ section 2 bands i):

$$
\begin{gathered}
r_{1}=r_{c}-n_{j} \frac{\left(r_{c}-r_{e}\right)}{N_{c}} \\
r_{2}=r_{c}-\left(n_{j}-1\right) \frac{\left(r_{c}-r_{e}\right)}{N_{c}} \\
h=\frac{r_{3}=r_{a}}{\sqrt{1_{c}^{2}+\left(r_{c}-r_{e}\right)^{2}}} \\
h_{23}=1_{a}+l_{m}+\left(n_{j}-1\right) h \\
h_{13}=l_{a}+1_{m}+n_{j} h
\end{gathered}
$$

between the aperture and the spacer section

(aperture $\leftrightarrow$ section 4): 


$$
\begin{gathered}
r_{1}=r_{2}=r_{c} \\
r_{3}=r_{a} \\
h_{23}=0 \\
h_{13}=l_{a}
\end{gathered}
$$

Shape Factors from Circular Sections to Other Circular Sections:

The following shape factor formulas are used between the end plate and the aperture: and between the end plate and the aperture and annulus combined.
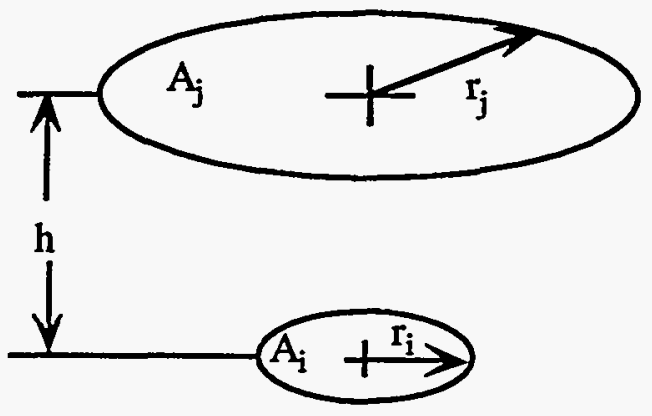

$$
F_{i-j}=\frac{1}{2}\left[1+\frac{h^{2}+r_{j}^{2}}{r_{i}^{2}}-\sqrt{\left[1+\frac{h^{2}+r_{j}^{2}}{r_{i}^{2}}\right]^{2}-4\left[\frac{r_{j}}{r_{i}}\right]^{2}}\right]
$$

between the end plate and the aperture

(section $1 \leftrightarrow$ aperture):

$$
\begin{gathered}
r_{i}=r_{e} \\
r_{j}=r_{a} \\
h=l_{a}+l_{m}+l_{c}
\end{gathered}
$$

between the end plate and the aperture and annulus combined (section $1 \leftrightarrow$ aperture + section 5): 


$$
\begin{gathered}
r_{i}=r_{e} \\
r_{j}=r_{c} \\
h=1_{a}+1_{m}+1_{c}
\end{gathered}
$$

For shape factors from the spacer section, bands of the hot cylindrical section, and bands of the frustum section to the annulus section the following relationship is used:

$$
F_{i-\text { annulus }}=F_{i-(\text { annulus }+ \text { aperture })}-F_{i} \text { - aperture }
$$


Appendix 15: Analytical Thermal Radiation Heat Loss Program Listing

REM

REM

REM

REM

REM

REM This program predicts the thermal radiative heat loss from

REM the cavity solar receiver using the net radiation method.

REM

REM

REM

\section{DIFFUSE GRAY BODY VERSION}

This section of the program is used to verify the thermal radiation

REM shape factor formulas of the solar cavity receiver.

REM

REM

REM

OPEN "Ther Rad Program Output" FOR OUTPUT AS \#1

WRITE\# 1,"aperture","operating","radiative"

WRITE\#1,"diameter","temperature","heat loss"

WRITE\# $1, "[\text { in }]^{*}, "$ "[ $\left.{ }^{\circ} \mathrm{F}\right]^{\prime \prime}, "$ "Watts]"
REM

REM nomenclature

REM

REM $r e=$ end plate radius

REM $r c=$ cavity radius

REM ra $=$ aperture radius

REM $\quad l c=$ length of frustum section

REM I $m=$ length of hot cylindrical section

REM la = length of cold cylindrical section

REM $\quad l b c=$ width of hot isothermal bands in frustum section

REM $\mathrm{lbm}=$ width of hot isothermal bands in hot cylindrical section

REM Nc = number of bands in frustum section

REM $\mathrm{Nm}=$ number of bands in hot cylindrical section

REM

REM constants

REM

$S=5.729^{*} 10 \wedge-8 \quad: R E M \quad$ Stephan-Boltzmann constant $W /\left(m^{\wedge} 2 K^{\wedge} 4\right)$

$\mathrm{pi}=3.14$

REM

REM CAVITY GEOMETRY

REM

$r e=.254 / 2$

$\mathrm{rc}=.33$

$\mathrm{Ic}=.292$

$\mathrm{la}=.14$

Im $=.686-1 \mathrm{c}-1 \mathrm{a}$

$\mathrm{Nm}=15$ !

$\mathrm{Ibm}=\mathrm{Im} / \mathrm{Nm}$

$\mathrm{Nc}=23$ !

$\mathrm{lbc}=S Q R\left((\mathrm{rc}-\mathrm{re})^{\wedge} 2+\mathrm{lc}^{\wedge} 2\right) / \mathrm{Nc}$

$h c=l c^{\star} \mid b c / S Q R\left((r c-r e)^{\wedge} 2+1 c^{\wedge} 2\right)$

DIM $\operatorname{rad}(12), T o p(12)$

FOR $n=1$ TO 12

READ $\operatorname{rad}(n)$

DATA $\quad 0.2286,0.2286,0.2286,0.2286, .0762, .0762, .1524, .1524, .2286, .2$ 
$286, .3302, .3302$

NEXT $n$

FOR $n=1$ TO 12

READ Top(n)

DATA $\quad 300,400,500,600,400,600,400,600,400,600,400,600$

NEXT $n$

Tdiff=20 :REM assumed temperature difference between inlet and outlet

REM

REM This section determines the total number of elements that make

REM up the internal surface of the cavity receiver.

REM

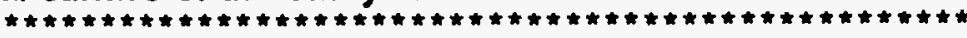

$\mathrm{NT}=\mathrm{Nc}+\mathrm{Nm}+4$

DIM $F(N T, N T), \operatorname{sum}(N T), A(N T, N T), E(N T), T(N T), C(N T), q(N T), G(N T, N T+1)$

,$M(N T+1)$

REM $F(1, J)$ is the shape factor matrix

REM sum(NT) is a shape factor verification array

REM $A(N T, N T)$ is the coefficient matrix

REM E(NT) is the emissivity array

REM T(NT) is the temperature array

REM C(NT) is the constant array

REM $G(N T, N T+1)$ is the augmented Gaussian matrix

REM $q(N T)$ is the outgoing radiant energy flux ( radiosity )

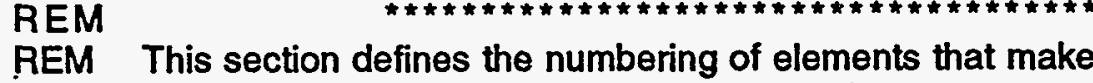

REM up the internal surface of the cavity receiver.

REM

REM aperture $=1$

REM annulus $=2$

REM spacer ring $=3$

REM end plate $=4$

REM hot cylindrical section is numbered 5 thru $\mathrm{Nm}+4$

REM frustum section is numbered $\mathrm{Nm}+5$ thru $\mathrm{Nc}+6$

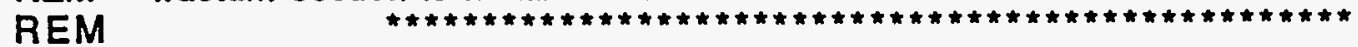

REM

REM

$E(1)=0$

$E(2)=.7$

$E(3)=.7$

$E(4)=.7$

EMISSIVITY ARRAY INPUT SECTION

FOR $n=5$ TO NT

$E(n)=.85$

NEXT $n$

REM

REM

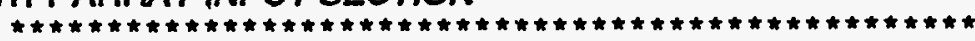

:REM emissivity of the aperture

:REM emissivity of the annulus

:REM emissivity of the spacer section

:REM emissivity of the end plate

REM

num $T=4$

FOR samp=1 TO 12

$\mathrm{ra}=\operatorname{rad}(\mathrm{samp})$

REM

REM

REM

REM

REM

REM

BEGINNING OF APERTURE RADIUS VARIATION LOOP

REM

SHAPE FACTORS CALCULATION SECTION

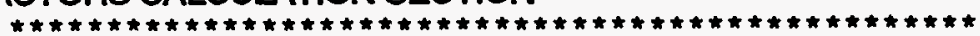

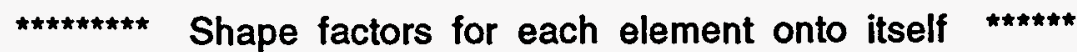

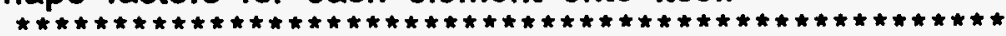

For flat surfaces $\mathrm{Fi}-\mathrm{i}=0$ 


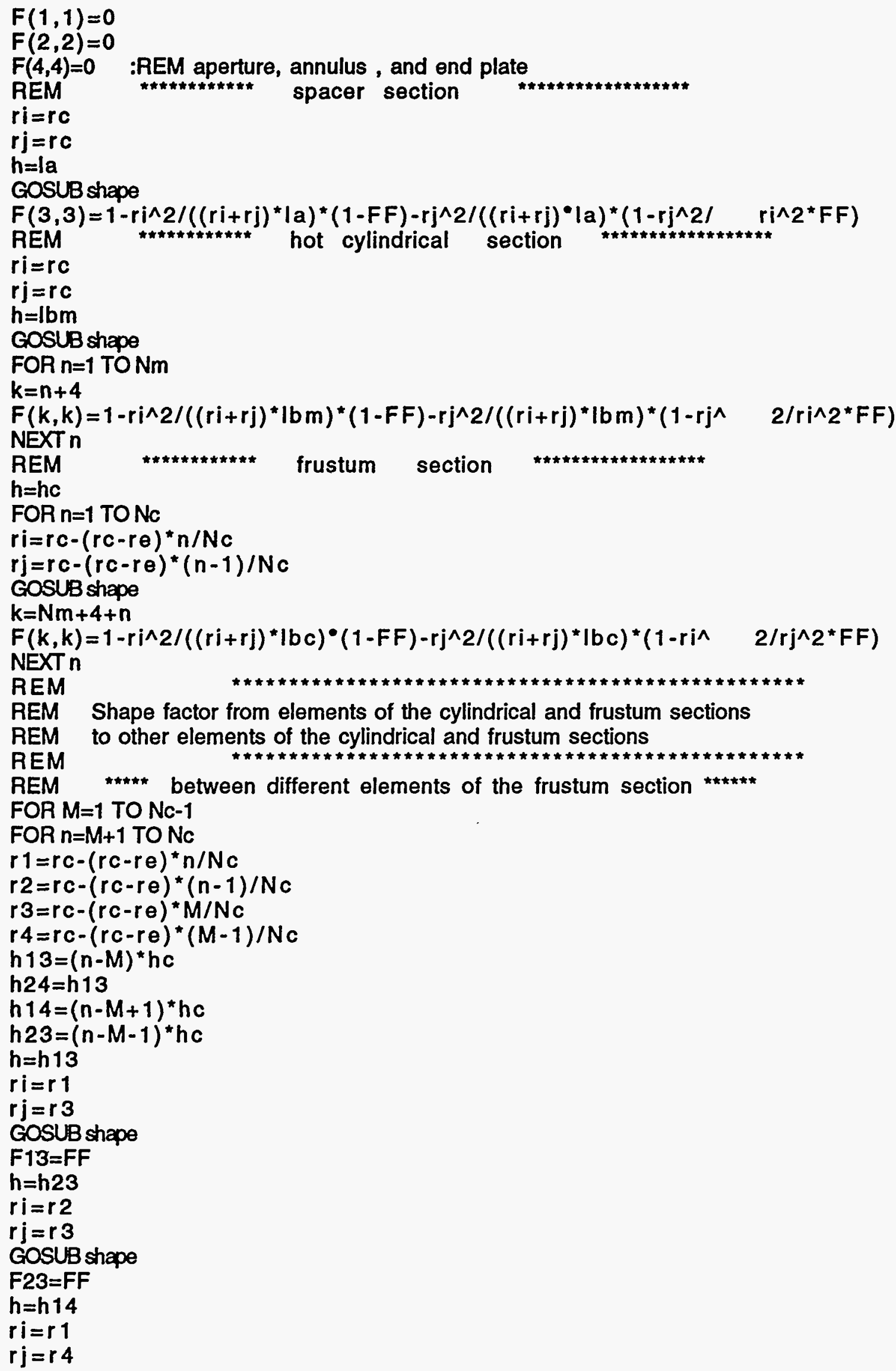




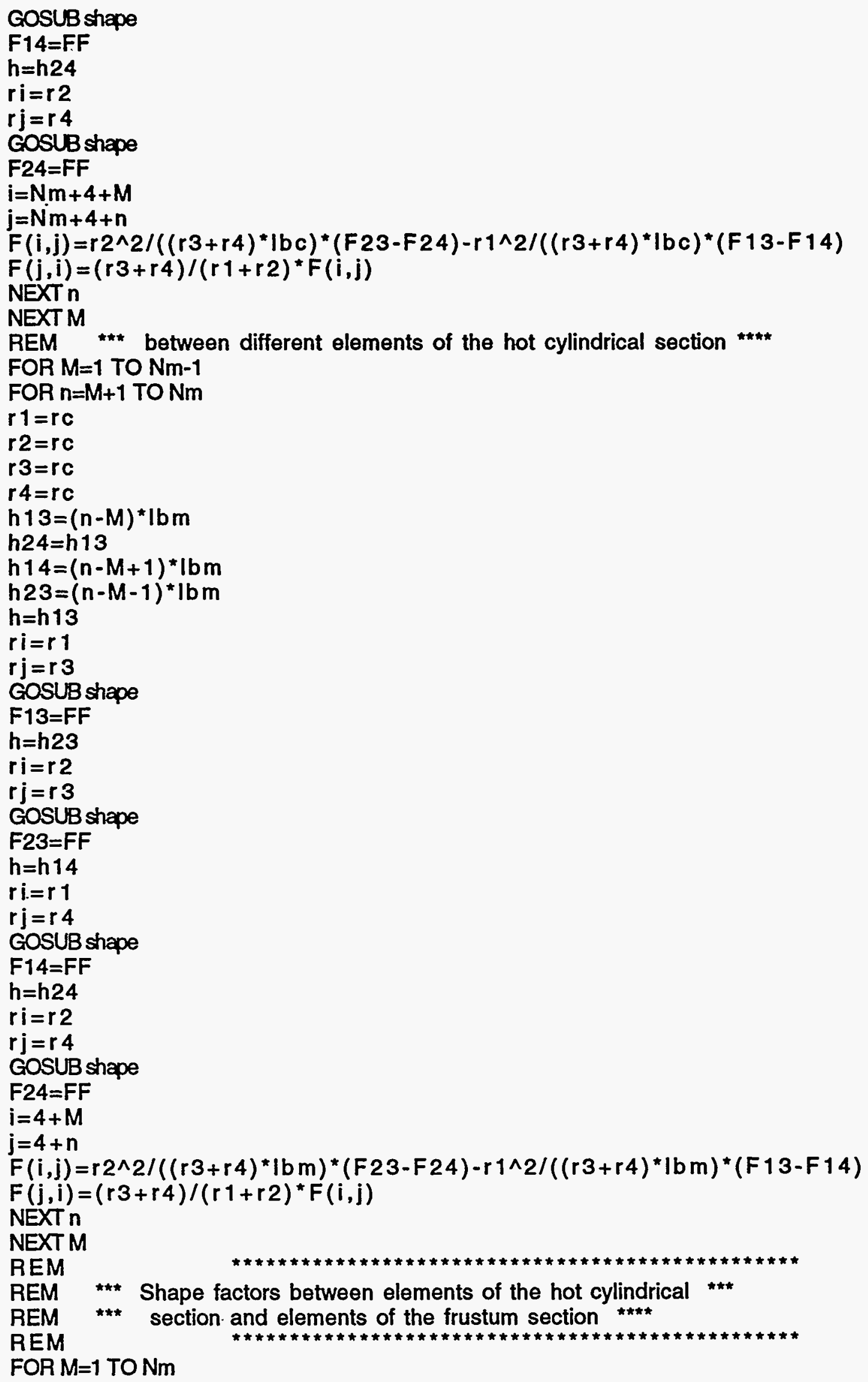




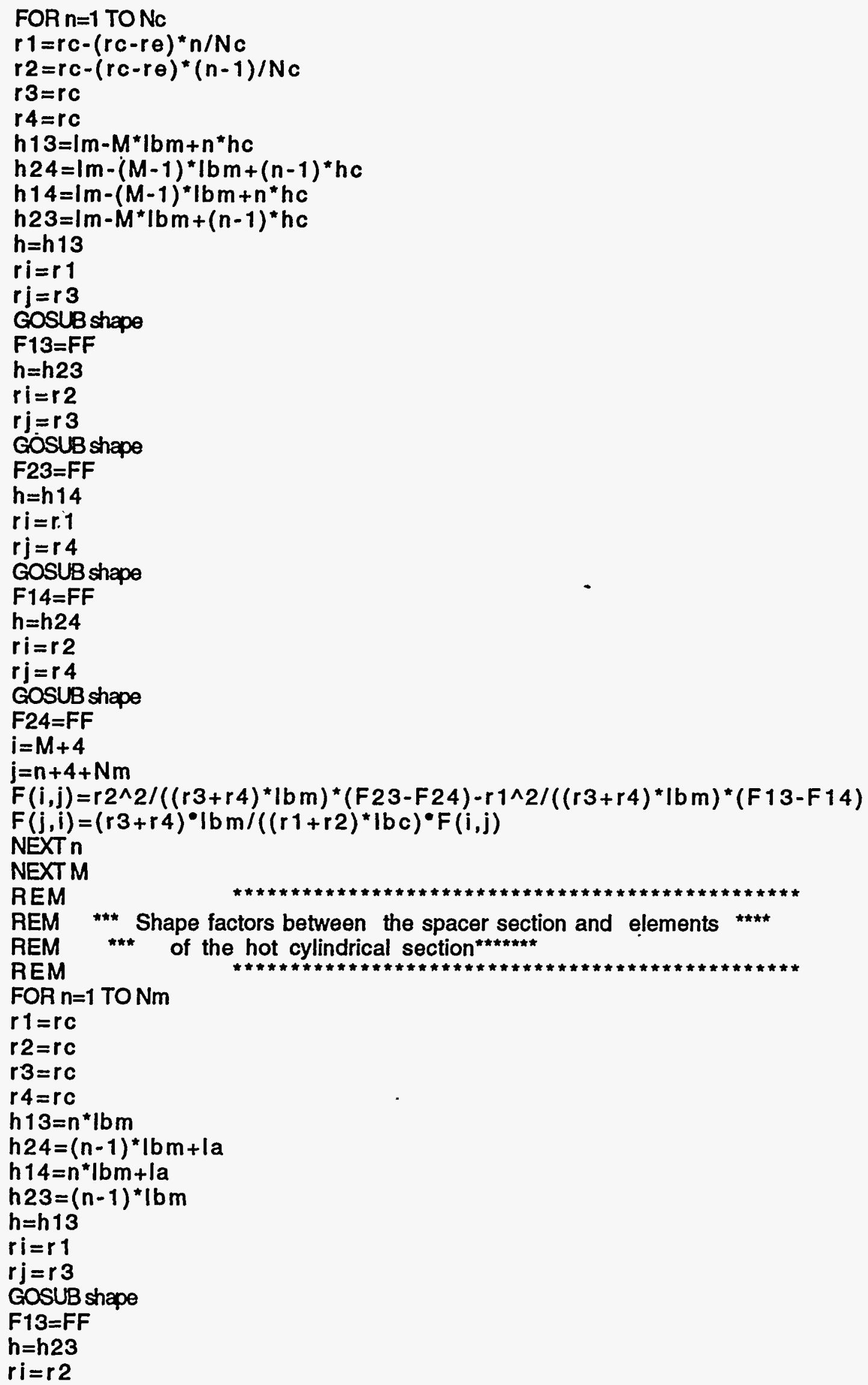




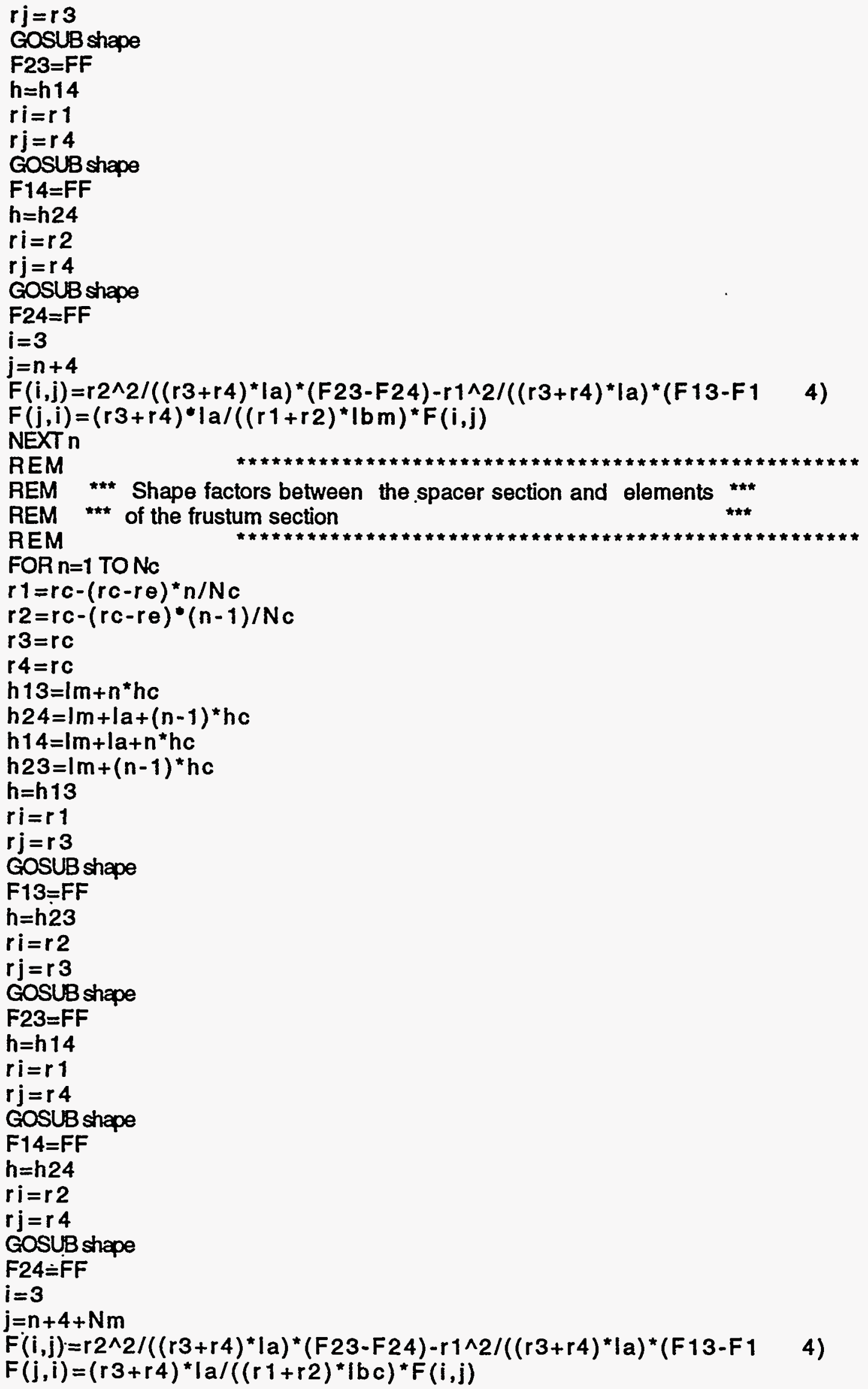




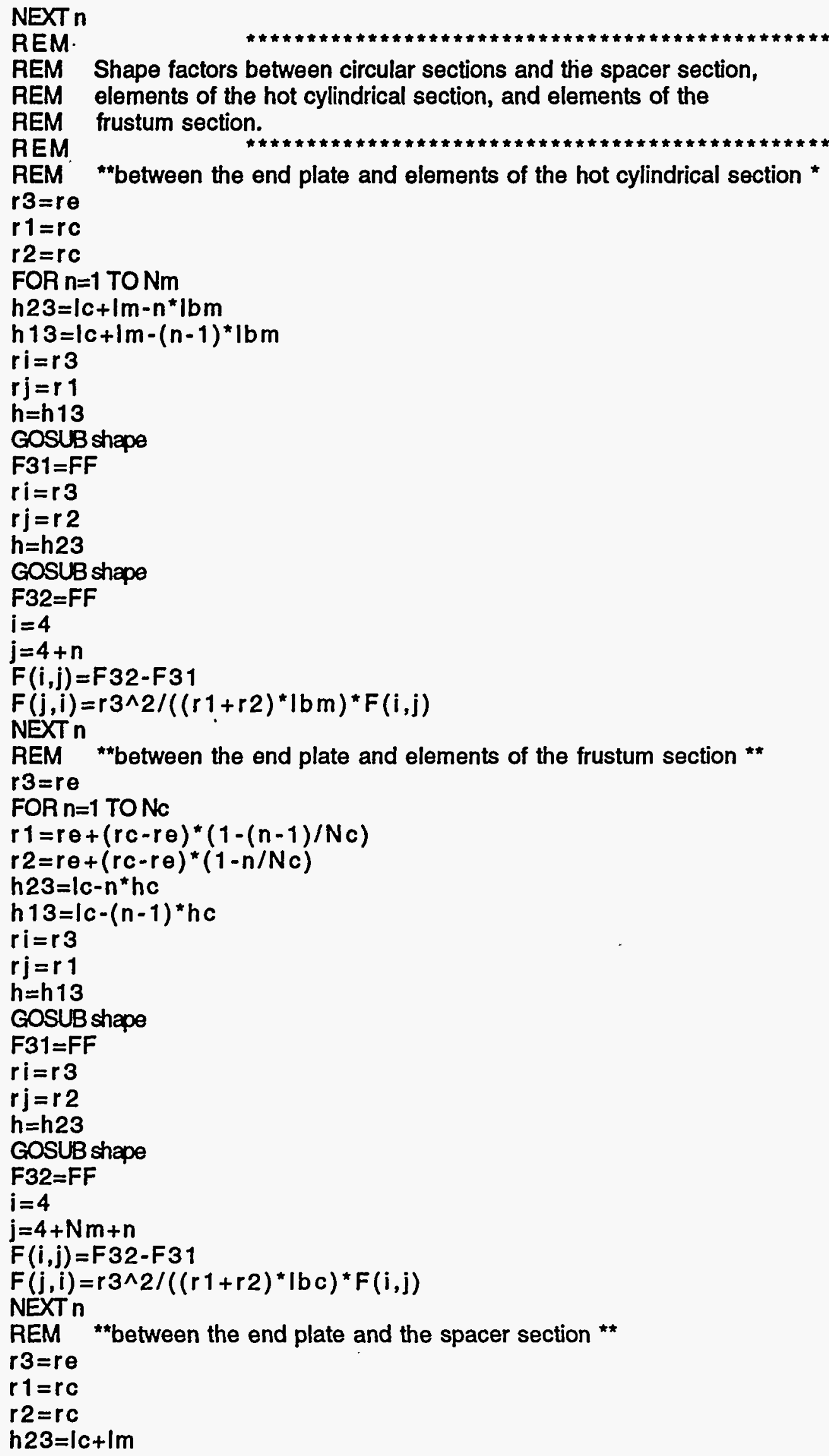

REM Shape factors between circular sections and the spacer section,

REM elements of the hot cylindrical section, and elements of the

REM frustum section.

REM

REM "between the end plate and elements of the hot cylindrical section *

$r 3=r e$

$r 1=r c$

$r 2=r c$

FOR $n=1$ TO Nm

h23 $=|c+| m-n * \mid b m$

$\mathrm{h} 13=1 \mathrm{c}+\mathrm{lm}-(\mathrm{n}-1) * \mathrm{lbm}$

$r i=r 3$

$r j=r 1$

$h=h 13$

GOSUB shape

F31 =FF

$\mathrm{ri}=\mathrm{r} 3$

$r j=r 2$

$h=h 23$

GOSUB shape

$F 32=F F$

$i=4$

$\mathrm{j}=4+\mathrm{n}$

$F(i, j)=F 32-F 31$

$F(j, i)=r 3^{\wedge} 2 /((r 1+r 2) * I b m) * F(i, j)$

NEXT n

REM *between the end plate and elements of the frustum section **

$r 3=r e$

FOR $n=1$ TONC

$r 1=r \theta+(r c-r \theta)^{*}(1-(n-1) / N c)$

$r 2=r \theta+(r c-r \theta)^{\star}(1-n / N c)$

h23 $=1 c-n * h c$

h13 $=1 c-(n-1){ }^{*} h c$

$r i=r 3$

$r j=r 1$

$h=h 13$

GOSUB shape

$F 31=F F$

$\mathrm{ri}=\mathrm{r} 3$

$r j=r 2$

$h=h 23$

GOSUB shape

F32 $=F F$

$i=4$

$\mathrm{j}=4+\mathrm{Nm}+\mathrm{n}$

$F(i, j)=F 32-F 31$

$F(j, i)=r 3 \wedge 2 /((r 1+r 2) * I b c) * F(i, j)$

NEXT $n$

REM *"between the end plate and the spacer section **

$r 3=r e$

$r 1=r c$

$\mathrm{r} 2=\mathrm{rc}$

$h 23=1 c+1 m$ 
$h 13=1 c+l m+l a$

$r i=r 3$

$r j=r 1$

$h=h 13$

GOSUB shape

F31=FF

$r i=r 3$

$r j=r 2$

$h=h 23$

GOSUB shape

F32=FF

$i=4$

$j=3$

$F(i, j)=F 32-F 31$

$F(j, i)=r 3^{\wedge} 2 /((r 1+r 2) \bullet / a) \bullet F(i, j)$

REM "between the aperture and elements of the hot cylindrical section **

$r 3=r a$

$r 1=r c$

$r 2=r c$

FOR $n=1$ TO $\mathrm{Nm}$

$\mathrm{h} 23=1 \mathrm{a}+(\mathrm{n}-1)^{\star} \mathrm{Ibm}$

$h 13=l a+n^{*} \mid b m$

$r i=r 3$

$r j=r 1$

$h=h 13$

GOSUB shape

F31=FF

$r i=r 3$

$r j=r 2$

$h=h 23$

GOSUB shape

$F 32=F F$

$\mathrm{i}=1$

$j=4+n$

$F(i, j)=F 32-F 31$

$F(j, i)=r 3^{\wedge} 2 /\left((r 1+r 2)^{*} \mid b m\right) * F(i, j)$

NEXT $n$

REM **between the aperture and elements of the frustum section **

$r 3=r a$

FOR $n=1$ TO Nc

$r 1=r c-n^{*}(r c-r e) / N c$

$r .2=r c-(n-1) *(r c-r e) / N c$

$h 23=l a+l m+(n-1)^{\star} h c$

$h 13=1 a+\operatorname{lm}+n^{*} h c$

$r i=r 3$

$r j=r 1$

$h=h 13$

GOSUB shape

F31=FF

$r i=r 3$

$r j=r 2$

$h=h 23$

GOSUB shape

$\mathrm{F} 32=\mathrm{FF}$

$i=1$ 


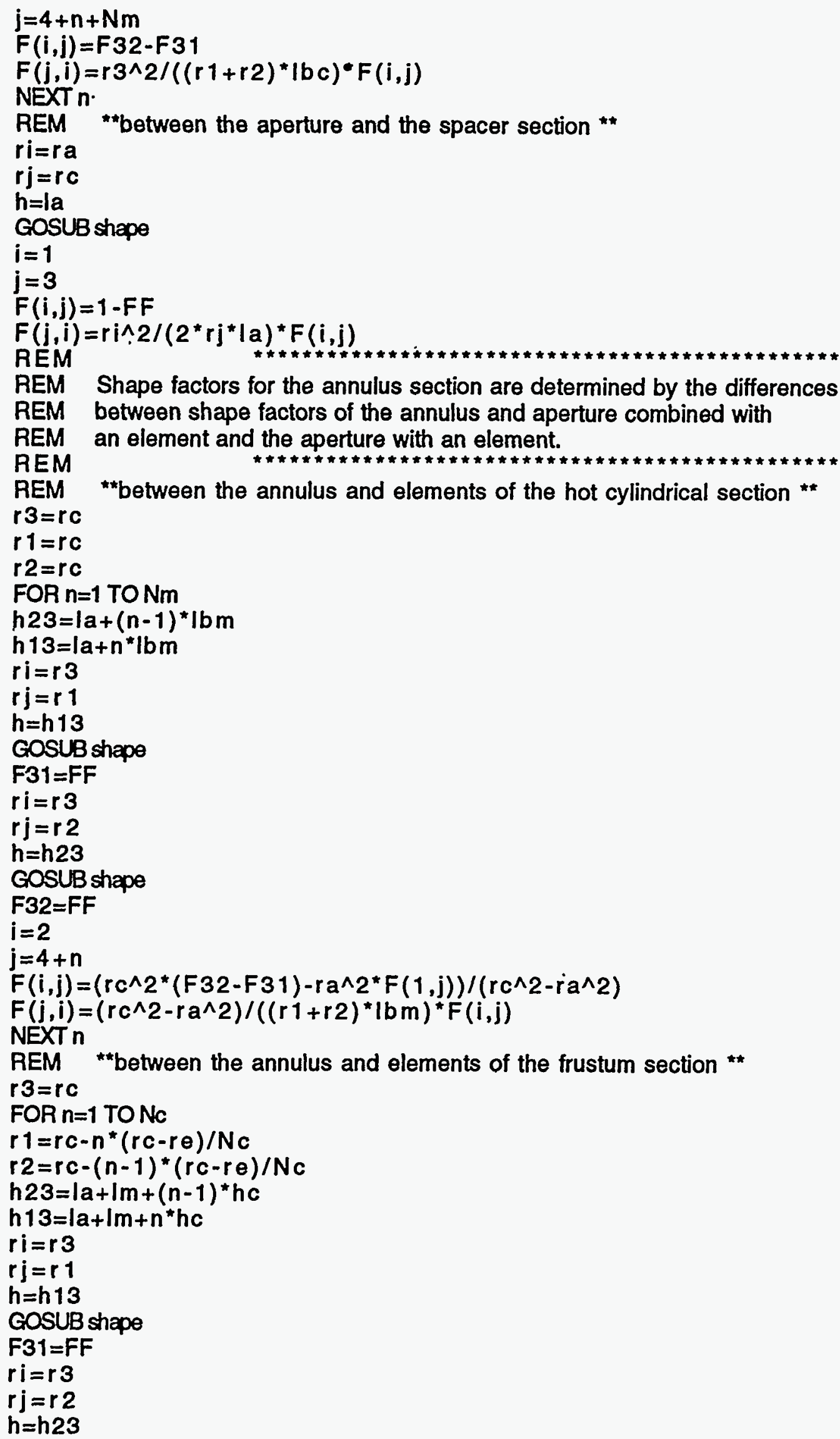




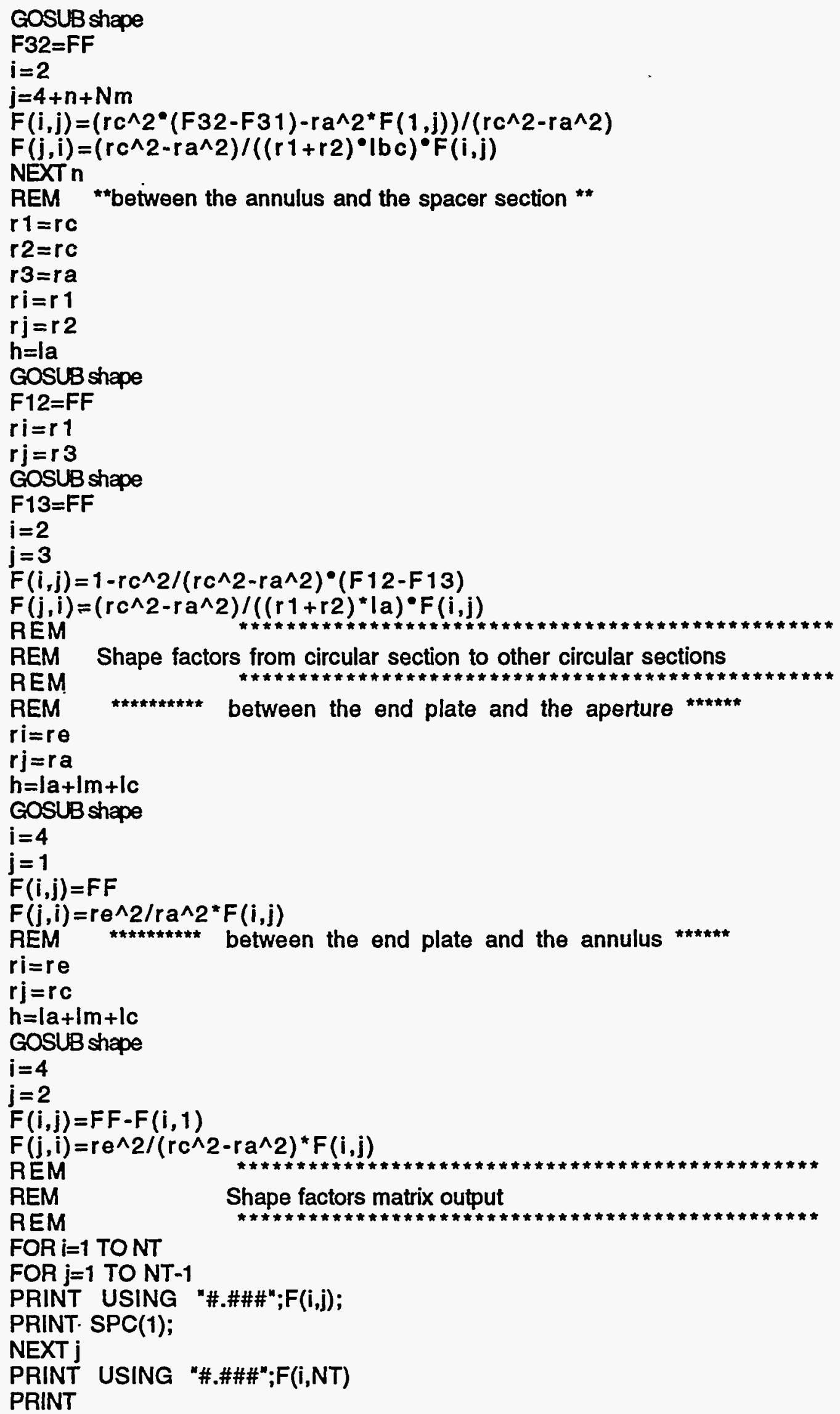




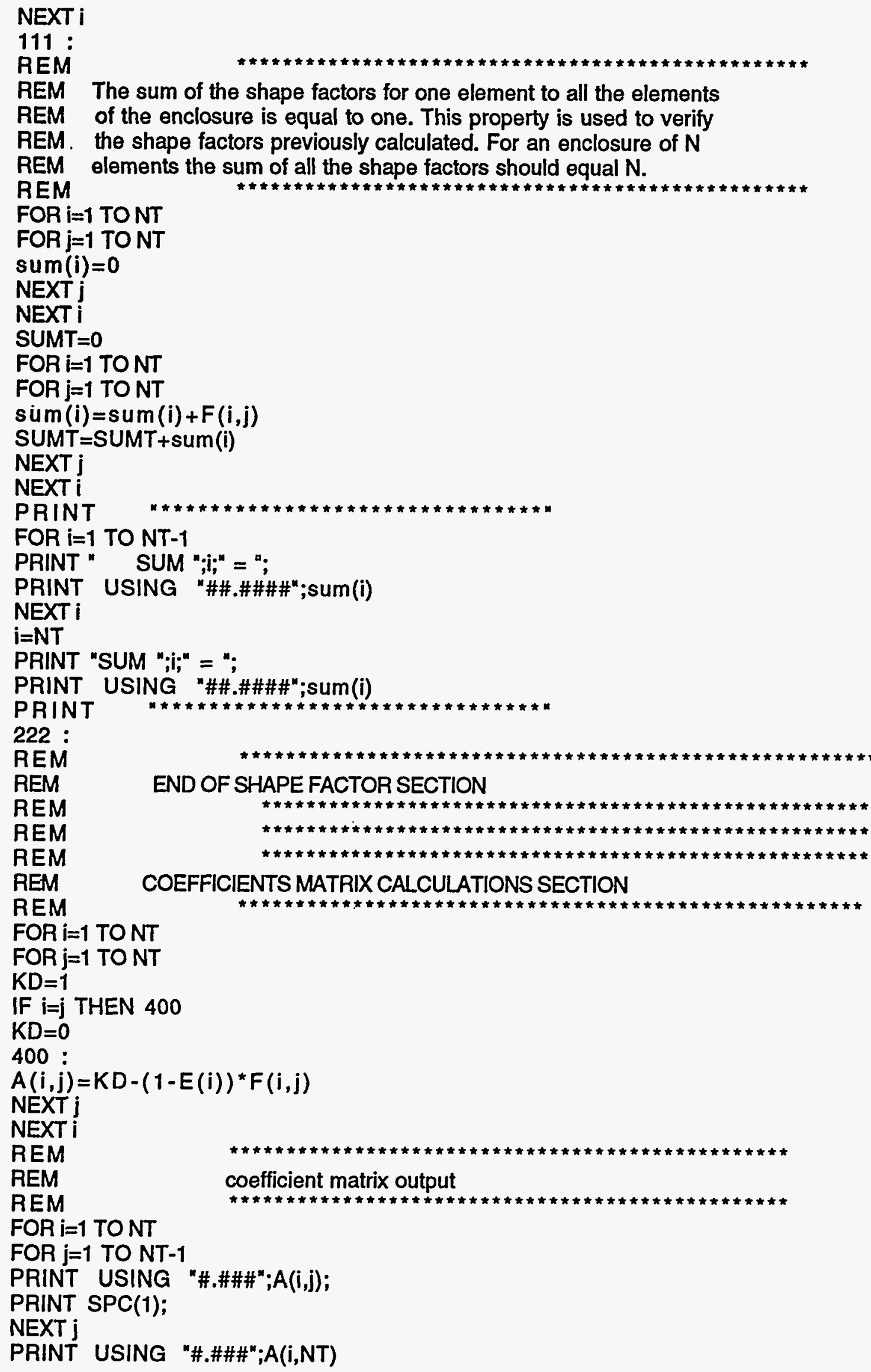


PRINT

NEXT:

333 :

REM

REM

REM

REM

REM

REM

BEGINNING OF TEMPERATURE

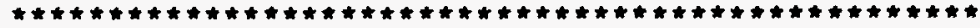

MPERATURE ARRAY INPUT SECTION

Tmean $=$ Top(samp)

Tin=Top(samp)+Tdiff/2:Tout=Top(samp)-Tdiff/2

PRINT Tin, Tout, Tmean

REM

REM Each element is assumed to be isothermal. Angular temperature

REM measurements for the hot cylindrical section and the frustum

REM section are averaged to give one temperature for each band. The

REM axial temperature values are determined from linear extrapolation

REM from band with temperature measurements. Temperature values

REM are in Kelvin.

$T(1)=0 \quad: R E M$ temperature of the aperture opening

FOR $n=2$ TO 4 :REM temperature of the refractory surfaces

$T(n)=((T$ mean -40$)-32) \star 5 / 9+273.15$

NEXT $n$

FOR $n=5$ TO NT

$T(n)=(($ Tout $+($ Tin - Tout $) *(n-5) /(N T-5))-32) * 5 / 9+273.15$

NEXT $n$

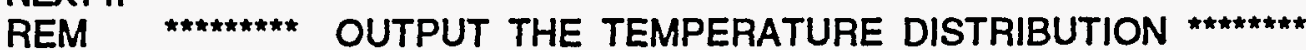

FOR $n=1$ TO NT

PRINT "T(";n;")= ";T(n)

NEXT $n$

REM

REM

CONSTANT ARRAY CALCULATION SECTION

REM

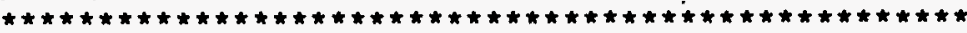

FOR $n=1$ TO NT

$C(n)=E(n)^{\star} S^{\star} T(n)^{\wedge} 4$

NEXT $n$

REM

REM

HEAT FLUX SOLUTIONS

REM

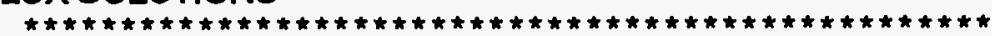

REM

REM Gaussian Elimination method is used to solve for the heat output

REM of each surface, including the total heat lost from the receiver

REM through the aperture.

REM

REM

$\star \star \star \star \star \star \star \star \star \star \star$ augmented matrix

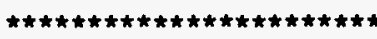

FOR $i=1$ TONT

FOR $\mathrm{j}=1$ TONT

$G(i, j)=A(i, j)$

NEXT j

$G(i, N T+1)=C(i)$

NEXT $i$

GOSUBGauss

REM

REM

REM

OUTPUT OF HEAT LOSS THROUGH APERTURE AND HEAT

RADIATED FROM ALL OTHER ELEMENTS 
REM

FOR $i=1$ TO 4

READ Nm\$

PRINT Nm\$;SPC(5);q(i)

NEXT $i$

FOR $i=5$ TO $\mathrm{Nm}+4$

PRINT "hot cylindrical element";SPC(5);q(i)

NEXT $i$

FOR $i=\mathrm{Nm}+5$ TO NT

PRINT "frustum element";SPC(5);q(i)

NEXT i

DATA "aperture","annulus","spacer ring","end plate"

RESTORE

REM

REM

REM

SUMMARY OUTPUT

PRINT

PRINT "

SUMMARY OUTPUT*

PRINT

PRINT SPC(2);"aperture";TAB(10);"operating";TAB(20);"radiative"

PRINT SPC(2);"diameter";TAB(10);"temperature";TAB(20);"heat loss"

PRINT SPC(4);"[in]";TAB(13);"['F]";TAB(23);"[Watts]"

PRINT SPC(4);

PRINT USING "\#\#\#.\#";ra*200/2.54;

PRINT TAB(13);Tmean;

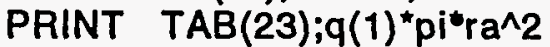

WRITE\#1,ra*200/2.54,Tmean, q(1)* pi*ra^2

BEEP

NEXT samp

FOR $k=1$ TO 5

BEEP

NEXT K

CLOSE\#1

END

shape:

$F F=.5^{\star}\left(1+\left(h^{\star} h+r j^{\star} r j\right) /\left(r i^{\star} r i\right)-S Q A\left(\left(1+\left(h^{\star} h+r j^{*} r j\right) /\left(r i^{*} r i\right)\right)^{\wedge} 2-4\right.\right.$

$*(r j / r i) \wedge 2))$

RETURN

Gauss:

REM

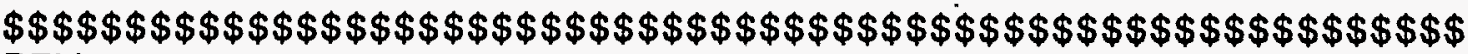

REM

GAUSSIAN ELIMINATION METHOD

REM

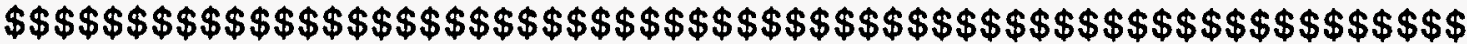

REM

REM

REM

REM For the Gaussian elimination method to work the $A(1,1)$ element

REM of the augmented matrix can not have a value of one. If $A(1,1)$ is

REM equal to one then rows of the matrix will be shifted until a non-

REM zero value is in element $A(1,1)$.

Flag $=0$

IF $G(1,1)<>0$ THEN Elimination

Flag $=$ Flag +1

FOR $j=1$ TO NT +1 
$M(j)=G(1, j)$

NEXT j

FOR $i=1$ TO NT- 1

FOR $\mathrm{j}=1$ TO NT+1

$G(i, j)=G(i+1, j)$

NEXT j

NEXT $i$

FOR $\mathrm{j}=1$ TO NT +1

$G(N T, j)=M(j)$

NEXT j

GOTO 444

REM

PRINT CYCLE

CS

FOR $M=1$ TONT

FOR $n=1$ TONT

PRINT $G(M, n) ; S P C(5)$;

NEXT $n$

PRINT G(M,NT+1)

NEXT M

REM

444 :

GOTOGauss

Elimination:

REM

Gaussian Elimination.

FOR $k=1$ TONT

$s s=G(k, k)$

FOR $\mathrm{j}=1$ TO $N T+1$

$G(k, j)=G(k, j) / s s$

NEXT j

FOR $i=k+1$ TO NT

$s s=G(i, k)$

FOR $\mathrm{j}=1$ TO $N T+1$

$G(i, j)=G(i, j)-s s^{\star} G(k, j)$

NEXT j

NEXT i

NEXT $k$

REM

FOR $k=1$ TO NT- 1

FOR $i=1$ TO NT-k

$s s=G(i, N T-k+1)$

FOR $\mathrm{j}=1$ TO NT+1

$G(i, j)=G(i, j)-s s^{\star} G(N T-k+1, j)$

NEXT j

NEXT $\mathrm{i}$

NEXT k

GOTO 555

REM

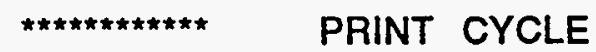

CS

FOR $M=1$ TONT

FOR $n=1$ TONT

PRINT $G(M, n) ; S P C(5)$;

NEXT $n$

PRINT G(M,NT+1)

NEXT M

REM 
555 :

FOR $i=1$ TONT

$q(i)=G(i, N T+1)$

NEXT $i$

IF Flag=0 GOTO 600

FOR $k=1$ TO Flag

$q q=q(N T)$

FOR $i=2$ TO NT

$q(i)=q(i-1)$

NEXT $i$

$q(1)=q q$

NEXT k

600 :

RETURN 
Appendix 16: Flow Meter Factory Calibration Specifications

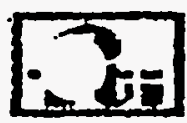

FI.OW TECHNIRLOESY, INC:MIECHANICAL DATASIHLET

7412

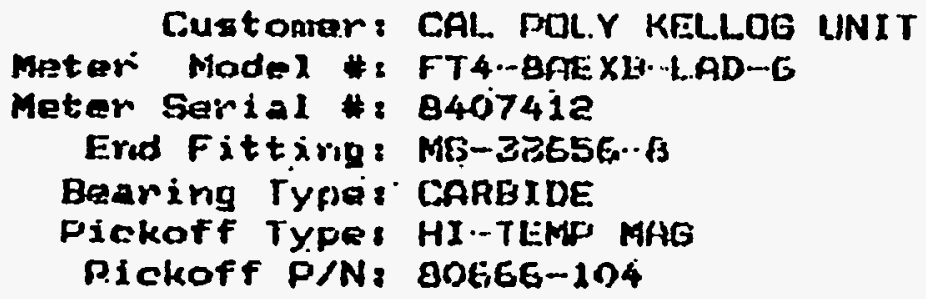

0. 17.07

113.86

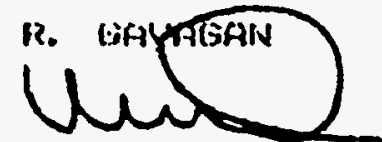

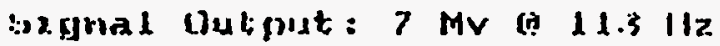

Cin] i brat.eri by:

respotifipad liys

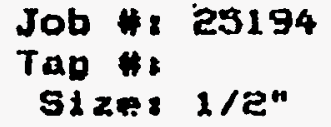

Meter.

K Factor (P/GAL)

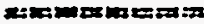

40034.49

40\%85. 28

40424. Ess

$40.501 \cdot 4.3$

40.391 .61

40198. 27

391345.03

39056.53

36542.37

33012.29
Frea $/$

Visconity.

(Hz/CTS)

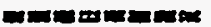

2464.262

1767.664

12:79. 887

933.099

671.420

490. 281

343. 411

2.4E. 761

181.309

136. 690

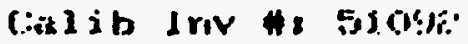 \\ Calib Recal Dates $112 / 1 / 137$ \\ Date: $4 / x(1 / 1) /$
}


Appendix 17: Flow Meters Voltage Output

\begin{tabular}{|c|c|c|c|c|c|c|}
\hline & & & & & & \\
\hline (volts) & volts & [rolts & [volts) & [volts] & [Yolts] & [volts] \\
\hline & 9652 & & & & 2131588 & .0554355 \\
\hline & & & & & 3735 & 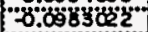 \\
\hline 5it & $\$ 5725$ & troor2 & 20205076 & 20.100002 & -0.2072758 & -0.0853022 \\
\hline$\infty 17$ & 597 & 10022 & 70.198573 & -0.00 & 8733 & -0.0983022 \\
\hline & (E) & 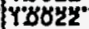 & "x:ryy5x & $=0.48$ & & उ०षे \\
\hline 1.7420 & 16329 & & To2t & Tist & 80169 & $0.150 \% 2952$ \\
\hline 1.8092 & 16.632T & 115240 & T.25848T & 1877 & 0.1164881 & ชర6в \\
\hline 1.4356 & 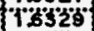 & fiotion & 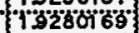 & . & otbos4tys & 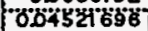 \\
\hline 1.8527 & \%ั635\% & 176344 & Y936899 & 188 & & 60359392 \\
\hline 2.5587 & & & 16 & & & 00 \\
\hline .2.5 & $755^{\circ}$ & & 26 & 38 & m1' & OD2107376 \\
\hline $3,5768^{\circ}$ & 18485 & fi. & 26552585 & 260881389 & $864: 23365$ & -gxts 1 \\
\hline 2.5844 & 118764 & 178493 & $2649 \times 204$ & 25944534 & 006620204 & 6.01005344 \\
\hline 2.7035 & Tिका5 & & 258 & & & \\
\hline 2.8526 & Y'g846" & & 29694006 & 522 & 8006 & 0104516224 \\
\hline 2.8821 & 19939 & & 2996539 & 29239843 & 5 & obsors452 \\
\hline 3.3314 & 2.1343 & 20 & $3.4 T 2$ & 33 & 2623 & $0006 \% 2448$ \\
\hline & 2 & & sits & & & \\
\hline & f.t. & & & & & \\
\hline 3.3411 & 2.1469 & 20886 & 3.4499709 & 3355 & $88 \% 5$ & 601451888 \\
\hline $3.3478^{\circ}$ & 22.1446 & 20852 & 3.44534 & 53 & 3584 & $=0$ \\
\hline 35408 & 2.7465 & & $3 x$ & 3 & & \\
\hline 3.7837 & 2. & & 58 & & & \\
\hline & & & $3 B^{2}$ & & & 64 \\
\hline 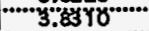 & 42385 & & 58 & 3 & & 60 \\
\hline 3.8510 & 2 & 2 & 58 & & & - \\
\hline 4.7 & 227 & & $4 . T$ & 4.13 & & \\
\hline$\because i$ & $2=$ & & 4.13 & & $=8.0$ & \\
\hline 4.6016 & 25413 & & 461 & 84 & 893 & 84 \\
\hline 7.61 81 & $\frac{2}{22}$ & & $7 x$ & & & 9 \\
\hline $4: 6$ & & & 45 & & & 3 \\
\hline 4.6270 & 2 & & $4 \beta^{\circ}$ & & $=0$ & 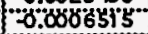 \\
\hline 316 & 2.6508 & & 4942 & 54 & 0.0 & 050 \\
\hline & & & & & & \\
\hline 4.9884 & पू & & & & 6.8 & \\
\hline 4.9888 & 26504 & & 49408344 & 24 & -0.0 & 30224 \\
\hline 9888 & 275535 & & 49503078 & 43 & & rim \\
\hline & & & 53 & 58 & & \\
\hline 3.3942 & 2 & & & & & 56 \\
\hline 22 & & & 53 & & & \\
\hline & 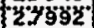 & & 53 & -57 & $=0$ & 76 \\
\hline 5.7831 & & & 53 & 5 & & $8 x$ \\
\hline 5.7987 & 2 & & 5 & & 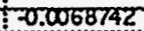 & $0 x$ \\
\hline & & & 53 & $5 \%$ & - & \\
\hline 5.8625 & 49346 & 23669 & -5.4 & 581 & 543 & \\
\hline & & & & & & \\
\hline & & & & & & \\
\hline 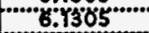 & & & & & & \\
\hline 365 & 3 & & 6.1 & 6.1 & 0 & \\
\hline & & & 6.1 & & & \\
\hline & & & & & & 64 \\
\hline 70 & & & 6.1 & 6.1 & $=0$ & 36 \\
\hline & & & & & & \\
\hline & & & है. & & & \\
\hline & & 42 & 6.1 & & $=0$ & 28 \\
\hline 6. & & & & & & \\
\hline & & & & & & \\
\hline & & & & & & \\
\hline & & & & & & \\
\hline & & & & & & \\
\hline & & & & & & \\
\hline & & & & & & \\
\hline & & & & & & \\
\hline & & & & & & \\
\hline & & & & & & \\
\hline & & & & & & \\
\hline & & & & & & \\
\hline 110 & 3 & & 37 & $y 8$ & -6 & 0 \\
\hline & & & & & & \\
\hline & & & & & & \\
\hline & & & & -43 & & \\
\hline & & & & & & \\
\hline & & & 6 & $\frac{73}{43}$ & & $\begin{array}{ll}\pi \\
6 \% 4\end{array}$ \\
\hline & & & & & & 94 \\
\hline $7 . x$ & & & & 736 & -0 & \\
\hline 7.4456 & & & 73 & 438 & $=0$. & \\
\hline & & & & & & \\
\hline & & & & & & \\
\hline.,$\angle 968$ & & & & & & \\
\hline 7.7998 & & & 4.58 & $7 y 7$ & & \\
\hline & & & & & & \\
\hline & 35445 & & 78013 & 78 & $=0.0$ & 3.0136855 \\
\hline & & & & & & \\
\hline
\end{tabular}


Appendix 18 Calibrated Thermocouple Probe Specification

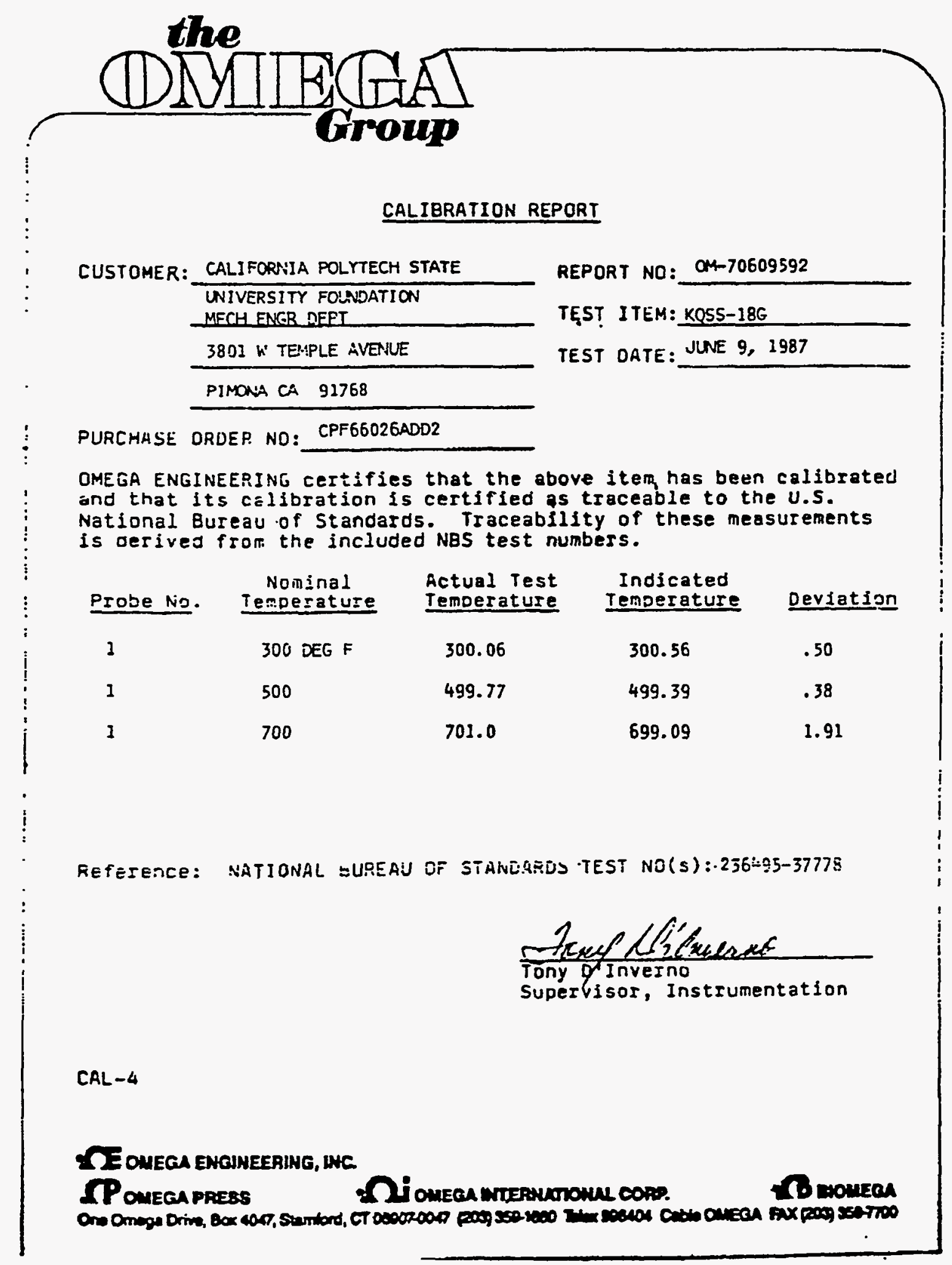


Appendix 19: Radiometer Calibration Specifications

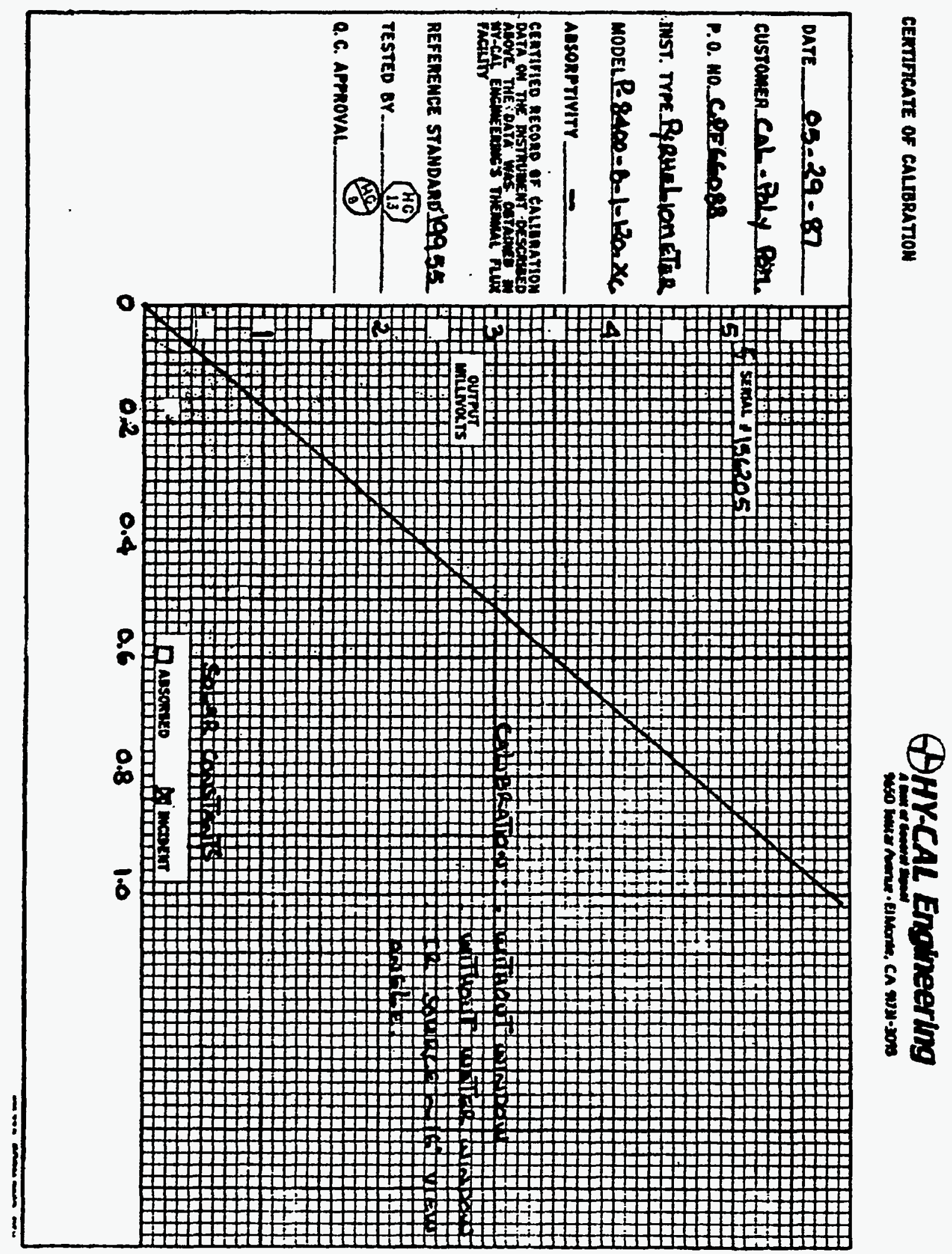


Appendix 20: Pyromark ${ }^{\circledR}$ Paint Specifications

\section{PYRO/INCOLOY;540C CURE; AS RECVD. EMITT}

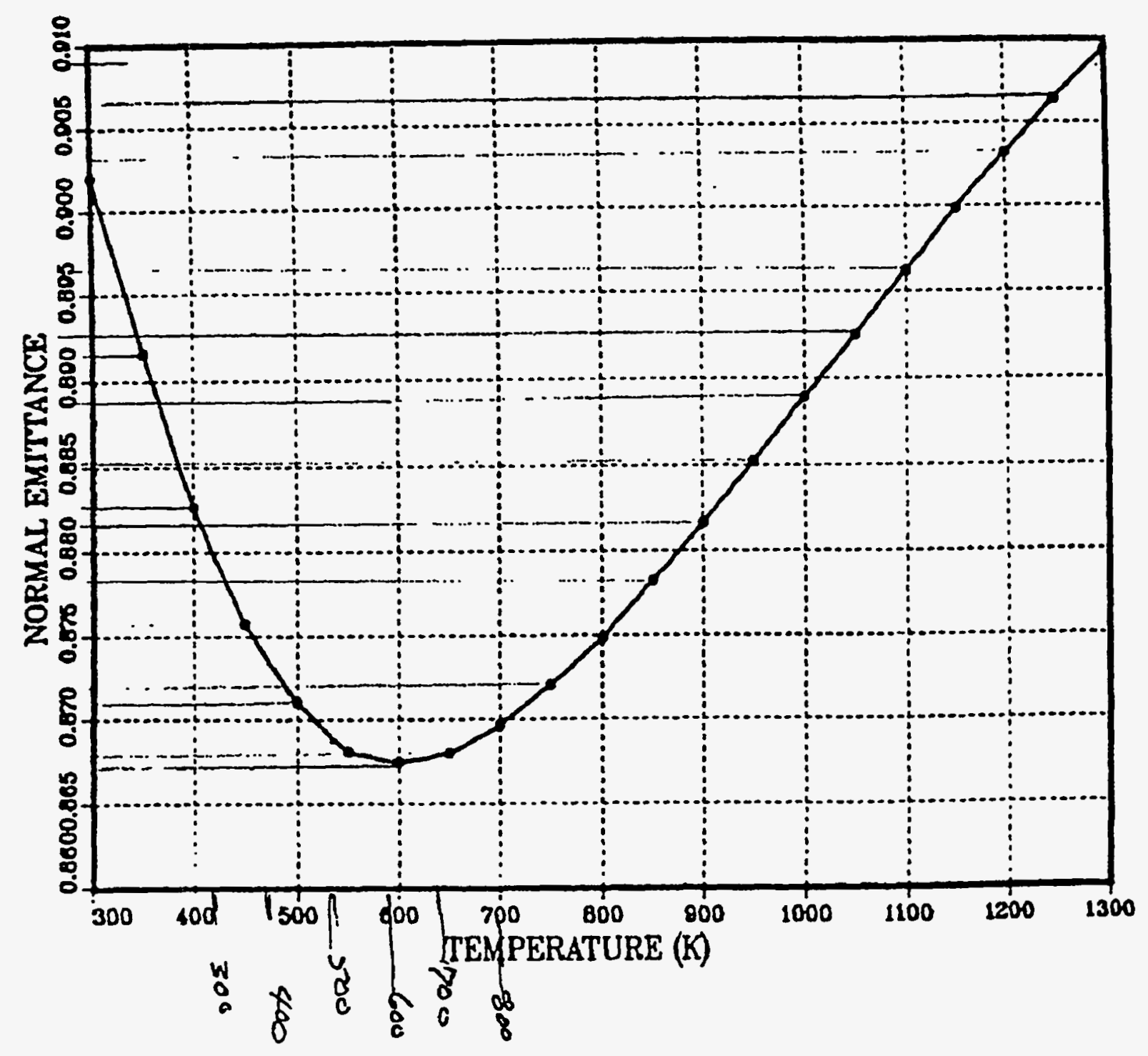




\section{PYROMARK/INCOLOY;540-1;540C CURE;AS RECD}

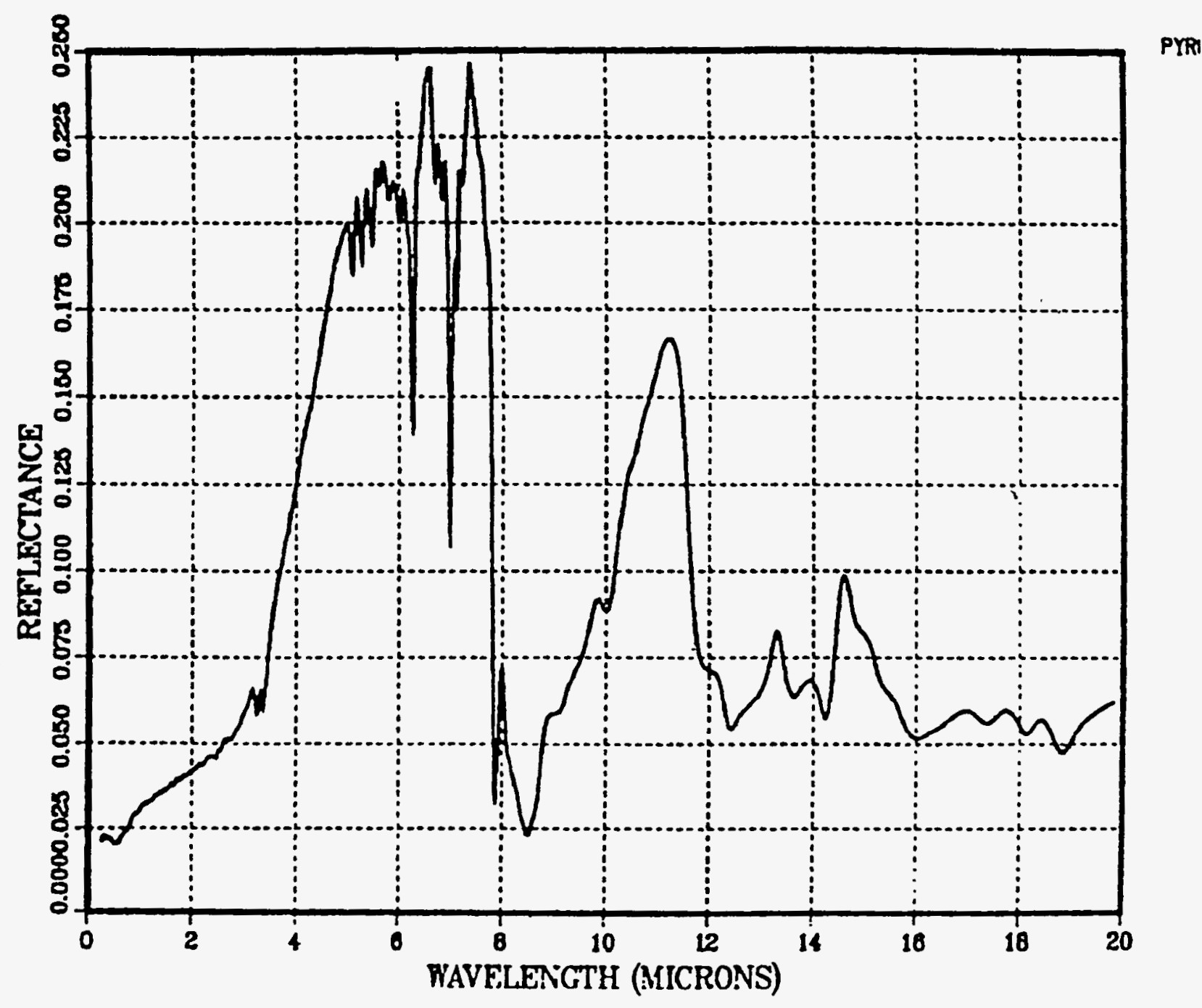




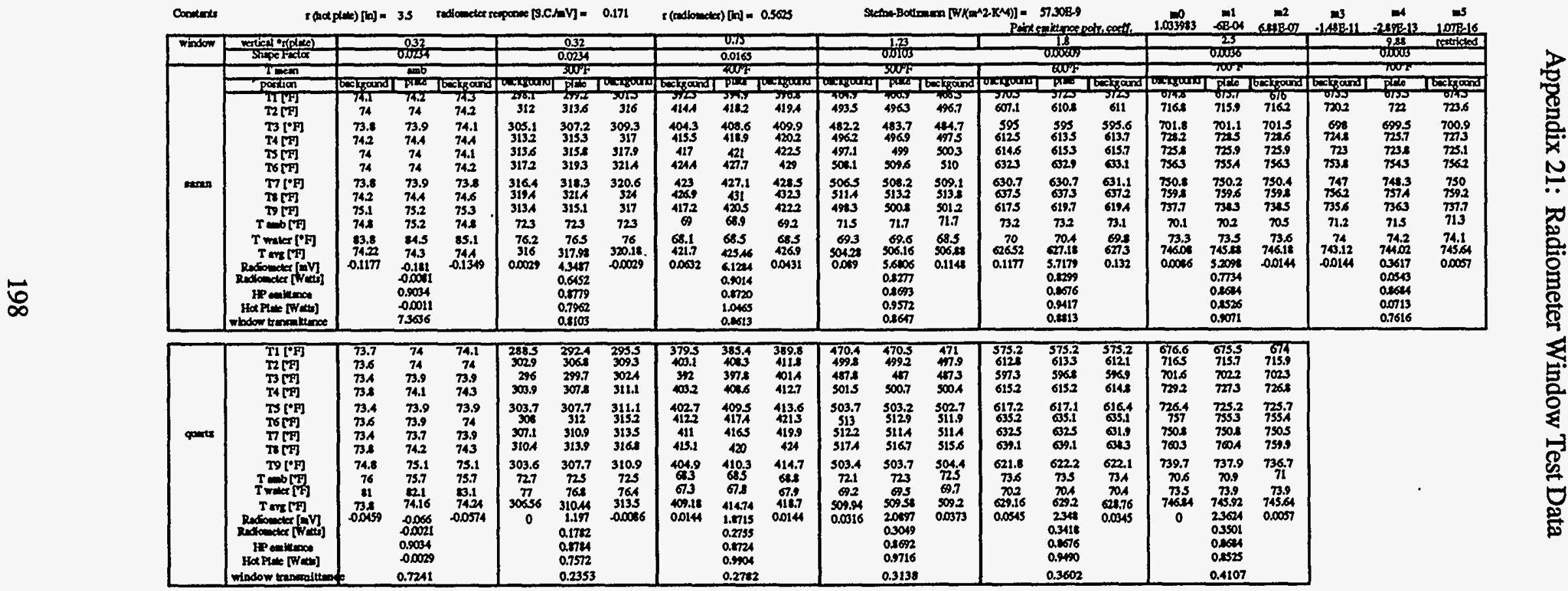




\begin{tabular}{|c|c|c|c|c|c|c|c|c|c|c|c|c|c|c|c|c|c|c|c|c|c|c|}
\hline sest & 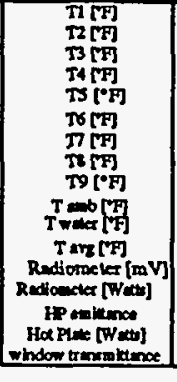 & 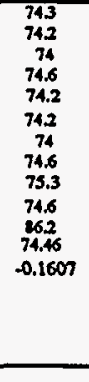 & 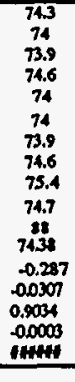 & 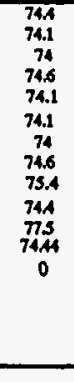 & 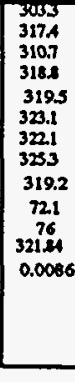 & 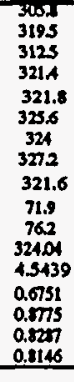 & 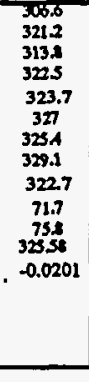 & 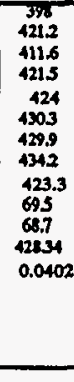 & 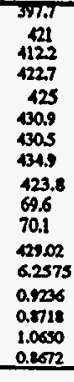 & 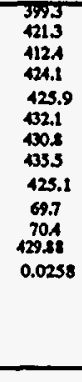 & 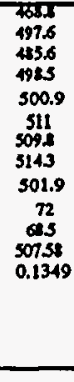 & 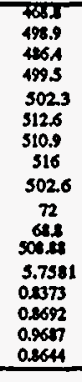 & 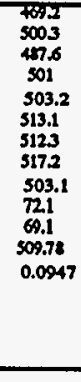 & 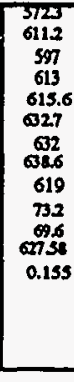 & 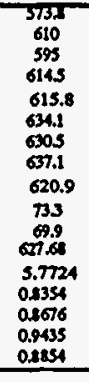 & 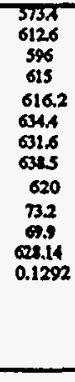 & 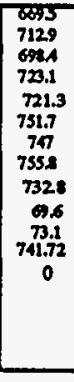 & 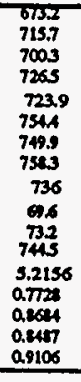 & 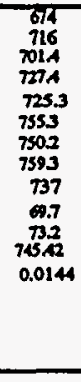 & & & \\
\hline & 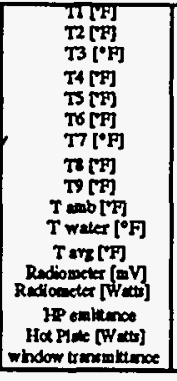 & 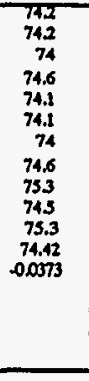 & 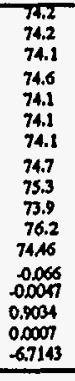 & 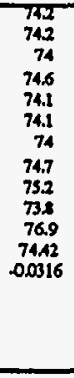 & 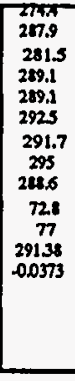 & 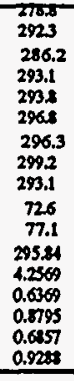 & 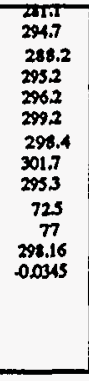 & 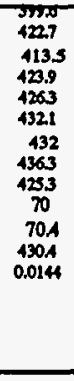 & 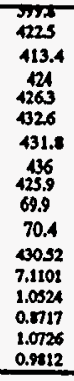 & 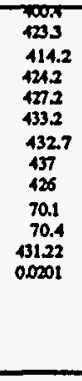 & 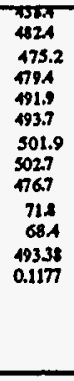 & 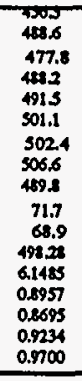 & 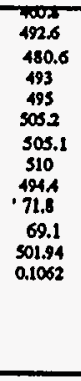 & 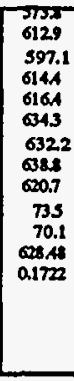 & 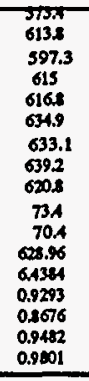 & 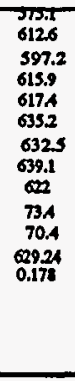 & 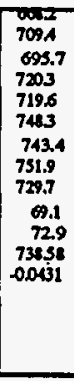 & 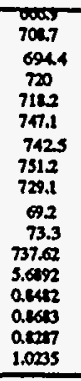 & 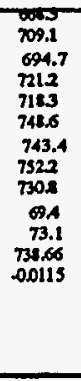 & 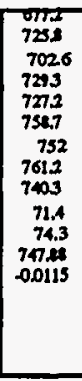 & 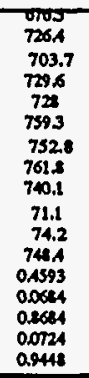 & 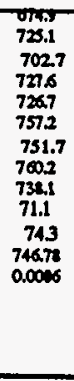 \\
\hline
\end{tabular}


Appendix 22: Saran Wrap ${ }^{\circledR}$ Specifications

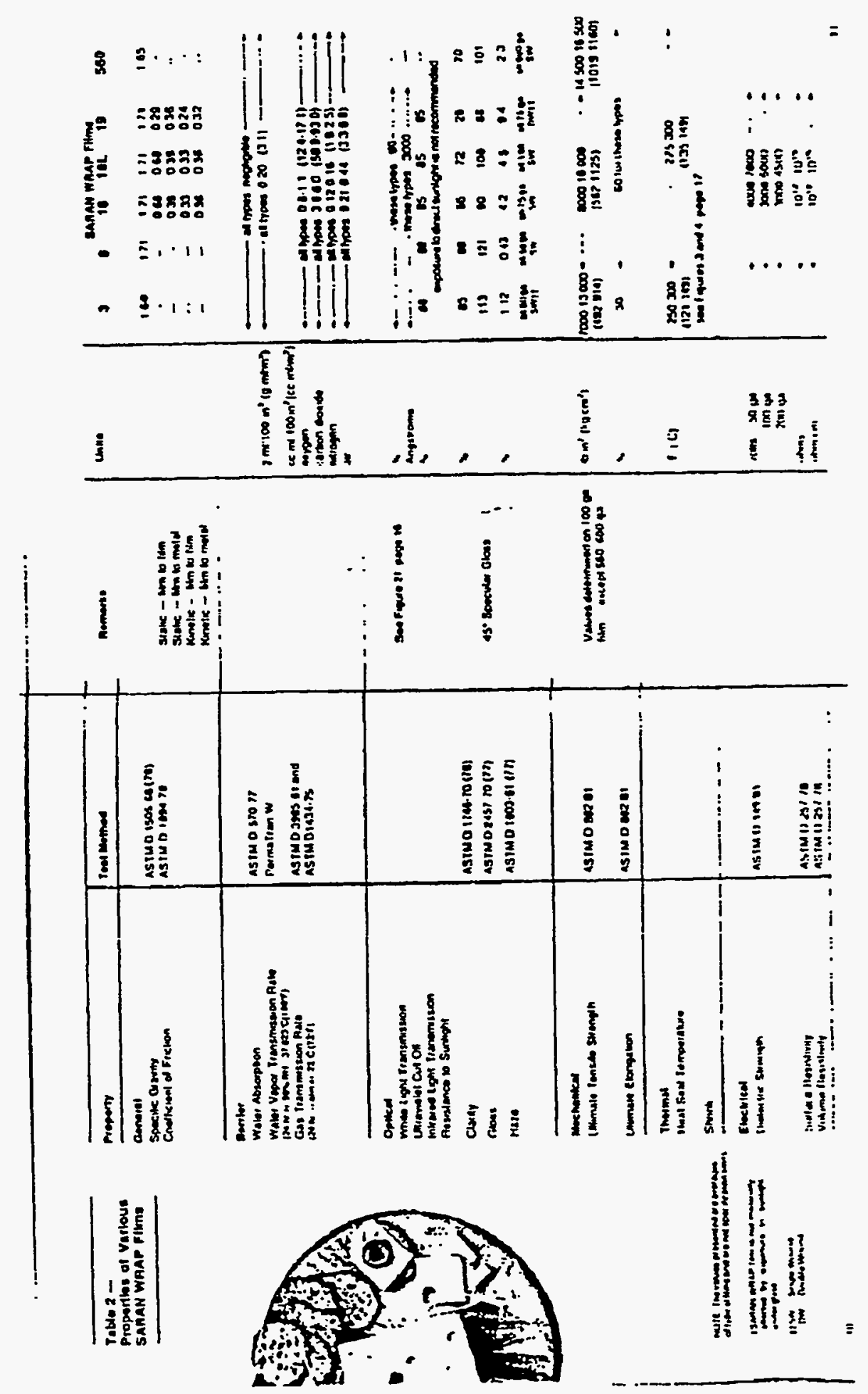




\section{Light Transmission Characteristics}

SARAN WRAP films offer good resistance to sunlight under glass. Such properties as tensile: strength, elongation, flexibility. and impermeability to water vapor and gases decrease only slightly. Outdoor exposure to direct sunlight, however, is not recommended. Figure 2 below shows typical light transmission values for SARAN WRAP films.
FDA and

\section{USDA Status}

SARAN WRAP films, when used unmodified and according to good manufacturing practices when used for lood conlact applications - can comply with the U.S. Food, Drug and Cosmetic Act as amended.

Many of these lilms also have been accepted by the U.S. Department of Agriculture for packaging of meat and meat
Figure 2 - Light Transmission vs Wave Length for 100 Gaugo SARAN WRAP $3,8,18$, 18L. and 19 Films

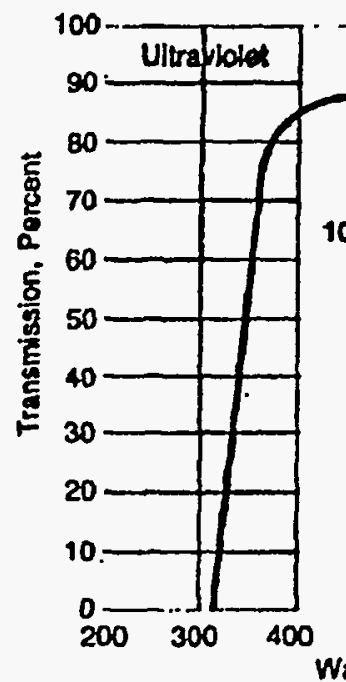

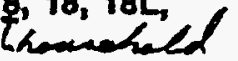

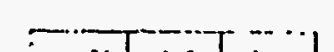

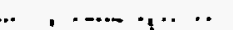

food products, and poultry and poultry products, prepared in Federally inspected plants.

Government regulations are subject to change. While it is the responsibility of users of SARAN WRAP to check the suilability of their intended use with regulalory agencies, resources of The Dow Chemical Company are available to assist customers with perlinent data and other information.

\section{Shrink \\ Characteristics}

SARAN WRAP plastic films be come highly oriented during manufacture. This orientalion makes the film susceplible to shrinkage on exposure to elevaled temperatures - a propenty very desirable in applications such as overwraps. Further, by control of the shrink-inducing temperature. the lilm user can control the degree of shrinkage obtained.

For use in laminates where shrink is undesirable, preshrunk SARAN WRAP $18 \mathrm{~L} \mathrm{film}$ is available. Differences in the shrinkage rates of $18 \mathrm{~L}$ and other films are shown in Figures 3 and 4.

$$
\begin{aligned}
0.4 \\
T<\kappa \Xi
\end{aligned}
$$

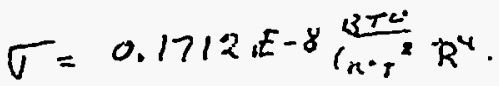

$$
\begin{aligned}
& T=5 .\left(6916 x-8 \frac{\omega}{\left.\sin ^{2} \cdot k^{4}\right)}\right.
\end{aligned}
$$




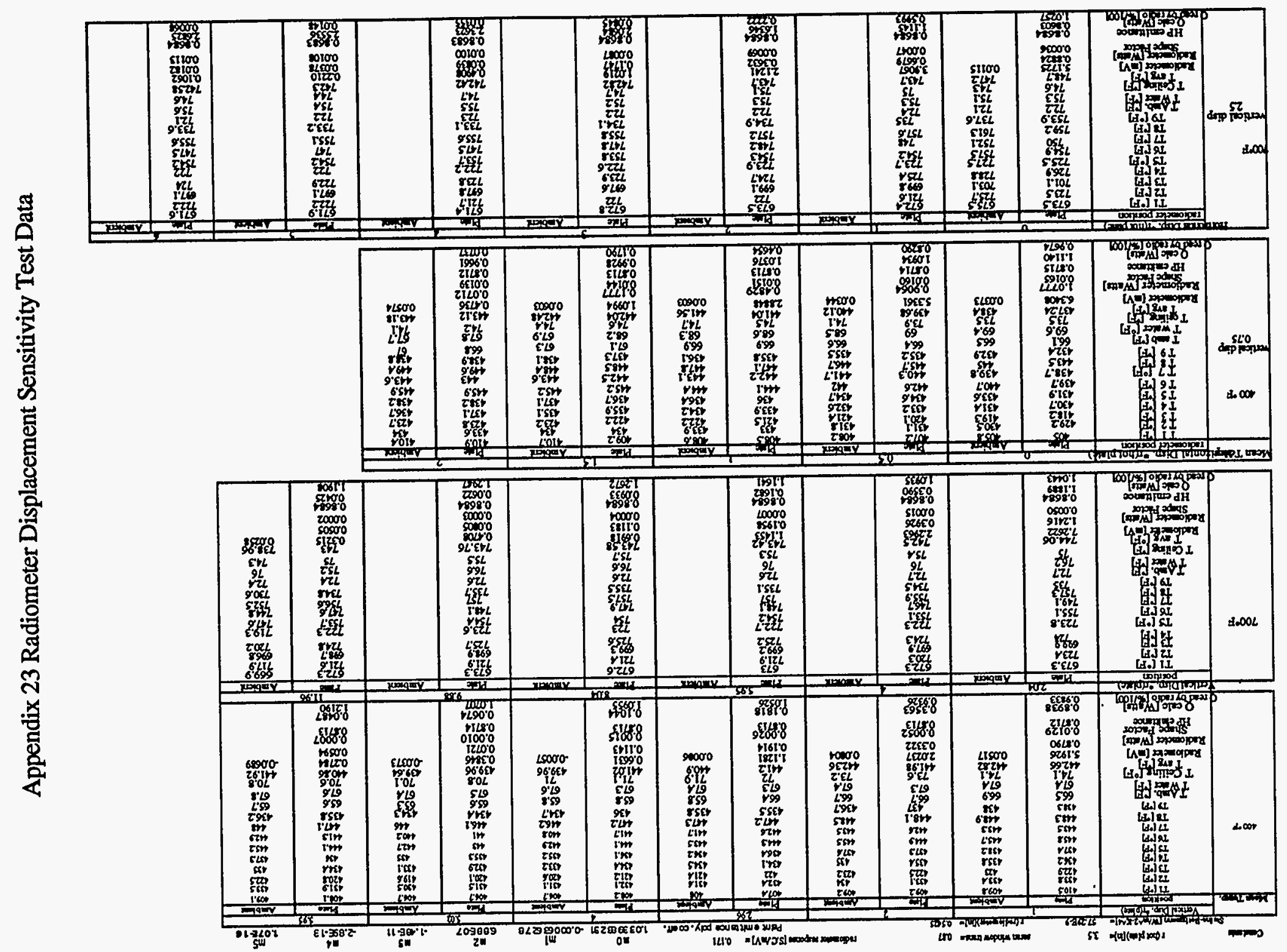


1. EINAL REPORT ON TEST OF STEP SHENANDOAH PARABOLIC DISH SOLAR COLLECTOR OUADRANT FACILITY; A. R. Saydah, A. A. Koenig, R. H. Lambert, D. A. Kugath; Contractor Report SAND82-7153, UC - 62a, April 1983.

2. EXPERIMENTAL STUDY OF HEAT LOSS THROUGH NATURAL CONVECTION FROM AN ISOTHERMAL CUBIC OPEN CAVITY; $P$. LeQuere, F. Penot, and M. Mirenayat; Laboratoire d'Energétique Solaire, 40 avenue du Recteur Pineau, 86022 Poitiers Cédex, France.

3. THERMAL PERFORMANCE OF SOLAR CONCENTRATOR/CAVITY RECEIVER SYSTEMS; James A. Harris and Terry G. Lenze; Solar Energy, vol. 34. \# 2, pp 135-142, 1985.

4. CONVECTIVE LOSSES FROM CAVITY SOLAR RECEIVERS-COMPARISONS BETWEEN ANALYTICAL PREDICTIONS AND EXPERIMENTAL RESULTS; A. M. Clausing; Journal of Solar. Energy Engineering, Vol. 105, p 29-33, Feb. 1983.

5. ESTIMATING CONVECTIVE ENERGY LOSSES FROM SOLAR CENTRAL BECEIVERS; D. L. Siebers \& J. S. Kraabel, Sandia National Laboratories Report, SAND84-8717, Unlimited Release, UC-62c, Printed April 1984.

6. CAVITY RECEIVER HEAT LOSS MEASUREMENTS; Wm. B. Sine \& C. G. McDonald, presented at the ASME Solar Energy Division Conference, Denver, Colorado, April 10-14, 1988.

7. ENERGY AND AYAILABILITY TRANSPORT LOSSES IN A POINT-FOCUS SOLAR CONCENTRATOR FIELD ; Wm. B. Sine \& A. A. Heckes, Sandia National Laboratories Report, SAND 86-0004A

8. CAVITY RECEIVER HEAT LOSS MEASUREMENTS (revised 10/20/89); Wm. B. Sine \& C. G. McDonald, presented at the International Solar Energy Society Solar World Congress 1989 Kobe, September 4-8, 1989, Kobe, Japan

9. EXPERIMENTAL STUDY OF HEAT LOSS THROUGH NATURAL CONVECTION FROM AN ISOTHERMAL CUBIC OPEN CAVITY; P. LeQuere, F. Penot, and M. Mirenayat; Laboratoire d'Energétique Solaire, 40 avenue du Recteur Pineau, 86022 Poitiers Cédex, France.

10. THERMAL PERFORMANCE OF SOLAR CONCENTRATOR/CAVITY RECEIVER SYSTEMS: James A. Harris and Terry G. Lenze; Solar Energy, vol. 34. \# 2, pp 135-142, 1985. 
11. CONVECTIVE LOSSES FROM CAVITY SOLAR RECEIVERS-COMPARISONS BETWEEN ANALYTICAL PREDICTIONS AND EXPERIMENTAL RESULTS;

A. M. Clausing; Journal of Solar Energy Engineering, Vol. 105, p 29-33, Feb. 1983.

12. ESTIMATING CONVECTIVE ENERGY LOSSES EROM SOLAR CENTRAL RECEIVERS; D. L. Siebers \& J. S. Kraabel, Sandia Report, SAND84-8717, Unlimited Release, UC-62c, Printed April 1984.

13. INSTALLATION \& OPERATION MANUAL, PRC-408 SERIES PULSE RATE CONVERTER; Flow Technology, Inc., 4250 E. Broadway Road, Phoenix, Arizona 850401986.

14. Bryan Wilson, Technical Support, Flow Technology, Inc., 4250 E. Broadway Road, Phoenix, Arizona 850401986.

15. OMEGA TEMPERATUREMEASUREMENT HANDBOOK AND ENCYCLOPEDIA; Omega Engineering, Inc., One Omega Drive, Stamford, CT 06907-0047, 1986.

16. DATA AND ERROR ANALYSIS IN THE INTRODUCTORY PHYSICS LABORATORY; William Lichten, Allyn and Bacon, Inc., Newton, Massachusetts, 02159, (C) 1988.

17. INFORMATION ABOUT SYLTHERM@ 800 HEAT TRANSFER LIOUID; Dow Corning Corporation, Midland, Michigan 48684-0994, Form \#22-761G-86, 1986.

18. "personal communication"; Bryan Wilson, Technical Support, Flow Technology, Inc., 4250 E. Broadway Road, Phoenix, Arizona 85040, October 1990.

19. ANALOG CONNECTION II MANUAL; Strawberry Tree Computers, $1010 \mathrm{~W}$. Fremont Ave., Sunnyvale, CA 94087, 1986.

20. THERMAL RADIATION HEAT TRANSEER. Second Edition; Robert Siegal and John R. Howell; Hemishere Publishing Corporation, New York, (C) 1981. 
U.S. Department of Energy (2)

Attn: R. (Bud) Annan

Code EE-13

Forrestal Building

1000 Independence Ave. SW

Washington, DC 20585

U.S. Department of Energy (5)

Attn: G. Burch

EE-132

S. Gronich

Forrestal Building

1000 Independence Ave. SW

Washington, DC 20585

U.S. Department of Energy

Attn: R. Hughey

San Francisco Operations Office

1333 Broadway

Oakland, CA 94612

U.S. Department of Energy (2)

Attn: N. Lackey

G. Tennyson

Albuquerque Operations Office

P.O. Box 5400

Albuquerque, NM 87115

Arizona Public Service Co.

Attn: Scott McLellan

P.O. Box 53999

MS 1424

Phoenix, AZ 85072-3999

Arizona Solar Energy Office Attn: Frank P. Mancini, Ph.D. Department of Commerce

$3800 \mathrm{~N}$. Central

Suite 1200

Phoenix, AZ 85012

Austrialian National University

Attn: Stephen Kaneff

Information Technology

0200 Canberra ACT, AUSTRALIA
Battelle Pacific Northwest Lab (2)

Attn: D. Brown

P.O. Box 999

Richland, WA 99352

California State Polytechnic University (10)

Attn: William B. Stine

Department of Mechanical Engineering

3801 West Temple Avenue

Pomona, CA 91768-4062

Clever Fellows

Attn: John A. Corey, P.E.

Innovation Consortium, Inc.

R.D. 1, Box 410, River Road

Melrose, NY 12121

Cummins Power Generation Inc. (2)

Attn: Isoroku (Rocky) Kubo

Mail Code 60125

P.O. Box 3005

500 Jackson Street

Columbus, IN 47202-3005

Cummins Power Generation South

Attn: Monte McGlaun

150 Tannehill Drive

Abilene, TX 79602

DLR

Attn: R. Buck

Pfaffenwaldring 38-40

7000 Stuttgart 80 GERMANY

Electric Power Research Institute

Attn: J. Schaeffer

P.O. Box 10412

3412 Hillview Avenue

Palo Alto, CA 94303

Energy Research Centre (2)

Attn: K. Inall

R. S. Phy. Sc.

Australian National University

Canberra ACT 2601 AUSTRALIA 
Energy Technology Engr. Center (2)

Attn: W. Bigelow

R. LeChevalier

Rockwell International Corp.

P.O. Box 1449

Canoga Park, CA 91304

Florida Solar Energy Center

Attn: Library

300 State Road, Suite 401

Cape Canaveral, FL 32920-4099

Georgia Power

Attn: W. King

7 Solar Circle

Shenandoah, GA 30265

Lawrence Berkeley Laboratory

Attn: Arlon Hunt

University of California

MS 90-2024

One Cyclotron Road

Berkeley, CA 94720

McDonnell-Douglas Astronautics Co. (3)

Attn: R.L. Gervais

J. Rogan

D. Steinmeyer

5301 Bolsa Avenue

Huntington Beach, CA 92647-2048

Mechanical Technology, Inc.

Attn: D. Dochat

968 Albany Shaker Road

Latham, NY 12110

National Renewable Energy Laboratory

Attn: Mark Bohn

G. Jorgensen

A. Lewandowski

L. M. Murphy

T. Wendelin

T. Williams

1617 Cole Blvd.

Branch 4710/132

Golden, CO 80401-3393
Northern Research and Eng. Corp.

Attn: J. Kesseli

39 Olympia Avenue

Woburn, MA 01801-2073

Pacific Gas and Electric Co.

Attn: G. Braun

3400 Crow Canyon Road

San Ramon, CA 94583

Pacific Power

Attn: P. Lynch

Park and Elizabeth Streets

GPO Box 5257, Sydney

New South Wales 2001

AUSTRALIA

Power Kinetics, Inc.

Attn: W.E. Rogers

415 River Street

Troy, NY 12180-2822

SBP - Schlaich, Bergermann und. Partner Attn: Wolfgang Schiel

Hohenzollernstr. 1

D-70178 Stuttgart, GERMANY

Science Applications International Corp.

Attn: Kelly Beninga

15000 W. 6 th Avenue

Suite 202

Golden, CO 80401

Science Applications International Corp.

Attn: Barry L. Butler

Room 2043, M/S C2J

10260 Campus Point Dr.

San Diego, CA 92121

Solar Energy Industries Association (2)

Attn: Ken Sheinkopf

S. Sklar

122 C Street, NW

4th Floor

Washington, DC 20001-2109 
Solar Kinetics, Inc. (2)

Attn: Gus Hutchison

D. White

10635 King William Drive

P.O. Box 540636

Dallas, TX 75354-0636

Stirling Machine World

Attn: B. Ross

1823 Hummingbird Court

West Richland, WA $99352-9542$

Stirling Technology Co.(2)

Attn: Maurice A. White

2952 George Washington Way

Richland, WA 99352

Stirling Thermal Motors (2)

Attn: Lennart Johansson

275 Metty Drive

Ann Arbor, MI 48103
Internal Distribution:

MS 0702

MS 0703

MS 0703

MS 0703

MS 0703

MS 0703

MS 0703

MS 0703

MS 0703

MS 0704

MS 0835

MS 0835

MS 1127

MS 1127

MS 1127

MS 1127

MS 1127

MS 1127

MS 0100

MS 0619

MS 0899

MS 9018
D.E. Arvizu, 6200

C.E. Andraka, 6216

R.B. Diver, 6216 (5)

D.R. Gallup, 6216

T.R. Mancini, 6216

D.F. Menicucci, 6216

J.B. Moreno, 6216

T.A. Moss, 6216

C.E. Tyner, 6216

P.C. Klimas, 6201

R.E. Hogan, Jr., 1513

R.D. Skocypec, 1513

J.M. Chavez, 6215

Cordeiro, 6215

V.E. Dudley, 6215

Library, 6215 (5)

A.R. Mahoney, 6215

K.S. Rawlinson, 6215

Document Proc. for DOE/OSTI, 7613-2 (2)

Print Media, 12615

Technical Library, 4414 ( 5)

Central Technical Files, 8523-2

Thermacore, Inc. (2)

Attn: Donald Ernst

780 Eden Road

Lancaster, PA 17601

University of Minnesota

Attn: E.A. Fletcher

1111 Church Street, SE

Dept. of Mech. Engr.

Minneapolis, MN 55455 


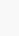





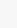




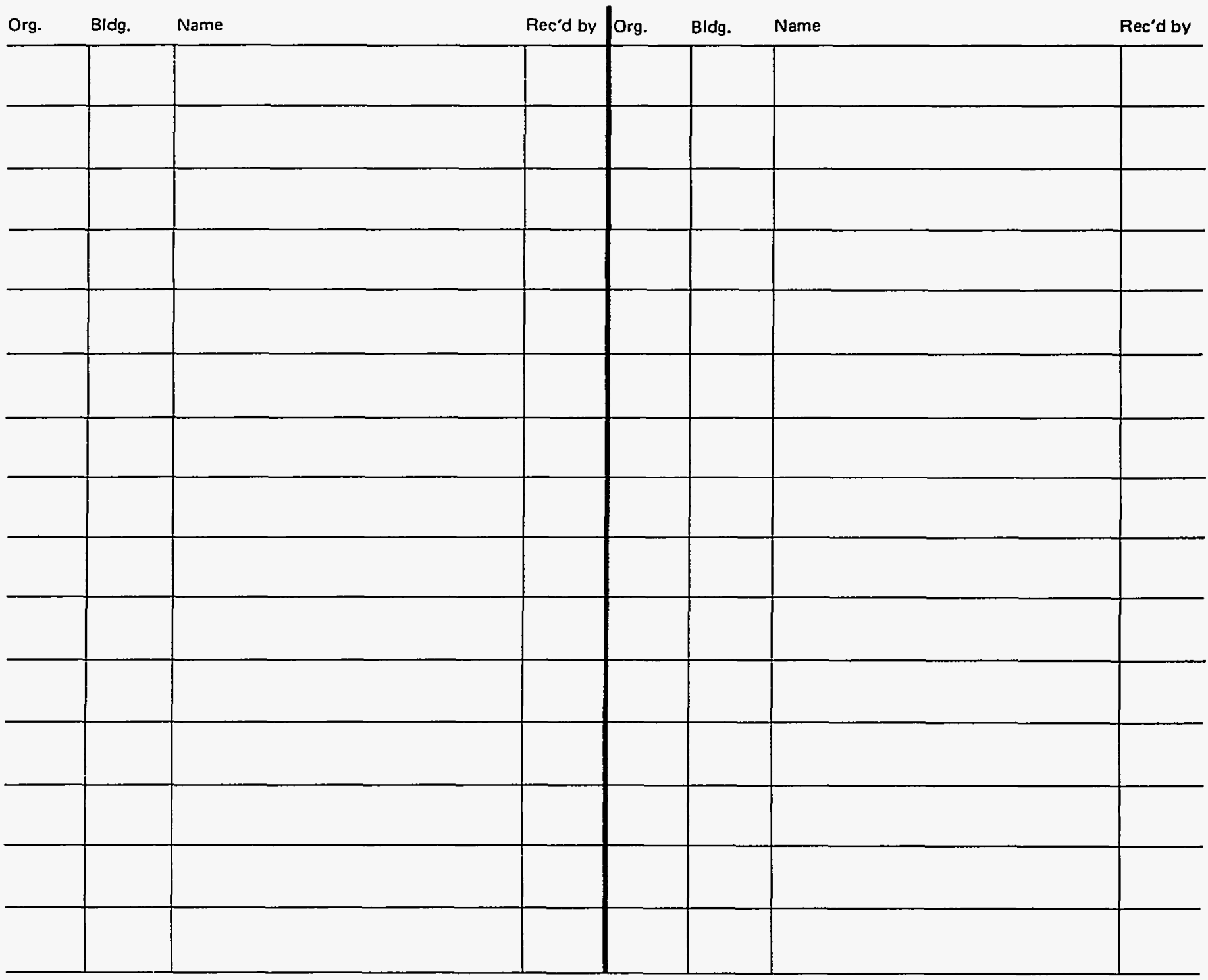

